NATASHE NICOLI BRANCO

ESTUDO ANALÍTICO DO MECANISMO DE BLOWOUT DE CHAMAS DE DIFUSÃO TURBULENTA 
NATASHE NICOLI BRANCO

ESTUDO ANALÍTICO DO MECANISMO DE BLOWOUT DE CHAMAS DE DIFUSÃO TURBULENTA

Dissertação apresentada para a Escola

Politécnica da Universidade de São Paulo para

obtenção de título de Mestre em Engenharia

São Paulo

2014 


\section{ESTUDO ANALÍTICO DO MECANISMO DE BLOWOUT DE CHAMAS DE DIFUSÃO TURBULENTA}

Dissertação apresentada à Escola Politécnica da Universidade de São Paulo para obtenção de título de Mestre em Engenharia

Área de concentração: Engenharia Mecânica de Energia e Fluidos

Orientador: Prof. Dr. Marcos de Mattos Pimenta 
Este exemplar foi revisado e corrigido em relação à versão original, sob responsabilidade única do autor e com a anuência de seu orientador.

São Paulo, de janeiro de 2014.

Assinatura do autor

Assinatura do orientador

\section{Branco, Natashe Nicoli}

Estudo analítico do mecanismo de de blowout de chamas de difusão turbulenta / N.N. Branco. -- versão corr. -- São Paulo, 2014.

$165 \mathrm{p}$.

Dissertação (Mestrado) - Escola Politécnica da Universidade de São Paulo. Departamento de Engenharia Mecânica.

1.Engenharia mecânica 2.Combustão 3.Energia 4.Mecânica dos fluidos 5.Turbulência I.Universidade de São Paulo. Escola Politécnica. Departamento de Engenharia Mecânica II.t. 
DEDICATÓRIA

Dedico este trabalho a minha família. 


\section{AGRADECIMENTOS}

A Deus, pela proteção, saúde, oportunidade, equilíbrio e persistência.

A meus pais, pelo amor, carinho e suporte financeiro.

A meu grande amigo e companheiro Diego Moura Cavlac, pela força, confiança, paciência e afeto.

Ao professor Dr. Marcos de Mattos Pimenta, pela orientação, confiança, dedicação e estímulo. Ao engenheiro Luciano Martinez Stefanini, pela amizade e conselhos.

A todos que colaboraram, direta ou indiretamente, na execução, conclusão e sucesso deste trabalho. 


\section{RESUMO}

A compreensão dos mecanismos de estabilidade de chamas é de extrema importância tanto para o projeto/dimensionamento de queimadores utilizados em fornos e fornalhas industriais, câmaras de combustão de turbinas a gás e flares; como para a substituição de combustíveis em queimadores existentes.

Há um intervalo de condições (como velocidade de "descarga" do jato e concentração de combustível na mistura gasosa) na qual a combustão estável pode ser mantida, sendo limitada por dois fenômenos denominados como liftoff (descolamento da base da chama do bocal e posterior estabilização desta a certa distância do bocal) e blowout (desprendimento e extinção da chama). Por razões de segurança, operações próximas às condições em que o blowout pode ocorrer devem ser evitadas.

Muitas teorias têm sido publicadas para descrever as características de liftoff e blowout de chamas de difusão turbulenta. Este trabalho apresenta algumas destas teorias, bem como as hipóteses assumidas e os processos físicos considerados responsáveis por estes fenômenos (liftoff e blowout). Correlações para a previsão da velocidade de blowout e resultados experimentais disponíveis na literatura também são apresentados.

Uma nova correlação para a velocidade de blowout é proposta, a qual se baseia nos movimentos de grande escala observados em jatos turbulentos e no adimensional número de Damköhler (relação entre o tempo de cinética química e o tempo de mistura dos reagentes e destes com os produtos da reação).

Comparações entre as previsões da correlação proposta com resultados experimentais e com previsões de outras correlações disponíveis na literatura foram realizadas, para diferentes combustíveis e diâmetros de bocais. A correlação proposta apresentou boa concordância com os resultados experimentais. A partir das análises desenvolvidas neste trabalho, verificou-se que a velocidade de blowout de chamas de difusão turbulenta é função das propriedades do combustível, das características do bocal, das condições do ambiente e do adimensional número de Damköhler.

Palavras-chave: Estabilidade de chamas, mecanismo de blowout, jatos, turbulência. 


\begin{abstract}
The study of flame stability is very important to the design of burners used in industrial ovens and furnaces, combustion chambers of gas turbines and flares; and fuel substitution in burners.

There is a range of conditions (for example gas velocity at the nozzle exit and jet fuel concentration in the gas mixture) at which stable combustion can be maintained, being limited by two phenomena called liftoff and blowout. Lift-off is the detachment of the flame from the fuel nozzle, and blowout its detachment and extinction. Operating conditions close to stability limits should be avoided for security reasons.

Many theories have been published to describe the blowout and lifted characteristics of turbulent jet diffusion flames. This document presents some theories, as well as the assumptions and physical processes considered responsible for these phenomena (liftoff and blowout). Correlations for predicting the blowout velocity and experimental results available in the literature are also shown.

A new correlation is proposed, which is based on large-scale motions observed in turbulent jets and the dimensionless Damköhler number (ratio of the characteristic chemical reaction time and the time associated with the mixing of reentrained hot products into fresh reactants).

Comparisons between the predictions of the proposed correlation with experimental results and predictions of other correlations available in the literature were performed for different fuels and nozzle diameters. The proposed correlation showed good agreement with the experimental results. The analyses developed in this work allow us to conclude that the blowout velocity of the turbulent diffusion flame depends on the fuel properties, characteristics of the nozzle, the environmental conditions and the Damköhler number.
\end{abstract}

Keywords: flame stability, blowout, jets, turbulence. 


\section{LISTA DE FIGURAS}

Figura 1.1. Esquema do deslocamento de uma chama de difusão (SOUSA, 2010).................22

Figura 1.2. Esquema da estrutura de chama tripla

Figura 2.1. Esquema da hipótese de Vanquickenborne e Van Tiggelen (1966). (SOUSA, 2010) 30

Figura 2.2. Número de Mach na saída do bocal que leva à blowout da chama........................33

Figura 2.3. Curva universal de estabilidade de blowout. (KALGHATGI, 1981).

Figura 2.4. Esquema dos perfis da velocidade média, $U i$, e da velocidade de chama turbulenta, $S_{T}$ 36

Figura 2.5. Curva adimensional da altura de descolamento. (KALGHATGI, 1984) 37 Figura 2.6. Velocidades de blowout em função do diâmetro do bocal do queimador. (KALGHATGI, 1981 apud BROADWELL; DAM; MUNGAL, 1984) 42

Figura 2.7. Valores calculados (linhas sólidas) de velocidade de blowout em função do raio do jato para cinco combustíveis hidrocarbonetos. As previsões são comparadas com os resultados experimentais (símbolos) de Kalghatgi (1981). (PITTS, 1989) 47

Figura 2.8. Comprimento da chama em função da altura de descolamento $h$, e as regiões pulsante, início de recuo, recuo e extinção durante o processo de blowout de uma chama de um jato simples de metano. (CHAO et al, 2000) 48

Figura 2.9. Desenho esquemático do mecanismo de blowout proposto por Wu et al (2006)...55

Figura 2.10. Mecanismo de arrastamento de ar ambiente e mistura deste ar com os produtos da combustão e excesso de combustível, em uma chama de difusão turbulenta (DAHM e DIBBLE, 1988). 60

Figura 2.11. Diagrama esquemático dos bocais. (KARBASSI, 1997). 62

Figura 2.12. Limites de estabilidade de uma chama não pré-misturada de metano em função da velocidade do fluxo de ar concorrente $\left(d_{n}=2,00 \mathrm{~mm}\right)$. (KARBASSI, 1997) 63

Figura 2.13. Limites de blowout medidos experimentalmente para a configuração coaxial com fluxo interno de metano $\left(d_{n, f}=3 \mathrm{~mm}\right)$ e fluxo de $\operatorname{ar} \operatorname{anular}\left(d_{n, a}=7 \mathrm{~mm}\right)$. (DAHM; MAYMAN, 1990)

Figura 2.14. Aumento da região de estabilidade da chama de metano com o aumento número swirl, S, para o queimador coaxial com diâmetros $d_{n, f}=3,4 \mathrm{~mm}$ e $d_{n, a}=$ $22,2 \mathrm{~mm}$ 
Figura 2.15. Efeito do ar coaxial na base da chama (FEIKEMA; CHEN; DRISCOLL, 1991).

Figura 3.1. Número de Mach $\left(M a_{b}\right)$ na saída do bocal no instante em que ocorre blowout da chama, em função do diâmetro do bocal de gás, para diferentes gases combustíveis.(KALGHATGI,1981) .82

Figura 3.2. Velocidade de blowout $U_{b \text {,exp }}$ obtida a partir de $M a_{b}$ digitalizado do trabalho de Kalghatgi (1981) em função do diâmetro do bocal de gás, para diferentes gases combustíveis. 85

Figura 3.3. Velocidades de blowout em função do diâmetro de saída do bocal de gás para diferentes combustíveis (BROADWELL; DAM; MUNGAL, 1984).

Figura 3.4. Velocidades de blowout em função do diâmetro de saída do bocal de gás para diferentes combustíveis (PITTS, 1989). 86

Figura 4.1. Valores de $U_{b}$ experimental (KALGHATGI, 1981) e previstos pelas correlações propostas por Kalghatgi (1981), Broadwell; Dam e Mungal (1984), Dahm e Mayman (1990), Sousa (2010) e Branco (2013) para o gás metano. 100

Figura 4.2. Valores de $U_{b}$ experimental (KALGHATGI, 1981) e previstos pelas correlações propostas por Kalghatgi (1981), Broadwell; Dam e Mungal (1984), Dahm e Mayman (1990), Sousa (2010) e Branco (2013) para o gás propano. 102

Figura 4.3. Valores de $U_{b}$ experimental (KALGHATGI, 1981) e previstos pelas correlações propostas por Kalghatgi (1981), Broadwell; Dam e Mungal (1984), Dahm e Mayman (1990), Sousa (2010) e Branco (2013) para o gás etileno. 104

Figura 4.4. Valores de $U_{b}$ experimental (KALGHATGI, 1981) e previstos pelas correlações propostas por Kalghatgi (1981), Broadwell; Dam e Mungal (1984), Dahm e Mayman (1990), Sousa (2010) e Branco (2013) para o gás acetileno. 106

Figura 4.5. Valores de $U_{b}$ experimental (KALGHATGI, 1981) e previstos pelas correlações propostas por Kalghatgi (1981), Broadwell; Dam e Mungal (1984), Dahm e Mayman (1990), Sousa (2010) e Branco (2013) para o gás hidrogênio. 108

Figura 4.6. Valores de $U_{b}$ experimental (KALGHATGI, 1981) e previstos pelas correlações propostas por Kalghatgi (1981), Broadwell; Dam e Mungal (1984), Dahm e Mayman (1990), Sousa (2010) e Branco (2013) para o gás butano comercial....110

Figura A.1. Variação temporal da componente axial da velocidade $U(t)$ na linha de centro de um jato turbulento (POPE, 2000). .128

Figura A.2. Perfil da velocidade média em jato 128 
Figura A.3. Variação da taxa de reação em reações de oxidação lenta e rápida (combustão).

Figura A.4. Esquema de uma frente de combustão em regime permanente. (SOUSA, 2010)

Figura A.5. Zonas de um jato livre genérico. (SOUSA, 2010)

Figura A.6. Esquema de jato emergindo de um bocal singular de área transversal circular. (SOUSA, 2010)

Figura C.1. Valores de $U_{b}$ experimentais e previstos pela correlação proposta por Kalghatgi (1981), sob as condições dos Casos 1 e 2 para o gás metano.

Figura C.2. Valores de $U_{b}$ experimentais e previstos pela correlação proposta por Kalghatgi (1981), sob as condições dos Casos 1 e 2 para o gás propano. 153

Figura C.3. Valores de $U_{b}$ experimentais e previstos pela correlação proposta por Kalghatgi (1981), sob as condições dos Casos 1 e 2 para o gás etileno. 155

Figura C.4. Valores de $U_{b}$ experimentais e previstos pela correlação proposta por Kalghatgi (1981), sob as condições dos Casos 1 e 2 para o gás acetileno. 157

Figura C.5. Valores de $U_{b}$ experimentais e previstos pela correlação proposta por Kalghatgi (1981), sob as condições dos Casos 1 e 2 para o gás hidrogênio.

Figura C.6. Valores de $U_{b}$ experimentais e previstos pela correlação proposta por Kalghatgi (1981), sob as condições dos Casos 1 e 2 para o butano comercial. 161

Figura C.1. Valores de $U_{b}$ experimentais e previstos pela correlação proposta por Kalghatgi (1981), sob as condições dos Casos 1 e 2 para o gás metano

Figura C.2. Valores de $U_{b}$ experimentais e previstos pela correlação proposta por Kalghatgi (1981), sob as condições dos Casos 1 e 2 para o gás propano.

Figura C.3. Valores de $U_{b}$ experimentais e previstos pela correlação proposta por Kalghatgi (1981), sob as condições dos Casos 1 e 2 para o gás etileno. 155

Figura C.4. Valores de $U_{b}$ experimentais e previstos pela correlação proposta por Kalghatgi (1981), sob as condições dos Casos 1 e 2 para o gás acetileno. 157

Figura C.5. Valores de $U_{b}$ experimentais e previstos pela correlação proposta por Kalghatgi (1981), sob as condições dos Casos 1 e 2 para o gás hidrogênio. 159

Figura C.6. Valores de $\boldsymbol{U} \boldsymbol{b}$ experimentais e previstos pela correlação proposta por Kalghatgi (1981), sob as condições dos Casos 1 e 2 para o butano comercial. 161 


\section{LISTA DE TABELAS}

Tabela 1.1. Poder calorífico superior e inferior de alguns combustíveis (PINTO). 27

Tabela 1.2. Características do BFG e do COG (CETAE, IPT e LETMCE, 2007). .................28

Tabela 2.1. Propriedades dos gases combustíveis utilizados por Kalghatgi (1981) .32

Tabela 2.2. Valores do parâmetro de blowout, Da $a_{\text {crit }}$ (BROADWELL; DAM; MUNGAL, 1984).

Tabela 2.3. Parâmetros estimados e medidos de cada condição observada para o processo de blowout. (WU et al, 2006) ..... .53

Tabela 2.4. Valores do número de Damköhler crítico. 57

Tabela 2.5. Velocidades de blowout $\left(U_{b}\right)$ para $U_{\infty}=0$. (KARBASSI, 1997) 64

Tabela 2.6. Parâmetros característicos das geometrais e dos combustíveis utilizados por Feikema; Chen e Driscoll (1990).

Tabela 3.1. Propriedades dos gases combustíveis utilizados por Kalghatgi (1981). (KALGHATGI, 1981)....

Tabela 3.2. Propriedades calculadas para os gases estudados por Kalghatgi (1981) (Caso 2) 89

Tabela 3.3. Valores do número de Damkhöler crítico, $D a_{\text {crit }}$.................................................90

Tabela 3.4. Valores do número de Damkhöler crítico, $D a_{\text {crit }}$ (SOUSA, 2010). ....................91

Tabela 3.5. Correlações analisadas pelo presente trabalho. 95

Tabela 4.1. Valores de $U_{b}$ previstos pelas correlações propostas por Kalghatgi (1981), Broadwell; Dam e Mungal (1984), Dahm e Mayman (1990), Sousa (2010) e Branco (2013) para o gás metano

Tabela 4.2. Valores dos desvios entre $U_{b, \exp }$ de Kalghatgi (1981) e $U_{b}$ previstos, $\Delta_{i-\exp }$, para o gás metano.

Tabela 4.3. Valores de $U_{b}$ previstos pelas correlações propostas por Kalghatgi (1981), Broadwell; Dam e Mungal (1984), Dahm e Mayman (1990), Sousa (2010) e Branco (2013) para o gás propano. 101

Tabela 4.4. Valores dos desvios entre $U_{b, \exp }$ de Kalghatgi (1981) e $U_{b}$ previstos, $\Delta_{i-\exp }$, para o gás propano. 102

Tabela 4.5. Valores de $U_{b}$ previstos pelas correlações propostas por Kalghatgi (1981), Broadwell; Dam e Mungal (1984), Dahm e Mayman (1990), Sousa (2010) e Branco (2013) para o gás etileno. 103 
Tabela 4.6. Valores dos desvios entre $U_{b, \exp }$ de Kalghatgi (1981) e $U_{b}$ previstos, $\Delta_{i \text {-exp }}$, para o gás etileno.

Tabela 4.7. Valores de $U_{b}$ previstos pelas correlações propostas por Kalghatgi (1981), Broadwell; Dam e Mungal (1984), Dahm e Mayman (1990), Sousa (2010) e Branco (2013) para o gás acetileno. 105

Tabela 4.8. Valores dos desvios entre $U_{b, \exp }$ de Kalghatgi (1981) e $U_{b}$ previstos, $\Delta_{i-\exp }$, para o gás acetileno 106

Tabela 4.9. Valores de $U_{b}$ previstos pelas correlações propostas por Kalghatgi (1981), Broadwell; Dam e Mungal (1984), Dahm e Mayman (1990), Sousa (2010) e Branco (2013) para o gás hidrogênio.

Tabela 4.10. Valores dos desvios entre $U_{b, \exp }$ de Kalghatgi (1981) e $U_{b}$ previstos, $\Delta_{i-\exp }$, para o gás hidrogênio 108

Tabela 4.11. Valores de $U_{b}$ previstos pelas correlações propostas por Kalghatgi (1981), Broadwell; Dam e Mungal (1984), Dahm e Mayman (1990), Sousa (2010) e Branco (2013) para o gás butano comercial.

Tabela 4.12. Valores dos desvios entre $U_{b, \exp }$ de Kalghatgi (1981) e $U_{b}$ previstos, $\Delta_{i-\exp }$, para o gás butano comercial.

Tabela 4.13. Média dos desvios entre $U_{b, \text { exp }}$ de Kalghatgi (1981) e $U_{b}$ previstos, $\Delta_{i-\exp }$, para os seis gases combustíveis analisados.

Tabela 4.14. Correlações mais adequadas (I e II) para prever a velocidade de blowout em função do gás analisado e a faixa de diâmetros na qual foram avaliadas 112

Tabela A.1. Velocidades de chama laminar, $S_{L}$, de alguns combustíveis gasosos 139

Tabela B.1. Valores de $U_{b, \exp }$ experimentais relatados por Kalghatgi (1981), Broadwell; Dam e Mungal (1984) e Pitts (1989) para o gás metano. 143

Tabela B.2. Valores de $U_{b}$ experimentais relatados por Kalghatgi (1981), Broadwell; Dam e Mungal (1984) e Pitts (1989) para o gás propano. 143

Tabela B.3. Valores de $U_{b}$ experimentais relatados por Kalghatgi (1981), Broadwell; Dam e Mungal (1984) e Pitts (1989) para o gás etileno. 144

Tabela B.4. . Valores de $U_{b}$ experimentais relatados por Kalghatgi (1981), Broadwell; Dam e Mungal (1984) e Pitts (1989) para o gás acetileno. 144

Tabela B.5. Valores de $U_{b}$ experimentais relatados por Kalghatgi (1981), Broadwell; Dam e Mungal (1984) e Pitts (1989) para o gás hidrogênio. 144

Tabela B.6. Valores de $U_{b}$ experimentais relatados por Kalghatgi (1981), Broadwell; Dam e Mungal (1984) e Pitts (1989) para o gás butano comercial. 145 
Tabela C.1. Números de Mach, $M a_{b}$, e respectivas velocidades de blowout, $U_{b, e x p}$, para o gás metano.

Tabela C.2. Previsões da correlação da velocidade de blowout, $U_{b}$, proposta por Kalghatgi (1981) para o gás metano (Caso 1).

Tabela C.3. Previsões da correlação da velocidade de blowout, $U_{b}$, proposta por Kalghatgi (1981) para o gás metano (Caso 2)

Tabela C.4. Valores da velocidade de blowout experimentais e previstos pela correlação proposta por Kalghatgi (1981) (Casos 1 e 2) para o gás metano, e os respectivos desvios.

Tabela C.5. Influência da incerteza da digitalização dos dados experimentais de Kalghatgi (1981) na velocidade de blowout, $U_{b}$, para o gás metano.

Tabela C.6. Valores da velocidade de blowout experimentais e previstos pela correlação proposta por Kalghatgi (1981) (Casos 1 e 2) para o gás propano, e os respectivos desvios. 152

Tabela C.7. Influência da incerteza da digitalização dos dados experimentais de Kalghatgi (1981) na velocidade de blowout, $U_{b}$, para o gás propano. 154

Tabela C.8. Valores da velocidade de blowout experimentais e previstos pela correlação proposta por Kalghatgi (1981) (Casos 1 e 2) para o gás etileno, e os respectivos desvios. 154

Tabela C.9. Influência da incerteza da digitalização dos dados experimentais de Kalghatgi (1981) na velocidade de blowout, $U_{b}$, para o gás etileno. 156

Tabela C.10. Valores da velocidade de blowout experimentais e previstos pela correlação proposta por Kalghatgi (1981) (Casos 1 e 2) para o gás acetileno, e os respectivos desvios. 156

Tabela C.11. Influência da incerteza da digitalização dos dados experimentais de Kalghatgi (1981) na velocidade de blowout, $U_{b}$, para o gás acetileno. 158

Tabela C.12. Valores da velocidade de blowout experimentais e previstos pela correlação proposta por Kalghatgi (1981) (Casos 1 e 2) para o gás hidrogênio, e os respectivos desvios. 158

Tabela C.13. Influência da incerteza da digitalização dos dados experimentais de Kalghatgi (1981) na velocidade de blowout, $U_{b}$, para o gás hidrogênio. 160

Tabela C.14. Valores da velocidade de blowout experimentais e previstos pela correlação proposta por Kalghatgi (1981) (Casos 1 e 2) para o gás butano comercial. 160 
Tabela C.15. Influência da incerteza da digitalização dos dados experimentais de Kalghatgi (1981) na velocidade de blowout, $U_{b}$, para o butano comercial......................... 162

Tabela D.1. Propriedades e velocidades dos gases metano e butano $\left(d_{n}=2,0 \mathrm{~mm}\right) \ldots \ldots \ldots \ldots \ldots . . . .165$ 


\section{LISTA DE ABREVIATURAS E SIGLAS}

BFG Blast Furnace Gas (Gás de alto-forno)

CETAE Centro de Tecnologias Ambientais e Energéticas

CFD Computational Fluid Dynamics (Mecânica dos Fluidos Computacionais)

COG Coke Oven Gas (Gás de coqueria)

DNS Direct Numerical Simulation (Simulação Direta do Escoamento)

IPT Instituto de Pesquisas Tecnológicas do Estado de São Paulo

LDG Linz Donawitz Gas

LES Large Eddy Simulation (Simulação dos Grandes Turbilhões)

LETMCE Laboratório de Energia Térmica, Motores, Combustíveis e Emissões

LI Limite inferior de flamabilidade

LS Limite superior de flamabilidade

PCI Poder Calorífico Inferior

PCS Poder Calorífico Superior

PDF Probability Density Function (Função Densidade de Probabilidade)

RANS Reynolds-averaged Navier-Stokes equations (Equação de Navier-Stokes com a média de Reynolds)

SIMPLE Semi-Implicit Method for Pressure-Linked Equations (Método semi-implícito para equações de pressão) 


\section{LISTA DE SÍMBOLOS}

C Constante

[ ]

$c_{p} \quad$ Calor específico a pressão constante

$[\mathrm{J} /(\mathrm{kg} \cdot \mathrm{K})]$

$c_{v} \quad$ Calor específico a volume constante

$[\mathrm{J} /(\mathrm{kg} \cdot \mathrm{K})]$

$d$ Diâmetro do jato

[m]

$d^{*} \quad$ Diâmetro de uma fonte conceitual.

[m]

$d_{e} \quad$ Diâmetro efetivo

[m]

$\mathcal{D} \quad$ Difusividade mássica

$\left[\mathrm{m}^{2} / \mathrm{s}\right]$

Da Número de Damköhler

$f \quad$ Fração de mistura

$h \quad$ Altura de descolamento da chama

[m]

$H_{L} \quad$ Distância axial a partir da saída do bocal na qual a concentração do combustível atinge o limite inferior de flamabilidade

[m]

$H_{s} \quad$ Distância axial a partir da saída do bocal na qual a concentração do combustível atinge o valor estequiométrico

$[\mathrm{m}]$

$H_{w} \quad$ Distância axial a partir da saída do bocal até posição de máximo raio do contorno estequiométrico

$[\mathrm{m}]$

$J \quad$ Fluxo de quantidade de movimento.

$\left[\mathrm{kg} \cdot \mathrm{m} / \mathrm{s}^{2}\right]$

$k \quad$ Condutividade térmica

$[\mathrm{W} /(\mathrm{m} \cdot \mathrm{K})]$

$l_{m} \quad$ Comprimento de mistura

[m]

$\ell \quad$ Escala de comprimento

$[\mathrm{m}]$

$L \quad$ Comprimento da chama

[m]

Le Número de Lewis

[]

$m$ Massa

[kg]

$\dot{m} \quad$ Vazão mássica

$[\mathrm{kg} / \mathrm{s})]$

$\dot{m}^{\prime \prime} \quad$ Fluxo de massa

$\left[\mathrm{kg} /\left(\mathrm{s} \cdot \mathrm{m}^{2}\right)\right]$

$\dot{m}_{f}^{\prime \prime \prime} \quad$ Taxa de reação (consumo de combustível).

$\left[\mathrm{kg} /\left(\mathrm{s} \cdot \mathrm{m}^{3}\right)\right]$

Ma Número de Mach

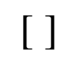

MM Massa molecular

[kg/kmol]

$P \quad$ Pressão

$[\mathrm{Pa}]$

Pr Número de Prandtl 
$r$ Distância entre o eixo e a periferia do jato

[m]

$r_{w} \quad$ Máxima distância radial entre o contorno elíptico estequiométrico e o eixo do jato

$R_{\rho} \quad$ Relação de densidade (gás combustível/ar)

Re Número de Reynolds

$S_{L} \quad$ Velocidade da chama laminar

$S_{T} \quad$ Velocidade da chama turbulenta

Sc Número de Schmidt

$T \quad$ Temperatura

Tempo químico característico

Tempo de mistura local

$t_{\text {resid }}$ Tempo de residência

$u \quad$ Velocidade relativa

$U \quad$ Velocidade local do escoamento

$\bar{U} \quad$ Velocidade média do escoamento

$\hat{U} \quad$ Velocidade do escoamento adimensional

Y Fração mássica

$\Delta_{\text {exp }} \quad$ Variação entre parâmetros obtidos a partir de dados experimentais ....

$\Delta_{i \text {-exp }}$ Variação entre parâmetros obtidos por correlação e experimento.

\section{Símbolos Gregos}

$\alpha \quad$ Difusividade térmica

$\left[\mathrm{m}^{2} / \mathrm{s}\right]$

$\dot{\epsilon} \quad$ Taxa de deformação característica

$\theta \quad$ Coordenada cilídrica [rad]

$\rho \quad$ Densidade $\left[\mathrm{kg} / \mathrm{m}^{3}\right]$

$\lambda \quad$ Razão de calores específicos $\left(c_{p} / c_{v}\right)$

$\mu \quad$ Viscosidade dinâmica

$v \quad$ Viscosidade cinemática $\left[\mathrm{m}^{2} / \mathrm{s}\right]$

$\xi \quad$ Erro

$\xi_{\text {exp }}$ Erro entre parâmetros obtidos a partir de dados experimentais $[\mathrm{m} / \mathrm{s}]$ 
$\varphi \quad$ Relação mássica ar/combustível

$\varphi^{\prime} \quad$ Relação mássica ar ambiente/fluido que emerge do bocal coaxial ....... [ ]

$\phi \quad$ Razão de equivalência

\section{Subscritos}

a Característica referente ao ar coaxial

$b \quad$ Condição de blowout

B Referente ao trabalho de Broadwell; Dam e Mungal (1984)

c Propriedade no eixo do jato

crit Condição crítica

D Referente ao trabalho de Dahm e Dibble (1988)

exp Parâmetro obtido experimentalmente

$f \quad$ Característica referente ao combustível em jatos concorrentes e coaxiais

F Referente ao trabalho de Feikema; Chen e Driscoll (1991)

inf Condição inferior

K Referente ao trabalho de Kalghatgi (1981) e Kalghatgi (1984)

max Condição máxima

min Condição mínima

$m \quad$ Propriedade da mistura

$n \quad$ Condição na saída do bocal

$N \quad$ Referente à análise do presente trabalho

$O_{x} \quad$ Propriedade do oxidante

p Característica referente à posição pulsante

$s \quad$ Condição estequiométrica

sup Condição superior

$u \quad$ Propriedade da mistura não queimada

$x \quad$ Propriedade na direção axial

$\theta \quad$ Propriedade na direção tangencial

$\infty$ Condição do ambiente no entorno do jato 


\section{SUMÁRIO}

1 INTRODUÇÃ

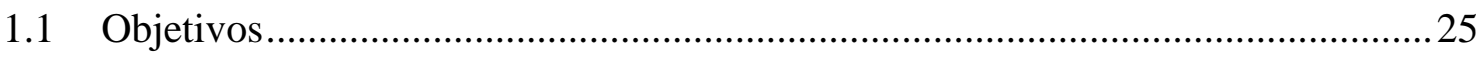

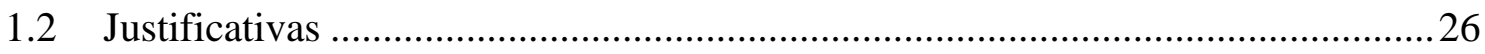

2 REVISÃO BIBLIOGRÁFICA ….............................................................................29

2.1 Estudos experimentais e analíticos do mecanismo de blowout de jatos simples em meio quiescente

2.2 Estudos experimentais e analíticos do mecanismo de blowout de jatos concorrentes

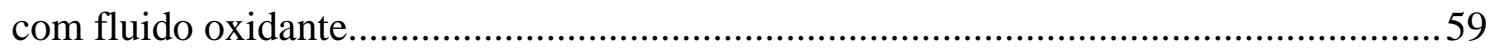

2.3 Estudos experimentais e analíticos do mecanismo de blowout de jatos coaxiais.. 68

2.4 Comentários referentes à Revisão Bibliográfica ................................................ 78

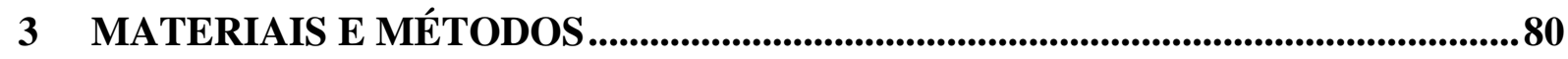

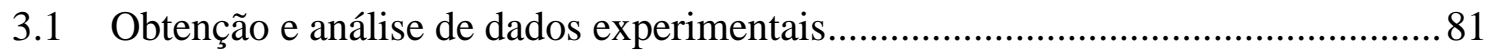

3.2 Análise das correlações disponíveis na Literatura para previsão da velocidade de blowout de jatos simples

3.3 Proposição de uma nova correlação para previsão da velocidade de blowout de jatos

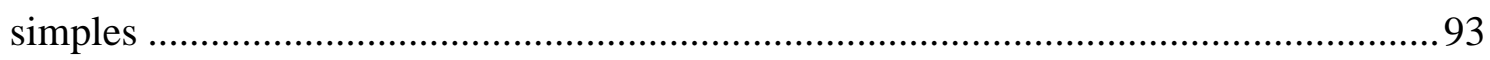

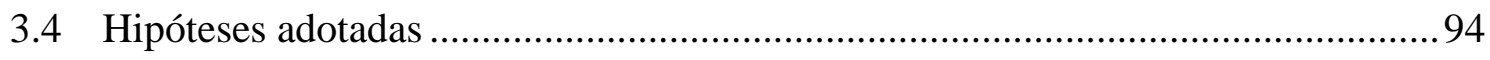

3.5 Critério para análise das previsões das correlações para a velocidade de blowout de jatos simples 95

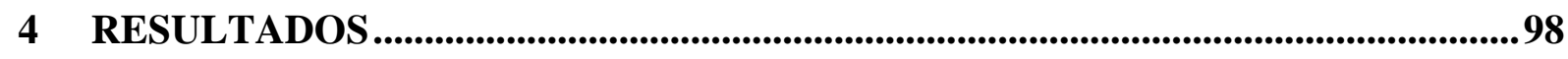

4.1 Análise das previsões das correlações para a velocidade de blowout ................... 98

4.2 Respostas às questões propostas .................................................................. 113

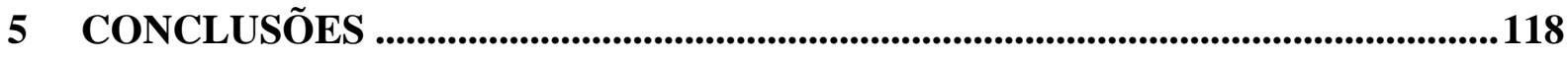

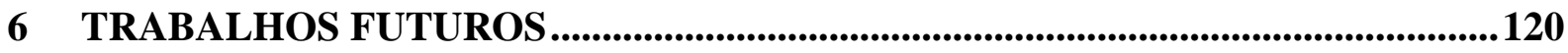

REFERÊNCIAS BIBLIOGRÁFICAS ......................................................................121 
APÊNDICE A - Conceitos fundamentais ........................................................................127

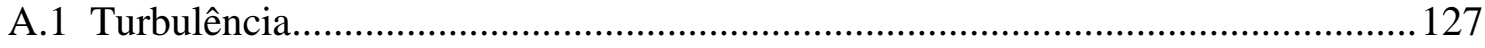

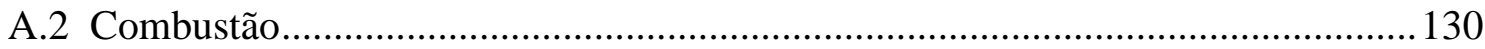

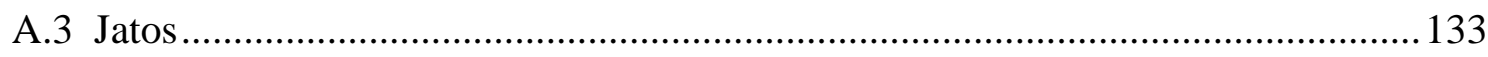

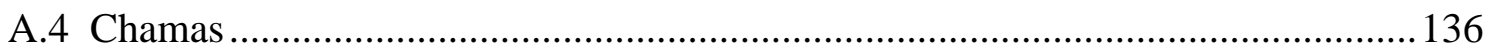

A.5 Limites de flamabilidade do combustível ........................................................... 137

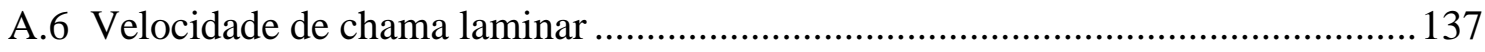

APÊNDICE B - Análise dos dados experimentais..............................................................142

APÊNDICE C - Análise do trabalho de Kalghatgi (1981) ......................................................146

APÊNDICE D - Exemplo de verificação da estabilidade da chama devido à substituição de combustível......................................................................................................................................164 


\section{INTRODUÇÃ̃o}

A combustão é uma reação química exotérmica entre combustível e comburente (reagentes), que ocorre a elevadas temperaturas e com taxas intensas. A velocidade com que essas transformações químicas se desenvolvem é denominada taxa de reação $\left(\dot{m}^{\prime \prime \prime}\right)$, caracterizada pela variação da concentração de uma das substâncias que participam das reações em função do tempo; e a região onde ocorrem é denominada frente de combustão, a qual se desloca em direção ao meio reagente.

A chama é uma propagação auto-sustentável de uma combustão localizada. Seu comportamento, tal como, estabilidade, forma e comprimento, depende do regime de escoamento dos reagentes e da velocidade de propagação de chama. Basicamente, a chama pode ser classificada como: pré-misturada, de difusão (ou não pré-misturada) ou mista; laminar ou turbulenta.

A chama pré-misturada é obtida em queimadores que promovem a mistura dos reagentes, com teor de combustível dentro dos limites de flamabilidade, antes que sejam lançados na câmara de combustão.

A chama de difusão (ou não pré-misturada) é obtida ao se realizar a descarga de gás combustível separadamente do comburente (ar), na região onde ocorre a combustão. Se as velocidades do gás combustível e do comburente forem baixas, a mistura (entre o gás, o ar e os produtos da combustão) ocorrerá basicamente por difusão molecular, estabelecendo-se, portanto, uma chama de difusão laminar. Entretanto, se pelo menos uma das velocidades for alta, a mistura ocorrerá devido ao transporte macroscópico de massa, formando então uma chama de difusão turbulenta. Nessas chamas, a taxa global da reação e, conseqüentemente, o comprimento da chama acoplada a determinado bocal são controlados principalmente pela mistura dos fluxos de gás combustível e ar. Assim, para um determinado bocal, o comprimento da chama não pode aumentar indefinidamente na medida em que se aumenta a vazão ou potência de operação, uma vez que com o aumento do número de Reynolds no bocal há o aparecimento da turbulência que aumenta acentuadamente a dinâmica da mistura entre os reagentes. (SOUSA, 2010) 
Para uma aplicação particular, o projetista de sistemas de combustão enfrenta muitas questões, como: forma, tamanho e estabilidade da chama; transferência de calor; e emissão de poluentes. O presente trabalho se concentra na estabilidade de chamas de difusão turbulenta. Detalhes da forma e comprimento destas chamas podem ser encontrados em Hottel e Sarofim (1967) e Stambuleanu (1976).

Chamas de difusão turbulenta ocorrem na maioria dos sistemas de combustão, como em: dispositivos destinados à fabricação de vidros e cimento, motores a diesel, caldeiras, póscombustores turbojatos, fornos industriais, flares, entre outros; principalmente devido à facilidade com que estas chamas podem ser controladas (TURNS, 2000).

Dada uma chama formada por um jato livre de gás, cuja velocidade de descarga perpendicular ao plano do bocal é $U_{n}$. A seção correspondente à base da chama localiza-se próxima ao plano do bocal (alguns milímetros de distância) se $U_{n}$ for baixo, e a chama é dita como colada (attached). À medida que se aumenta a velocidade de descarga, a base da chama começa a se afastar cada vez mais da saída do bocal, fenômeno este denominado liftoff. Este fenômeno é acompanhado pelo aumento da instabilidade da chama, caracterizado por uma variação quase periódica da distância de liftoff. Se, após esta situação, $U_{n}$ for progressivamente aumentada, atingirá um valor limite, $U_{b}$, no qual a chama é soprada e se extingue, ou seja, ocorre blowout. Logo, há uma faixa de condições (como velocidade de "descarga" do jato e concentração de combustível na mistura) na qual a combustão estável pode ser mantida, sendo limitada por dois fenômenos denominados liftoff (descolamento da base da chama do bocal e posterior estabilização desta a certa distância do bocal) e blowout (desprendimento e extinção da chama). Por razões de segurança, operações próximas a estas condições devem ser evitadas. A Figura (1.1) ilustra a altura de liftoff, $h$, de uma chama de difusão formada por um jato simples de gás combustível, descarregado por um bocal de diâmetro $d_{n}$ e velocidade $U_{n}$, em um meio em repouso.

A importância dos fenômenos de estabilidade, liftoff e blowout, na combustão turbulenta é evidente, porém a compreensão destes é quase inteiramente empírica (DAHM; MAYMAN, 1990).

CETAE; IPT e LETMCE, (2007) adotam o seguinte critério de estabilidade: "Uma chama é estável se a velocidade de descarga do combustível (ou mistura de combustível, ar e inertes) à saída do bocal for menor que a velocidade de blowout”. 


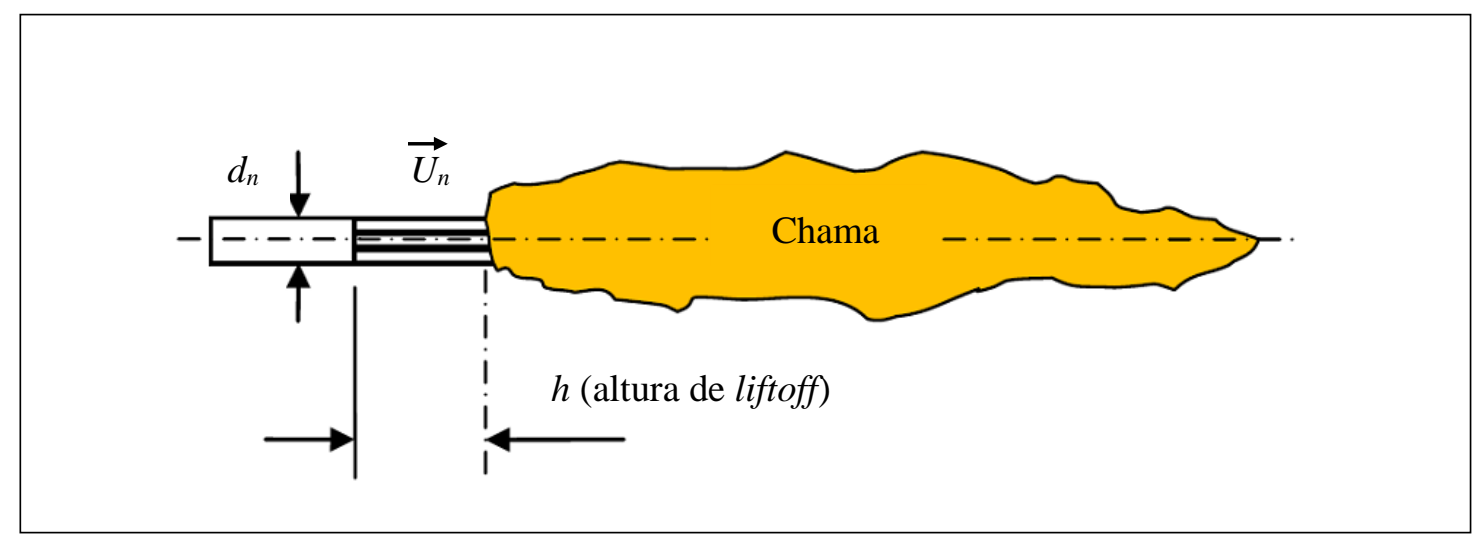

Figura 1.1. Esquema do deslocamento de uma chama de difusão (SOUSA, 2010).

Durante várias décadas, o fenômeno blowout tem sido considerado como um ponto especial que limita a estabilidade de chamas descoladas de jatos laminares e turbulentos. Consequentemente, vários modelos e mecanismos físicos têm sido propostos visando prever o limite de blowout e revelar o mecanismo de estabilização das chamas descoladas. Dentre estes, têm-se:

1. o modelo de combustão pré-misturada, apresentado por Wohl et al (1949) e utilizado por Vanquickeborne e Van Tiggelen (1966) e Kalghatgi (1984). Nele, o fenômeno de blowout é interpretado em termos dos conceitos de uma chama turbulenta prémisturada, em que é assumido que a base da chama descolada se estabiliza em uma região na qual a composição estequiométrica é alcançada e onde a velocidade de chama turbulenta é igual à velocidade local do escoamento. Nesta visão, o blowout ocorre para uma vazão na qual a velocidade de chama turbulenta, cai mais rapidamente do que a velocidade local do escoamento. Kalghatgi (1981) utiliza esta abordagem para propor uma correlação para estimar a velocidade de blowout de jatos simples, baseado em seus resultados experimentais.

2. o modelo de extinção dos flamelets, articulado por Janicka e Peters (1982) e Peters e Williams (1983), interpreta a chama de difusão turbulenta como um conjunto de "farrapos de chama" (flamelets) de difusão laminares que podem ser extintos quando submetidos a taxas de deformação superiores a um valor crítico.

3. o modelo de mistura em larga escala, proposto por Broadwell; Dam e Mungal (1984) e utilizado por Dahm e Dibble (1988), Dahm e Mayman (1990) e Feikema, Chen e 
Driscoll (1991) entre outros, aborda o blowout baseado no comportamento de mistura das grandes estruturas turbulentas do jato. Este modelo físico é descrito em termos do adimensional número de Damkhöler $(D a)$, ou seja, na razão entre o tempo de mistura turbulenta desses vórtices com o jato $\left(t_{d}\right)$ e o tempo de cinética química $\left(t_{c}\right)$. O blowout ocorre quando o número de Damkhöler é menor que um valor crítico.

4. o modelo combinado de propagação da chama pré-misturada e de extinção dos flamelets (MIAKE-LYE; HAMMER, 1988), o qual assume que os modelos de combustão pré-misturada e de extinção dos flamelets laminares são relevantes no processo de blowout, ou seja, adota os modelos (1) e (2).

5. o modelo de chama tripla, baseado na estrutura de chama tripla, definida pelos contornos onde a concentração do jato de combustível atinge os limites de flamabilidade (inferior e superior) e a estequiométrica, ou seja, $Y_{f, \min }, Y_{f, \max }$ e $Y_{f, s}$, respectivamente. Este modelo tem origem mais recente e foi articulado por Müller; Breitbach e Peters, (1995), Wu et al (2006), entre outros. A Figura (1.2) apresenta um esquema da estrutura de chama tripla. Wu et al (2006) afirmam que a posição $H_{w}$ (distância axial a partir da saída do bocal até posição de máximo raio do contorno estequiométrico) é o ponto de divisão entre as regiões instáveis e estáveis de chamas descoladas no processo de blowout; e que quando a base da chama é empurrada para uma distância $x>H_{w}$, a chama passa para uma região pulsante (instável), desencadeando o processo de blowout. Nesta situação, a velocidade de descarga do gás combustível é igual à velocidade de blowout do mesmo $\left(U_{n}=U_{b}\right)$.

Teorias e modelos utilizados para prever os limites de blowout são semelhantes aos que descrevem o mecanismo de estabilização das chamas descoladas. Portanto, várias teorias e modelos existentes de blowout baseiam-se no mecanismo de estabilização da chama descolada. Uma visão global deste assunto pode ser encontrada no trabalho de Pitts (1988) e Lyons (2007).

Todos os modelos apresentados acima são semi-empíricos e incluem parâmetros e/ou coeficientes determinados a partir de resultados experimentais. Portanto, suas aplicações são limitadas apenas a tipos específicos de condições de operação (KARBASSI, 1997). 


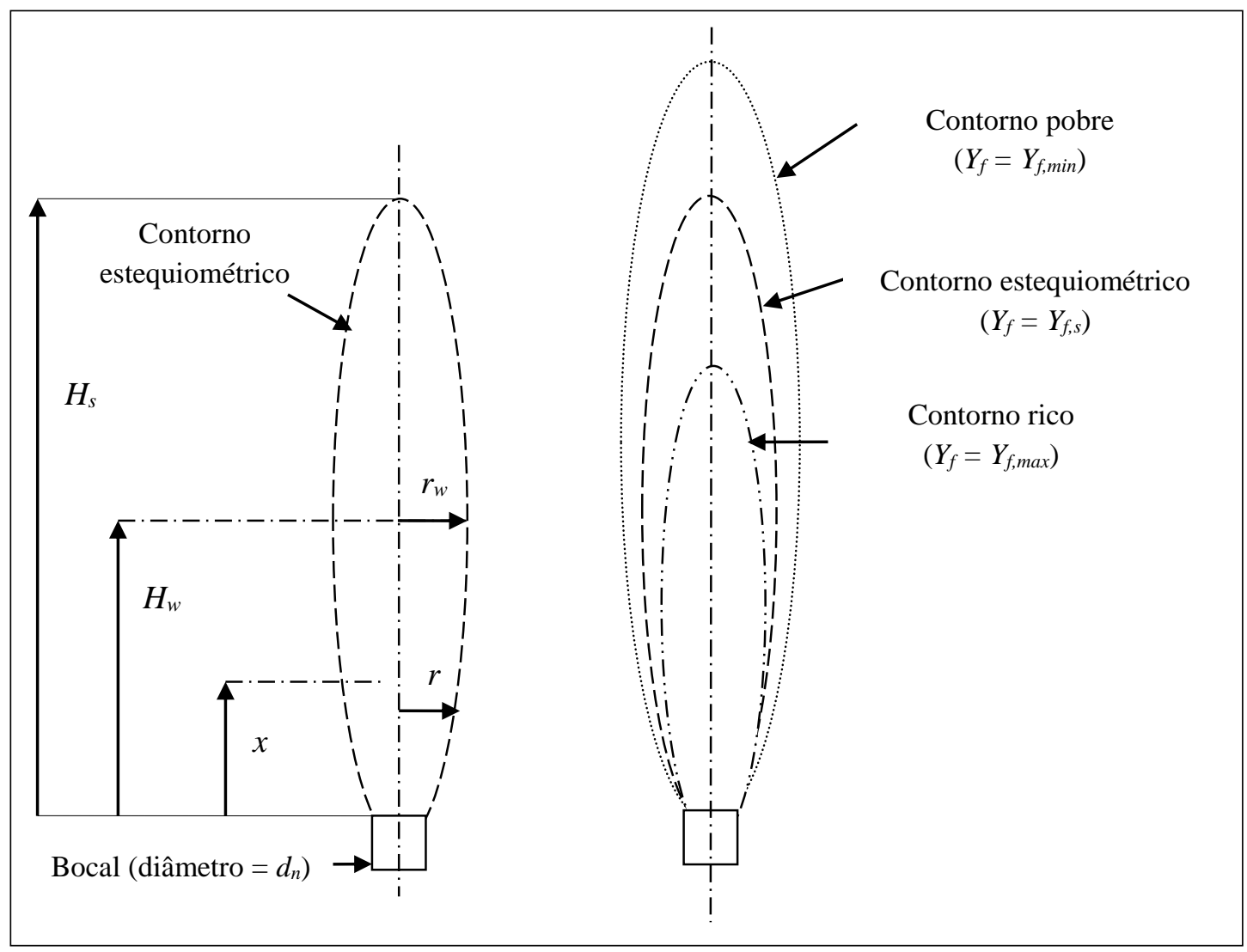

Figura 1.2. Esquema da estrutura de chama tripla.

O que dificulta a compreensão dos fenômenos de liftoff e blowout é o fato de estarem diretamente associados com a turbulência, que segundo Bradshaw (1971), é caracterizada por um movimento tridimensional e dependente do tempo, em que vórtices causam flutuações de velocidade, as quais se espalham em todos os comprimentos de onda entre um mínimo determinado pelas forças viscosas e um máximo determinado pelas condições de contorno do fluxo. É um estado comum no movimento de fluidos, exceto em escoamentos que apresentam baixos números de Reynolds.

Escoamentos turbulentos são muito mais comuns do que escoamentos laminares, principalmente, devido a sua maior capacidade de transporte e de mistura de fluidos (REYNOLDS, 1883). Porém a descrição matemática de escoamentos turbulentos e a solução das equações de conservação de massa e de energia são muito mais complexas do que as de escoamentos laminares. Soluções analíticas e numéricas destes escoamentos são aproximações e, mesmo para as geometrias simples, estão sujeitas a grandes erros se não for selecionado o modelo de turbulência adequado. Devido à enorme importância dos escoamentos turbulentos em engenharia e em outras aplicações, tem sido feito muito esforço para se entender a 
turbulência e desenvolver métodos descritivos e preditivos úteis no projeto de dispositivos (HINZE, 1959).

O presente trabalho irá abordar fenômenos complexos como combustão, turbulência e estabilidade; e pretende esclarecer algumas dúvidas com relação a estes mecanismos.

\subsection{Objetivos}

Os objetivos deste trabalho são:

1. Fazer um levantamento do conhecimento do estado da arte em estabilidade de chamas;

2. Apresentar as correlações para a velocidade de descarga que ocasiona blowout e as condições operacionais em que são válidas;

3. Identificar ou propor uma nova correlação, formalismo ou metodologia para prever a velocidade de blowout. O objetivo não é desenvolver modelos diferenciais que prevejam a estabilidade de chama. No entanto, modelos deste tipo poderão ser usados durante o desenvolvimento da correlação proposta para verificar a consistência teórica e faixa de validade das previsões;

4. Aplicar a nova correlação, formalismo ou metodologia a Casos de referência;

5. Comparar os resultados com dados experimentais e teóricos da Literatura; e

6. Realizar uma análise crítica sobre as possíveis causas dos desvios entre as previsões e os dados experimentais dos Casos de referência.

Durante o desenvolvimento do presente trabalho pretende-se responder as seguintes questões com relação à estabilidade de chamas difusão turbulenta, resultantes de um jato simples de gás combustível em um meio quiescente:

1. A altura de liftoff, $h$, depende do diâmetro do bocal, $d_{n}$ (conforme Fig. 1.1)?

2. É possível definir uma altura de blowout, $h_{b}$, como sendo a altura de descolamento imediatamente antes do blowout? 
3. Esta altura de blowout, $h_{b}$, depende do diâmetro do bocal, $d_{n}$ ? Por quê?

4. Qual critério (teoria/modelo) é mais adequado para definir estabilidade de chama de difusão turbulenta?

5. Como a adição de um fluxo oxidante concorrente ao jato de gás combustível influi na estabilidade da chama?

6. Chamas de determinado gás combustível são mais estáveis quando emergem de bocais simples ou de bocais coaxiais?

\subsection{Justificativas}

A compreensão dos mecanismos de estabilidade de chamas de difusão é de extrema importância para o dimensionamento de queimadores industriais e/ou substituição de gás combustível em queimadores existentes. Atualmente, o projeto destes equipamentos é baseado em resultados experimentais para determinadas condições de operação. Quando se deseja alterar vazão, temperatura, combustível, entre outras condições, enfrenta-se a ausência de correlações que prevejam características de instabilidade.

Este fato foi vivenciado recentemente pelas equipes do CETAE, IPT e LETMCE (2007) (informação verbal) ${ }^{1}$. Em uma determinada situação, uma companhia siderúrgica necessitava reduzir o uso dos combustíveis estabilizadores, principalmente o gás de coqueria (COG), nas caldeiras de sua central termoelétrica. O COG é proveniente do processo de coqueificação do carvão mineral e é considerado um gás nobre por possuir alto teor de hidrogênio (cerca de $61 \%$ em volume). O hidrogênio $\left(\mathrm{H}_{2}\right)$ apresenta elevado poder calorífico, ou seja, libera grande quantidade de energia ao sofrer combustão. A Tabela (1.1) apresenta valores de poder calorífico superior (PCS) e inferior (PCI) de alguns combustíveis. O PCI é o calor liberado pela combustão

\footnotetext{
${ }^{1}$ Informação fornecida por um ex-engenheiro do Instituto de Pesquisas Tecnológicas de São Paulo (IPT) que participou do trabalho do CETAE, IPT e LETMCE (2007).
} 
com o vapor de água não condensado; e o PCS é obtido pela soma do PCI e da entalpia de vaporização da água.

Além do poder calorífico elevado, o $\mathrm{H}_{2}$ possui alta difusividade em outros gases. Esta propriedade permite que, a uma distância muito pequena do bocal de descarga, já exista no entorno do jato de $\mathrm{COG}$, uma mistura de $\mathrm{H}_{2}$ e $\mathrm{O}_{2}$ (oxigênio) próxima da condição estequiométrica e, na presença de uma chama escorvadora (piloto), a reação de combustão deste hidrogênio inicia-se rapidamente. Isto resulta em uma chama mais estável, com menor propensão ao descolamento e, conseqüentemente, ao blowout. Esta característica da chama de jato de $\mathrm{H}_{2}$ será discutida na Seção (2) "Revisão bibliográfica".

Tabela 1.1. Poder calorífico superior e inferior de alguns combustíveis (PINTO).

\begin{tabular}{lcccc}
\hline \hline Combustível & PCS & PCS & PCI \\
{$[\mathrm{kcal} / \mathrm{kg}]$} & {$[\mathrm{kJ} / \mathrm{kg}]$} & $\begin{array}{c}\text { PCI } \\
{[\mathrm{kcal} / \mathrm{kg}]}\end{array}$ & {$[\mathrm{kJ} / \mathrm{kg}]$} \\
\hline Hidrogênio, $\mathrm{H}_{2}$ & 33947 & 142129 & 28681 & 120082 \\
Metano, $\mathrm{CH}_{4}$ & 13267 & 55546 & 11957 & 50062 \\
Etano, $\mathrm{C}_{2} \mathrm{H}_{6}$ & 12392 & 51883 & 11352 & 47529 \\
Propano, $\mathrm{C}_{3} \mathrm{H}_{8}$ & 12035 & 50388 & 11081 & 46394 \\
Butano, $\mathrm{C}_{4} \mathrm{H}_{10}$ & 11839 & 49568 & 10906 & 45661 \\
\hline \hline
\end{tabular}

$1 \mathrm{kcal}=4186,8 \mathrm{~J}$.

PCS e PCI avaliados a $15,5^{\circ} \mathrm{C}$ e 1 atm.

O combustível responsável pela maior parcela da potência fornecida para as caldeiras da companhia siderúrgica citada acima era o gás misto - mistura de BFG (Blast Furnace Gas) e LDG (Linz Donawitz Gas), podendo incluir menores proporções de COG e gás natural. Este gás apresenta velocidade de chama laminar baixa, logo, tem alta propensão ao descolamento (blowout). O COG era injetado coaxialmente com as chamas principais (de gás misto), com o objetivo de estabilizá-las. O fabricante das caldeiras recomendava que pelo menos $10 \%$ da potência total fornecida às caldeiras deveria provir do combustível estabilizador (COG), porém não forneceu nenhuma base teórica para esta restrição ou justificativas para seu redimensionamento. Para manter a demanda térmica requerida pelas caldeiras, com a redução de COG, seria necessário aumentar a vazão de gás misto e, conseqüentemente, a velocidade de descarga no bocal dos queimadores (uma vez que estes componentes seriam mantidos). Neste caso, o problema era: quanto é possível reduzir a utilização de COG, sem comprometer a 
estabilidade das chamas principais, ou seja, sem haver risco de blowout? Para responder esta questão, o CETAE; IPT e LETMCE (2007) investiram meses pesquisando e estudando sobre o assunto e perceberam a exigüidade de estudos direcionados para o mecanismo de blowout em chamas de difusão de jatos coaxiais, assunto fundamental para o dimensionamento de queimadores e alteração de condições operacionais. A raridade de trabalhos sobre este assunto também foi verificada pela presente autora durante o desenvolvimento da revisão bibliográfica.

A Tabela (1.2) apresenta as propriedades do BFG e do COG, segundo CETAE; IPT e LETMCE (2007).

Tabela 1.2. Características do BFG e do COG (CETAE; IPT; LETMCE, 2007).

\begin{tabular}{lcc}
\hline \hline Parâmetro & BFG & COG \\
\hline Teor de $\mathrm{H}_{2}$ [frac. vol.] & 0,040 & 0,607 \\
Teor de $\mathrm{CH}_{4}$ [frac. vol.] & 0,000 & 0,251 \\
Teor de $\mathrm{C}_{2} \mathrm{H}_{2}$ [frac. vol.] & 0,000 & 0,001 \\
Teor de $\mathrm{C}_{2} \mathrm{H}_{4}$ [frac. vol.] & 0,000 & 0,018 \\
Teor de $\mathrm{C}_{2} \mathrm{H}_{6}$ [frac. vol.] & 0,000 & 0,006 \\
Teor de $\mathrm{CO}$ [frac. vol.] & 0,245 & 0,063 \\
Teor de $\mathrm{CO}_{2}$ [frac. vol.] & 0,220 & 0,017 \\
Teor de $\mathrm{N}_{2}$ [frac. vol.] & 0,495 & 0,027 \\
Teor de $\mathrm{O}_{2}$ [frac. vol.] & 0,000 & 0,002 \\
Densidade [kg/Nm ${ }^{3}$ ] & 1,371 & 0,453 \\
PCI [kJ/Nm ${ }^{3}$ ] & 3495,310 & 18598,398 \\
PCI [kJ/kg] & 2550,242 & 41096,891 \\
PCS [kJ/Nm${ }^{3}$ ] & 3574,349 & 21110,385 \\
PCS [kJ/kg] & 2607,910 & 46647,631 \\
\hline \hline
\end{tabular}

Situações como a apresentada acima, em que uma indústria deseja substituir o combustível utilizado em seus processos ou alterar suas condições operacionais, são comuns. Fatores como o aumento da fiscalização com relação à emissão de poluentes, a variação da oferta e, conseqüentemente, dos preços de determinados combustíveis, e a busca por eficiência energética para ganho de competitividade, têm levado as empresas a procurarem combustíveis alternativos, menos poluentes, mais acessíveis e/ou provenientes de processos internos. Porém, quando tomam esta decisão, as empresas enfrentam a mesma dificuldade relatada por CETAE; IPT e LETMCE (2007). 


\section{REVISÃO BIBLIOGRÁFICA}

Por muitas décadas, o fenômeno de blowout tem sido considerado um ponto limite da estabilidade da altura de descolamento (liftoff) de chamas laminares e turbulentas. Vários modelos e mecanismos físicos têm sido propostos para explicar o blowout; dos quais, muitos são similares aos que descrevem o mecanismo de descolamento. A seguir estão descritas algumas teorias e trabalhos que abordam os fenômenos de descolamento e de blowout, em diferentes configurações de escoamento turbulento reativo.

\subsection{Estudos experimentais e analíticos do mecanismo de blowout de jatos simples em meio quiescente}

Nesta Subseção são apresentados estudos referentes à estabilidade de chamas de difusão turbulenta resultantes de um jato de gás combustível emergindo em um meio oxidante quiescente, isto é, em repouso. A compreensão dos fenômenos de descolamento e de blowout nesta configuração de escoamento é essencial para a análise dos mesmos fenômenos em outras configurações, apresentadas nas Subseções (2.2) e (2.3), as quais são encontradas em muitos equipamentos industriais, como em fornos, flares, chaminés, turbinas a gás, entre outros.

\subsubsection{Vanquickenborne e Van Tiggelen (1966)}

Vanquickenborne e Van Tiggelen (1966) apresentaram o primeiro trabalho com sólida argumentação teórica sobre chamas descoladas de bocais. A hipótese básica desse trabalho é que a chama descolada se estabiliza numa abscissa $h$ (a partir do bocal), tal que a velocidade do escoamento, próxima à periferia do jato (em uma distância radial $r$ na qual a concentração do gás no ar esteja entre os limites de flamabilidade) é igual à velocidade de chama turbulenta da pré-mistura estequiométrica de ar e gás. Esta hipótese está representada na Figura (2.1). 
A velocidade máxima de chama turbulenta depende da velocidade máxima de chama laminar e de parâmetros locais de turbulência, como intensidade das flutuações de velocidades e comprimento das estruturas turbulentas (vórtices). A partir dessa hipótese e de um trabalho extenso de medições de concentração, velocidade e intensidade de turbulência em um jato livre de metano, Vanquickenborne e Van Tiggelen (1966) demonstraram que:

1. a base da chama descolada se estabiliza num círculo de raio $r$ tal que nessa região existe pré-mistura de ar e gás e as concentrações estão entre os limites de flamabilidade; e

2. na região em que a base da chama se estabiliza, o escoamento é turbulento.

Quando a velocidade de descarga do jato é aumentada, a altura de liftoff atinge uma posição na qual a velocidade local do jato aumenta mais rapidamente do que a velocidade local de chama turbulenta e, consequentemente, a combustão não pode ser sustentada. Nesta abordagem, o blowout ocorre devido à diferença dessas velocidades.

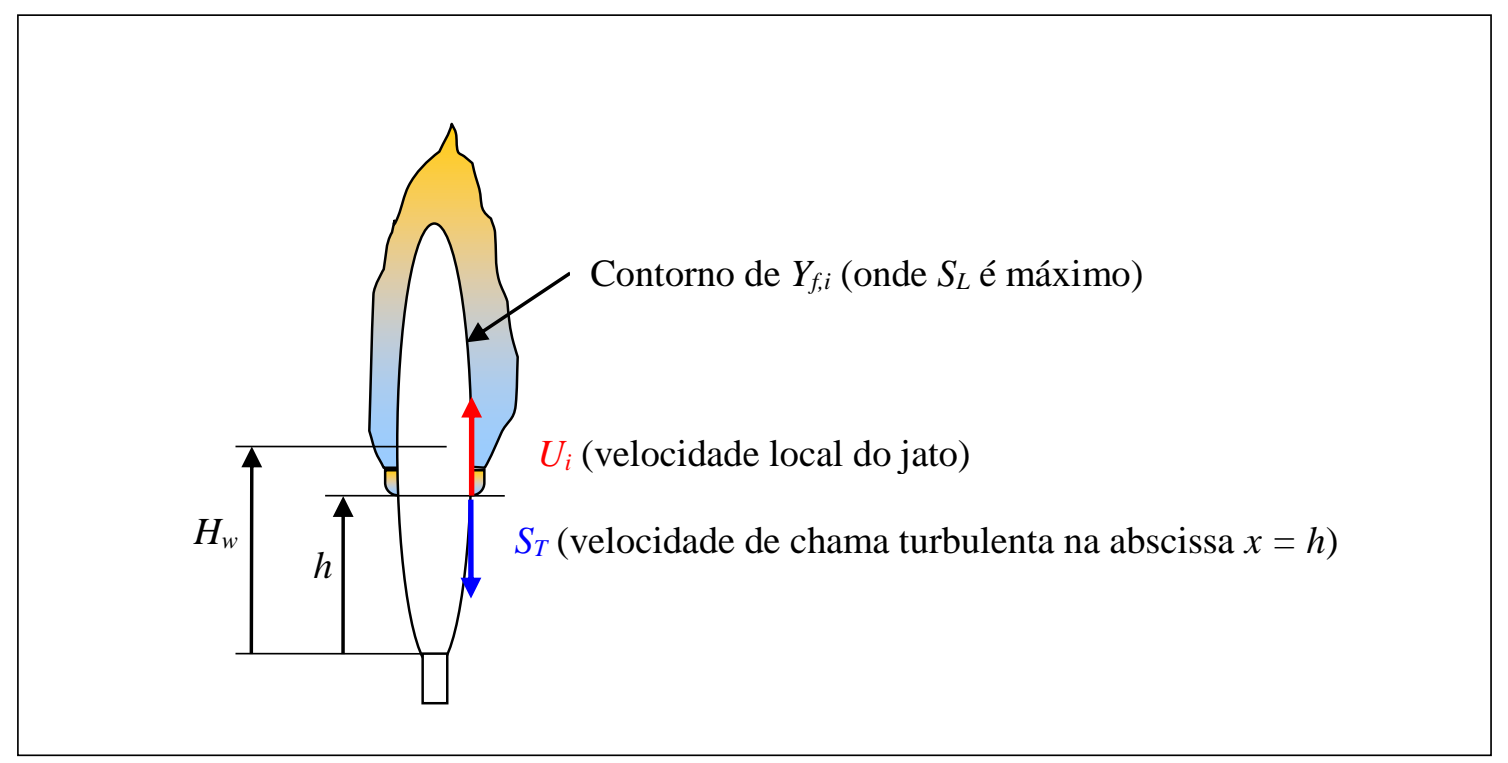

Figura 2.1. Esquema da hipótese de Vanquickenborne e Van Tiggelen (1966). (SOUSA, 2010)

Vanquickenborne e Van Tiggelen (1966) especularam que este fenômeno ocorria quando a abscissa $x$, onde a chama se estabilizaria, era maior que aquela correspondente ao maior raio do contorno estequiométrico, $H_{w}$ (vide Fig. 1.2). Recentemente, este fato foi discutido em detalhe no trabalho de $\mathrm{Wu}$ et al (2006). Esta abordagem para o blowout tem sido também 
utilizada ou sugerida por outros grupos de pesquisa, como Günther e Lenze (1979), Günther;

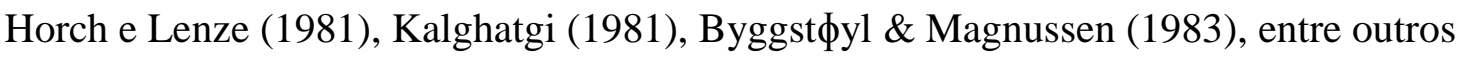

Günther e Lenze (1979) e Günther; Horch e Lenze (1981) estudaram o fenômeno de descolamento de jatos de gás natural e de misturas deste com hidrogênio; e relataram dados de descolamento, blowout e reinserção das chamas provenientes destes jatos.

\subsubsection{Kalghatgi (1981)}

Kalghatgi (1981) realizou um estudo experimental da estabilidade de blowout de jatos de chamas de difusão em ar baseado na abordagem de Vanquickenborne e Van Tiggelen (1966), em que o blowout ocorre devido ao desequilíbrio entre $S_{T}$ e $U_{i}$. A partir de uma análise teórica do fenômeno, verificou que a velocidade de saída do queimador que leva à blowout, $U_{b}$, depende de $H_{S}$ (vide Fig. 1.2), $S_{L}, v_{f, n}$ e $\left(\rho_{f, n} / \rho_{\infty}\right)$; e por análise dimensional simples (por exemplo, Lydersen, 1979) obteve:

$$
\frac{U_{b}}{S_{L}}=f\left(R e_{H_{S}} \frac{\rho_{f, n}}{\rho_{\infty}}\right)
$$

onde $S_{L}$ é a velocidade de chama laminar; $\rho_{f, n}$ e $\rho_{\infty}$ são as densidades do gás combustível na saída do bocal e do ar no entorno do jato, respectivamente; e $R e_{H_{S}}$ é o número de Reynolds baseado na posição $H_{s}$.

$$
R e_{H_{S}}=\frac{H_{s} S_{L}}{v_{f, n}}
$$

e $H_{s}$ é a distância a partir da seção de saída do bocal, onde a concentração de combustível cai para a estequiométrica. É pouco provável que a base da chama estável será descolada à jusante deste ponto. Segundo Kalghatgi (1981), $H_{s}$ independe da velocidade de saída do gás do queimador e é obtida por meio da Eq. $(2.3)^{2}$ :

\footnotetext{
${ }^{2}$ No trabalho de Kalghatgi (1981) o termo 5,8 da Eq. (2.3) aparece com sinal negativo. Este fato foi analisado pela presente autora, quem verificou que o sinal correto, para este termo, é positivo.
} 


$$
H_{s}=\left[4 \cdot \frac{Y_{f, n}}{Y_{f, s}}\left(\frac{\rho_{f, n}}{\rho_{\infty}}\right)^{\frac{1}{2}}+5,8\right] \cdot d_{n}
$$

onde $Y_{f, n}$ e $Y_{f, s}$ são as frações mássicas de combustível na saída do bocal e na condição estequiométrica, respectivamente; e $d_{n}$ é o diâmetro do bocal.

A relação funcional (Eq. 2.1) foi obtida por meio de experimentos realizados por Kalghatgi (1981). Os combustíveis utilizados e suas propriedades estão listados na Tabela (2.1). A temperatura de estagnação, $T_{0}$, foi assumida como sendo igual à temperatura ambiente, $290 \mathrm{~K}$.

Tabela 2.1. Propriedades dos gases combustíveis utilizados por Kalghatgi (1981).

\begin{tabular}{lcccccc}
\hline \hline Gás & $\begin{array}{c}\text { Composição } \\
{[\% \text { volume }]}\end{array}$ & $\begin{array}{c}\boldsymbol{M} \boldsymbol{M} \\
{[\mathrm{kg} / \mathrm{kmol}]}\end{array}$ & $\begin{array}{c}\boldsymbol{\mu} \text { a } 0^{\circ} \mathrm{C} \\
{[\text { poise] }}\end{array}$ & $\begin{array}{c}\boldsymbol{S}_{\boldsymbol{L}} \\
{[\mathrm{m} / \mathrm{s}]}\end{array}$ & $\left(\boldsymbol{c}_{\boldsymbol{p}} / \boldsymbol{c}_{\boldsymbol{v}}\right)$ & $\boldsymbol{Y}_{\boldsymbol{f}, \boldsymbol{s}}$ \\
\hline Metano & 99 & 16 & $1,03 \cdot 10^{-4}$ & 0,39 & 1,31 & 0,055 \\
Propano & 99 & 44 & $7,40 \cdot 10^{-5}$ & 0,45 & 1,13 & 0,06 \\
Etileno & 95 & 28 & $9,10 \cdot 10^{-5}$ & 0,75 & 1,255 & 0,063 \\
Acetileno & 95 & 26 & $9,35 \cdot 10^{-5}$ & 1,63 & 1,25 & 0,07 \\
Hidrogênio & 99 & 2 & $8,42 \cdot 10^{-5}$ & 3,06 & 1,4 & 0,028 \\
Butanos & 28 isobutano; & 54,1 & $8,00 \cdot 10^{-5}$ & 0,44 & 1,1 & 0,06 \\
comerciais & 42 $n$-butano; & & & & & \\
& 26 propano; & & & & & \\
& 4 outros. & & & & & \\
\hline \hline
\end{tabular}

Na Figura (2.2), o número Mach, Ma, na saída do queimador quando a chama sofre blowout é plotado em função do diâmetro do bocal, $d_{n}(2,0 \mathrm{~mm}-12,0 \mathrm{~mm})$, para diferentes gases. A partir desta figura, verifica-se que $M a$ aumenta quase linearmente com $d_{n}$ para todos os gases. Os mesmos dados são mostrados na Figura (2.3), como parcelas de uma velocidade adimensional $\widehat{U}_{b}$ em função do número de Reynolds, $R e_{H_{s}}$. Nesta figura, $\widehat{U}_{b}$ é dada por:

$$
\widehat{U}_{b}=\frac{U_{b}}{S_{L}} \cdot\left(\frac{\rho_{f, n}}{\rho_{\infty}}\right)^{3 / 2}
$$

Verifica-se que os dados dos diferentes gases colapsam em uma única curva, dada por:

$$
\widehat{U}_{b}=0,017 \cdot R e_{H_{S}} \cdot\left(1-3,5 \cdot 10^{-6} \cdot R e_{H_{S}}\right)
$$




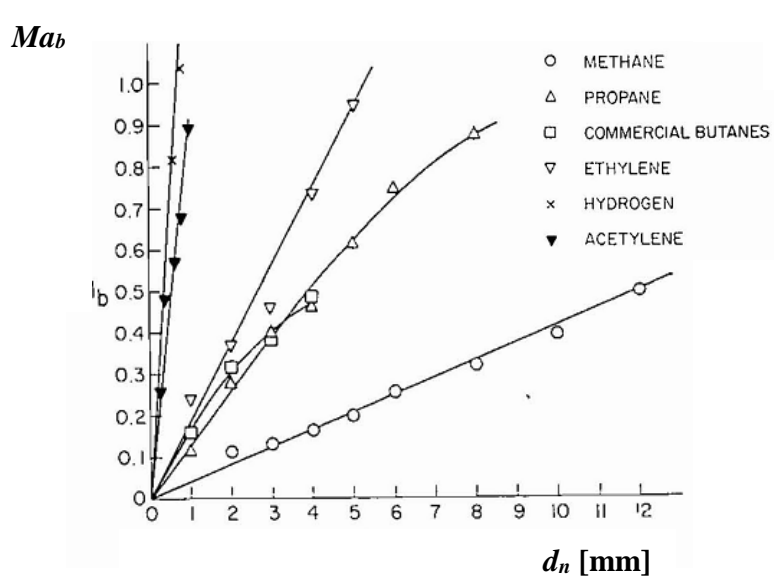

Figura 2.2. Número de Mach na saída do bocal que leva à blowout da chama.

(KALGHATGI, 1981)

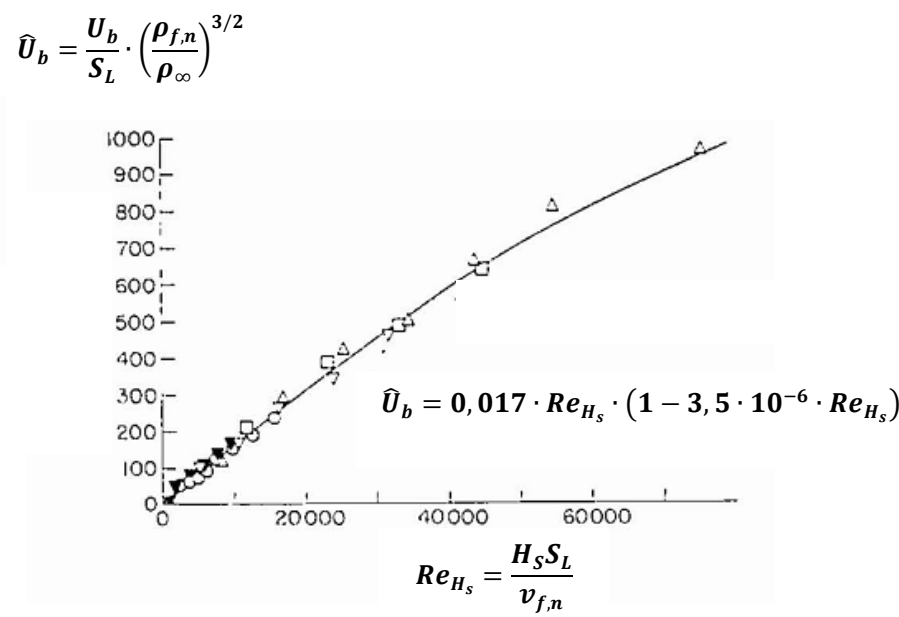

Figura 2.3. Curva universal de estabilidade de blowout. (KALGHATGI, 1981)

Substituindo a Eq. (2.4) na Eq. (2.5) e isolando $U_{b}$, obtemos:

$$
U_{b}=\left[0,017 \cdot R e_{H_{S}} \cdot\left(1-3,5 \cdot 10^{-6} \cdot R e_{H_{S}}\right)\right] \cdot S_{L} \cdot\left(\frac{\rho_{f, n}}{\rho_{\infty}}\right)^{-3 / 2}
$$

Kalghatgi (1981) nomeou a Eq. (2.5) de "fórmula universal”, cuja validade foi confirmada pelo estudo do blowout de chamas dos gases combustíveis apresentados na Tabela (2.1) e de misturas de metano/ar, metano/ $\mathrm{CO}_{2}$, propano/ar e propano/ $\mathrm{CO}_{2}$. Este autor verificou que a adição de $\mathrm{CO}_{2}$ e/ou ar (como diluentes) no jato de combustível reduz consideravelmente $U_{b}$, tendo o $\mathrm{CO}_{2}$ maior influência. Os resultados foram extrapolados para os casos em que o fluxo na saída do queimador, na condição de blowout, está blocado.

\subsubsection{Byggst $\phi y l$ e Magnussen (1983)}

Byggst $\phi y l$ e Magnussen (1983) propuseram um modelo para a extinção local da chama de um jato simples baseado no conceito de dissipação de vórtices (EDC, Eddy Dissipation Concept) no escoamento turbulento. A extinção ocorre nas menores estruturas (pequenos vórtices), responsáveis pela dissipação da turbulência e de energia mecânica. De acordo com este modelo, a chama deslocada do bocal se estabiliza em uma posição na qual sua base apresenta um contorno estequiométrico. Atribuem o descolamento da chama a um fenômeno de extinção 
local da combustão e mantêm o conceito de Vanquickenborne e Van Tiggelen (1966) de que o blowout decorre da impossibilidade de equilibrar $U_{i}$ e $S_{T}$ em qualquer seção sobre o contorno de $Y_{f, i}$ (vide Fig. 2.1). Os autores forneceram uma relação entre a altura de descolamento, $h$, e a velocidade de descarga do gás, $U_{n}$, a qual apresentou boa concordância com resultados experimentais.

\subsubsection{Peters e Williams (1983)}

Peters e Williams (1983) realizaram uma análise teórica sobre descolamento de chamas de difusão turbulentas. Argumentam que o grau de mistura molecular de jatos axissimétricos turbulentos é insuficiente para suportar o conceito de combustão pré-misturada apresentada por Vanquickenborne e Van Tiggelen (1966). Estes propõem o modelo dos flamelets ("farrapos de chamas") laminares, no qual uma chama de difusão turbulenta é considerada como um conjunto de flamelets de difusão laminares que podem ser extintos quando submetidos a taxas de tensão superiores a um valor crítico. Com o aumento da velocidade de saída do jato, os flamelets são esticados mais e mais, podendo resultar na extinção de uma grande fração destes na borda de uma chama colada no bocal e levando-a ao descolamento. A chama será estabilizada em algum lugar a jusante da saída do bocal, onde as taxas de deformação são suficientemente baixas e uma fração razoável dos flamelets permanece não extinta. Logo, o fenômeno de descolamento é atribuído à extinção dos "farrapos de chama" (flamelets). Eles especularam que este mecanismo poderia explicar o fenômeno de blowout. No entanto, concluíram que o blowout ocorria a distâncias $(x)$ muito menores do que o previsto pelo mecanismo de extinção das flamelets. Também especularam que as grandes estruturas turbulentas (grandes vórtices) poderiam influenciar esse fenômeno. Suas previsões do comportamento de descolamento são consistentes com as observações experimentais de Günther; Horch e Lenze (1981).

\subsubsection{Kalghatgi (1984)}

Kalghatgi (1984) segue o modelo proposto por Vanquickenborne e Van Tiggelen (1966), o qual supõe que a mistura ar-combustível seja totalmente pré-misturada na base da chama descolada 
e descreve um estudo sistemático dos fatores que afetam a altura de descolamento, $h$ (distância entre o plano de saída do queimador e a base da chama descolada). Segundo este autor, quase todos os resultados anteriormente publicados para $h$, foram para as chamas de metano. Em seu trabalho, apresenta resultados para chamas de propano, hidrogênio e etileno, além de metano, descarregados por bocais de diâmetros, $d_{n}$, entre $1,08 \mathrm{~mm}$ e $10,1 \mathrm{~mm}$. Para o hidrogênio, os resultados foram extendidos para o regime em que o fluxo na saída do queimador é blocado $(M a=1)$.

Kalghatgi (1984) identificou agrupamentos adimensionais de vários parâmetros do escoamento e do gás que influenciam $h$; e encontrou uma única curva empírica em termos destes agrupamentos, a qual descreve todas as suas observações experimentais.

As alturas de descolamento, $h$, dos quatro gases combustíveis analisados foram plotadas em função da velocidade de descarga dos gases, $U_{n}$, para os vários diâmetros de bocais; e verificouse que $h$ :

1. independe do diâmetro do bocal; e

2. aumenta linearmente com $U_{n}$; exceto perto do limite de blowout $\left(U_{n} \cong U_{b}\right)$, pois neste caso há o surgimento de uma região de instabilidade da chama.

Segundo Kalghatgi (1984), há um consenso razoável entre seus resultados para o metano e os obtidos por Vanquickenborne e Van Tiggelen (1966). No entanto, as alturas de descolamento para o metano e propano medidos em seu trabalho são, em geral, maiores do que as obtidas por Annushkin e Sverdlov (1979).

Segundo Vanquickenborne e Van Tiggelen (1966), a chama estabiliza-se em uma região prémisturada na borda externa da camada de mistura do jato turbulento e, no anel de estabilização, a velocidade local do escoamento médio, $U_{i}$, é igual à velocidade de chama turbulenta local, $S_{T}$. Os dois perfis de velocidades, $U_{i}$ e $S_{T}$, na altura $h$, estão apresentados na Figura (2.4), onde $r$ é a coordenada radial e $U_{c}$ é a velocidade na linha de centro do jato. A presente autora opinou por apresentar $S_{T}$ em módulo (diferente de KALGHATGI, 1984 e de VANQUICKENBORNE; VAN TIGGELEN, 1966), pois a direção de $S_{T}$ é oposta a direção do escoamento principal, ou seja, oposta a $U_{i}$. Kalghatgi (1984) assume que a chama se estabiliza, onde o valor de $S_{T}$ é máximo. Nos limites de flamabilidade inferior e superior, $S_{T}$ é nulo e espera-se que o valor máximo de $S_{T}$ ocorra a uma distância radial, $r_{S}$, onde a concentração de combustível é tal que 
a velocidade de chama laminar, $S_{L}$, tem o seu valor máximo. Segundo Kalghatgi (1984), quando $S_{L}$ é máximo, $Y_{f}=Y_{f, s}$. Para hidrocarbonetos, $H_{s}$ é aproximadamente igual à distância radial $r_{s}$, em que a mistura combustível-comburente é estequiométrica $\left(Y_{f}=Y_{f, s}\right)$ (KALGHATGI, 1984).

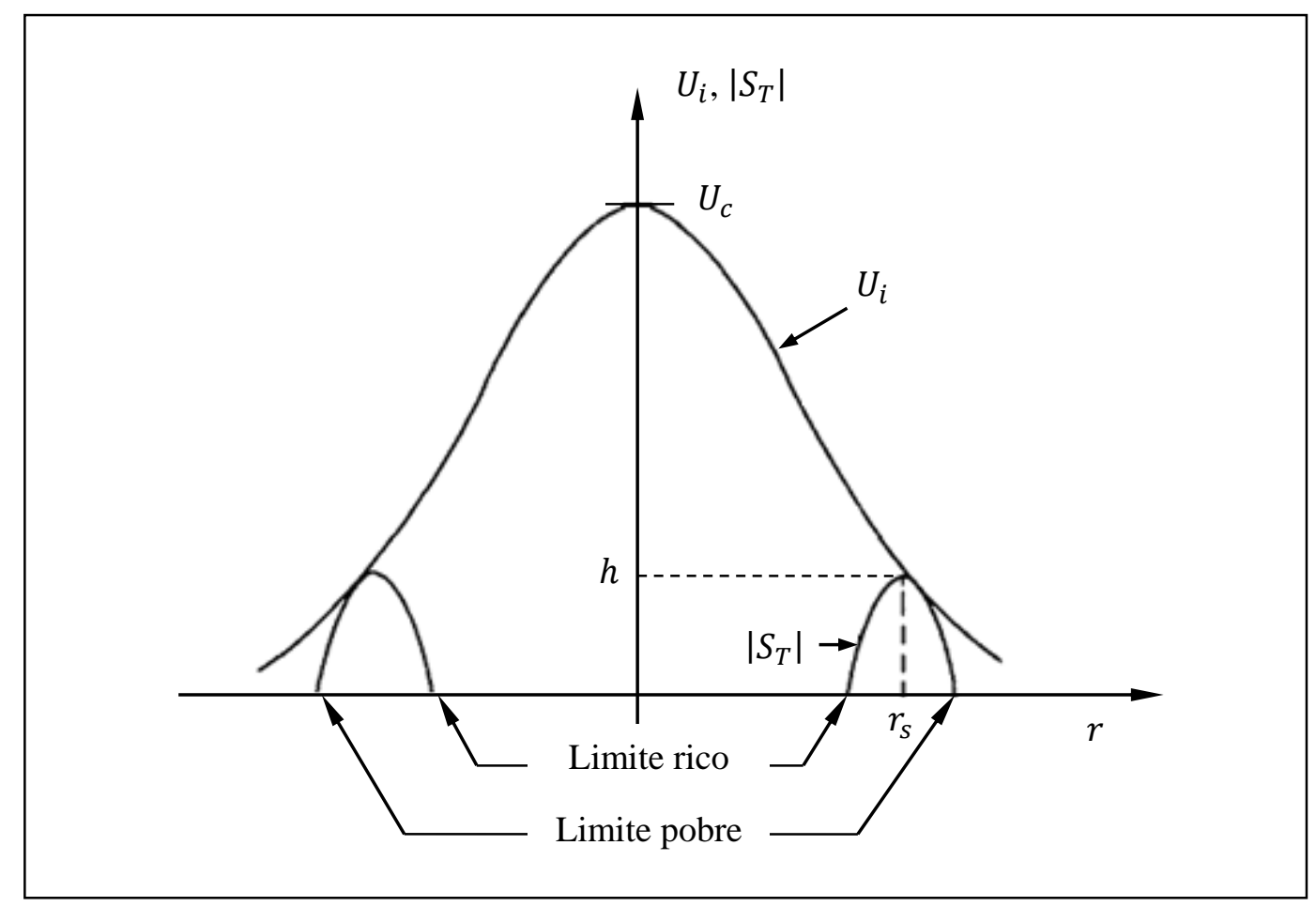

Figura 2.4. Esquema dos perfis da velocidade média, $U_{i}$, e da velocidade de chama turbulenta, $S_{T}$.

O valor máximo de $S_{T}$ depende de $S_{L}$ e dos parâmetros locais de turbulência. Estes valores e a velocidade local do fluxo médio na região externa da camada de mistura, $U_{i}$, dependem da velocidade, $U_{n}$, da viscosidade cinemática do gás na condição de saída do bocal, $v_{f, n}$, e da relação de densidades $\left(\rho_{f, n} / \rho_{\infty}\right)$ no entorno do jato. Conseqüentemente, espera-se que $h$ seja uma função de $S_{L}, U_{n}, v_{f, n}$ e $\left(\rho_{f, n} / \rho_{\infty}\right)$. Por análise dimensional simples (por exemplo, LYDERSEN, 1979), espera-se que:

$$
R e_{h} \equiv \frac{h S_{L}}{v_{f, n}}=f\left(\frac{U_{n}}{S_{L}} ; \frac{\rho_{f, n}}{\rho_{\infty}}\right)
$$

Na verdade, Kalghatgi (1984) plotou $R e_{h}$ em função de $\widehat{U}_{n}$, definido por:

$$
\widehat{U}_{n}=\frac{U_{n}}{S_{L}} \cdot g\left(\frac{\rho_{f, n}}{\rho_{\infty}}\right)
$$


e a função $g\left(\frac{\rho_{f, n}}{\rho_{\infty}}\right)$ é definida como

$$
g\left(\frac{\rho_{f, n}}{\rho_{\infty}}\right)=0,04+0,46\left(\frac{\rho_{f, n}}{\rho_{\infty}}\right)+0,5\left(\frac{\rho_{f, n}}{\rho_{\infty}}\right)^{2}
$$

Para gases hidrocarbonetos de metano a butano, em que $0,5<\left(\frac{\rho_{f, n}}{\rho_{\infty}}\right)<2$ :

$$
g\left(\frac{\rho_{f, n}}{\rho_{\infty}}\right) \cong\left(\frac{\rho_{f, n}}{\rho_{\infty}}\right)^{3 / 2}
$$

Kalghatgi (1984) percebeu que os resultados experimentais de $h$ em função de $U_{n}$ (para todos os combustíveis) poderiam ser interpolados em uma única curva empírica em termos dos agrupamentos adimensionais $R e_{h}$ e $\widehat{U}_{n}$, conforme mostrado na Figura (2.5).

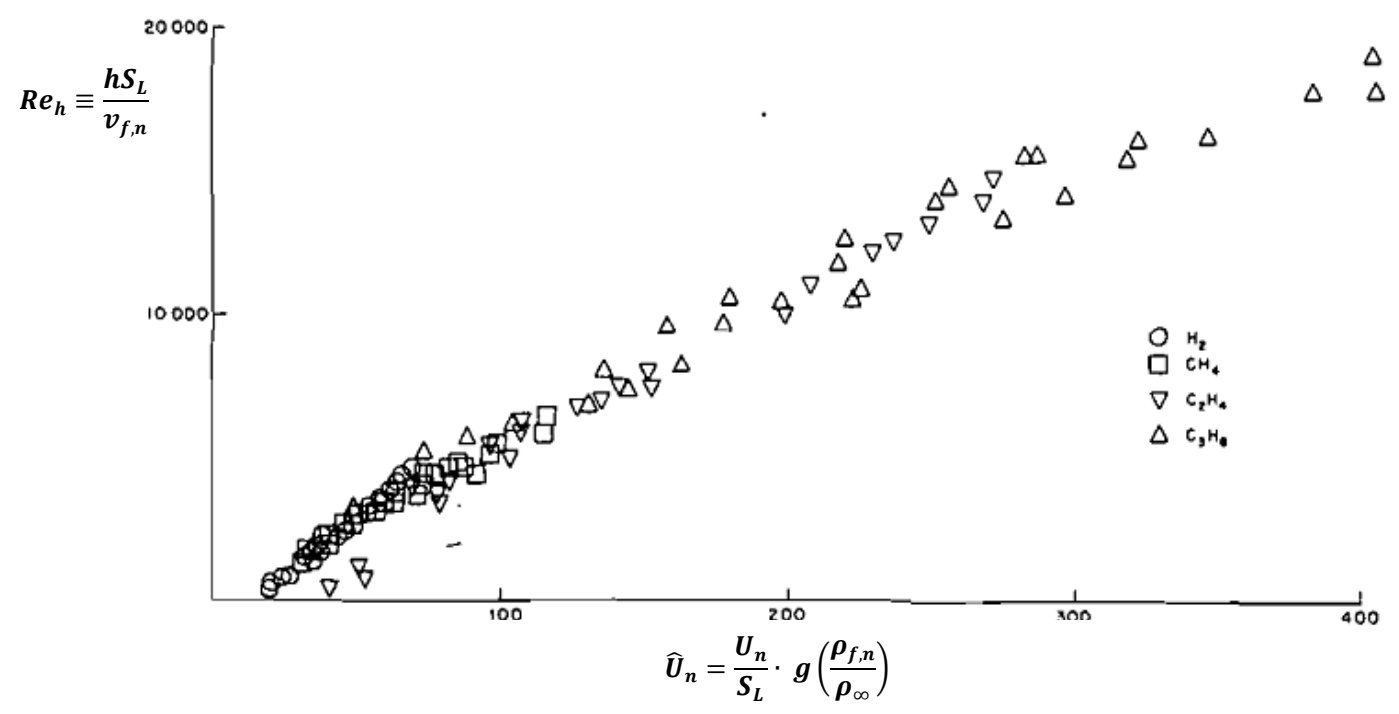

Figura 2.5. Curva adimensional da altura de descolamento. (KALGHATGI, 1984)

Kalghatgi (1984) apresenta que, no limite de estabilidade de blowout, a velocidade $U_{n}$ pode ser correlacionada por uma função da forma:

$$
\frac{U_{n}}{S_{L}}\left(\frac{\rho_{f, n}}{\rho_{\infty}}\right)^{3 / 2}=C_{K, 1}\left(\frac{H_{S} S_{L}}{v_{f, n}}\right)
$$

onde $H_{S}$ é a distância do plano de saída em que a concentração média de gás no eixo do jato cai para a estequiométrica; e $C_{K, 1}$ é uma constante entre 0,013 e 0,015 . 
A partir da Figura (2.5), Kalghatgi (1984) apresenta, para gases de hidrocarbonetos:

$$
\left(\frac{h S_{L}}{v_{f, n}}\right)=C_{K, 2}\left(\frac{U_{n}}{S_{L}}\right)\left(\frac{\rho_{f, n}}{\rho_{\infty}}\right)^{3 / 2}
$$

ou

$$
h=C_{K, 2} v_{f, n}\left(\frac{U_{n}}{S_{L}^{2}}\right)\left(\frac{\rho_{f, n}}{\rho_{\infty}}\right)^{3 / 2}
$$

onde $C_{\mathrm{K}, 2}$ é uma constante, cujo valor é aproximadamente 50; os subscritos $n$ e $\infty$ referem-se respectivamente às propriedades do gás na saída do bocal e do ar ambiente.

Das Eqs. (2.10) e (2.11), pode-se deduzir que as chamas de difusão turbulentas sofrem blowout quando a relação $h / H_{s}\left(=C_{\mathrm{K}, 1} \cdot C_{\mathrm{K} .2}\right)$ atinge valor entre 0,65 e 0,75. Segundo Kalghatgi (1984), isto é consistente com a proposição de Hall et al (1980), que o blowout ocorre quando a base da chama atinge a posição axial, $H_{w}$, onde a coordenada radial do perfil de concentração estequiométrica é máxima, $r_{w}$.

Analisando a Eq. (2.12), verifica-se que a altura de liftoff de chamas de difusão turbulentas, $h$, independe do diâmetro do bocal $\left(d_{n}\right)$ e das propriedades difusivas do gás combustível, como as difusividades mássica $(\mathcal{D})$ e térmica $\left(\alpha_{f}\right)$.

\subsubsection{Chung e Lee (1991)}

Chung e Lee (1991) realizaram um estudo experimental e analítico sobre chamas de difusão laminares. Eles defendem que o número de $\operatorname{Schmidt}\left(S c=v_{f} / \mathcal{D}\right)$ e o número de Lewis $(L e=$ $\left.\alpha_{f} / \mathcal{D}\right)$ são parâmetros importantes para a estabilização de chamas laminares, pois o transporte de massa nos escoamentos laminares é dominado pela difusividade mássica molecular. Apresentaram uma relação entre a altura de liftoff, $h$, e o número de Schmidt do combustível, $S c$, para um jato laminar axissimétrico com perfil de velocidade uniforme na saída do bocal.

$$
h=C^{\prime} d_{n}^{2} U_{n}^{(2 S c-1) /(S c-1)}
$$

onde $d_{n}$ é o diâmetro do bocal, $U_{n}$ é a velocidade na saída do bocal e $C^{\prime}$ é uma constante que depende do tipo de combustível. 
Baseados nesta equação, Chung e Lee (1991) propuseram que: (1) quando $S c>1$, é possível a formação de uma chama laminar descolada (por exemplo, a chama de propano); (2) quando 1 $>S c>0,5$, não é possível a formação de uma chama laminar descolada (por exemplo, as chamas de metano e etano); e (3) quando $S c<0,5$, a chama laminar permanece colada no bocal (por exemplo, a chama de hidrogênio).

Chung e Lee (1991) defendem que o número de Schmidt, Sc, é um "parâmetro chave" para descrever as características de descolamento de chamas laminares, e que para estas chamas $h$ é função de $d_{n}$, diferente do que ocorre em chamas turbulentas.

A abordagem exposta por Kalghatgi (1984) permite calcular um valor fixo da altura de liftoff de chamas de difusão turbulentas (vide Eq. 2.12). No entanto, essa altura varia com o tempo, uma vez que existem flutuações de velocidade e de concentração em cada ponto do jato (pois o escoamento é turbulento). A magnitude dessa variação de $h$ está associada à amplitude das flutuações e ao valor de $U_{n}$. Portanto, ao se aumentar a velocidade de descarga, não apenas se aumenta o valor de $h$, mas também a instabilidade da chama. Uma abordagem detalhada sobre o surgimento de uma região de instabilidade da chama, previamente ao blowout, pode ser encontrada no trabalho de Wu et al (2006).

Kalghatgi (1984) também propõe uma equação que relaciona a velocidade de chama turbulenta, $S_{T}$, com a velocidade de chama laminar, $S_{L}$, na base da chama descolada, ou seja, quando $x=$ $h$ :

$$
\frac{S_{T}^{2}}{S_{L}^{2}}=C_{K, 3} \cdot R e_{l} \cdot f\left(Y_{S}, \frac{\rho_{f, n}}{\rho_{\infty}}\right)
$$

onde $C_{K, 3}$ é uma constante, cujo valor varia entre 0,56 e 1,3, para os gases analisados; $f$ é uma função que depende da fração mássica de gás combustível na mistura estequiométrica, $Y_{s}$, e da razão de densidades do gás e do $\operatorname{ar}, \rho_{f, n} / \rho_{\infty}$ (metano $f=0,138$; propano $f=0,123$, etileno $f$ $=0,14$; hidrogênio $f=0,3$ ); e $R e_{l}$ é o número de Reynolds turbulento local com base na escala integral:

$$
R e_{l}=\frac{u^{\prime} l}{v_{s}}
$$

onde $u^{\prime}$ é a raiz quadrada da média das flutuações de velocidade na direção axial; $v_{S}$ é a viscosidade cinemática da mistura estequiométrica $\left(v_{s} \cong 2,3 \cdot 10^{-5} \mathrm{~m}^{2} / \mathrm{s}\right)$; e $l$ é o comprimento da escala integral. 


\subsubsection{Broadwell; Dam e Mungal (1984)}

Broadwell; Dam e Mungal (1984) propõem outra abordagem para o blowout, baseada no comportamento de mistura das grandes estruturas turbulentas do jato. O modelo físico apresentado é descrito em termos do número adimensional de Damkhöler $(D a)$, ou seja, na relação entre o tempo de mistura turbulenta desses vórtices com o jato $\left(t_{d}\right)$ e o tempo de cinética química $\left(t_{c}\right)$.

O tempo de mistura $t_{d}$ é proporcional à $\left(d_{x} / U_{c, x}\right)$, isto é,

$$
t_{d} \sim \frac{d_{x}}{U_{c, x}}
$$

onde $d_{x}$ e $U_{c, x}$ são o diâmetro e a velocidade locais do jato.

O tempo químico $t_{c}$ está relacionado com a velocidade de chama laminar, $S_{L}$, e a difusividade térmica, $\alpha_{s}$, da seguinte forma:

$$
t_{c} \sim \frac{\alpha_{s}}{S_{L}^{2}}
$$

onde $\alpha_{s}=k / \rho c_{p}$ ( $k$ é a condutividade térmica; e $c_{p}$ é o calor específico a pressão constante da mistura combustível/ar estequiométrica).

Broadwell; Dam e Mungal (1984) postulam que o blowout ocorre para um valor crítico do número de Damkhöler, $D a_{c r i t}$, onde

$$
\left.D a_{c r i t}=\frac{t_{d}}{t_{c}}\right)_{c r i t}=\frac{d_{H_{S}} / U_{c, H_{S}}}{\alpha_{S} / S_{L}^{2}}
$$

onde o subscrito $H_{S}$ indica que $d_{H_{S}}$ e $U_{c, H_{S}}$ são avaliados na abscissa $H_{s}$, que é proporcional ao comprimento da chama, $L$; e o subscrito $c$ indica que $U$ é avaliado na linha central do jato.

Pode-se mostrar, por similaridade e conservação da quantidade de movimento (TENNEKES; LUMLEY, 1972), que

$$
d_{x}=C_{B, 1} x
$$

ou seja, que o diâmetro do jato, $d_{x}$, aumenta linearmente com a distância $x$ a partir do bocal; e que

$$
U_{c, x}=C_{B, 2} U_{n} \frac{d_{n}}{x}\left(\frac{\rho_{f, n}}{\rho_{\infty}}\right)^{1 / 2}
$$


Portanto,

$$
\frac{d_{H_{s}}}{U_{c, H_{S}}}=\frac{C_{B, 1}}{C_{B, 2}} \frac{H_{s}^{2}}{U_{n} d_{n}}\left(\frac{\rho_{f, n}}{\rho_{\infty}}\right)^{-1 / 2}
$$

Broadwell; Dam e Mungal (1984) assumem que o comprimento da chama, $L$, é dado por $L=$ $C_{B, 3} d_{n}\left(\rho_{f, n} / \rho_{\infty}\right)^{1 / 2} \varphi_{s}$; e que a distância $H_{s}$ é proporcional à $L$, ou seja, $H_{s} \sim L$. Logo,

$$
H_{s}=C_{B, 4} d_{n}\left(\frac{\rho_{f, n}}{\rho_{\infty}}\right)^{1 / 2} \varphi_{s}
$$

onde $\varphi_{s}$ é a relação mássica estequiométrica ar/combustível. Substituindo $H_{S}$ na Eq. (2.21),

$$
t_{d} \sim \frac{d_{H_{s}}}{U_{c, H_{s}}} \sim \frac{d_{n}}{U_{n}}\left(\frac{\rho_{f, n}}{\rho_{\infty}}\right)^{1 / 2} \varphi_{s}^{2}
$$

Substituindo as Eqs. (2.17) e (2.23) na Eq. (2.18), tem-se que:

$$
D a_{c r i t}=\frac{d_{n} S_{L}^{2}}{U_{b} \alpha_{s}}\left(\frac{\rho_{f, n}}{\rho_{\infty}}\right)^{1 / 2} \varphi_{s}^{2}
$$

Observe que, na condição de blowout, $U_{n}=U_{b}$ e que todas as constantes foram unidas em $D a_{\text {crit }}$ (vide Eq. 2.18).

Segundo a Eq. (2.24), a velocidade de blowout aumenta:

1. linearmente com o diâmetro do bocal do queimador, $d_{n}$;

2. com o quadrado da velocidade de chama laminar, $S_{L}$, e da razão mássica estequiométrica ar/combustível, $\varphi_{s} ; \mathrm{e}$

3. com a raiz quadrada da razão de densidades de combustível/ar.

A Figura (2.6), extraída do trabalho de Broadwell; Dam e Mungal (1984), apresenta os resultados experimentais de Kalghatgi (1981). A partir desta Figura, verifica-se que $U_{b}$ varia, aproximadamente, de forma linear com $d_{n}$ para os gases combustíveis analizados, como é previsto pela Eq. (2.24).

Segundo Broadwell; Dam e Mungal (1984), $d_{n} / U_{b}$ é aproximadamente constante para cada gás; $\operatorname{logo}, D a_{\text {crit }}$ (vide Eq. 2.24) precisa ser avaliado apenas para cada gás, com $d_{n} / U_{b}$ determinado pelas inclinações das linhas da Figura (2.6). As outras variáveis necessárias na expressão para $D a_{c r i t}$ estão contidas na Tabela (2.2), com exceção de $\alpha_{s}$, a qual é admitida como sendo a mesma para todos os gases e (arbitrariamente) igual a difusividade do ar a 2000K e pressão 
ambiente. Esta hipótese é válida, pois as temperaturas de chama adiabática dos gases analisados são aproximadamente iguais, exceto para o hidrogênio.

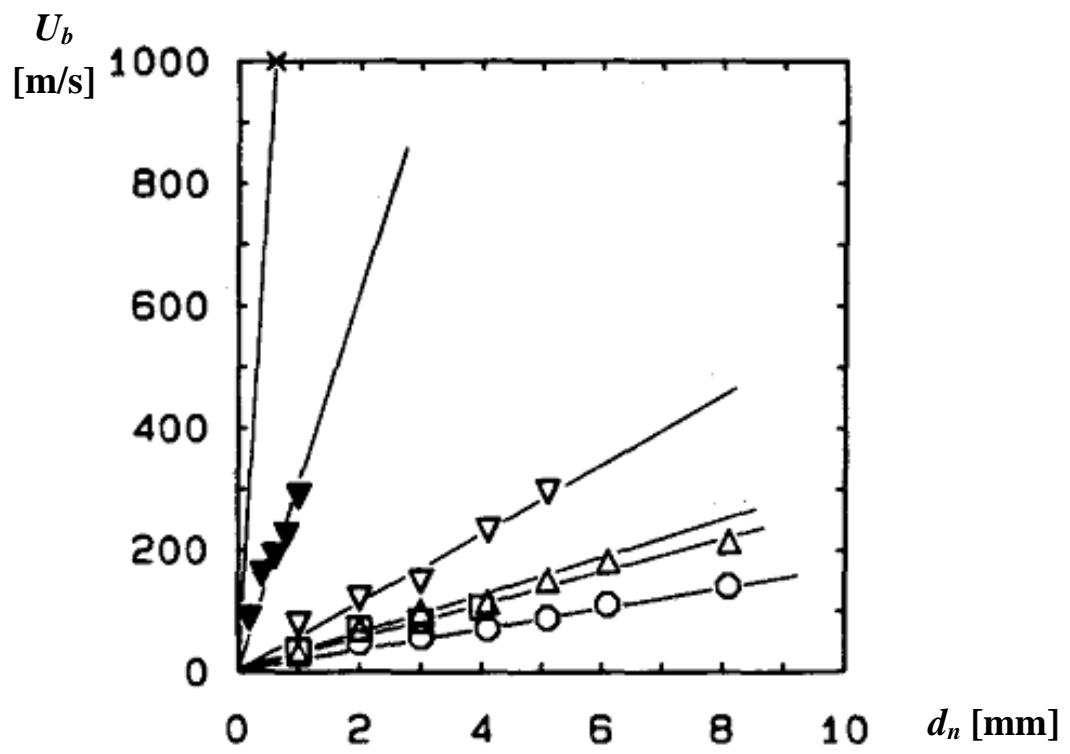

Figura 2.6. Velocidades de blowout em função do diâmetro do bocal do queimador. (KALGHATGI, 1981 apud BROADWELL; DAM; MUNGAL, 1984)

$\circ$ - metano; $\Delta$ - propano; $\nabla$ - etileno; $\times$ - hidrogênio; $\square$ - butano; $\nabla$ - acetileno.

Os resultados $\left(D a_{\text {crit }}\right)$ são apresentados na Tabela $(2.2)$, na qual se verifica que $D a_{\text {crit }}$ é aproximadamente o mesmo para todos os gases. Broadwell; Dam e Mungal (1984) sugerem que se use o valor médio de $D a_{\text {crit }}=4,8$ para realizar estimativas da velocidade de blowout. Segundo Sousa (2010), esta aproximação fornece valores completamente diferentes dos resultados de Kalghatgi (1981), dos quais Broadwell; Dam e Mungal (1984) partiram.

Tabela 2.2. Valores do parâmetro de blowout, $D a_{\text {crit }}$ (BROADWELL; DAM; MUNGAL, 1984).

\begin{tabular}{cc}
\hline \hline Gás & $\boldsymbol{D \boldsymbol { a } _ { \text { crit } }}$ \\
\hline Metano & 4,6 \\
Propano & 5,6 \\
Etileno & 5,3 \\
Acetileno & 3,9 \\
Butano & 4,8 \\
Hidrogênio & 4,4 \\
Valor médio & $\mathbf{4 , 8}$ \\
\hline \hline
\end{tabular}


Isolando $U_{b}$ na Eq. (2.24), obtem-se:

$$
U_{b}=\frac{d_{n} S_{L}^{2}}{D a_{c r i t} \alpha_{s}}\left(\frac{\rho_{f, n}}{\rho_{\infty}}\right)^{1 / 2} \varphi_{s}^{2}
$$

Comparando as previsões analíticas com os experimentos de combustíveis diluídos, realizados por Kalghatgi (1981), Broadwell; Dam e Mungal (1984) sugerem a Eq. (2.26) para obter uma relação entre a velocidade de blowout do combustível puro, $\left(U_{b}\right)_{f}$, e a velocidade de blowout da mistura deste combustível com $\mathrm{CO}_{2},\left(U_{b}\right)_{m}$, dada por:

$$
\frac{\left(U_{b}\right)_{m}}{\left(U_{b}\right)_{f}}=\left(\frac{S_{L_{m}}}{S_{L_{f}}}\right)^{2}\left(\frac{\varphi_{m}}{\varphi_{f}}\right)^{2}\left(\frac{\rho_{m}}{\rho_{f}}\right)^{1 / 2}
$$

em que os subscritos $m$ e $f$ referem-se a mistura e ao combustível puro, respectivamente. $\mathrm{O}$ símbolo $\varphi_{m}$ denota a massa de ar necessária para queimar o combustível por unidade de massa da mistura de combustível-CO $\mathrm{CO}_{2}$. Segundo Broadwell; Dam e Mungal (1984) as previsões concordam qualitativamente com os resultados experimentais.

A partir de simplificações nas expressões do trabalho de Kalghatgi (1981), Broadwell; Dam e Mungal (1984) propõem a Eq. (2.27) para determinação da velocidade de blowout.

$$
U_{b}=0,068 \frac{d_{n} S_{L}^{2}}{v_{f, n}}\left(\frac{\rho_{f, n}}{\rho_{\infty}}\right)^{-1} \varphi_{s}
$$

onde $\varphi_{s}$ é a razão mássica estequiométrica ar/combustível $\left(\varphi_{s}=\frac{1}{Y_{f, s}}-1 \cong \frac{1}{Y_{f, s}}\right)$; e $v_{f, n}$ é a viscosidade cinemática do gás combustível na saída do bocal.

Para obter a equação (2.27), Broadwell; Dam e Mungal (1984) realizaram as seguintes simplificações:

1. desprezaram o termo 5,8 da expressão (2.3);

2. desprezaram o termo $\left(3,5 \cdot 10^{-6} \cdot R e_{H_{S}}\right)$ da expressão $(2.5)$;

3. consideraram $Y_{f, n}=1$, ou seja, combustível puro saindo do bocal; e

4. consideraram o número de Prandtl próximo da unidade, ou seja, $v_{f, n} \cong \alpha_{f, n}$. 
Os autores também apresentaram a expressão (2.28) para a altura de descolamento, $h$, em função da velocidade de saída do jato, mas a validade desta expressão não foi verificada por eles.

$$
h \sim\left[U_{n} d_{n}\left(\frac{\rho_{f, n}}{\rho_{\infty}}\right)^{1 / 2} \frac{\alpha_{f, n}}{S_{L}^{2}}\right]^{1 / 2}
$$

A Eq. (2.28) discorda do trabalho de Kalghatgi, pois segundo este autor, $h$ independe $d_{n}$.

\subsubsection{Mike-Lye e Hammer (1988)}

Mike-Lye e Hammer (1988) mediram experimentalmente a altura de descolamento, $h$, de jatos de metano e etileno, ambos diluídos com ar; e mostraram, assim como Kalghatgi (1984), que $h$ aumenta com o acréscimo da velocidade de descarga do jato e/ou com a quantidade de diluição. Estes autores desenvolveram um modelo baseado na taxa de deformação, devido aos movimentos de grande escala, em uma chama descolada proveniente de um jato simples turbulento axissimétrico, para predizer uma relação linear entre a altura de descolamento e a velocidade de saída do jato. Segundo eles, os resultados deste modelo estão de acordo com alturas de descolamento previamente medidas para vários combustíveis puros.

\subsubsection{Muller, Breitbach e Peters (1994)}

Muller, Breitbach e Peters (1994) utilizaram a teoria dos flamelets parcialmente pré-misturados para preverem as alturas de descolamento de chamas de jatos simples de metano relatadas por Kalghatgi (1984) e Miake-Lye e Hammer (1988). Concluíram que ambos os modelos de estabilização da propagação das chamas parcialmente pré-misturado e de extinção dos flamelets laminares são relevantes. 


\subsubsection{Pitts (1989)}

Pitts (1989) realizou um estudo sobre as teorias que descrevem as características de descolamento e de blowout de chamas de difusão turbulentas. Resumiu as hipóteses feitas quanto ao processo físico responsável por esses fenômenos para cada modelo e comparou com os comportamentos reais de combustível de jatos turbulentos não queimados. Concluiu que nenhuma das teorias avaliadas para a estabilização da chama era satisfatória e que experimentos ainda são necessários para prever com exatidão a altura de descolamento e a velocidade de blowout.

Pitts (1989) apresenta a Eq. (2.29.a) para determinação da velocidade de blowout, obtida a partir do trabalho de Kalghatgi (1981) e das simplificações de Broadwell; Dam e Mungal (1984), com exceção da última $(\operatorname{Pr} \approx 1)$.

$$
U_{b}=0,136 \cdot \frac{r_{e}}{Y_{f, s}} \cdot \frac{S_{L}^{2}}{v_{f, n}} \cdot \frac{1}{R_{\rho}^{3 / 2}}
$$

onde $R_{\rho}=\left(\frac{\rho_{f, n}}{\rho_{\infty}}\right) ; r_{e}$ é o raio efetivo $r_{e}=r_{n} \cdot\left(\frac{\rho_{f, n}}{\rho_{\infty}}\right)^{1 / 2}$; e $r_{n}=\frac{d_{n}}{2}$. Substituindo estas relações na Eq. (2.26.a), obtemos a Eq. (2.29.b) que é igual a Eq. (2.27) apresentada por Broadwell; Dam e Mungal (1984).

$$
U_{b}=0,068 \cdot \frac{d_{n}}{Y_{f, s}} \cdot \frac{S_{L}^{2}}{v_{f, n}} \cdot\left(\frac{\rho_{f, n}}{\rho_{\infty}}\right)^{-1}
$$

Pitts (1989) também apresenta a Eq. (2.30.a), oriunda do trabalho de Broadwell; Dam e Mungal (1984), como alternativa para determinar $U_{b}$.

$$
U_{b}=0,417 \cdot r_{e} \cdot \frac{S_{L}^{2}}{\alpha} \cdot \varphi_{s}^{2}
$$

Substituindo $r_{e}=\frac{d_{n}}{2} \cdot\left(\frac{\rho_{f, n}}{\rho_{\infty}}\right)^{1 / 2}$ na Eq. (2.30.a) obtemos a Eq. (2.30.b), que é igual a Eq. (2.25) proposta por Broadwell; Dam e Mungal (1984) admitindo $D a_{c r i t}=4,8$ (valor médio do número de Damkhöler crítico dos gases analisados).

$$
U_{b}=0,208 \cdot d_{n} \cdot\left(\frac{\rho_{f, n}}{\rho_{\infty}}\right)^{1 / 2} \cdot \frac{S_{L}^{2}}{\alpha} \cdot \varphi_{s}^{2}
$$


Segundo Pitts (1989), a Eq. (2.30.a) correlaciona muito bem os resultados experimentais de Kalghatgi (1981). Esta afirmação foi analisada está apresentada nas subseções (4.1) (item 4.1.2) e (4.2).

A partir da Tabela (2.1) verifica-se que os valores de $Y_{f, s}$ são pequenos $(\approx 0,06$ para os hidrocarbonetos e 0,028 para o hidrogênio) e os valores de $\varphi_{s}$ são aproximadamente iguais a $\left(1 / Y_{f, s}\right)$. As Eqs. (2.29.a) e (2.30.a) tem dependências iguais com relação a $S_{L}$ e $r_{e}$, e diferentes com relação a $Y_{f, s}, v_{f, s}$, e $R_{\rho}$. Valores de $Y_{f, s}$ para os hidrocarbonetos são quase constantes $(0,055-0,07)$, portanto a grande diferença entre as duas correlações está no produto $\left(v_{f, s} \cdot R_{\rho}^{3 / 2}\right)$, presente na Eq. (2.29.a) e ausente na Eq. (2.30.a).

Para o hidrogênio, o produto $\left(v_{f, s} \cdot R_{\rho}^{3 / 2}\right)$ é muito menor que os valores obtidos para os hidrocarbonetos. Por esta razão, as Eqs. (2.29) e (2.30) dão estimativas muito diferentes para a velocidade de blowout do hidrogênio. Kalghatgi (1981) relatou duas medições experimentais de $U_{b}$ para chamas de jato de hidrogênio $\left(d_{n}=0,6 \mathrm{~mm}\right.$ e $\left.0,8 \mathrm{~mm}\right)$.

Pitts (1989) afirma que:

1. a Eq. (2.30) fornece boas estimativas para a velocidade de blowout do hidrogênio, enquanto as previsões usando a Eq. (2.29) são muito altas (cerca de duas vezes maiores); $\mathrm{e}$

2. o sucesso da Eq. (2.30) para este combustível (hidrogênio) proporciona a verificação de que o termo $\left(v_{f, s} \cdot R_{\rho}^{3 / 2}\right)$ não deve ser incluído nas correlações de blowout, ou seja, que a correlação proposta por Broadwell; Dam e Mungal (1984) admitindo $D a_{\text {crit }}=4,8$ (Eq. 2.27) é mais adequada que a correlação de Kalghatgi (1981) simplificada, Eq. (2.29), para prever $U_{b}$ para todos os gases estudados (metano, propano, etileno, acetileno, hidrogênio e butano comercial).

A presente autora realizou uma análise destas afirmações (1 e 2), segundo a metodologia apresentada na Seção (3); os resultados encontram-se na Subseção (4.1). Em resumo, verificouse que a equação proposta por Broadwell; Dam e Mungal (1984) Eq. (2.30) é mais adequada para prever $U_{b}$ do hidrogênio do que a Eq. (2.29), simplificação da equação proposta por Kalghatgi (1981). Porém, isso nem sempre é verdade para os demais gases estudados (metano, propano, etileno, acetileno e butano comercial). 
A Figura (2.7) foi extraída do trabalho de Pitts (1989) e compara os valores previstos de $U_{b}$ com os resultados experimentais, em função de $r_{n}$ (raio do bocal, $r_{n}=d_{n} / 2$ ) para cinco gases de hidrocarbonetos.

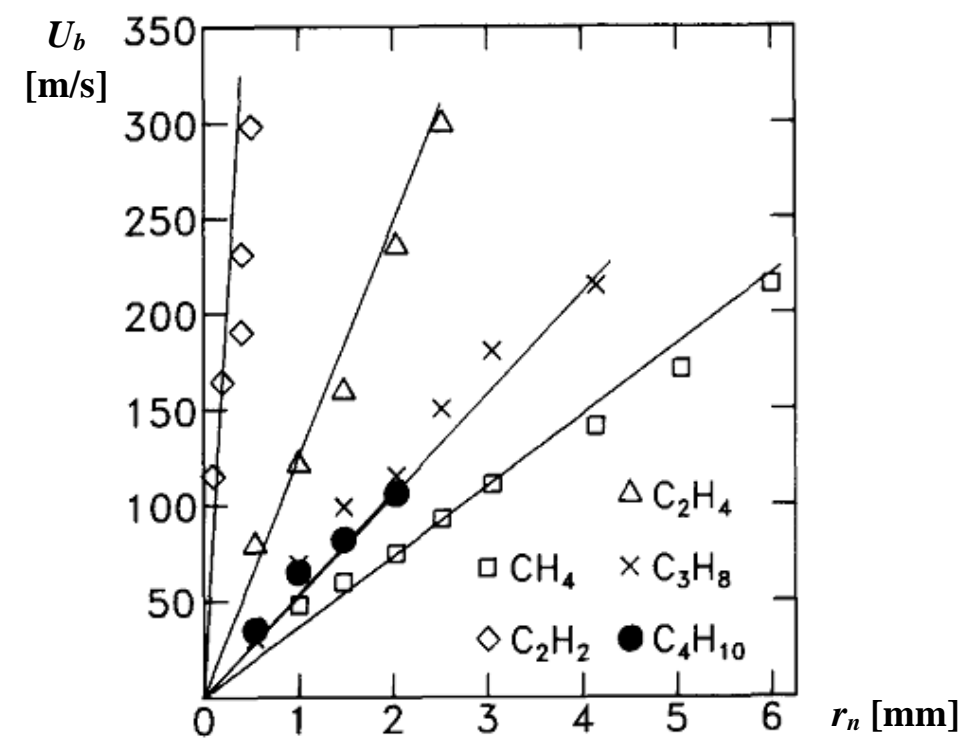

Figura 2.7. Valores calculados (linhas sólidas) e resultados experimentais (símbolos) da velocidade de blowout de cinco combustíveis em função do raio do bocal. (PITTS, 1989)

\subsubsection{Chao et al (2000)}

Chao et al (2000) realizaram um estudo experimental com metano, utilizando técnicas e dispositivos de observação não intrusivos, para investigar o processo de blowout. Verificaram que o processo pode ser dividido em quatro regiões (pulsante, início do recuo, recuo e extinção) de acordo com a estrutura e o comportamento da chama.

A Figura (2.8) mostra o comportamento geral de um processo de blowout da chama proveniente de um jato de metano, cujo bocal possui $10,0 \mathrm{~mm}$ de diâmetro, $d_{n}$. Esta figura apresenta o comprimento da chama, $L$, em função da altura de descolamento $h$; e fotografias da chama nas regiões pulsante, início de recuo, recuo e extinção, durante o processo de blowout. É possível verificar que $L$ diminui à medida que a base da chama se afasta do bocal, ou seja, à medida que $h$ aumenta. Na região pulsante (I), a chama é muito instável e é caracterizada pela coloração azul. Ela pode permanecer nesta posição por um longo período (por exemplo, mais de 20 
segundos) ou, após algumas oscilações, se afastar do bocal até sua extinção. Quando a base da chama alcança certa altura $h$ (neste caso, $h=13,5 \mathrm{~cm}$ ), a chama começa a recuar, sendo incapaz de retornar a posição inicial e se extingue. Esta é a região de início de recuo (II), na qual é possível verificar a presença de faixas avermelhadas na chama azul. À medida que a chama se afasta do bocal, a ponta da chama torna-se avermelhada, enquanto que sua base permanece azul. Esta é a região de recuo (III). Aparentemente, é nesta situação em que o comprimento da chama, $L$, é mais afetado pela altura de descolamento, $h$. Quando $h=28 \mathrm{~cm}$, o comprimento da chama torna-se muito pequeno, cerca de 6,5 $d_{n}$, reduzindo-se a medida que $h$ aumenta, até a extinção da chama. Esta é a região de extinção (IV), onde se observa novamente a coloração azul no vestígio de chama.

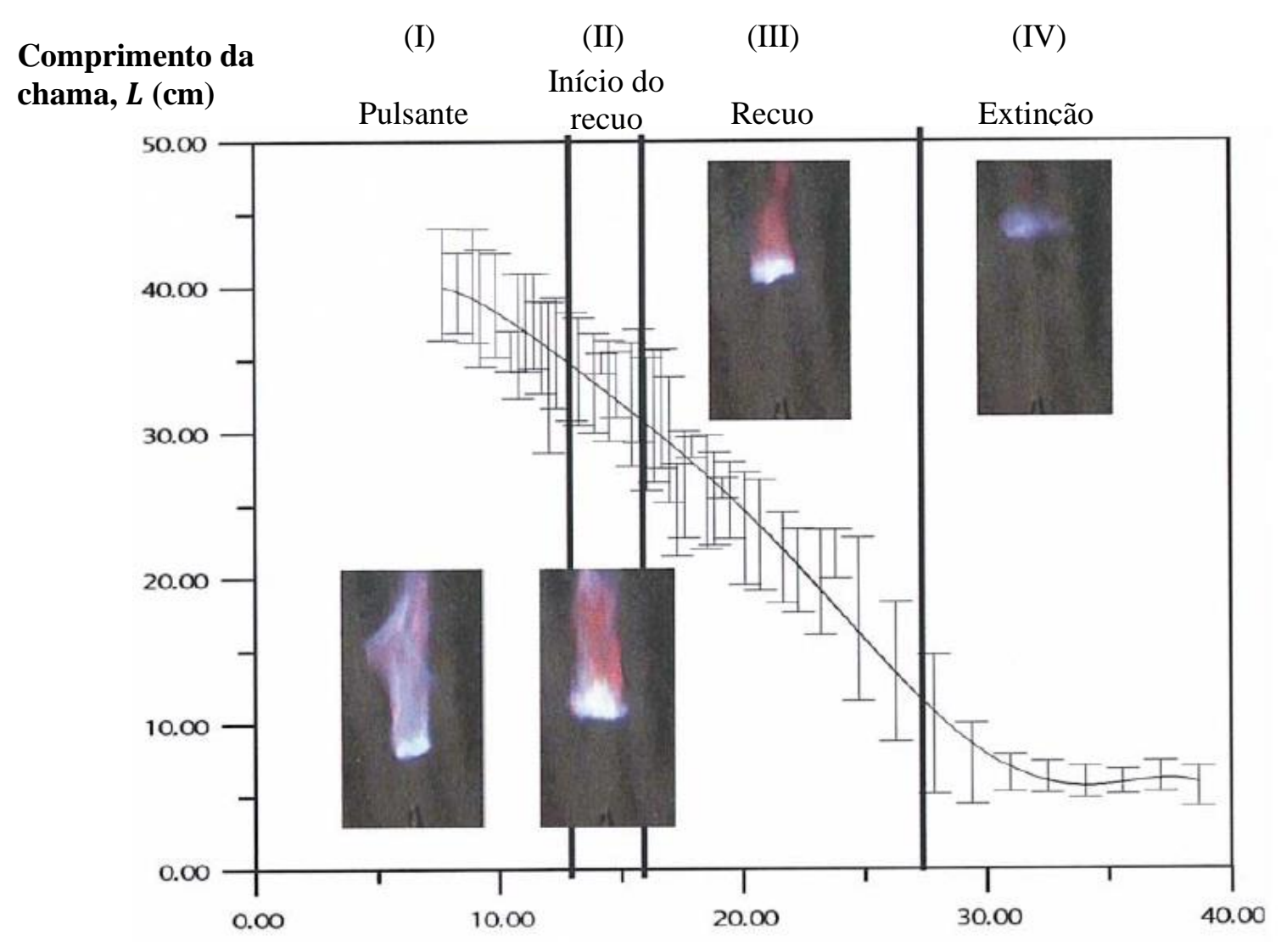

Altura de descolamento, $h(\mathrm{~cm})$

Figura 2.8. Comprimento da chama em função da altura de descolamento $h$, e as regiões pulsante, início de recuo, recuo e extinção durante o processo de blowout de uma chama de um jato simples de metano.

(CHAO et al, 2000)

Apartir dos resultados experimentais, Chao et al (2000) afirmam que as instabilidades na frente de chama, na região (II), podem ter um papel fundamental no desencadeamento do processo de 
blowout; defendem a possível existência da estrutura de chama tripla na base da chama nas regiões (II) e (III); e verificaram altas taxas de tensão na base da chama na região (II), maiores que as taxas de extinção, as quais podem ser consideradas o fator proeminente no processo de blowout.

\subsubsection{Chao et al (2004)}

Chao et al (2004) examinaram as teorias de blowout propostas por Kalghatgi (1981) e por Broadwell; Dam e Mungal (1984) usando um extenso banco de dados de jatos de chamas de metano, propano e hidrogênio com diluentes inertes (hélio, argônio, nitrogênio e dióxido de carbono), obtidos experimentalmente. Os resultados mostraram que a fórmula universal proposta por Kalghatgi (1981), Eq. (2.6), fornece previsões da velocidade de blowout mais próximas das medidas para uma faixa de condições de operação maior. Devido a este fato, os autores sugerem uma modificação no modelo proposto por Broadwell; Dam e Mungal (1984), que inclui o efeito do número de Schimidt e do número de Reynolds, quando este é inferior a 30000 (isto é, $R e \leq 3,0 \cdot 10^{4}$ ).

$$
\frac{U_{b, e x p}}{U_{b}}=300 \cdot S c^{0,065} \cdot R e^{-0,512}
$$

onde $U_{b, \exp }$ e $U_{b}$ são as velocidades de blowout medida experimentalmente e prevista pela Eq. (2.26) proposta por Broadwell; Dam e Mungal (1984), respectivamente; Sc é o número de Schmidt do combustível diluído com inerte $(S c=v / \mathcal{D})$; e $R e$ é o número de Reynolds do escoamento.

Chao et al (2004) também defendem que a influência do número de Schmidt (ou seja, das propriedades difusivas) é muito inferior à influência do número de Reynolds no que se refere ao fenômeno de blowout de chamas turbulentas; $\log 0, S c$ não é parâmetro dominante, diferente do blowout de chamas laminares (vide CHUNG e LEE, 1991). 


\subsubsection{Lipatnikov e Chomiak (2005)}

Lipatnikov e Chomiak (2005) realizaram um extenso estudo sobre os parâmetros que influem na velocidade de chama turbulenta, $S_{T}$, de chamas pré-misturadas e apresentaram diversos dados experimentais e de simulação numérica $(D N S)$ para fundamentar a afirmação de que $S_{T}$ é substancialmente afetada pela(s):

1. caracteristícas da turbulência (como a flutuação da velocidade, $u^{\prime}$ );

2. velocidade de chama laminar, $S_{L}$;

3. diferença entre os coeficientes de difusão molecular do combustível, $\mathcal{D}_{f}$, e do oxidante, $\mathcal{D}_{o} ; \mathrm{e}$

4. difusividade térmica da mistura, $\alpha$;

não só para turbulência fraca $\left(u^{\prime}<S_{L}\right)$, como para turbulência moderada e elevada $\left(u^{\prime} \approx u_{m}^{\prime}\right)$.

Os valores de $u_{m}^{\prime}$ também dependem de $S_{L}, \mathcal{D}_{f}, \mathcal{D}_{o}$ e $\alpha$. Também afirmam que embora existam vários conceitos para explicar o efeito de $S_{L}, \mathcal{D}_{f}, \mathcal{D}_{o}$ e $\alpha$ em $S_{T}$, ainda não foi elaborado um modelo fisicamente consistente e capaz de predizer a dependência de $S_{T}\left(S_{L}, \mathcal{D}_{f}, \mathcal{D}_{o}\right.$ e $\left.\alpha\right)$. Assim, a determinação da influência do transporte molecular na velocidade da chama turbulenta é um dos grandes desafios para a comunidade de combustão turbulenta (LIPATNIKOV e CHOMIAK, 2005).

Foi apresentado anteriormente que o modelo proposto por Vanquickenborne e Van Tiggelen (1966) - e adotado por Kalghatgi (1981), entre outros pesquisadores - assume que a mistura ar-combustível seja totalmente pré-misturada na base da chama descolada turbulenta (ou seja, que o comportamento da chama de difusão seja semelhante ao de uma chama pré-misturada na região de estabilização) e que o blowout de tal chama ocorre quando a velocidade local do escoamento é superior à velocidade local de chama turbulenta, $S_{T}$;

Logo, é coerente afirmar que as propriedades difusivas do combustível, do comburente e da mistura influem no mecanismo de blowout. Esta afirmação contraria muitos autores - como Kalghatgi (1984), Chung e Lee (1991), Chao et al (2000), Chao et al (2004), Wu et al (2006), entre outros: 
1. a análise de Kalghatgi (1984) defende que a distância entre o bocal e a base da chama de difusão turbulenta, no momento em que o blowout ocorre, está diretamente relacionada com a altura de liftoff, $h$; e que esta altura $h$ independe do diâmetro do bocal $\left(d_{n}\right)$ e das propriedades difusivas do gás combustível, como as difusividades mássica $\left(\mathcal{D}_{f}\right)$ e térmica $\left(\alpha_{f}\right)$; e

2. Chung e Lee (1991), Chao et al (2000), Chao et al (2004) e, posteriormente, Wu et al (2006) afirmam que as propriedades difusivas não desempenham um papel importante no processo de blowout turbulento.

\subsubsection{Wu et al (2006)}

Wu et al (2006) estudaram experimentalmente os mecanismos de estabilização da chama de jatos simples de combustíveis gasosos (metano e propano) diluídos com inertes (nitrogênio e ar), por meio de técnicas e dispositivos de observação não intrusivos, assim como em Chao et al (2000). Identificaram a estrutura de chama tripla, delimitada pelas posições nas quais a concentração de combustível atinge o valor estequiométrico e os limites de flamabilidade inferior e superior (vide Fig. 2.9). Verificaram que três pontos definidos por esta estrutura desempenham um papel importante na estabilização da chama descolada dentro das regiões estável e instável. São eles:

1. $H_{w}$, distância axial a partir da saída do bocal até posição de máximo raio do contorno estequiométrico, $r_{w}$ (definido como a máxima distância radial entre o contorno elíptico estequiométrico e o eixo do jato);

2. $H_{s}$, distância axial a partir da saída do bocal na qual a concentração do combustível atinge o valor estequiométrico; e

3. $H_{L}$, distância axial a partir da saída do bocal na qual a concentração do combustível atinge o limite inferior de flamabilidade.

A distância $H_{w}$ pode ser considerada como o ponto de divisão que separa as regiões instáveis e estáveis de chamas descoladas no processo de blowout. Se a base da chama é empurrada para uma distância $x>H_{w}\left(r=r_{w}\right)$, a chama passa para a região pulsante e torna-se instável, 
desencadeando o processo de blowout. Na região pulsante $\left(h_{p, i n f}<x<h_{p \text {,sup }}\right)$, o ponto de estabilização da chama tripla move-se ao longo do contorno estequiométrico, estabilizando a chama onde a base desta é limitada pelos contornos dos limites de flamabilidade (inferior e superior). Se a chama é deslocada além da ponta do contorno estequiométrico, $H_{s}$, o ponto de estabilização e a estrutura de chama tripla desaparecem e a chama torna-se pobre. Em seguida, ela recua a jusante de forma contínua e, finalmente, extingue-se $\left(x \cong h_{b}\right)$.

Assim, Wu et al (2006) categorizam o processo de blowout em quatro regiões características: pulsante $\left(h_{p, \text { inf }}<x<h_{p, \text { sup }}\right)$, início de recuo, recuo, e extinção $\left(x \geq h_{b}\right)$. As posições $h_{p, i n f}$, $h_{p, \text { sup }}$ e $h_{b}$ foram obtidas experimentalmente.

Para identificar as posições de $H_{w}, H_{s}$ e $H_{L}$, Wu et al (2006) adotaram o modelo teórico proposto por Birch et al (1978) para a distribuição de concentração de um jato livre. Assim, o perfil normalizado axial, $Y_{f, c} / Y_{f, n}$, em um jato livre pode ser obtido por:

$$
\frac{Y_{f, c}}{Y_{f, n}}=\frac{k_{1} d_{e}}{\left(x+k_{2}\right)}
$$

onde $Y_{f}, \rho, x$, e $d_{e}=d_{n}\left(\frac{\rho_{f, n}}{\rho_{\infty}}\right)^{1 / 2}$ são a fração mássica de combustível, densidade, distância axial a partir da saída do jato, e diâmetro efetivo, respectivamente; os subscritos $n, c$ e $\infty$ indicam propriedades na saída do jato, em uma posição $x$ qualquer no eixo do jato e na condição ambiente, respectivamente; $k_{1}$ e $k_{2}$ são constantes e iguais a 4,0 e $\left(-5,8 d_{n}\right)$, respectivamente. Assim, a distância ao longo do eixo do jato a partir da saída do jato, $H_{s}$, para o local onde a concentração de combustível cai para o nível estequiométrico, $Y_{f, c}=Y_{f, s}$, pode ser derivada da Eq. (2.32), obtendo-se:

$$
H_{s}=\left[4 \frac{Y_{f, n}}{Y_{f, s}}\left(\frac{\rho_{f, n}}{\rho_{\infty}}\right)^{1 / 2}+5,8\right] d_{n}
$$

onde o subscrito $s$ indica as propriedades na condição estequiométrica. A equação (2.33) também pode ser usada para calcular a distância $H_{L}$, na qual o limite de flamabilidade inferior é atingido, pela substituição de $Y_{f, s}$ pela fração mássica de combustível na condição de limite de flamabilidade inferior. Além disso, para um jato de perfil radial, o perfil normalizado de fração mássica média é descrito com precisão pela seguinte função Gaussiana (BIRCH et al, 1978 e BECKER; HOTTEL e WILLIAMS, 1967): 


$$
\frac{Y_{f}}{Y_{f, c}}=\exp \left[-k_{3}\left(\frac{r}{x}\right)^{2}\right]
$$

onde $k_{3}$ é uma constante, cujo valor é 73,6.

Substituindo a Eq. (2.32) na Eq. (2.34) e assumindo $Y_{f}=Y_{f, s}$, o contorno estequiométrico pode ser expresso como uma função de $r$ e $x$ :

$$
r^{2}+\frac{x^{2}}{73,6} \ln \left[\frac{Y_{f, s}\left(x-5,8 d_{n}\right)}{4 Y_{f, n} d_{e}}\right]
$$

A Eq. (2.35) pode ser usada para encontrar o máximo raio do contorno estequiométrico, definido por $d r / d x=0$, e obtendo-se:

$$
2 \ln \left(\frac{Y_{s}}{4 Y_{n} d_{e}} x-\frac{5,8 d_{n} Y_{f, s}}{4 Y_{f, n} d_{e}}\right)=-\frac{x}{x-5,8 d_{n}}
$$

A Eq. (2.36) é resolvida numericamente para $x$ para encontrar a distância $H_{w}$. As distâncias $H_{S}$, $H_{L}$ e $H_{w}$, estimadas com as Eqs. (2.33) e (2.36) estão listadas na Tabela (2.3) e foram verificadas por meio de medições experimentais.

Tabela 2.3. Parâmetros estimados e medidos de cada condição observada para o processo de blowout $\left(d_{n}=\right.$ $5,0 \mathrm{~mm}$ ). (WU et al, 2006) ${ }^{3}$

\begin{tabular}{lcccc}
\hline \hline & $30 \% \mathrm{~N}_{2} \mathrm{em} \mathrm{CH}_{4}$ & $30 \%$ ar em $\mathrm{CH}_{4}$ & $50 \% \mathrm{~N}_{2} \mathrm{em} \mathrm{C}_{3} \mathrm{H}_{8}$ & $50 \%$ ar em $\mathrm{C}_{3} \mathrm{H}_{8}$ \\
\hline $\boldsymbol{U}_{\boldsymbol{b}}(\mathrm{m} / \mathrm{s})^{(*)}$ & 42,6 & 34,0 & 52,6 & 47,6 \\
$\boldsymbol{S}_{\boldsymbol{L}}(\mathrm{cm} / \mathrm{s})$ & 31,6 & 32,3 & 36,9 & 37,7 \\
$\boldsymbol{H}_{\boldsymbol{w}}(\mathrm{x} / \mathrm{d})$ & 24,0 & 22,0 & 32,0 & 30,0 \\
$\boldsymbol{h}_{\boldsymbol{w}}(\mathrm{x} / \mathrm{d})$ & 20,0 & 19,0 & 26,0 & 25,0 \\
$\boldsymbol{h}_{\boldsymbol{p} \text {,inf }}(\mathrm{x} / \mathrm{d})$ & 21,0 & 18,0 & 28,0 & 23,0 \\
$\boldsymbol{H}_{\boldsymbol{S}}(\mathrm{x} / \mathrm{d})$ & 42,2 & 39,3 & 54,5 & 51,0 \\
$\boldsymbol{h}_{\boldsymbol{S}}(\mathrm{x} / \mathrm{d})$ & 35,0 & 37,5 & 51,0 & 49,5 \\
$\boldsymbol{h}_{\boldsymbol{p}, \text { sup }}(\mathrm{x} / \mathrm{d})$ & 32,0 & 38,0 & 50,0 & 49,0 \\
$\boldsymbol{H}_{\boldsymbol{L}}(\mathrm{x} / \mathrm{d})$ & 63,8 & 59,3 & 82,4 & 76,9 \\
$\boldsymbol{h}_{\boldsymbol{b}}(\mathrm{x} / \mathrm{d})$ & 59,0 & 61,0 & 88,0 & 80,0 \\
\hline \hline
\end{tabular}

${ }^{(*)}$ Proposto por Chao; Chen e Cheng (2004).

\footnotetext{
${ }^{3} \mathrm{Na}$ tabela apresentada por Wu et al (2006), as siglas $\eta_{p l}$ e $\eta_{p h}$ estão trocadas.
} 
Na Tabela (2.3) os parâmetros em letras maiúsculas representam os dados previstos pelas equações e, em minúsculas, os dados medidos experimentalmente; $h_{p, \text { sup }}$ e $h_{p, \text { inf }}$ são as posições máxima e mínima, respectivamente, que delimitam a região pulsante; e $h_{b}$ é a posição onde a chama descolada extingue-se completamente (ocorre blowout).

Vanquickenborne e Van Tigglen (1966) mostraram que o processo de blowout pode ser acionado quando a base da chama é empurrada a jusante de $H_{w}$, onde o contorno da fração mássica estequiométrica $\left(Y_{f}=Y_{f, s}\right)$ atinge sua largura máxima radial, $r_{w}$. Tendo em vista a boa correspondência entre $h_{w}$ e $h_{p, i n f}$, torna-se razoável considerar $H_{w}$ como um ponto que separa as regiões estáveis e instáveis. $\mathrm{O}$ aparecimento da instabilidade pulsante pode desencadear o processo de blowout. Além disso, a correspondência entre $h_{s}$ e $h_{p, s u p}$ mostra que o início do recuo no processo de blowout tem uma forte ligação com a diminuição da concentração estequiométrica; e o acordo entre $H_{L}$ e $h_{b}$ implica que a condição de combustível pobre desempenha um papel importante no recuo e extinção da chama no processo de blowout.

Wu et al (2006), baseados na estrutura de chama tripla, propuseram o mecanismo para o processo de blowout ilustrado na Figura (2.9) e descrito a seguir:

1. Quando $U_{n}<U_{l}$ (máxima velocidade de descarga de um gás, para a qual a chama não apresenta descolamento do bocal), a chama é estável e encontra-se colada no bocal do queimador;

2. Quando $U_{l}<U_{n}<U_{b}$, a chama se descola do bocal e sua base se estabiliza numa abscissa menor que $H_{w}$. Nesta região, verifica-se boa concordância entre resultados experimentais e previsões teóricas das alturas de descolamento (KALGHATGI, 1884 e PITTS, 1989). Em geral, a altura de descolamento é proporcional à velocidade de saída do jato $\left(U_{n}\right)$ e inversamente proporcional ao quadrado da velocidade máxima de chama laminar $\left(S_{L}\right)$;

3. Quando $U_{n}>U_{b}$, a base da chama oscila com determinada amplitude $\left(h_{p, \text { inf }}<x<\right.$ $h_{p, \text { sup }}$ ) e/ou se afasta indefinidamente de $H_{w}$ até a extinção (blowout), ou seja, $x=h_{b}$. 


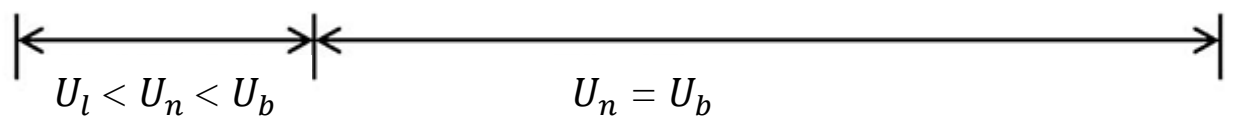

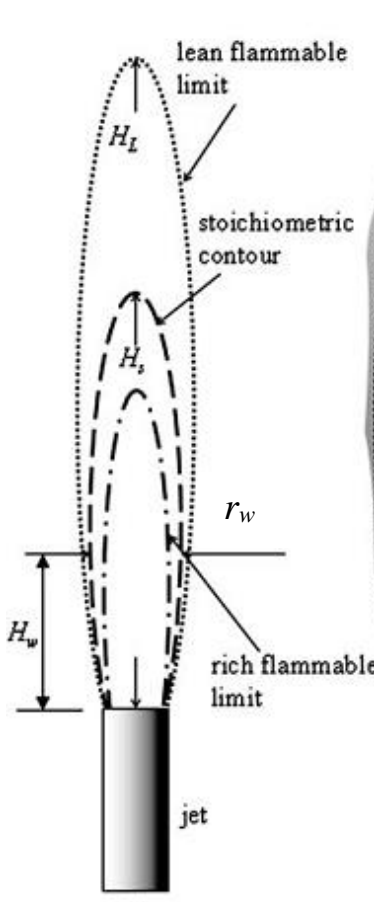

(a)

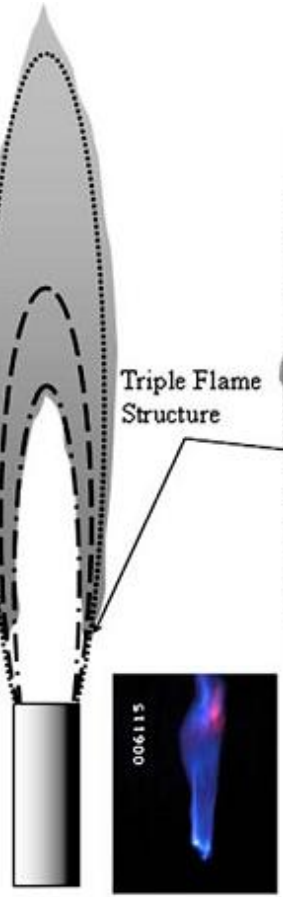

(b)

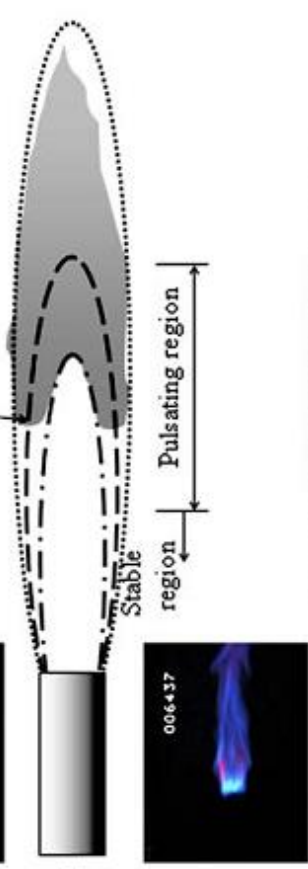

(c)

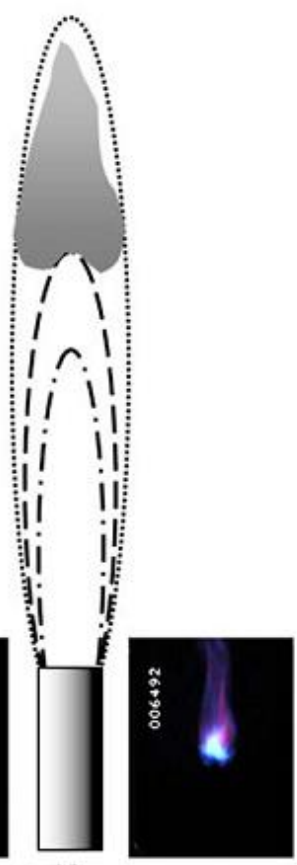

(d)

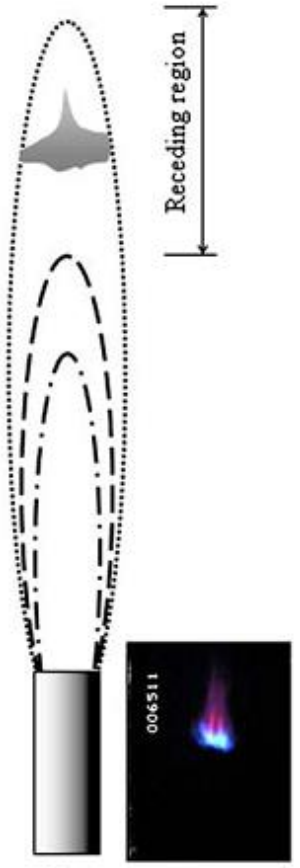

(e)

Figura 2.9. Desenho esquemático do mecanismo de blowout proposto por Wu et al (2006).

Wu et al (2006) também verificaram experimentalmente que a velocidade à frente da base da chama é aproximadamente igual à velocidade de chama laminar, $S_{L}$, quando a base da chama está localizada dentro da ponta do contorno estequiométrico $\left(x<H_{S}\right)$, o que concorda com resultados de Muñiz e Mungal (1997) e com o modelo de chama tripla de Kioni et al (1993) e Ruetsch; Vervisch e Liñán (1995); e que as propriedades difusivas (mássicas e térmicas) não são parâmetros dominantes no blowout de chamas de jatos turbulentos, ou seja, o número de Schmidt $(S c)$ não desempenha um papel importante no processo de blowout turbulento.

\subsubsection{Sousa (2010)}

Sousa (2010), após uma longa análise teórica do fenômeno, seguindo o raciocínio de Broadwell; Dam e Mungal (1984), perfis de velocidade (Eq. 2.20) ao longo de jatos simples, definição de velocidade de chama laminar (Eq. 2.34) proposta por Turns (2000), e taxa de arraste de gases 
do meio provocado por um jato livre axial (Eq. 2.39), sugere uma expressão (Eq. 2.42) para estimar a velocidade de blowout.

Segundo Turns $(2000)^{4}$ :

$$
S_{L}=\left[-2 \alpha\left(\varphi_{s}+1\right) \frac{\dot{m}_{f}^{\prime \prime \prime}}{\rho_{u}}\right]^{1 / 2}
$$

onde $\alpha$ é a difusividade térmica $\left(\mathrm{m}^{2} / \mathrm{s}\right) ; \varphi_{s}$ é a razão mássica oxidante/combustível estequiométrica; $\dot{m}_{f}^{\prime \prime \prime}$ é a taxa mássica de consumo de combustível por unidade de volume $\left(\mathrm{kg} / \mathrm{s} \cdot \mathrm{m}^{3}\right) ;$ e $\rho_{u}$ é a densidade dos gases não queimados $\left(\mathrm{kg} / \mathrm{m}^{3}\right) \rho_{u} \approx \rho_{\infty}$.

A Eq. (2.37) mostra que $S_{L}$ é proporcional à raiz quadrada da taxa de reação $\dot{m}_{f}^{\prime \prime \prime}$. Como esta taxa é inversamente proporcional ao tempo químico característico, $t_{c}$, temos que:

$$
t_{c} \sim \frac{\alpha\left(\varphi_{s}+1\right)}{S_{L}^{2}}
$$

Sousa (2010) utiliza a Eq. (2.39) para calcular $H_{s}$, obtida a partir da correlação utilizada por Hinze e van der Hegge Zijnen (1949) para calcular a taxa de arraste de gases do meio provocado por um jato livre axial, ao invés da Eq. (2.22) usada por Broadwell; Dam e Mungal (1984).

$$
H_{s}=C_{S, 1} d_{n}\left(\frac{\rho_{f, n}}{\rho_{\infty}}\right)^{1 / 2}\left(1+\varphi_{s}\right)
$$

onde $C_{S, 1}$ é uma constante.

Substituindo a Eq. (2.39) na Eq. (2.16) e assumindo que o perfil de $U_{c, H_{s}}$ é igual ao utilizado por Broadwell; Dam e Mungal (1984), Eq. (2.20), temos:

$$
t_{d} \sim \frac{d_{H_{S}}}{U_{c, H_{S}}} \sim \frac{d_{n}}{U_{n}}\left(\frac{\rho_{f, n}}{\rho_{\infty}}\right)^{1 / 2}\left(1+\varphi_{s}\right)^{2}
$$

Substituindo as Eqs. (2.38) e (2.40) na Eq. (2.18), e admitindo que na condição de blowout $U_{n}$ $=U_{b}$, temos:

$$
D a_{c r i t}=\frac{d_{n} S_{L}^{2}}{U_{b} \alpha}\left(\frac{\rho_{f, n}}{\rho_{\infty}}\right)^{1 / 2}\left(1+\varphi_{s}\right)
$$

\footnotetext{
${ }^{4}$ Vide subseção (A.5) "Velocidade de chama laminar" disponível no Apêndice (A) “Conceitos fundamentais".
} 
Sousa (2010) utilizou os dados dos combustíveis apresentados no trabalho de Kalghatgi (1981) para comparar as previsões de $D a_{c r i t}$ de sua equação com as previsões da equação proposta por Broadwell; Dam e Mungal (1984). Os valores de $D a_{\text {crit }}$ obtidos por Sousa (2010) e por Broadwell; Dam e Mungal (1984) encontram-se na Tabela (2.4).

Sousa (2010) sugere que se use a Eq. (2.42) para o cálculo de $U_{b}$ :

$$
U_{b}=\frac{d_{n} S_{L}^{2}}{D a_{c r i t} \alpha}\left(\frac{\rho_{f, n}}{\rho_{\infty}}\right)^{1 / 2}\left(1+\varphi_{s}\right)
$$

onde $\alpha$ é a difusividade térmica $\left(\mathrm{m}^{2} / \mathrm{s}\right)$ assumida como igual a do ar a temperatura ambiente; e $D a_{c r i t}$ refere-se ao valor apresentado na penúltima coluna da Tabela (2.4).

Tabela 2.4. Valores do número de Damköhler crítico.

\begin{tabular}{lcc}
\hline \hline Gás & $\boldsymbol{D a} \boldsymbol{a}_{\text {crit }}$ & $\boldsymbol{D a}_{\text {crit }}$ \\
& (BROADWELL; DAM; MUNGAL, 1984) & (SOUSA, 2010) \\
\hline Metano, $\mathrm{CH}_{4}$ & 4,6 & 5,7 \\
Propano, $\mathrm{C}_{3} \mathrm{H}_{8}$ & 5,6 & 7,7 \\
Etileno, $\mathrm{C}_{2} \mathrm{H}_{4}$ & 5,3 & 7,8 \\
Acetileno, $\mathrm{C}_{2} \mathrm{H}_{2}$ & 3,9 & 6,4 \\
Butano, $\mathrm{C}_{4} \mathrm{H}_{10}$ & 4,8 & 6,6 \\
Hidrogênio, $\mathrm{H}_{2}$ & 4,4 & 2,7 \\
\hline \hline
\end{tabular}

A diferença entre os valores de $D a_{c r i t}$ apresentados por Broadwell; Dam e Mungal (1984) e Sousa (2010), para um mesmo gás, se deve ao fato da correlação proposta por Sousa (2010), Eq. (2.42):

1. possuir o termo $\left(1+\varphi_{s}\right)$, ao invés de $\varphi_{s}^{2}$, como na proposta por Broadwell; Dam e Mungal (1984), Eq. (2.25); e

2. utilizar a difusividade térmica do ar, $\alpha$, avaliada na temperatura ambiente ( $T=298 \mathrm{~K}$ ), ao invés da avaliada na temperatura de chama adiabática média $(T=2000 \mathrm{~K})$ dos gases hidrocarbonetos (metano, propano, etileno, acetileno e butano comercial) como proposto por Broadwell; Dam e Mungal (1984), Eq. (2.25).

As previsões das correlações propostas por Broadwell; Dam e Mungal (1984) e Sousa (2010) - Eqs. (2.25) e (2.42), respectivamente - foram calculadas e analisadas pela presente autora e 
encontram-se nas Subseções (4.1) e (4.2). Verificou-se que, em geral, a correlação proposta por Sousa (2010) fornece previsões de $U_{b}$ mais próximos dos valores obtidos experimentalmente por Kalghatgi (1981) do que a correlação proposta por Broadwell; Dam e Mungal (1984).

Recentemente, alguns pesquisadores têm adotado uma metodologia para a previsão do blowout baseada em simulações em um aplicativo de CFD (Computational Fluid Dynamics), ou seja, através de resultados obtidos por simulação numérica; fundamentados pelos conceitos de estabilidade de chamas e escoamentos turbulentos reativos.

Wang e Jin (2011) investigaram a estabilidade de blowout de chamas não pré-misturadas estabilizadas por uma calha em forma de $\mathrm{V}$, por meio da metodologia do número Damkhöler, $D a$. As escalas de tempo do escoamento, $t_{d}$, e químico, $t_{c}$, foram extraídas dos resultados de simulações numéricas realizadas em um aplicativo comercial de CFD (ANSYS FLUENT), em uma base de célula por célula. Os autores afirmam que ao examinar os campos do número de Damkhöler, pode-se estimar a estrutura da chama e a possibilidade de blowout.

Para as simulações, Wang e Jin (2011) adotaram os seguintes modelos disponíveis no aplicativo: (1) o modelo de turbulência $k$ - $\varepsilon$ realizável com função de parede; (2) o modelo de combustão não pré-misturada (Unsteady Laminar Flamelet Model); e (3) o algoritmo de acomplamento pressão-velocidade SIMPLE. A intensidade média da turbulência foi estimada em cerca de $4 \%$ a partir de uma correlação empírica para escoamentos em tubo ${ }^{5}$. O mecanismo químico foi aplicado para o querosene, contendo 297 reações irreversíveis e 66 espécies químicas, reduzidas com base em Wang e Jin (2010).

As previsões das simulações foram comparadas com resultados experimentais dos autores. Eles afirmam que o método proposto pode prever o limite de blowout de forma razoavelmente consistente com os dados experimentais disponíveis, por meio do ajuste do número Damkhöler crítico, $D a_{\text {crit }}$.

Logo, do ponto de vista da Engenharia, os projetistas de sistemas de combustão podem determinar $D a_{\text {crit }}$ com base em dados experimentais disponíveis e, em seguida, obter uma previsão razoável do limite de blowout, a preços computacionais acessíveis (WANG e JIN, 2011). A partir da perspectiva da pesquisa acadêmica, os autores afirmam que pretendem explorar o método para superar a deficiência empírica e aleatória do número de Damkohler

\footnotetext{
${ }^{5}$ Wang e Jin (2011) não especificam correlação empírica utilizada para estimar a intensidade de turbulência.
} 
crítico (observada ao longo do trabalho que realizaram) e validar o método em mais configurações de combustores.

\subsection{Estudos experimentais e analíticos do mecanismo de blowout de jatos concorrentes com fluido oxidante}

A seguir são apresentados alguns estudos referentes à estabilidade de chamas de difusão turbulenta resultantes de um jato de gás combustível emergindo em um meio oxidante em movimento (paralelo ao eixo do jato). Esta configuração pode ser encontrada em muitos equipamentos industriais, como em fornos, flares, chaminés (chama piloto para queima de gases combustíveis e tóxicos), entre outros. Por isso, o conhecimento da influência do movimento do meio ao redor do jato de gás na estabilidade da chama é de grande importância para o projeto e definição das condições sob as quais o equipamento irá operar.

\subsubsection{Dahm e Dibble (1988)}

Dahm e Dibble (1988) apresentaram resultados de investigações experimentais e teóricas dos mecanismos de liftoff e blowout de chamas de difusão turbulenta em um meio em movimento $\left(U_{\infty} \neq 0\right)$. Os limites de estabilidade de blowout foram formulados em termos de uma proposta de mecanismo de estabilização baseada na organização, em grande escala, do arraste de fluido do entorno do jato (ar ambiente "frio") e da mistura deste com o fluido do jato (excesso de combustível e produtos quentes resultantes da reação de combustão). A Figura (2.10) ilustra este processo.

As características do limite de liftoff também foram documentadas, e uma possível relação entre os mecanismos de liftoff e blowout foi discutida. A partir da abordagem de Broadwell; Dam e Mungal (1984) e de uma longa análise de escalas de jatos turbulentos, Dahm e Dibble (1988) propuseram a Eq. (2.43), que correlaciona o número de Damkhöler crítico, $D a_{\text {crit }}$. 


$$
D a_{c r i t}=C_{D, 1} \cdot \frac{J_{r}}{U_{\infty}} \cdot \frac{S_{L}{ }^{2}}{\alpha} \cdot f_{1}\left(\frac{x_{b}}{J_{r}}\right) \cdot f_{2}\left(\frac{x_{b}}{J_{r}}\right)
$$

Onde $C_{D, 1}$ é uma constante dada por:

$$
C_{D, 1}=\frac{2}{\pi^{2}} \cdot I_{1}^{2} \cdot\left[\frac{f_{1}^{\prime}(0)}{f_{2}^{\prime}(0)}\right]^{3} \cdot\left(\frac{Y_{f, c}}{Y_{f, n}}\right)^{2}
$$

$x_{b}$ é a posição axial na qual a falha do critério de estabilização leva a blowout. Os autores propõem $x_{b}=L$ (comprimento da chama); $I_{1} \approx 0,103$ (DAHM; DIMOTAKIS, 1987 apud DAHM; DIBBLE, 1988); $Y_{f, c}$ é a concentração do combustível no eixo do jato; $f_{1}$ e $f_{2}$ são funções apresentadas no trabalho de Bradbury e Riley (1967) e Everitt e Robins (1978) apud Dahm e Dibble (1988); $u$ é o decaimento da velocidade do eixo central $\left(u=U-U_{\infty}\right)$; e $J_{r}$ é o fluxo de quantidade de movimento radial do escoamento.

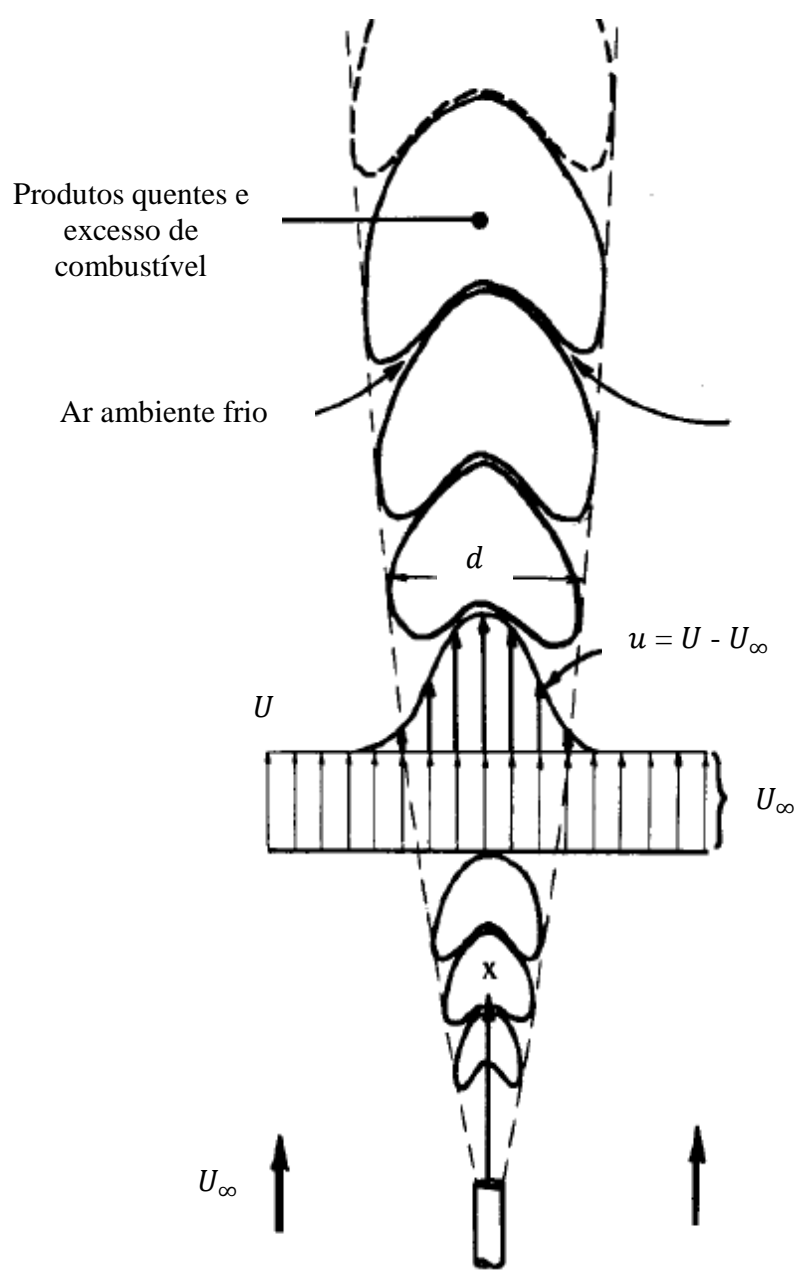

Figura 2.10. Mecanismo de arrastamento de ar ambiente e mistura deste ar com os produtos da combustão e excesso de combustível, em uma chama de difusão turbulenta (DAHM e DIBBLE, 1988). 
Dahm e Dibble (1988) realizaram experimentos em uma instalação composta por um túnel de vento vertical de seção transversal quadrada $(0,3 \mathrm{~m} \times 0,3 \mathrm{~m} \times 2 \mathrm{~m})$ e um jato axissimétrico de combustível. Dois bocais foram usados: um cujo diâmetro interno era 3,3 mm e outro de 5,2 $\mathrm{mm}$. Metano e propano foram usados como combustíveis e as velocidades do escoamento no túnel e no bocal foram calculadas por meio de medidores de fluxo de massa. Os autores observaram que, embora a velocidade do escoamento externo seja pequena $\left(U_{\infty} \leq 1,0 \mathrm{~m} / \mathrm{s}\right)$ em comparação com a velocidade de descarga no bocal, as velocidades na ponta da chama e de blowout decaem consideravelmente em relação à condição de um jato simples de gás em ar parado. Além disso, perceberam que quando $D a_{\text {crit }}=4,3$ a velocidade $U_{b}$ diminui drasticamente com o aumento de $U_{\infty}$, mesmo quando esta velocidade é relativamente baixa. A partir dos resultados, Dahm e Dibble (1988) argumentam que a taxa de mistura - entre o ar, os produtos de combustão e o combustível - do escoamento pode ser o mecanismo controlador do blowout em chamas de difusão turbulenta.

\subsubsection{Karbassi (1997)}

Karbassi (1997) analisou os limites de estabilidade de jatos de chamas não pré-misturadas concorrentes com um fluido oxidante escoando em um combustor vertical de aço aberto para a atmosfera, de seção transversal quadrada $\left(127\right.$ x $\left.127 \mathrm{~mm}^{2}\right)$ e altura de $1300 \mathrm{~mm}$. Realizou estudos experimentais e analíticos, e apresentou quatro limites de estabilidade: descolamento, reinserção, blowout em chamas descoladas e blowout em chamas anexadas no bocal. Segundo ele, quando a velocidade do fluxo concorrente é baixa, o blowout ocorre em chamas descoladas; para velocidades altas do fluxo concorrente, o blowout pode ocorrer em chamas anexadas no bocal. Assim, definiu o limite da velocidade do fluxo concorrente como a velocidade mínima deste fluxo com a qual o blowout de chamas anexadas no bocal pode ocorrer. Em seu trabalho, refere-se à velocidade máxima do jato que leva a extinção da chama como limite de blowout.

Karbassi (1997) realizou uma série de experimentos com o objetivo de obter curvas de estabilidade de combustíveis gasosos puros (metano, propano, etileno e hidrogênio) e misturados, e os efeitos da geometria do bocal e da adição de diluentes no jato de combustível e no fluxo concorrente ao jato nos limites de estabilidade. A Figura (2.11) apresenta esquemas dos três bocais utilizados. Foram utilizados dois bocais do tipo A - um com diâmetro interno 
$d_{n}=2,00 \mathrm{~mm}(e=1,82 \mathrm{~mm})$ e outro com $d_{n}=2,82 \mathrm{~mm}(e=1,33 \mathrm{~mm})-$ e um do tipo B $\left(d_{n}=\right.$ $2,00 \mathrm{~mm})$.

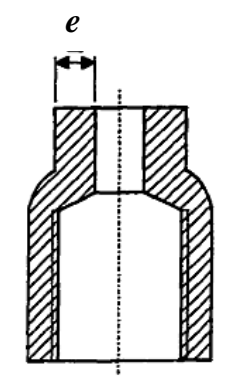

(a) Tipo A.

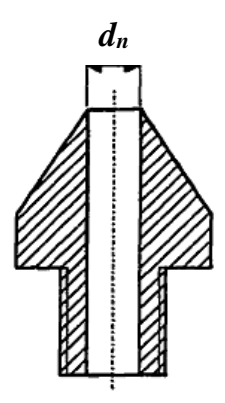

(b) Tipo B.

Figura 2.11. Diagrama esquemático dos bocais. (KARBASSI, 1997)

A partir dos experimentos, o autor verificou que:

1. A velocidade do fluxo concorrente afeta significantemente a estabilidade da chama. Dependendo da magnitude desta velocidade, três diferentes regiões foram reconhecidas. Em baixas velocidades do fluxo oxidante concorrente (região I) observa-se apenas o blowout de chamas descoladas, enquanto que em maiores velocidades (região III) ocorre apenas o blowout de chamas anexadas (também denominado como blowoff). Para valores médios (região II), tanto o blowout como o blowoff são observados. Nesta região (II), verifica-se que as chamas descoladas são menos estáveis que as anexadas; logo, as chamas descoladas devem ser evitadas. A Figura (2.12) apresenta estas regiões e os limites de estabilidade de uma chama não pré-misturada de metano em função da velocidade do fluxo de ar concorrente, para um jato de diâmetro, $d_{n}$, igual a 2,00 mm;

2. Reduzindo-se a velocidade de descarga do jato, uma chama que se encontra descolada do bocal pode reinserir-se a este, ou seja, pode retornar a condição de chama anexada no bocal de descarga do jato;

3. A forma do bocal tem menor efeito em chamas descoladas do que em chamas anexadas no bocal. Isto ocorre, pois a posição da região de estabilização da chama descolada é localizada mais a jusante do bocal. As condições do escoamento próximas ao bocal são responsáveis pela estabilização das chamas anexadas a este (bocal); logo, o efeito da variação da configuração do bocal nos limites de descolamento e de blowout destas chamas (anexadas) é muito mais significativo do que em chamas descoladas. Para 
bocais de parede espessa (tipo A), a zona de recirculação de ar, formada entre o jato de combustível e o fluxo oxidante concorrente, proporciona um efeito significativo de estabilização em chamas anexadas (TAKAHASHI e SCHMOLL, 1990). Consequentemente, os limites de descolamento (liftoff) e de blowout de chamas anexadas são maiores para o bocal do tipo A do que do tipo B, ambos com $d_{n}=2,00$ mm. Numericamente, para um jato de metano, a utilização do bocal A aumenta em $20 \%$ o limite de blowout de chamas anexadas e $10 \%$ o limite de chamas descoladas. A forma do bocal não influi no limite da velocidade do escoamento concorrente (fluxo de ar) com o jato;

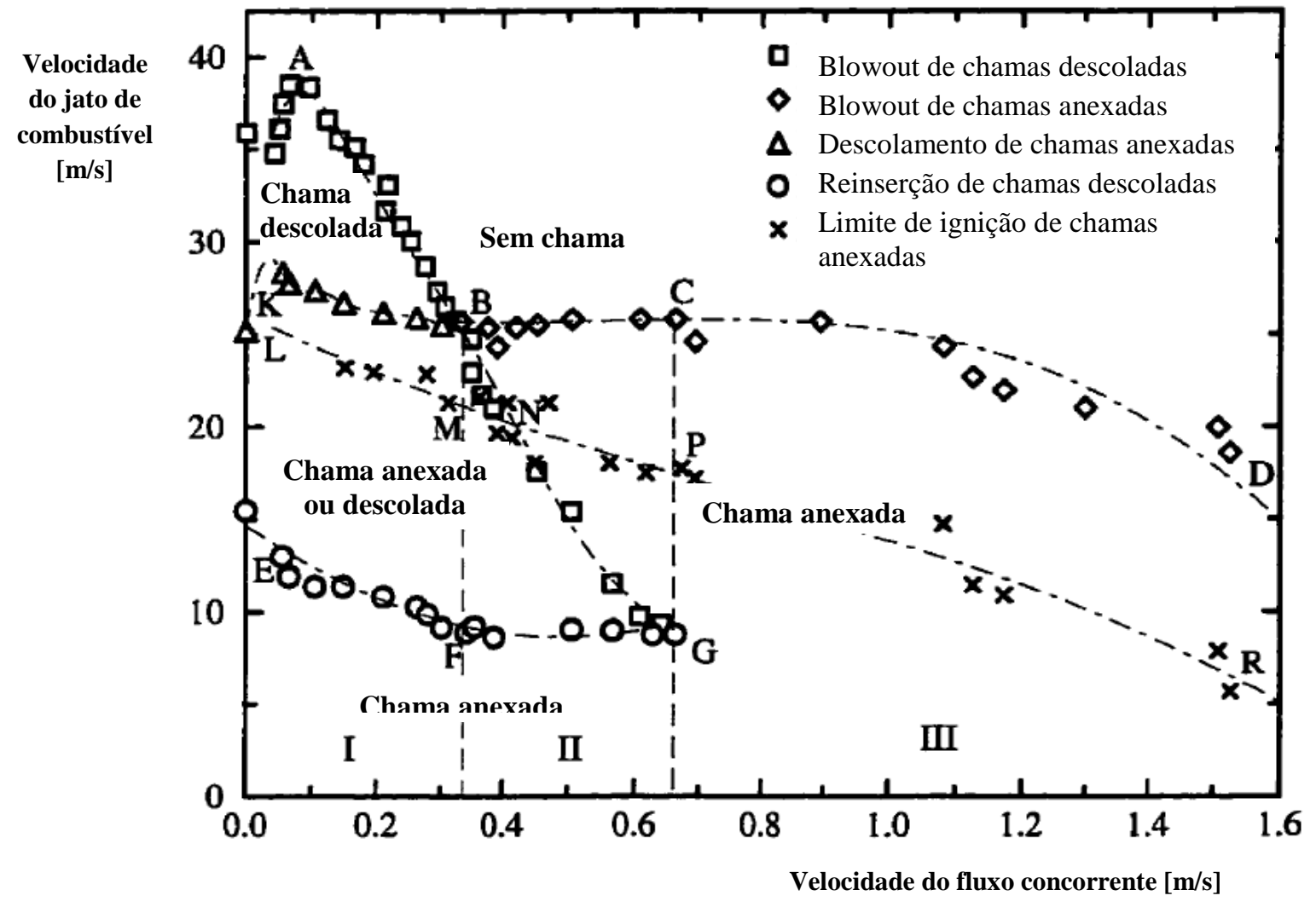

Figura 2.12. Limites de estabilidade de uma chama não pré-misturada de metano em função da velocidade do fluxo de ar concorrente $\left(d_{n}=2,00 \mathrm{~mm}\right)$. (KARBASSI, 1997)

4. Os limites de estabilidade de chamas descoladas aumentam com diâmetro do bocal_tipo A) e os limites de chamas anexadas diminuem com o mesmo; 
5. Reduzindo-se a velocidade do fluxo concorrente a zero, as velocidades de blowout dos gases analisados correspondem aos resultados obtidos por Kalghatgi (1981), como mostrado na Tabela (2.5);

Tabela 2.5. Velocidades de blowout $\left(U_{b}\right)$ para $U_{\infty}=0$. (KARBASSI, 1997)

\begin{tabular}{ccc}
\hline \hline Combustível & $\boldsymbol{U}_{\boldsymbol{b}}[\mathrm{m} / \mathrm{s}]$ & $\boldsymbol{U}_{\boldsymbol{b}}[\mathrm{m} / \mathrm{s}]$ \\
& $($ KARBASSI, 1997) & $($ KALGHATGI, 1981) \\
\hline Metano & 36 & 35,5 \\
Propano & 51 & 57 \\
Etileno & 119 & 124 \\
\hline \hline
\end{tabular}

6. O limite de blowout (velocidade de descarga do jato de gás combustível, $U_{b}$ ) de chamas descoladas com fluxo oxidante concorrente foi maior para o hidrogênio, seguido pelo etileno, propano e metano - como foi verificado por Kalghatgi (1981), Broadwell; Dam e Mungal (1984), Pitts (1989) e Sousa (2010) para jatos emergindo em um meio quiescente;

7. A adição de nitrogênio, dióxido de carbono e hélio em um jato de metano diminuem o limite de blowout; e a adição de hidrogênio aumenta este limite; Isto ocorre porque os diluentes alteram as propriedades do jato, como a densidade $(\rho)$, a viscosidade dinâmica $(\mu)$ e a velocidade de chama laminar $\left(S_{L}\right)$; além da fração mássica de combustível $\left(Y_{f}\right)$;

8. A adição de diluentes (nitrogênio e dióxido de carbono) no fluxo de ar concorrente tem maior efeito (redução) no limite de blowout do jato do que quando diluídos neste; Isto ocorre devido ao arrastamento de grande parte da mistura ar-diluente pelo jato no local de estabilização da chama antes do blowout;

9. A adição de combustível auxiliar (metano, propano, etileno e hidrogênio) no fluxo de ar concorrente aumenta o limite de blowout.

Karbassi (1997) também propôs um modelo para o blowout baseado na abordagem de Broadwell; Dam e Mungal (1984), em que este fenômeno é função de $D a_{\text {crit }}$. A principal diferença de seu modelo está na definição do tempo de mistura, $t_{d}$, o qual é assumido como proporcional a micro-escala de tempo de Kolmogorov, $t_{k}$. 


$$
t_{d} \sim t_{k} \equiv\left(\frac{v}{\epsilon}\right)^{1 / 2}
$$

onde $v$ é a viscosidade cinemática do fluido; e $\epsilon$ é a taxa de energia dissipada pelos pequenos turbilhões, a qual é considerada como sendo proporcional a taxa de energia fornecidade pelos maiores turbilhões, $u^{3} / l$ :

$$
\epsilon \sim \frac{u^{3}}{l}
$$

em que $u$ e $l$ são a velocidade e o comprimento característicos dos maiores turbilhões, respectivamente; assumidos como

$$
u \sim U_{c} \quad \text { e } \quad l \sim d_{u}
$$

onde $U_{c}$ a velocidade máxima local no centro do jato e $d_{u}$ o diâmetro do jato, em que $\left[\left(u-U_{\infty}\right)=\left(U_{c}-U_{\infty}\right) / 2\right]$, sendo $U_{\infty}$ a velocidade do fluxo concorrente.

Substituindo $u$ e $l$ na Eq. (2.46) e esta na Eq. (2.45), tem-se que:

$$
t_{d} \sim t_{k} \sim\left(\frac{d_{u} v}{U_{c}^{3}}\right)^{1 / 2}
$$

Substituindo $t_{d}$ e $t_{c}$ (definido na Eq. 2.17) na definição de $D a_{c r i t}$ :

$$
D a_{c r i t}=\frac{t_{d}}{t_{c}}=\left(\frac{d_{u} v}{U_{c}^{3}}\right)^{1 / 2}\left(\frac{S_{L}^{2}}{\alpha}\right)
$$

O blowout é esperado quando $D a \leq D a_{\text {crit }}$. Karbassi (1997) afirma que as previsões deste modelo concordam com os seus resultados experimentais.

\subsubsection{Kim; Won e Chung (2007)}

Kim; Won e Chung (2007) investigaram experimentalmente a influência da variação da temperatura inicial do jato de gás combustível e do ar concorrente a este $\left(294 \mathrm{~K} \leq T_{n} \leq 900 \mathrm{~K}\right)$ nas características das chamas de difusão turbulenta. O gás combustível utilizado foi propano (com pureza superior a 99\%). Apesar de estes autores defenderem que a altura de descolamento, 
$h$, e a velocidade de blowout, $U_{b}$, são influenciadas pela velocidade do fluxo de ar concorrente ao jato de combustível, $U_{\infty}$, esta velocidade foi fixada em $0,5 \mathrm{~m} / \mathrm{s}$. A partir dos experimentos, Kim; Won e Chung (2007) verificaram que, no regime turbulento:

1. a altura de descolamento, $h$, aumenta linearmente com a velocidade do jato de gás combustível na saída do bocal, $U_{n}$; e diminuiu com a temperatura inicial do gás combustível e do ar concorrente, $T_{n}$;

2. as velocidades com que a base da chama descola do bocal e se reinsere a este independem da variação da temperatura inicial $T_{n}$.

Os comportamentos da altura de descolamento, $h$, e da velocidade de blowout, $U_{b}$, foram investigados com base nos seguintes modelos de chamas descoladas turbulentas: (1) modelo de chamas pré-misturadas (VANQUICKENBORNE; VAN TIGGELEN, 1966; KALGHATGI, 1981); e (2) modelo de mistura em grande escala (BROADWELL; DAM; MUNGAL, 1984).

Na predição da altura de descolamento, $h$, o modelo de chamas pré-misturadas mostrou-se eficaz, independente da temperatura inicial $T_{n}$; uma vez que os parâmetros que influenciam no valor de $h$ (isto é, $S_{L}, v_{f, n}, \rho_{f, n}$ e $\rho_{\infty}$ ), segundo este modelo, são avaliados a $T_{n}$. No caso do modelo de mistura em grande escala, verificou-se que a utilização da difusividade térmica da mistura estequiométrica, $\alpha_{s}$, avaliada à temperatura inicial $T_{n}$ é mais adequada (ou seja, fornece valores de $h$ mais próximos dos dados experimentais) do que $\alpha_{s}$ avaliada à temperatura de chama adiabática do gás combustível, originalmente proposta por Broadwell; Dam e Mungal (1984). A partir destes resultados, Kim; Won e Chung (2007) defendem que a mistura não queimada, na região entre a saída do bocal e a base da chama descolada, controla a estabilização da chama; diferente do que é defendido pelo modelo de mistura em larga escala, no qual estabilidade é controlada pela reentrada de gás queimado no jato.

Na predição da velocidade de blowout, $U_{b}$, Kim, Won e Chung (2007) verificaram que o efeito da variação da temperatura inicial $T_{n}$ deve ser considerado tanto no modelo de chama prémisturada quanto no modelo de mistura em grande escala; e sugerem: 
1. Para o modelo de chama pré-misturada, que $H_{S}$ (distância a partir da seção de saída do bocal onde a concentração de combustível cai para a estequiométrica), definida na Eq. (2.3), seja calculada a partir da Eq. (2.50).

$$
H_{s}^{\prime}=\left[4 \cdot \frac{Y_{f, n}}{Y_{f, s}}\left(\frac{\rho_{f, n}}{\rho_{\infty}}\right)^{1 / 2}+5,8\right] d_{n} \cdot\left(\frac{\Delta T}{T_{n}}\right)^{1 / 2}
$$

Na qual $\Delta T$ é a diferença entre a temperatura do gás combustível queimado $T_{f, b u r n}$ e a temperatura do gás combustível (e do ar concorrente) na saída do bocal $T_{n}$, isto é, $\Delta T=$ $\left(T_{f, \text { burn }}-T_{n}\right)$. Assim, a velocidade de blowout $U_{b}$ pode ser prevista a partir da Eq. (2.51).

$$
U_{b}=\left[0,017 \cdot R e_{H_{s}^{\prime}} \cdot\left(1-3,5 \cdot 10^{-6} \cdot R e_{H_{s}^{\prime}}\right)\right] \cdot S_{L} \cdot\left(\frac{\rho_{f, n}}{\rho_{\infty}}\right)^{-3 / 2}
$$

Onde $R e_{H_{s}^{\prime}}$ é o número de Reynolds baseado na posição $H_{s}^{\prime}$, ou seja,

$$
R e_{H_{s}^{\prime}}=\frac{H_{S}^{\prime} S_{L}}{v_{f, n}}
$$

E os parâmetros $S_{L}, v_{f, n}, \rho_{f, n}$ e $\rho_{\infty}$ são avaliados a $T_{n}$.

2. Para o modelo de mistura em grande escala, a Eq. (2.53).

$$
U_{b}=\mathrm{C}\left[d_{n} S_{L}^{2} \frac{\varphi_{s}^{2}}{\alpha_{s}}\left(\frac{\rho_{f, n}}{\rho_{\infty}}\right)^{3 / 2}\right] \cdot\left(\frac{\Delta T}{T_{n}}\right)^{1 / 2}
$$

Onde C é uma constante obtida experimentalmente, cujo valor é 0,0028; e $\alpha_{s}$ é a difusividade térmica da mistura estequiométrica avaliada à temperatura do gás combustível e do ar concorrente na saída do bocal, $T_{n}$; e $\Delta T=\left(T_{f, \text { burn }}-T_{n}\right)$, sendo $T_{f, \text { burn }}$ a temperatura do gás combustível queimado. 


\subsection{Estudos experimentais e analíticos do mecanismo de blowout de jatos coaxiais}

Muitos equipamentos utilizam bocais coaxiais, dos quais se destacam as turbinas a gás e os queimadores industriais (FEIKEMA; CHEN; DRISCOLL, 1991). Por este motivo, é de grande importância - para o projeto do equipamento e definição das condições de operação - conhecer como e quanto o ar coaxial influi na estabilidade da chama. A seguir são apresentados alguns estudos referentes à estabilidade de chamas de difusão turbulenta resultantes de jatos coaxiais.

\subsubsection{Dahm e Mayman (1990)}

Dahm e Mayman (1990) apresentaram uma formulação para o limite de blowout de chamas de difusão de jatos turbulentos emitidas de bocais coaxiais com geometrias arbitrárias em ambientes quiescentes. Introduziram o conceito de uma "fonte equivalente de campo distante", e expressaram a taxa de mistura molecular local no fluxo em termos das leis de escala associadas a este campo distante. Defendem que a taxa de mistura molecular na ponta da chama controla as suas características de blowout. Também seguem o raciocínio de Broadwell; Dam e Mungal (1984), em que o blowout ocorre quando o número de Damkhöler atinge um valor crítico e propuzeram a Eq. (2.54) para calcular esse valor.

$$
D a_{c r i t}=\frac{\sqrt{\pi}}{2} \cdot \frac{\left(d^{*}\right)^{2} S_{L}^{2}\left(1+\varphi_{s}^{\prime}\right)^{2}\left(\rho_{\infty}\right)^{1 / 2}}{\alpha\left(J_{n, x}\right)^{1 / 2}}
$$

onde $\varphi_{s}^{\prime}$ é a razão entre a massa de ar ambiente e a massa de fluido que emerge da fonte (bocal coaxial), na condição estequiométrica; e $d^{*}$ é o diâmetro de uma fonte conceitual dada por:

$$
d^{*} \equiv \frac{2 \dot{m}_{n, x}}{\left(\pi \rho_{\infty} J_{n, x}\right)^{1 / 2}}
$$

em que $\dot{m}_{n, x}$ é a vazão mássica e $J_{n, x}$ é o fluxo de quantidade de movimento axial da fonte. 
Dahm e Mayman (1990) realizaram experimentos utilizando metano e etileno como combustíveis, dióxido de carbono e ar como diluentes, para medir o limite de blowout em várias configurações de fontes coaxiais. A Figura (2.13) apresenta os resultados experimentais (limites de blowout) medidos experimentalmente para a configuração coaxial com fluxo interno de metano (diâmetro do jato de combustível, $d_{n, f}=3 \mathrm{~mm}$ ) e fluxo de ar anular (diâmetro do jato de ar, $\left.d_{n, a}=7 \mathrm{~mm}\right)$.

Segundo Dahm e Mayman (1990), as previsões da Eq. (2.54), proposta por eles, apresentam boa concordância com os resultados obtidos experimentalmente, porém não quantificam os desvios encontrados entre as previsões e os dados experimentais.

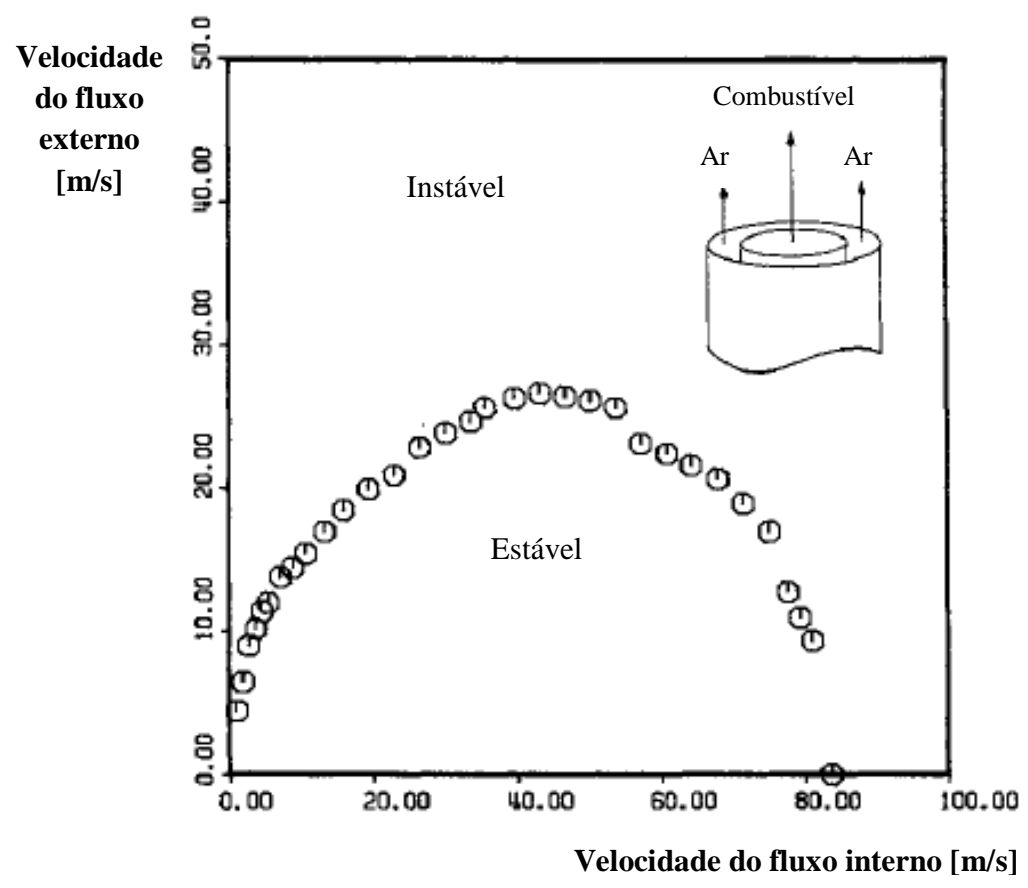

Figura 2.13. Limites de blowout medidos experimentalmente para a configuração coaxial com fluxo interno de metano $\left(d_{n, f}=3 \mathrm{~mm}\right)$ e fluxo de $\operatorname{ar} \operatorname{anular}\left(d_{n, a}=7 \mathrm{~mm}\right)$. (DAHM e MAYMAN, 1990)

\subsubsection{Feikema; Chen e Driscoll (1990)}

Feikema; Chen e Driscoll (1990) mediram experimentalmente os limites de blowout de uma chama não pré-misturada (de metano e deste gás combustível diluído com hidrogênio), 
emergindo de um jato coaxial com e sem swirl. A velocidade do combustível no limite de blowout $\left(U_{f, n}\right)_{b}$ foi medida enquanto que quatro parâmetros foram sistematicamente variadas: (1) o diâmetro do tubo de combustível $\left(d_{n, f}\right)$ e de ar $\left(d_{n, a}\right)$, mantendo a relação $d_{n, f} / d_{n, a}$ constante e igual a 0,15 ; (2) o tipo de combustível e, portanto, a velocidade de reação, a qual está relacionada com a velocidade máxima de chama laminar $\left(S_{L}\right)$; (3) a velocidade do ar coaxial $\left(U_{a, n}\right)$; e (4) o número de swirl, $S$. Os parâmetros característicos das geometrias e dos combustíveis utilizados por Feikema; Chen e Driscoll (1990) encontram-se na Tabela (2.6).

Tabela 2.6. Parâmetros característicos das geometrias e dos combustíveis utilizados por Feikema; Chen e Driscoll (1990)

\begin{tabular}{lccccc}
\hline \hline & $\mathrm{CH}_{4}$ & $\mathrm{CH}_{4}$ & $\mathrm{CH}_{4}$ & $\begin{array}{c}0,67 \mathrm{CH}_{4} \\
0,33 \mathrm{H}_{2} \\
(\mathrm{em} \text { volume })\end{array}$ & $\begin{array}{c}0,45 \mathrm{CH}_{4} \\
0,55 \mathrm{H}_{2} \\
(\mathrm{em} \text { volume })\end{array}$ \\
\hline$d_{n, a}(\mathrm{~m})$ & 0,0314 & 0,0222 & 0,0144 & 0,0144 & 0,0144 \\
$d_{n, f}(\mathrm{~m})$ & 0,0048 & 0,0034 & 0,0022 & 0,0022 & 0,0022 \\
$d_{n, f} / d_{n, a}$ & 0,15 & 0,15 & 0,15 & 0,15 & 0,15 \\
$d_{n, f}^{\prime} / d_{n, f}$ & 1,42 & 1,41 & 1,44 & 1,44 & 1,44 \\
$S_{L}(\mathrm{~m} / \mathrm{s})$ & 0,39 & 0,39 & 0,39 & 0,55 & 0,76 \\
$\alpha_{f, n}\left(\mathrm{~m}^{2} / \mathrm{s}\right)$ & $2,03 \cdot 10^{-5}$ & $2,03 \cdot 10^{-5}$ & $2,03 \cdot 10^{-5}$ & $4,31 \cdot 10^{-5}$ & $6,52 \cdot 10^{-5}$ \\
$D a_{K}^{-1}(\mathrm{Eq} .2 .49)$ & 2,7 & 2,7 & 2,7 & 6,1 & 8,8 \\
$D a_{B}^{-1}(\mathrm{Eq} .2 .51)$ & 2,3 & 2,3 & 2,3 & 4,5 & 6,7 \\
$D a_{o}^{-1}$ & 2,2 & 2,4 & 2,4 & 5,8 & 9,4 \\
$\left(\right.$ medido p/ $\left.U_{a, n}=0\right)$ & & & & & \\
\hline \hline
\end{tabular}

Estes autores verificaram experimentalmente que, pouco antes do fenômeno de blowout, três tipos de chamas podem ser observadas:

1. Chama descolada, semelhante à chama de um jato simples. Sua base da chama é azul, o que indica apreciável mistura de combustível e ar na região de descolamento. A altura de descolamento, $h$, deste tipo de chama (com swirl) é constante e independente da velocidade do combustível (diferente da chama de um jato simples, em que $h$ aumenta com a velocidade do combustível). Esta chama parece se estabilizar imediatamente a jusante da zona de recirculação; 
2. Chama longa colada no bocal, a qual sofre blowout sem apreciável descolamento deste, o que indica que a porção a montante da zona de recirculação está a estabilizar a chama. Quando a velocidade do combustível $U_{f, n}$ excede um valor crítico, as condições da região a jusante da zona de recirculação não são favoráveis à estabilização da chama, de modo que o jacto de chama inteiro de repente sopra; e

3. Chama curta colada, a qual também sofre blowout sem apreciável descolamento. Esta chama sempre aparece azulada. Neste tipo de chama há uma forte zona de recirculação e sofre blowout quando a velocidade do combustível $U_{f, n}$ é reduzida de forma significativa (ela não sofre blowout devido a velocidade excessiva de combustível, mas sim porque é tensionada fortemente pela recirculação dos vórtices).

Logo, o blowout pode ser causado pelo aumento da velocidade de descarga do gás combustível $U_{f, n}$ acima de um "limite rico" (chama longa colada, rica em combustível) ou redução de $U_{f, n}$ abaixo de um "limite pobre" (chama curta colada, pobre em combustível). Isto pode ser verificado na Figura (2.14), a qual apresenta os limites de blowout, $\left(U_{f, n}\right)_{b}$, do gás combustível metano em função da velocidade de ar coaxial, $U_{a, n}$, para o queimador coaxial com diâmetros $d_{n, f}=3,4 \mathrm{~mm}$ e $d_{n, a}=22,2 \mathrm{~mm}$.

Na prática, deseja-se maximizar a razão entre estes dois limites, o que pode ser conseguido com o aumento do número de swirl, S (FEIKEMA; CHEN; DRISCOLL, 1990).

Apartir dos resultados experimentais, Feikema; Chen e Driscoll (1990) também verificaram que:

1. O swirl provoca uma interação jato-vórtice, de modo que o vórtice de recirculação reduz a velocidade do jato de combustível na linha de centro, o que estabiliza fortemente a chama descolada;

2. Outra vantagem do swirl é que ele torna possível a operação de uma chama pobre em combustível (chama curta colada, tipo 3); na mesma condição, a chama sem swirl seria instável;

3. O aumento do diâmetro do tubo de combustível, $d_{n, f}$, e a adição de hidrogênio (aumento de $S_{L}$ ) torna a chama com swirl mais estável (isto também ocorre com uma chama de jato simples, sem swirl); 
4. para cada valor do número de swirl, $S$, há uma velocidade de ar $U_{a, n}$ máxima, acima da qual não é possível obter chamas estáveis; logo, dado um valor de $U_{a, n}$, existe um $S$ mínimo.

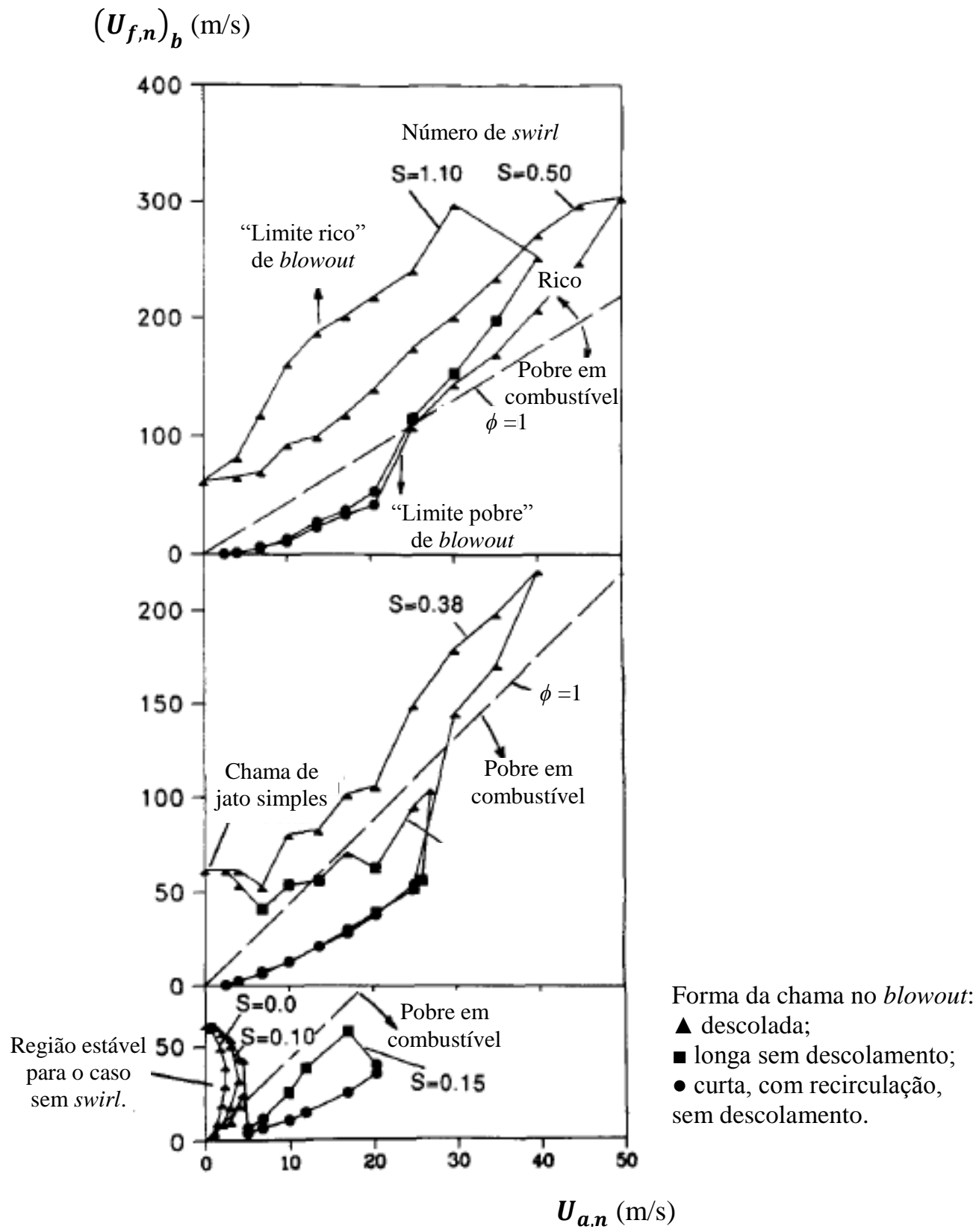

Figura 2.14. Aumento da região de estabilidade da chama de metano com o aumento número swirl, $\mathrm{S}$, para o queimador coaxial com diâmetros $d_{n, f}=3,4 \mathrm{~mm}$ e $d_{n, a}=22,2 \mathrm{~mm}$.

(FEIKEMA; CHEN; DRISCOLL, 1990) 
Feikema; Chen e Driscoll (1990) demonstraram que os limites de blowout de uma chama com swirl podem ser comparados com os limites de blowout de chamas de difusão simples sem swirl, utilizando o inverso do número Damkohler, $\mathrm{Da}^{-1}$, definido por eles como:

$$
D a^{-1}=\frac{U_{f, n} / d_{n, f}}{S_{L}^{2} / \alpha_{f, n}}
$$

onde é $\alpha_{f, n}$ a difusividade térmica do combustível na saída do bocal. Observe que esta definição difere da apresentada por Broadwell; Dam e Mungal (1984).

A partir da definição de $D a^{-1}$, Eq.(2.56), Feikema; Chen e Driscoll (1990) analisam as equações para previsão do blowout de chamas de jatos simples propostas por Kalghatgi (1981) e Broadwell; Dam e Mungal (1984) e as apresentam das seguintes formas:

$$
\frac{\left(U_{f, n}\right)_{b} / d_{n, f}}{S_{L}^{2} / \alpha_{f, n}}=D a_{K}^{-1}
$$

onde

$$
D a_{K}^{-1}=0,017\left(\frac{\alpha_{f, n}}{v_{f, n}}\right)\left(\frac{\rho_{a, n}}{\rho_{f, n}}\right)^{2}\left[\frac{4}{Y_{s}}\left(\frac{\rho_{f, n}}{\rho_{a, n}}\right)^{1 / 2}-5,8\right]
$$

$\mathrm{e}$

$$
\frac{\left(U_{f, n}\right)_{b} / d_{n, f}}{S_{L}^{2} / \alpha_{f, n}}=D a_{B}^{-1}
$$

onde

$$
D a_{B}^{-1}=\frac{\left(1+\varphi_{\mathrm{s}}\right)^{2}}{4,8}\left(\frac{\rho_{f, n}}{\rho_{a, n}}\right)^{1 / 2}\left(\frac{\alpha_{f, n}}{\alpha_{s}}\right)
$$

na qual $\alpha_{s}$ é a difusividade térmica da mistura combustível-ar na condição estequiométrica e na temperatura de chama adiabática.

A Eq.(2.4) é oriunda da Eq. (2.6) proposta por Kalghatgi (1981), considerando o termo (3,5 $10^{-6} \cdot R e_{H_{S}}$ ) da expressão (2.5) desprezível e $Y_{f, n}=1$, ou seja, combustível puro saindo do bocal. A Eq.(2.54) é oriunda da Eq. (2.25) proposta por Broadwell; Dam e Mungal (1984), admitindo $D a_{\text {crit }}=4,8$ e substituindo o termo $\varphi_{s}^{2}$ por $\left(1+\varphi_{\mathrm{s}}\right)^{2}$, como sugerido por Dahm e Mayman (1990). 
Feikema; Chen e Driscoll (1990) também analisam a Eq. (2.54) proposta por Dahm e Mayman (1990) e a apresentam da seguinte forma:

$$
U_{a, n}^{2}=\xi \beta^{4 / 3} \eta d_{a, n}^{2 / 3} U_{f, n}^{4 / 3}-\beta \eta U_{f, n}^{2}
$$

onde $U_{a, n}$ é a velocidade de ar coaxial que ocasiona blowout para um dado combustível com velocidade $U_{f, n}$; e

$$
\beta=\left(\frac{\rho_{f, n}}{\rho_{a, n}}\right)\left(\frac{d_{n, f}}{d_{n, a}}\right)^{2} \quad \eta=\frac{1}{\left[1-\left(d_{n, f}^{\prime} / d_{n, a}\right)^{2}\right]} \quad \xi=\left[\frac{S_{L}^{2}}{\alpha} \frac{\left(1+\varphi_{s}\right)^{2}}{D a_{c r i t}}\right]^{2 / 3}
$$

Feikema; Chen e Driscoll (1990) assumem $D a_{\text {crit }}=4,8$ para todos os casos analisados, como sugerido por Broadwell; Dam e Mungal (1984). Para chamas de metano com ar coaxial, temse que $\xi=808 s^{-2 / 3} ; \beta=0,0124$; e $\eta=1,05$, uma vez que $\left(d^{\prime}{ }_{n, f} / d_{n, a}\right)$ é constante.

A Eq. (2.59) é obtida a partir da Eq. (2.54), considerando um jato coaxial com fluxo de gás combustível interno e fluxo de ar coaxial, de modo que a vazão mássica da fonte, $\dot{m}_{n}$, e o fluxo total de quantidade de movimento, $J_{n, x}$, são:

$$
\dot{m}_{n, x}=\dot{m}_{f, n}+\dot{m}_{a, n}=\frac{\pi}{4}\left[\rho_{f, n} d_{n, f}^{2} U_{n, f}+\rho_{a, n}\left(d_{n, a}^{2}-d_{n, f}^{\prime 2}\right) U_{a, n}\right]
$$

e

$$
J_{n, x}=\dot{m}_{f, n} U_{f, n}+\dot{m}_{a, n} U_{a, n}=\frac{\pi}{4}\left[\rho_{f, n} d_{n, f}^{2} U_{f, n}^{2}+\rho_{a, n}\left(d_{n, a}^{2}-d_{n, f}^{2}\right) U_{a, n}^{2}\right]
$$

Segundo Feikema; Chen e Driscoll (1990), substituindo $\dot{m}_{n}$, e $J_{n, x}$ na Eq. (2.54) e rearranjando os termos, obtem-se a Eq. (2.59), a qual é válida apenas para zero swirl. Este fato foi analisado pela presente autora, quem verificou que o resultado da substituição de $\dot{m}_{n, x}$, e $J_{n, x}$ na Eq. (2.54) é:

$$
U_{a, n}^{2}=\xi \eta d_{n, a}^{2 / 3}\left(\beta U_{f, n}+\eta^{-1} U_{a, n}\right)^{4 / 3}-\beta \eta U_{f, n}^{2}
$$

ou seja, Feikema; Chen e Driscoll (1990) desprezaram o termo $\left(\eta^{-1} U_{a, n}\right)$ presente na Eq. (2.62). De qualquer maneira, as previsões da Eq. (2.59) concordam com as curvas de blowout obtidas experimentalmente por Feikema; Chen e Driscoll (1990), quando utiliza-se metano puro como combustível. O mesmo não ocorre quando hidrogênio é adicionado ao metano, ou seja, as 
previsões são inferiores aos valores experimentais. Os autores acreditam que esta diferença se deve ao valor de $S_{L}$ utilizado para os cálculos (vide Tab. 2.6).

Feikema; Chen e Driscoll (1990) afirmam que quando swirl é adicionado, a chama torna-se cinco vezes mais estável (com base na velocidade máxima de combustível). Para explicar o efeito do swirl, os autores fazem uma extensão da teoria de blowout de chamas sem swirl utilizada por Dahm e Mayman (1990), sugerindo um número de Damkohler com base na velocidade angular, $U_{\theta}$ :

$$
\frac{U_{f, n} / d_{n, f}}{S_{L}^{2} / \alpha_{f, n}} \cdot D a_{B}=1+\frac{\left(U_{\theta}-U_{\theta, c r i t}\right) / d_{n, a}}{S_{L}^{2} / \alpha_{f, n}} \cdot D a_{B} \cdot C_{F, 1} \cdot\left(\frac{d_{n, a}}{d_{n, f}}\right)^{2}
$$

onde $U_{\theta}$ é a velocidade angular na saída do bocal; $U_{\theta, \text { crit }}$ é a velocidade angular crítica requerida para criar uma zona de recirculação (parâmetro experimental); e $C_{F, 1}$ é uma constante obtida experimentalmente, cujo valor é 1,50. Os autores acreditam que $C_{F, 1}$ depende da geometria do bocal.

\subsubsection{Feikema; Chen e Driscoll (1991)}

Feikema; Chen e Driscoll (1991), em contraste com os trabalhos apresentados anteriormente, se concentraram em um diferente limite de blowout, isto é, na velocidade máxima de ar coaxial, $U_{a, n}$, ao invés da velocidade máxima do combustível. Os autores demonstram como aperfeiçoar parâmetros para maximizar a quantidade de ar coaxial que pode ser fornecida para um jato de combustível não pré-misturado sem causar a extinção da chama. Maximizar a velocidade do ar coaxial é importante para reduzir o comprimento da chama e, consequentemente, a emissão de óxidos de nitrogênio, $\mathrm{NO}_{x}$, em turbinas a gás e queimadores industriais (que representam a maioria dos equipamentos que utilizam ar coaxial). Segundo estes autores, esta velocidade deve ser suficiente para encurtar a chama até um comprimento especificado (para reduzir as emissões de $N O_{x}$ ), porém este comprimento não pode ser inferior a um valor mínimo, $L_{m i n}$, pois o ar coaxial causará blowout.

Feikema; Chen e Driscoll (1991) apresentam a Eq. (2.64), derivada do trabalho de Dahm e Mayman (1990), para previsão do comprimento da chama, $L$. 


$$
\frac{\left(L / d_{n, f}\right)}{\left(L / d_{n, f}\right)_{o}}=\left[1+\left(\frac{\rho_{a, n}}{\rho_{f, n}}\right)\left(\frac{U_{a, n}}{U_{f, n}}\right)^{2}\left(\frac{d_{n, a}}{d_{n, f}}-1\right)\right]^{-1 / 2}
$$

O mínimo comprimento de chama possível $\left(L_{\min }\right)$ será aquele observado quando o ar coaxial provocar o blowout da chama, ou seja, quando $U_{a, n}=\left(U_{a, n}\right)_{\max }$. Uma vez que, a Eq. (2.59) prediz a velocidade do ar que provoca blowout, o comprimento mínimo da chama pode ser previsto por meio da substituição de $U_{a, n}$ (Eq. 2.59) na Eq. (2.64). Assim, segundo Feikema; Chen e Driscoll (1991), tem-se:

$$
\frac{\left(L / d_{n, f}\right)_{\min }}{\left(L / d_{n, f}\right)_{o}}=\left(C_{F, 2} \cdot \frac{U_{f, n}}{d_{n, f}}\right)^{1 / 3}
$$

onde

$$
C_{F, 2}=\frac{4,8}{\left(S_{L}^{2} / \alpha_{s}\right)} \frac{1}{\left(1+\varphi_{\mathrm{s}}\right)^{2}}\left(\frac{\rho_{a, n}}{\rho_{f, n}}\right)^{2}
$$

$\left(L / d_{n, f}\right)_{o}$ é o comprimento da chama normalizado na condição de $U_{a, n}=0 \mathrm{~m} / \mathrm{s} ;\left(L / d_{n, f}\right)_{o}=$ 200 para o metano (BROADWELL; DAM; MUNGAL, 1984) ; e $C_{F, 2}$ é uma constante que depende somente das propriedades do combustível; para o hidrogênio, $C_{F, 2}=0,95 \mu$ s; e para o metano, $C_{F, 2}=58,4 \mu$ s (FEIKEMA; CHEN e DRISCOLL, 1991).

A presente autora também analisou a substituição de $U_{a, n}$ (Eq. 2.59) na Eq. (2.64) e obteve:

$$
\frac{\left(L / d_{n, f}\right)_{\min }}{\left(L / d_{n, f}\right)_{o}}=\left(C_{N, 1} \cdot \frac{U_{f, n}}{d_{n, f}}\right)^{1 / 3} \cdot\left(\frac{d_{n, a}}{d_{n, f}}\right)^{2 / 3}
$$

onde

$$
C_{N, 1}=\frac{D a_{c r i t}}{\left(S_{L}^{2} / \alpha_{s}\right)} \frac{1}{\left(1+\varphi_{s}\right)^{2}}\left(\frac{\rho_{a, n}}{\rho_{f, n}}\right)^{2}
$$

Assim, a Eq. (2.65.a) assume $d_{n, a} \cong d_{n, f}$ e $D a_{c r i t}=4,8$ (como sugerido por Broadwell; Dam e Mungal (1984). A primeira hipótese $\left(d_{n, a} \cong d_{n, f}\right)$ é muito grosseira, uma vez que Feikema; Chen e Driscoll (1991) utilizam em seus experimentos $d_{n, f}=0,15 d_{n, a}$ e precisa ser verificada. 
Feikema; Chen e Driscoll (1991) também propuseram a Eq. (2.67) para prever a velocidade máxima do ar coaxial $\left(U_{a, n}\right)_{\max }$ acima da qual nenhuma chama pode ser estabilizada, independente da velocidade do combustível, $U_{n, f}$.

$$
\frac{\left[\left(U_{a, n}\right)_{\max } / d_{n, a}\right]}{\left(S_{L}^{2} / \alpha_{s}\right)}=0,080\left(1+\varphi_{s}\right)^{2}\left(\frac{\rho_{f, n}}{\rho_{a, n}}\right)\left(\frac{d_{n, f}}{d_{n, a}}\right)^{2} \cdot\left[1-\left(d_{n, f}^{\prime} / d_{n, a}\right)^{2}\right]^{-1}
$$

onde $\alpha_{s}$ é a difusividade térmica da mistura combustível-ar na condição estequiométrica em temperatura elevada $\left(\alpha_{s}=4,5 \cdot 10^{-4} \mathrm{~m}^{2} / \mathrm{s}\right)$.

A Eq. (2.67) é derivada da Eq. (2.59) proposta por Dahm e Mayman (1990). Apartir desta equação verifica-se que grandes valores de velocidade de ar $\left(U_{a, n}\right)_{\max }$ podem ser alcançados selecionando-se elevados valores da razão de diâmetros $d_{n, a} / d_{n, f}$.

Para avaliar as previsões das expressões propostas (Eqs. 2.65 e 2.67), Feikema; Chen e Driscoll (1991) realizaram experimentos e medições de $L_{\min }$ e $\left(U_{a, n}\right)_{\max }$. Ambas apresentaram boa concordância com os resultados experimentais. Os autores também avaliaram os efeitos da adição de swirl no jato de ar coaxial. Durante as análises, foram variados: velocidades do combustível e do ar, diâmetro do tubo de combustível $\left(d_{n, f}\right)$ e do tubo coaxial de ar $\left(d_{n, f} / d_{n, a}=\right.$ 0,15), tipo de combustível (metano, hidrogênio e uma combinação dos dois) e o número de swirl, S. A Figura (2.15) apresenta um esquema dos aparatos experimentais utilizados pelos autores e o efeito do ar coaxial na base da chama (a) sem swirl e (b) com swirl. A linha sólida na Figura (2.15.b) delimita a região de recirculação.

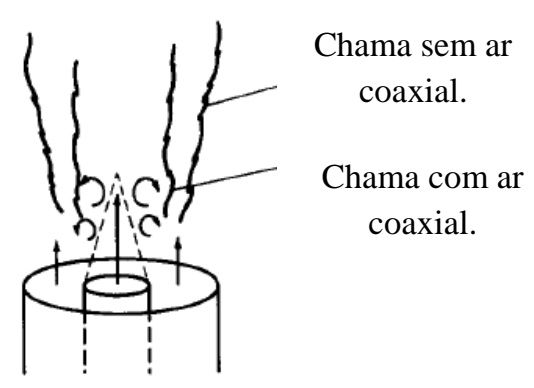

(a) sem swirl

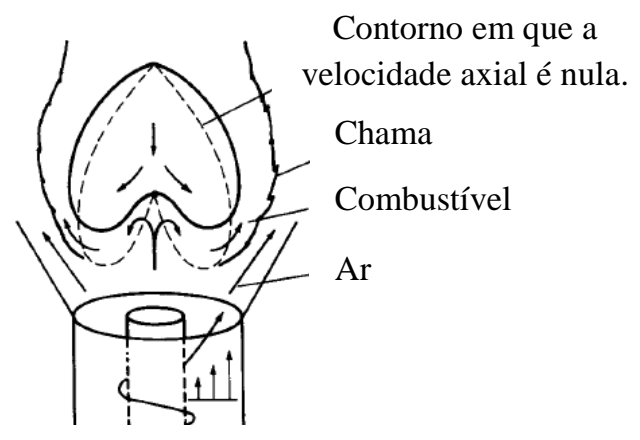

(b) com swirl

Figura 2.15. Efeito do ar coaxial na base da chama (FEIKEMA; CHEN; DRISCOLL, 1991). 
As medições demonstram que somente ar coaxial (sem swirl) pode reduzir o comprimento da chama pela metade, e que a adição de swirl aumenta seis vezes a velocidade limite de blowout. Os autores defendem que o swirl é benéfico, ou seja, é a favor da estabilidade da chama, pois ele reduz as velocidades e as taxas de deformações locais, próximas ao ponto onde a chama é estabilizada (vide Apêndice A, Subseção A.4 "Jatos").

\subsection{Comentários referentes à Revisão Bibliográfica}

A pesquisa bibliográfica apresentada faz uma revisão dos recentes progressos na compreensão de chamas de difusão turbulenta descoladas do bocal e as condições em que estas chamas se estabilizam. Outras revisões sobre o presente tema podem ser encontradas, com maiores detalhes, no trabalho de Pitts (1988) e de Lyons (2007). Estes autores fazem uma análise crítica das teorias, trabalhos relacionados, resultados experimentais, conclusões sobre o estado do campo e sugestões para futuras pesquisas experimentais.

A partir da presente pesquisa, verificou-se que o blowout de uma chama de difusão turbulenta é um processo transitório, com uma série de eventos que ocorrem consecutivamente, e acontece de forma rápida e imprevisível (Wu et al, 2006). Logo, é interessante notar o esforço dos autores em estimar e caracterizar não só o limite de blowout, mas também o processo de blowout e os comportamentos dinâmicos que o acompanham, com base na velocidade inicial/número de Reynolds do jato e nas propriedades do gás combustível na saída do bocal, ou seja, não utilizam nas correlações propostas parâmetros do escoamento ao longe, como intensidade de turbulência, taxa de mistura, gradientes de temperatura, de pressão, de concentração, entre outros.

Além disso, todas as correlações propostas e apresentadas na presente revisão bibliográfica foram desenvolvidas com base em modelos empíricos (baseados em resultados experimentais) e validadas para condições de operação específicas (geometria do queimador, tipo de combustível, condições ambiente, etc). Portanto, deve-se ter cautela ao utilizá-las, bem como ao adotar valores para os parâmetros necessários. Dentre eles, os mais problemáticos são:

1. Velocidade de chama laminar, $S_{L}$ : é a velocidade com a qual a onda de combustão se propaga. Esta velocidade pode ser determinada experimentalmente e/ou calculada por 
meio de expressões empíricas. Deve-se ter cuidado ao adotar um valor para este parâmetro para calcular a velocidade de blowout. Os valores utilizados por Kalghatgi (1981), por exemplo, são diferentes dos apresentados por Turns (2000) para combustíveis puros. O mesmo ocorre com o trabalho de Wu et al (2006), em que $S_{L}$ de misturas diferem dos apresentados por Karbassi (1997). ${ }^{6}$

2. Limites de flamabilidade de misturas: Os limites de flamabilidade representam os valores extremos (máximo e mínimo) do teor de combustível em uma mistura (envolvendo a espécie oxidante) que quando sujeita a uma fonte de ignição gera uma chama estável. Valores experimentais de limite de flamabilidade de determinados combustíveis puros são extensivamente reportados na literatura, enquanto que dados relativos a misturas são restritos a situações muito específicas de composição, bem como número e tipo de espécies químicas envolvidas. Embora haja a possibilidade de extrapolação de dados de combustíveis puros usando regras empíricas de mistura disponíveis na literatura, estas correlações não são universalmente aplicáveis e freqüentemente geram erros grosseiros (VIVAS, 2010).

\footnotetext{
"Seção (5.2.3 do trabalho de Karbassi, 1997) "Diluente no jato de combustível” (pág 95) e Fig. (5.7) para
} velocidade de chama laminar (pág 97 do trabalho de Karbassi, 1997). 


\section{MATERIAIS E MÉTODOS}

Os dois primeiros objetivos deste trabalho ("levantamento" do conhecimento do estado da arte em estabilidade de chamas e apresentação das correlações para a velocidade de descarga que ocasiona blowout), bem como as respostas das questões propostas na Subseção (1.1) “Objetivos”, foram atingidos por meio da detalhada revisão bibliográfica apresentada na Seção (2). As respostas das questões propostas estão apresentadas na Subseção (4.2).

Para atingir os demais objetivos (identificação e/ou proposição de uma correlação ou formalismo que forneça valores da velocidade de blowout, $U_{b}$, mais precisos, validação da mesma e análise crítica dos resultados) adotou-se-se a seguinte metodologia:

1. Obtenção e análise dos dados experimentais (erro associado à digitalização dos dados e condições ambientes em que foram obtidos, respectivamente), os quais serão adotados como referência;

2. Análise das correlações propostas para a velocidade de blowout, $U_{b}$, (apresentadas na seção 2 "Revisão bibliográfica") e dos parâmetros que são englobados, os quais influem no mecanismo de blowout;

3. Definição de hipóteses simplificadoras e condições de operação;

4. Cálculo de $U_{b}$ por meio das correlações apresentadas;

5. Definição de um critério para avaliar os resultados;

6. Comparação entre o valor de $U_{b}$ previsto e o valor experimental, $U_{b, \text { exp }}$;

7. Identificação da correlação que fornece valores de $U_{b}$ mais próximos dos dados experimentais;

8. Análise crítica das possíveis causas dos desvios entre as previsões e os dados experimentais;

9. Proposição de uma nova correlação que forneça valores de $U_{b}$ tão precisos ou melhores que as correlações analisadas anteriormente, disponíveis na Literatura; 
10. Validação da nova correlação (comparação entre $U_{b}$ previsto e $U_{b, e x p}$ ) e análise crítica de suas previsões com base nos conceitos de estabilidade de chamas de difusão turbulentas (apresentados na seção 2 "Revisão bibliográfica”).

A seguir, cada etapa da metodologia adotada será apresentada detalhadamente.

\subsection{Obtenção e análise de dados experimentais}

Kalghatgi (1981) realizou uma série de experimentos com os gases combustíveis: metano, propano, etileno, acetileno, hidrogênio e butano comercial; com o objetivo de medir a velocidade de blowout dos mesmos. O autor apresenta seus resultados experimentais em gráfico do número de Mach $\left(M a_{b}\right)$ na saída do bocal (na condição de blowout da chama) em função do diâmetro deste, para diferentes gases combustíveis (como apresentado na Fig. 3.1). Os valores de $M a_{b}$ foram calculados com base na pressão de estagnação do gás (medida experimentalmente pelo autor) no instante em que este se expande para a pressão atmosférica.

Os dados experimentais de $M a_{b}$ foram digitalizados a partir do trabalho de Kalghatgi (1981) utilizando-se o aplicativo Plot Digitizer ${ }^{7}$. O erro associado ao processo de digitalização é de aproximadamente \pm 0,015 em $M a_{b}$ (em "unidades" de $M a$ ). Este valor foi estimado com base na incerteza da leitura dos valores não publicados, mas lançados em gráfico (ou seja, no tamanho do ponto utilizado pelo autor para indicar os resultados experimentais em seu gráfico). A Figura (3.1) apresenta os dados digitalizados.

Kalghatgi (1981) não mensiona nem quantifica os possíveis erros associados as suas medições experimentais (como imprecisão dos equipamentos de medição) e aos valores das propriedades dos gases combustíveis adotados em seus cálculos (como velocidade de chama laminar, viscosidade cinemática, temperatura de estagnação, composição, entre outros).

\footnotetext{
${ }^{7}$ http://plotdigitizer.sourceforge.net/
} 


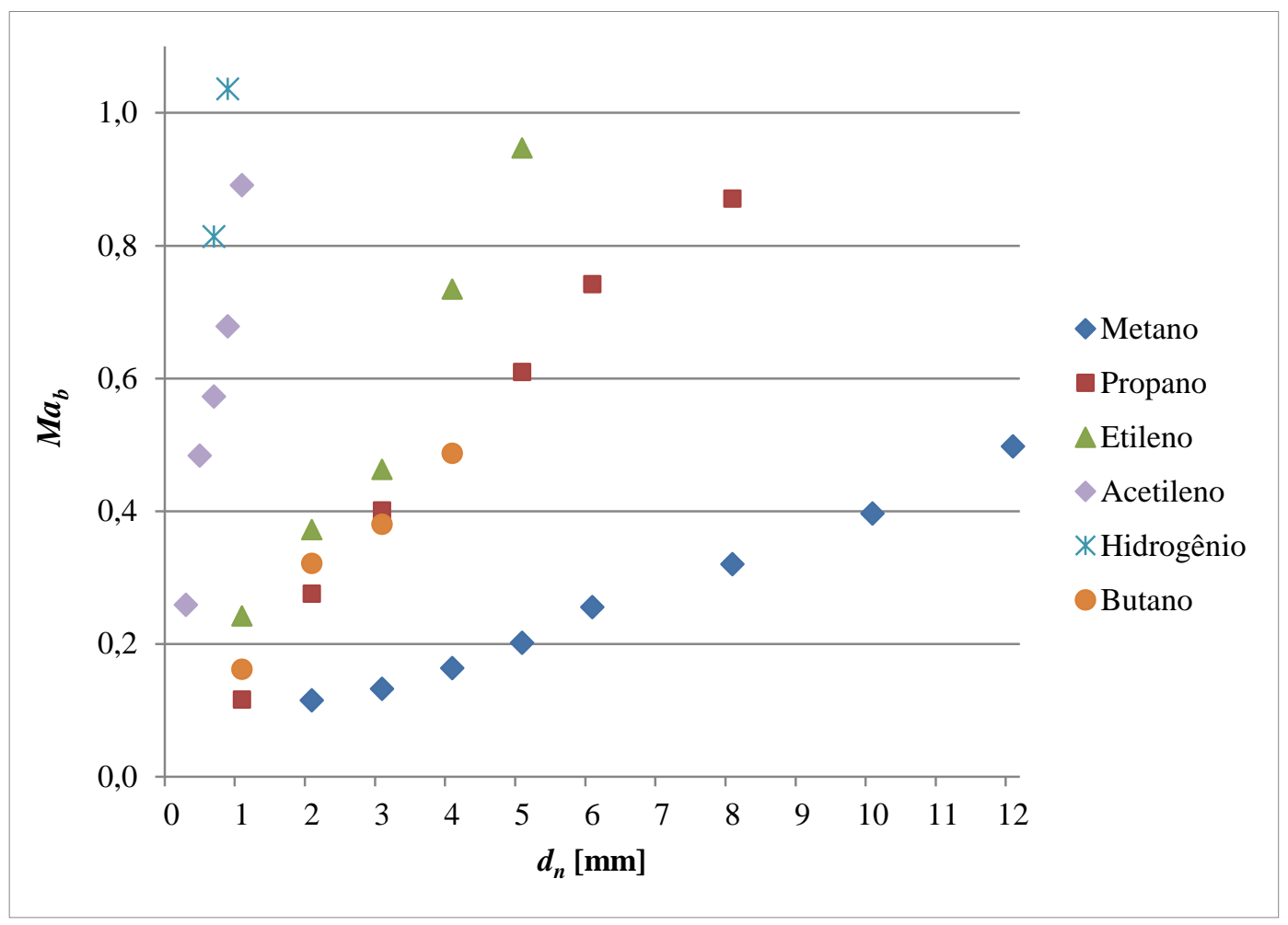

Figura 3.1. Número de Mach $\left(M a_{b}\right)$ na saída do bocal no instante em que ocorre blowout da chama, em função do diâmetro do bocal de gás, para diferentes gases combustíveis. (KALGHATGI, 1981)

A fim de obter valores da velocidade de blowout, $U_{b, \text { exp }}$, a partir dos dados experimentais de $M a_{b}$ apresentados por Kalghatgi (1981), adotaram-se as seguintes hipóteses:

1. Escoamento do gás através do bocal é isoentrópico;

2. Os fluidos (gás combustível e ar) comportam-se como gases perfeitos;

3. Os calores específicos, $c_{p}$ e $c_{v}$, dos gases são constantes;

4. A temperatura e pressão ambientes são iguais a $T_{\infty}=298 \mathrm{~K}$ e $P_{\infty}=101325 \mathrm{~Pa}(1 \mathrm{~atm})$, respectivamente;

5. A pressão do gás combustível na saída do jato é igual à pressão atmosférica $\left(P_{f, n}=P_{\infty}\right)$;

6. O ar no entorno do jato é uma mistura composta por $79 \%$ de nitrogênio e $21 \%$ de oxigênio (em volume);

7. As propriedades dos gases são iguais às apresentadas na tabela (3.1), extraídas do trabalho de Kalghatgi (1981). 
Tabela 3.1. Propriedades dos gases combustíveis utilizados por Kalghatgi (1981). (KALGHATGI, 1981)

\begin{tabular}{lcccccc}
\hline \hline Gás & $\begin{array}{c}\text { Composição } \\
{[\% \text { volume }]}\end{array}$ & $\begin{array}{c}\boldsymbol{M} \boldsymbol{M} \\
{[\mathrm{kg} / \mathrm{kmol}]}\end{array}$ & $\begin{array}{c}\boldsymbol{\mu}_{\boldsymbol{f}}{ }^{(*)} \\
{[\mathrm{Pa} \cdot \mathrm{s}]}\end{array}$ & $\begin{array}{c}\boldsymbol{S}_{\boldsymbol{L}} \\
{[\mathrm{m} / \mathrm{s}]}\end{array}$ & $\begin{array}{c}\boldsymbol{\gamma}_{\boldsymbol{f}} \\
\left(c_{p} / c_{\boldsymbol{v}}\right)\end{array}$ & $\boldsymbol{Y}_{\boldsymbol{f}, \boldsymbol{s}}$ \\
\hline Metano & 99 & 16 & $1,03 \mathrm{E}-05$ & 0,39 & 1,31 & 0,055 \\
Propano & 99 & 44 & $7,40 \mathrm{E}-06$ & 0,45 & 1,13 & 0,060 \\
Etileno & 95 & 28 & $9,10 \mathrm{E}-06$ & 0,75 & 1,26 & 0,063 \\
Acetileno & 95 & 26 & $9,35 \mathrm{E}-06$ & 1,63 & 1,25 & 0,070 \\
Hidrogênio & 99 & 2 & $8,42 \mathrm{E}-06$ & 3,06 & 1,40 & 0,028 \\
Butanos & 28 isobutano; & 54,1 & $8,00 \mathrm{E}-06$ & 0,44 & 1,10 & 0,060 \\
comerciais & 42 -butano; & & & & & \\
& 26 propano; & & & & & \\
& 4 outros. & & & & & \\
\hline \hline
\end{tabular}

(*) Viscosidade dinâmica avaliada a $273,15 \mathrm{~K}\left(0^{\circ} \mathrm{C}\right)$.

Para um escoamento isoentrópico de um gás perfeito que apresenta calor específico constante, temos que sua temperatura na saída do bocal, $T_{f, n}$, é (BORGNAKKE, 2003):

$$
T_{f, n}=T_{o}\left[1+\frac{\left(\gamma_{f}-1\right)}{2} M a_{b}^{2}\right]^{-1}
$$

onde $T_{o}$ é a temperatura de estagnação $\left(T_{o}=290 \mathrm{~K}\right)$ e $\gamma_{f}$ é a razão de calores específicos do gás, $\gamma_{f}=\left(c_{p} / c_{v}\right)_{f}$.

A velocidade do som na saída do bocal é dada por:

$$
c=\sqrt{\gamma_{f} R_{f} T_{f, n}}=\sqrt{\gamma_{f} R_{f} T_{o}} \cdot\left[1+\frac{\left(\gamma_{f}-1\right)}{2} M a_{b}^{2}\right]^{-1 / 2}
$$

onde $R_{f}$ é a constante do gás, dada por $R_{f}=\bar{R} / M M_{f}$; em que $\bar{R}$ é a constante dos gases (8315 $\mathrm{J} / \mathrm{kmolK}) ; T_{f, n}$ é a temperatura do gás na saída do bocal; e $M M_{f}$ é a massa molecular do gás $[\mathrm{kg} / \mathrm{kmol}]$.

Assim, da definição do número de Mach $(M a=c / U)$, obtem-se a velocidade de blowout, $U_{b, \exp }$, com base nos resultados experimentais:

$$
U_{b, \exp }=M a_{b} \cdot c
$$


Ou, substituindo a Eq. (3.2) na Eq. (3.3):

$$
U_{b, \exp }=M a_{b} \cdot \sqrt{\gamma_{f} R_{f} T_{0}} \cdot\left[1+\frac{\left(\gamma_{f}-1\right)}{2} M a_{b}^{2}\right]^{-1 / 2}
$$

Na qual, $M a_{b}$ é o número Mach digitalizado do trabalho de Kalghatgi (1981); $\gamma_{f}$ é a razão de calores específicos do gás dado por $\gamma_{f}=\left(c_{p} / c_{v}\right)_{f} ; R_{f}$ é a constante do gás; e $T_{0}$ é a temperatura de estagnação $\left(T_{o}=290 \mathrm{~K}\right)$.

A Figura (3.2) apresenta os valores de $U_{b, \exp }$ calculados a partir da Eq. (3.4), para cinco gases combustíveis e diferentes diâmetros de bocais, analisados experimentalmente por Kalghatgi (1981). Este autor também realiza experimentos com o gás hidrogênio, mas os valores de $U_{b, \exp }$ deste gás não estão apresentados na Figura (3.2), pois são muito superiores e a representação destes dificultaria a visualização de $U_{b, \exp }$ dos demais gases.

Broadwell; Dam e Mungal (1984) e Pitts (1989) também apresentam, graficamente, os valores experimentais da velocidade de blowout, $U_{b, \text { exp }}$, extraídos do trabalho de Kalghatgi (1981).

A fim de validar as hipóteses adotadas e, consequentemente, o equacionamento realizado - Eq. (3.1) a Eq. (3.4) - pela presenta autora para obter $U_{b, \exp }$ a partir dos dados experimentais de $M a_{b}$ extraídos do trabalho de Kalghatgi (1981), decidiu-se por digitalizar os valores de $U_{b, \exp }$ dos trabalhos de Broadwell; Dam e Mungal (1984) e de Pitts (1989) e utilizá-los para comparação. Para isso, utilizou-se também o aplicativo Plot Digitizer. Os resultados da digitalização estão apresentados nas Figuras (3.3) e (3.4), respectivamente. O erro $\xi_{\text {exp }}$ associado ao processo de digitalização foi estimado em, aproximadamente, $\pm 5 \mathrm{~m} / \mathrm{s}$, com base na incerteza da leitura dos valores lançados em gráfico por estes autores.

O critério adotado para avaliar e comparar os dados experimentais de Kalghatgi (1981), Broadwell; Dam e Mungal (1984) e Pitts (1989) encontra-se no Item (3.1.1) a seguir. 


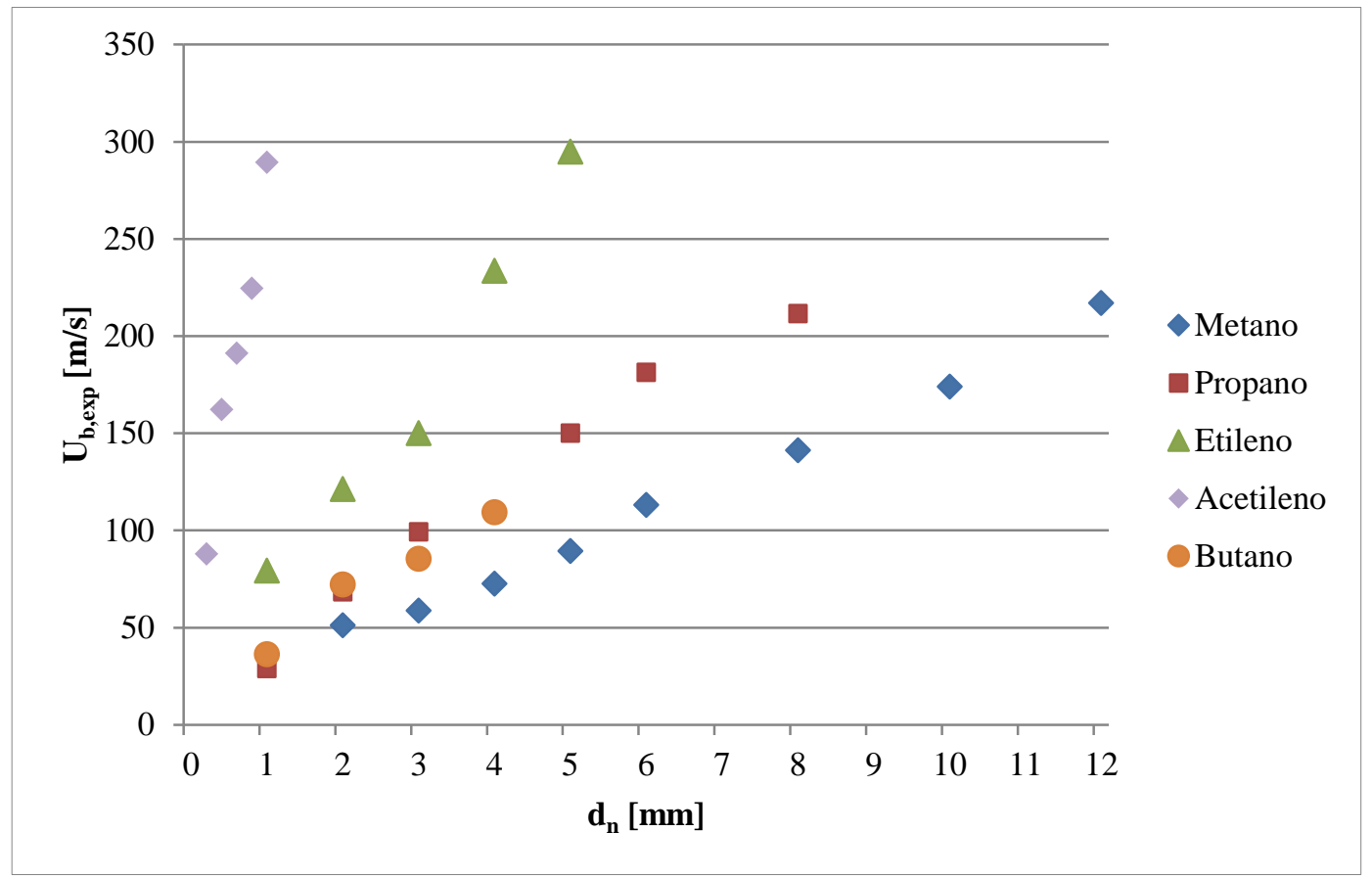

Figura 3.2. Velocidade de blowout $U_{b, \text { exp }}$ obtida a partir de $M a_{b}$ digitalizado do trabalho de Kalghatgi (1981) em função do diâmetro do bocal de gás, para diferentes gases combustíveis.

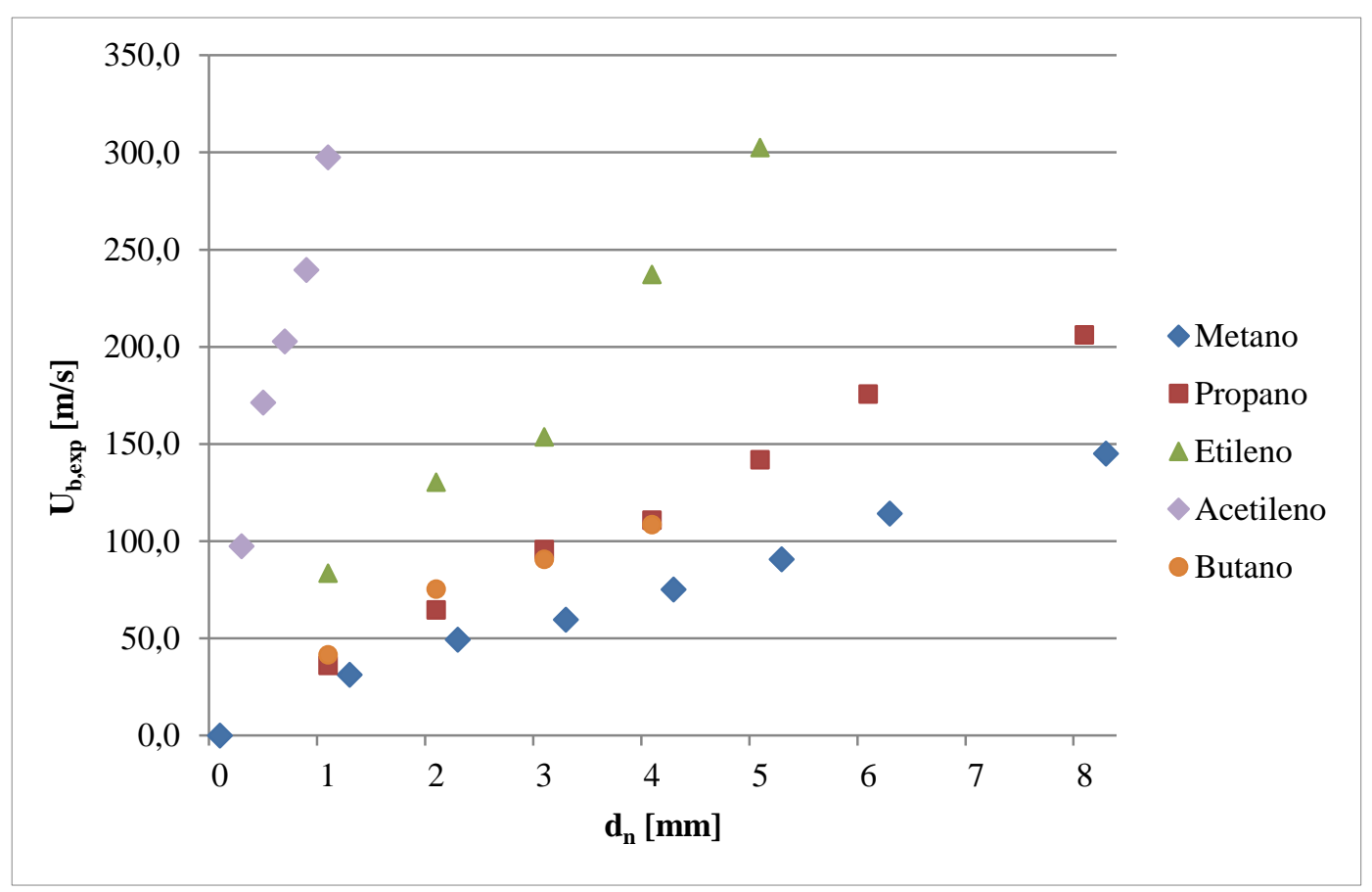

Figura 3.3. Velocidades de blowout em função do diâmetro de saída do bocal de gás para diferentes combustíveis (BROADWELL; DAM; MUNGAL, 1984). 


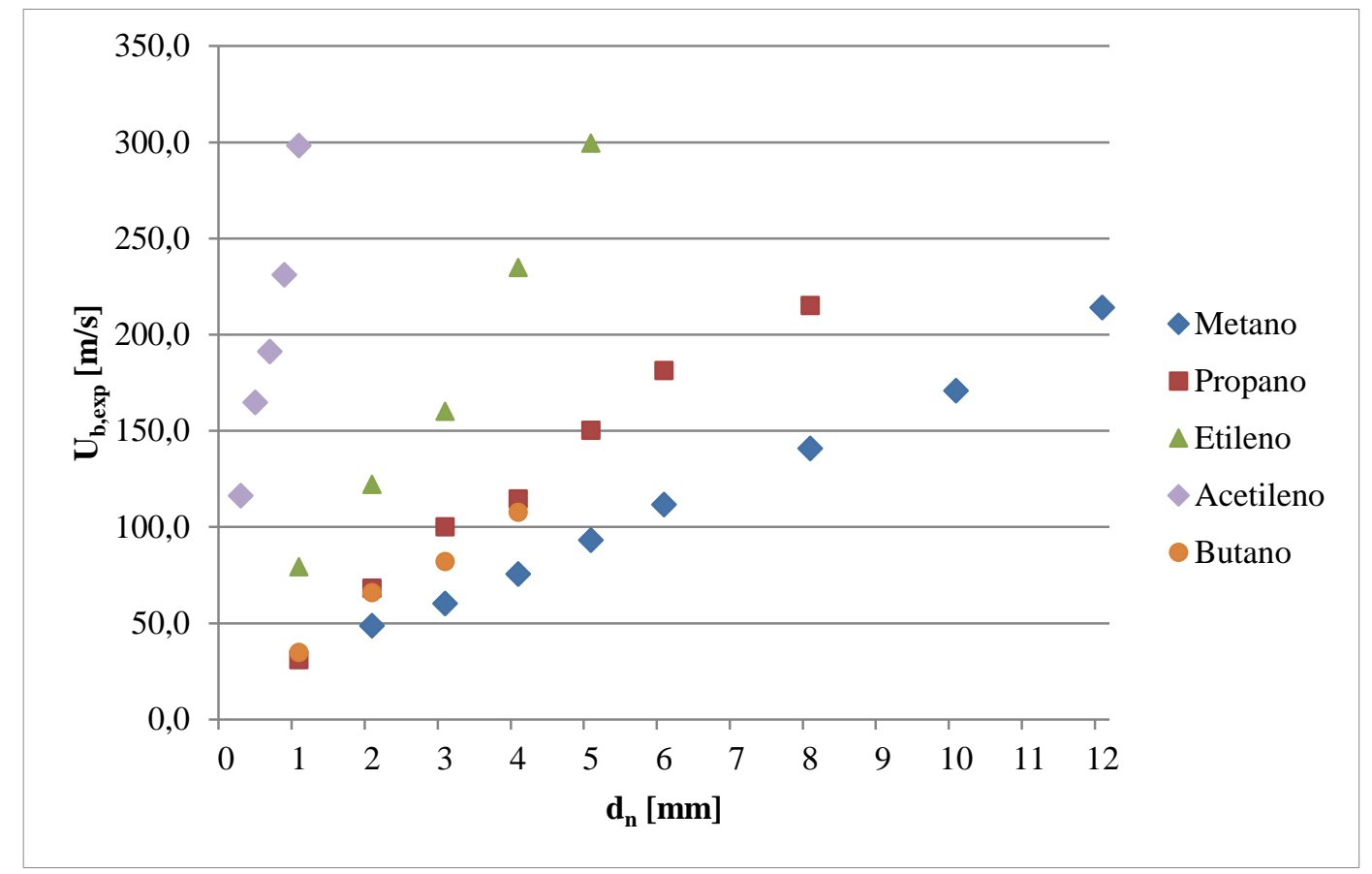

Figura 3.4. Velocidades de blowout em função do diâmetro de saída do bocal de gás para diferentes combustíveis (PITTS, 1989).

\subsubsection{Critério para análise dos dados experimentais}

Uma vez que Kalghatgi (1981) não menciona nem quantifica os possíveis erros associados a seus experimentos e coleta de dados, a incerteza nos valores de $M a_{b}$ foi estimada em $\pm 0,015$ em $M a_{b}$ (em "unidades" de $M a$ ), considerando-se apenas o processo de digitalização realizado pela presente autora.

Para avaliar a influência da incerteza de \pm 0,015 em $M a_{b}$ (devido ao processo de digitalização dos dados experimentais utilizados como referência) nos valores de $U_{b, \text { exp }}$, utilizou-se os seguintes parâmetros:

1. $\left|\xi_{\text {exp }}\right|$, que representa o módulo da diferença entre o valor de $U_{b, \text { exp }}$ obtido a partir de $M a_{b}$ digitalizado e $U_{b, \exp }$ obtido a partir de $M a_{b} \pm 0,015$, ambos calculados por meio da Eq. (3.4);

$$
\left|\xi_{\text {exp }}\right|=\left|U_{b, \exp }-U_{b, \exp }^{*}\right|
$$


2. $\Delta_{\text {exp }}$, que representa a variação entre o valor de $U_{b, \exp }$ obtido a partir de $M a_{b}$ digitalizado e $U_{b, \exp }^{*}$ obtido a partir de $M a_{b} \pm 0,015$, com relação ao primeiro, ambos calculados por meio da Eq. (3.4);

$$
\Delta_{\exp }(\%)=\frac{U_{b, \exp }-U_{b, \exp }^{*}}{U_{b, \exp }} \cdot 100=\frac{\xi_{\text {exp }}}{U_{b, \exp }} \cdot 100
$$

Devido a ausência de informações com relação às incertezas associadas aos dados de $U_{b, \exp }$ apresentados por Broadwell; Dam e Mungal (1984) e Pitts (1989), adotou-se um erro de \pm 5,00 $\mathrm{m} / \mathrm{s}$ no valor de $U_{b, \text { exp }}$ digitalizado (isto é, $\xi_{\text {exp }}= \pm 5,00 \mathrm{~m} / \mathrm{s}$ ). Este valor foi estimado com base na incerteza da leitura dos valores lançados em gráfico por estes autores (ou seja, no tamanho do ponto utilizado para indicar os resultados experimentais no gráfico).

Os dados de $U_{b, \exp }$ (digitalizados e calculados) estão disponíveis em tabelas no Apêndice (B) do presente trabalho. Verificou-se que os valores de $U_{b, \exp }$ (considerando a incerteza de \pm 5,00 $\mathrm{m} / \mathrm{s}$ em $U_{b, \text { exp }}$ ) digitalizados do trabalho de por Broadwell; Dam e Mungal (1984) e de Pitts (1989) encontram-se dentro da faixa delimitada pelos valores calculados de $U_{b, \exp } \pm \xi_{\text {exp }}$ do trabalho de Kalghatgi (1981), para todos os gases combustíveis e diâmetros de bocais. Logo, conclui-se que a metodologia utilizada para obter $U_{b, \exp }$ a partir de $M a_{b}$ é válida; e, portanto, os valores de $U_{b, \exp }$ adotados como referência são os obtidos a partir dos experimentos realizados por Kalghatgi (1981) e das Eqs. (3.1) a (3.4).

\subsection{Análise das correlações disponíveis na Literatura para previsão da velocidade de blowout de jatos simples}

Esta Subseção apresenta uma análise das correlações para a velocidade de blowout, $U_{b}$, propostas por Kalghatgi (1981), Broadwell; Dam e Mungal (1984), Dahm e Mayman (1990) e Sousa (2010) - apresentadas na Seção (2) "Revisão bibliográfica" - e a metodologia utilizada (incluindo hipóteses simplificadoras e condições de operação) para obter a previsão de $U_{b}$ por meio das correlações apresentadas. Também é sugerida, pela presente autora, uma correlação para o cálculo de $U_{b}$, a qual é denominada como Branco (2013). Os resultados previstos de $U_{b}$ 
são comparados com dados experimentais $U_{b, \exp }$ adotados como referência no presente trabalho; e estão disponíveis na Subseção (4.1).

\subsubsection{Análise da correlação proposta por Kalghatgi (1981)}

Kalghatgi (1981) propôs a Eq. (3.7) para prever a velocidade de blowout, $U_{b}$, de um jato de gás combustível emergindo de um bocal simples:

$$
U_{b}=\left[0,017 \cdot R e_{H_{S}} \cdot\left(1-3,5 \cdot 10^{-6} \cdot R e_{H_{S}}\right)\right] \cdot S_{L} \cdot\left(\frac{\rho_{f, n}}{\rho_{\infty}}\right)^{-3 / 2}
$$

onde $R e_{H_{S}}$ é o número de Reynolds baseado na posição $H_{S}$, ou seja, distância ao longo do eixo do jato onde a concentração de combustível cai para a estequiométrica (vide Fig. 1.2);

$$
\begin{gathered}
R e_{H_{S}}=\frac{H_{S} S_{L}}{v_{f, n}} \\
H_{S}=\left[4 \cdot \frac{Y_{f, n}}{Y_{f, s}}\left(\frac{\rho_{f, n}}{\rho_{\infty}}\right)^{1 / 2}+5,8\right] \cdot d_{n}
\end{gathered}
$$

têm-se como incógnitas (parâmetros não apresentados na Tabela de propriedades do autor, Tab. 3.1): as densidades do gás na saída do bocal e do ar no entorno do jato $\left(\rho_{f, n}\right.$ e $\left.\rho_{\infty}\right)$. Considerando ambos os fluidos como gases perfeitos, suas densidades podem ser obtidas por meio da seguinte equação de estado:

$$
\rho=\frac{P}{R T}
$$

onde $\rho, P, R$ e $T$ são a densidade, a pressão, a constante do gás e a temperatura.

Para o ar no entorno do jato tem-se:

$$
\begin{gathered}
M M_{a r}=0,79 \cdot M M_{N_{2}}+0,21 \cdot M M_{O_{2}}=0,79 \cdot 28+0,21 \cdot 32=28,84 \mathrm{~kg} / \mathrm{kmol} \\
R_{a r}=\frac{\bar{R}}{M M_{a r}}=\frac{8315}{28,84}=288,31 \mathrm{~J} / \mathrm{kgK}
\end{gathered}
$$




$$
\rho_{\infty}=\frac{P_{\infty}}{R_{a r} T_{\infty}}=\frac{101325}{288,31 \cdot 298}=1,18 \mathrm{~kg} / \mathrm{m}^{3}
$$

Para o gás do jato há duas possibilidades:

1. Caso 1: o escoamento de gás combustível pelo bocal é compressível, ou seja, a densidade do gás varia com $M a_{b}$ (pois $T_{f, n}$ varia); logo a viscosidade cinemática $\left(v_{f, n}\right)$ também varia. Neste caso, $\rho_{f, n}$ é obtido a partir da Eq. (3.11), com $T_{f, n}$ calculado por meio da Eq. (3.1); e, conseqüentemente, tem-se $v_{f, n}$, obtida de sua definição (= $\mu_{f}\left(\rho_{f, n}\right)$; onde a viscosidade dinâmica $\mu_{f}$ é considerada constante e igual ao valor apresentado na Tabela (3. 1);

$$
\rho_{f, n}=\frac{P_{\infty}}{R_{f} T_{f, n}}=\frac{P_{\infty}}{R_{f} T_{0}} \cdot\left[1+\frac{\left(\gamma_{f}-1\right)}{2} M a_{b}^{2}\right]
$$

2. Caso 2: o escoamento de gás combustível pelo bocal é considerado incompressível, ou seja, a densidade deste é constante (não varia com $M a_{b}$ ) e é calculada nas condições ambientes. Assim, $\rho_{f, n}$ é obtido a partir da Eq. (3.12) com $T_{f, n}=T_{\infty}$. A Tabela (3.2) apresenta as propriedades calculadas no presente trabalho para os gases estudados por Kalghatgi (1981).

$$
\rho_{f, n}=\frac{P_{\infty}}{R_{f} T_{\infty}}
$$

Tabela 3.2. Propriedades calculadas para os gases estudados por Kalghatgi (1981) (Caso 2)

\begin{tabular}{lcc}
\hline \hline Gás & $\boldsymbol{\rho}_{\boldsymbol{f}, \boldsymbol{n}}\left[\mathrm{kg} / \mathrm{m}^{3}\right]$ & $\boldsymbol{v}_{\boldsymbol{f}, \boldsymbol{n}}\left[\mathrm{m}^{2} / \mathrm{s}\right]$ \\
\hline Metano & 0,654 & $1,57 \mathrm{E}-05$ \\
Propano & 1,799 & $4,11 \mathrm{E}-06$ \\
Etileno & 1,145 & $7,95 \mathrm{E}-06$ \\
Acetileno & 1,063 & $8,79 \mathrm{E}-06$ \\
Hidrogênio & 0,082 & $1,03 \mathrm{E}-04$ \\
Butano & 2,212 & $3,62 \mathrm{E}-06$ \\
\hline \hline
\end{tabular}

As previsões da correlação proposta por Kalghatgi (1981), Eq. (3.7), foram calculadas e analisadas pela presente autora para ambos os Casos (1 e 2), e todos os combustíveis e diâmetros de bocais estudados experimentalmente por Kalghatgi (1981). Em resumo, verificou-se que a 
hipótese de escoamento incompressível no bocal de gás combustível (Caso 2) fornece previsões da velocidade de blowout muito próximas das previsões obtidas sob a hipótese de escoamento compressível (Caso 1). Logo, os resultados apresentados na Subseção (4.1) são os obtidos segundo o Caso 2. Detalhes desta análise encontram-se no Apêndice (C) do presente trabalho.

\subsubsection{Análise do trabalho de Broadwell; Dam e Mungal (1984)}

Broadwell; Dam e Mungal (1984) propõem uma correlação (Eq. 3.13), conforme apresentado no Item (2.1.7), para determinação da velocidade de blowout, baseada no adimensional número de Damkhöler crítico, $D a_{c r i t}$, e utilizam os dados experimentais de Kalghatgi (1981) para validá-la.

$$
U_{b}=\frac{d_{n} S_{L}^{2}}{D a_{c r i t} \alpha}\left(\frac{\rho_{f, n}}{\rho_{\infty}}\right)^{1 / 2} \varphi_{s}^{2}
$$

onde $\varphi_{s}$ é a razão mássica estequiométrica ar/combustível $\left(\varphi_{s}=\frac{1}{Y_{f, s}}-1\right)$; e $\alpha$ é difusividade térmica, admitida como sendo a mesma para todos os gases e (arbitrariamente) igual à difusividade do ar a $2000 \mathrm{~K}$, ou seja, $\alpha=4,89 \cdot 10^{-4} \mathrm{~m}^{2} / \mathrm{s}$ (TURNS, 2000).

A Tabela (3.3) apresenta os valores do número de Damkhöler crítico, $D a_{c r i t}$, obtidos a partir da Eq. (3.13) e dos resultados experimentais de Kalghatgi (1981).

Tabela 3.3. Valores do número de Damkhöler crítico, $D a_{c r i t}$ (BROADWELL; DAM; MUNGAL, 1984).

\begin{tabular}{cc}
\hline \hline Gás combustível & $\boldsymbol{D a}_{\text {crit }}$ \\
\hline Metano & 4,6 \\
Propano & 5,6 \\
Etileno & 5,3 \\
Acetileno & 3,9 \\
Butano & 4,8 \\
Hidrogênio & 4,4 \\
Valor médio & $\mathbf{4 , 8}$ \\
\hline \hline
\end{tabular}


Os autores sugerem que se use o valor médio de $D a_{\text {crit }}$, ou seja, $D a_{c r i t}=4,8$, para prever $U_{b}$ a partir da Eq. (3.13), ou seja,

$$
U_{b}=\frac{d_{n} S_{L}^{2}}{4,8 \alpha}\left(\frac{\rho_{f, n}}{\rho_{\infty}}\right)^{1 / 2} \varphi_{s}^{2}
$$

Broadwell; Dam e Mungal (1984) também propõem a Eq. (3.15) obtida a partir de simplificações na correlação (Eq. 3.7) proposta por Kalghatgi (1981).

$$
U_{b}=0,068 \frac{d_{n} S_{L}^{2}}{v_{f, n}}\left(\frac{\rho_{f, n}}{\rho_{\infty}}\right)^{-1} \varphi_{s}
$$

As previsões das correlações propostas por estes autores (Eq. 3.13, Eq. 3.14 e Eq. 3.15) foram comparadas com os valores de $U_{b, \exp }$ digitalizados do trabalho de Kalghatgi (1981) para os gases metano, propano, etileno, acetileno, hidrogênio e butano comercial; e estão apresentadas na Subseção (4.1).

\subsubsection{Análise do trabalho de Sousa (2010)}

Sousa (2010) propõe a seguinte equação para prever $U_{b}$, obtida por meio de correções do trabalho Broadwell; Dam e Mungal (1984):

$$
U_{b}=\frac{d_{n} S_{L}^{2}}{D a_{c r i t} \alpha}\left(\frac{\rho_{f, n}}{\rho_{\infty}}\right)^{1 / 2}\left(1+\varphi_{s}\right)
$$

onde $\alpha$ é a difusividade térmica $\left(\mathrm{m}^{2} / \mathrm{s}\right)$ assumida como igual a do ar nas condições ambientes $\left(\alpha=2,22 \cdot 10^{-5} \mathrm{~m}^{2} / \mathrm{s}\right)$; e $D a_{c r i t}$ é o número de Damkhöler crítico do gás em estudo (Tabela 3.4).

Tabela 3.4. Valores do número de Damkhöler crítico, $D a_{c r i t}$ (SOUSA, 2010).

\begin{tabular}{cc}
\hline \hline Gás & $\boldsymbol{D a}_{\text {crit }}$ \\
\hline Metano & 5,75 \\
Propano & 7,74 \\
Etileno & 7,8 \\
Acetileno & 6,44 \\
Butano & 6,59 \\
Hidrogênio & 2,67 \\
\hline \hline
\end{tabular}




\subsubsection{Análise do trabalho de Dahm e Mayman (1990)}

Dahm e Mayman (1990) seguem o raciocínio de Broadwell; Dam e Mungal (1984), em que o blowout ocorre quando o número de Damkhöler atinge um valor crítico, e propõem a Eq. (3.17) para obter o limite de blowout de chamas de difusão de jatos turbulentos emitidas de bocais coaxiais.

$$
D a_{c r i t}=\frac{\sqrt{\pi}}{2} \cdot \frac{\left(d^{*}\right)^{2} S_{L}^{2}\left(1+\varphi_{s}^{\prime}\right)^{2}\left(\rho_{\infty}\right)^{1 / 2}}{\alpha\left(J_{n, x}\right)^{1 / 2}}
$$

onde $\varphi_{s}^{\prime}$ é a razão entre a massa de ar ambiente e a massa de fluido que emerge da fonte (bocal coaxial), na condição estequiométrica; e $d^{*}$ é o diâmetro de uma fonte conceitual dada por:

$$
d^{*} \equiv \frac{2 \dot{m}_{n, x}}{\left(\pi \rho_{\infty} J_{n, x}\right)^{1 / 2}}
$$

em que $\dot{m}_{n, x}$ é a vazão mássica e $J_{n, x}$ é o fluxo de quantidade de movimento axial da fonte.

Para validar a Eq. (3.17), Dahm e Mayman (1990) realizaram experimentos utilizando metano e etileno como combustíveis; e bocais de diâmetro interno de $3 \mathrm{~mm}$ e $5 \mathrm{~mm}$, e diâmetro externo de $7 \mathrm{~mm}$ e $10 \mathrm{~mm}$. Segundo estes autores, as previsões da Eq. (2.17) apresentam boa concordância com os resultados obtidos experimentalmente.

O objetivo de Dahm e Mayman (1990) é estudar a estabilidade de jatos coaxiais. Neste caso, considerando um jato de gás combustível com um fluxo de ar coaxial (ambos com perfis de densidade e de velocidade uniformes na saída do bocal), tem-se que a vazão mássica da fonte, $\dot{m}_{n}$, e o fluxo total de quantidade de movimento, $J_{n, x}$, são:

$$
\dot{m}_{n, x}=\dot{m}_{f, n}+\dot{m}_{a, n}=\frac{\pi}{4}\left[\rho_{f, n} d_{n, f}^{2} U_{f, n}+\rho_{a, n}\left(d_{n, a}^{2}-d_{n, f}^{\prime 2}\right) U_{a, n}\right]
$$

$\mathrm{e}$

$$
J_{n, x}=\dot{m}_{f, n} U_{f, n}+\dot{m}_{a, n} U_{a, n}=\frac{\pi}{4}\left[\rho_{f, n} d_{n, f}^{2} U_{f, n}^{2}+\rho_{a, n}\left(d_{n, a}^{2}-d_{n, f}^{\prime 2}\right) U_{a, n}^{2}\right]
$$

O presente trabalho tem como foco a análise de jatos simples, ou seja, sem fluxo de ar coaxial $\left(U_{a, n}=0\right)$. Neste caso: 


$$
\dot{m}_{n, x}=\dot{m}_{f, n}=\frac{\pi}{4} d_{n, f}^{2} \rho_{f, n} U_{f, n}
$$

$\mathrm{e}$

$$
J_{n, x}=\dot{m}_{f, n} U_{f, n}=\frac{\pi}{4} d_{n, f}^{2} \rho_{f, n} U_{f, n}^{2}
$$

Substituindo as Eqs. (3.18), (3.21) e (3.22) na Eq. (3.17); assumindo $D a_{\text {crit }}=4,8$ conforme sugerido por Dahm e Mayman (1990); e considerando combustível puro saindo do bocal ( $\varphi_{s}^{\prime}=$ $\left.\varphi_{\mathrm{s}}\right)$, tem-se:

$$
U_{b}=\frac{d_{n}}{4,8} \frac{S_{L}^{2}}{\alpha}\left(\frac{\rho_{f, n}}{\rho_{\infty}}\right)^{1 / 2}\left(1+\varphi_{s}\right)^{2}
$$

A Eq. (3.23) é semelhante à Eq. (3.14) de Broadwell; Dam e Mungal (1984), com exceção do fator $\left(1+\varphi_{s}\right)^{2}$, presente na Eq. (3.23). Na correspondente expressão de Broadwell; Dam e Mungal (1984), Eq. (3.14), tem-se $\varphi_{s}^{2}$ ao invés de $\left(1+\varphi_{s}\right)^{2}$. Para calcular $U_{b}$ adotou-se $\alpha$ como sendo a mesma para todos os gases e (arbitrariamente) igual à difusividade térmica do ar a 2000K, ou seja, $\alpha=4,89 \cdot 10^{-4} \mathrm{~m}^{2} / \mathrm{s}$ (TURNS, 2000), como feito por Broadwell; Dam e Mungal (1984).

\subsection{Proposição de uma nova correlação para previsão da velocidade de blowout de jatos simples}

Após extensa análise do fenômeno de blowout, dos parâmetros que o influenciam e das correlações para previsão de $U_{b}$ disponíveis na Literatura, a presente autora propõe a Eq. (3.24) para previsão da velocidade de blowout de chamas turbulentas provenientes de jatos simples (emergindo em ambiente quiescente e de bocais cuja seção transversal é circular):

$$
U_{b}=\frac{d_{n}}{D a_{\text {crit }}} \frac{S_{L}^{2}}{\alpha}\left(\frac{\rho_{f, n}}{\rho_{\infty}}\right)^{1 / 2}\left(1+\varphi_{s}\right)^{2}
$$

Nesta equação os valores de $D a_{\text {crit }}$ estão especificados na Tabela (3.3). A difusividade térmica, $\alpha$, foi admitida como sendo a mesma para todos os gases e (arbitrariamente) igual à difusividade térmica do ar a 2000K (isto é, $\alpha=4,89 \cdot 10^{-4} \mathrm{~m}^{2} / \mathrm{s}$ ) como feito por Broadwell; Dam e Mungal (1984). 
A Eq. (3.24) é resultante da simplificação da Eq. (3.17) proposta por Dahm e Mayman (1990) para análise de jatos coaxiais, e será referenciada como correlação proposta por Branco (2013), ou seja, a presente autora.

A fim de validar a Eq. (3.24), as previsões de $U_{b}$ foram calculadas sob as hipóteses apresentadas na Subseção (3.4) e comparadas com os dados experimentais adotados como referência. Os resultados encontram-se na Subseção (4.1).

\subsection{Hipóteses adotadas}

A fim de comparar as previsões de $U_{b}$ por meio das correlações propostas por Kalghatgi (1981), Broadwell; Dam e Mungal (1984), Dahm e Mayman (1990), Sousa (2010) e Branco (2013), com os dados experimentais de Kalghatgi (1981), adotaram-se as seguintes hipóteses:

1. Os fluidos (gás combustível e ar) comportam-se como gases perfeitos;

2. Escoamento do gás através do bocal é isoentrópico;

3. A razão $\gamma_{f}$ entre os calores específicos, $c_{p}$ e $c_{v}$, de cada gás é constante;

4. A temperatura e pressão ambientes são iguais a $T_{\infty}=298 \mathrm{~K}$ e $P_{\infty}=101325 \mathrm{~Pa}(1 \mathrm{~atm})$, respectivamente;

5. O ar no entorno do jato é uma mistura composta por $79 \%$ de nitrogênio e $21 \%$ de oxigênio (em volume);

6. As propriedades dos gases são iguais às apresentadas nas Tabelas (3.1) e (3.2);

7. Os perfis de velocidade e densidade são uniformes na saída do bocal. 


\subsection{Critério para análise das previsões das correlações para a velocidade de blowout de jatos simples}

Esta Subseção apresenta o critério adotado para avaliar os valores da velocidade de blowout, $U_{b}$, previstos pelas correlações propostas por Kalghatgi (1981), Broadwell; Dam e Mungal (1984), Dahm e Mayman (1990), Sousa (2010) e Branco (2013). ATabela (3.5) apresenta as correlações analisadas.

Tabela 3.5. Correlações analisadas pelo presente trabalho.

\begin{tabular}{|c|c|c|}
\hline Pesquisador & Correlação & Eq. \\
\hline Kalghatgi (1981) & $\begin{array}{c}U_{b}=\left[0,017 \cdot R e_{H_{s}} \cdot\left(1-3,5 \cdot 10^{-6} \cdot R e_{H_{S}}\right)\right] \cdot S_{L} \\
\cdot\left(\frac{\rho_{f, n}}{\rho_{\infty}}\right)^{-3 / 2}\end{array}$ & $(3.7)$ \\
\hline Broadwell et al (1984) & $U_{b}=0,068 \frac{d_{n} S_{L}^{2}}{v_{f, n}}\left(\frac{\rho_{f, n}}{\rho_{\infty}}\right)^{-1} \varphi_{s}$ & $(3.15)$ \\
\hline Broadwell et al (1984) & $U_{b}=\frac{d_{n} S_{L}^{2}}{D a_{c r i t} \alpha}\left(\frac{\rho_{f, n}}{\rho_{\infty}}\right)^{1 / 2} \varphi_{s}^{2}$ & $(3.13)$ \\
\hline Broadwell et al (1984) & $U_{b}=\frac{d_{n} S_{L}^{2}}{4,8 \alpha}\left(\frac{\rho_{f, n}}{\rho_{\infty}}\right)^{1 / 2} \varphi_{s}^{2}$ & $(3.14)$ \\
\hline Sousa (2010) & $U_{b}=\frac{d_{n} S_{L}^{2}}{4,8 \alpha}\left(\frac{\rho_{f, n}}{\rho_{\infty}}\right)^{1 / 2} \varphi_{s}^{2}$ & $(3.16)$ \\
\hline $\begin{array}{l}\text { Dahm e Mayman } \\
\text { (1990) }\end{array}$ & $U_{b}=\frac{d_{n}}{4,8} \frac{S_{L}^{2}}{\alpha}\left(\frac{\rho_{f, n}}{\rho_{\infty}}\right)^{1 / 2}\left(1+\varphi_{s}\right)^{2}$ & $(3.23)$ \\
\hline Branco (2013) & $U_{b}=\frac{d_{n}}{D a_{\text {crit }}} \frac{S_{L}^{2}}{\alpha}\left(\frac{\rho_{f, n}}{\rho_{\infty}}\right)^{1 / 2}\left(1+\varphi_{s}\right)^{2}$ & $(3.24)$ \\
\hline
\end{tabular}

Conforme apresentado na Subseção (3.1), decidiu-se por adotar como dados experimentais de referência os valores de $U_{b, \exp }$ calculados a partir de $M a_{b}$ digitalizados do trabalho de Kalghatgi (1981). Esta hipótese é coerente, uma vez que os valores de $U_{b, \exp }( \pm 5,00 \mathrm{~m} / \mathrm{s})$ apresentados por Broadwell; Dam e Mungal (1984) e Pitts (1989) encontram-se dentro da faixa delimitada por $U_{b, \exp } \pm \xi_{\text {exp }}$ do trabalho de Kalghatgi (1981), para todos os gases combustíveis e diâmetros de bocais.

Para facilitar a comparação entre o valor de $U_{b, \exp }$ de referência e $U_{b}$ previsto pelas correlações, foram utilizados os seguintes parâmetros: 
1. $\left|\xi_{i-\exp }\right|$, que representa o módulo da diferença entre o valor de $U_{b, \exp }$ (obtido a partir de $M a_{b}$ digitalizado) e o valor de $U_{b}$ previsto pela correlação $i$, ou seja, $\left|U_{b, \exp }-U_{b, i}\right|$;

$$
\left|\xi_{i-\exp }\right|=\left|U_{b, \exp }-U_{b, i}\right|
$$

2. $\Delta_{i-\exp }$, que representa a variação da previsão da correlação $i$ com relação ao dado experimental, $U_{b, \exp }$ (obtido a partir de $M a_{b}$ digitalizado), para determinado gás e diâmetro de bocal;

$$
\Delta_{i-\exp }(\%)=\frac{U_{b, \exp }-U_{b, i}}{U_{b, \exp }} \cdot 100=\frac{\xi_{i-\exp }}{U_{b, \exp }} \cdot 100
$$

As previsões de $U_{b}$ (obtidas a partir das correlações apresentadas nas Subseções 3.2 e 3.3) e os valores dos desvios $\Delta_{\exp }$ e $\Delta_{i-\exp }$ estão apresentados na Subseção (4.1), para os gases combustíveis metano, propano, etileno, acetileno, hidrogênio e butano comercial.

Para facilitar a visualização dos resultados decidiu-se por apresentá-los em gráficos de $U_{b, \exp } \mathrm{e}$ $U_{b}$ em função do diâmetro do bocal, $d_{n}$, os quais também estão disponíveis na Subseção (4.1), Figuras (4.1), (4.2), (4.3), (4.4), (4.5) e (4.6), nas quais os dados experimentais plotados referem-se aos valores de $U_{b, \exp }$ extraídos do trabalho de Kalghatgi (1981), segundo a metodologia apresentada na Subseção (3.1).

O critério para análise das previsões da velocidade de blowout, $U_{b}$, segundo as correlações apresentadas por Kalghatgi (1981), Broadwell; Dam e Mungal (1984), Dahm e Mayman (1990), Sousa (2010) e Branco (2013), será:

1. Se $\Delta_{i-\exp }<\Delta_{\text {exp }}$, a correlação $i$ (para determinado gás e diâmetro de bocal) fornece um valor de $U_{b}$ que se encontra entre $U_{b, \exp } \pm \xi_{\text {exp }}$; logo, a diferença entre a previsão de $U_{b}$ e o dado experimental, $U_{b, \text { exp }}$, pode ser associada à incerteza do processo de digitalização; e, portanto, esta correlação $i$ será considerada adequada.

2. Se $\Delta_{i-\exp }>\Delta_{\text {exp }}$, para determinado gás e diâmetro de bocal, a diferença entre a previsão de $U_{b}$ (por meio da correlação $i$ ) e o dado experimental, $U_{b, \text { exp }}$, não pode ser associada somente à incerteza do processo de digitalização; e, portanto, a correlação $i$ necessita ser verificada, assim como as hipóteses adotadas, disponíveis na Subseção (3.4). 
A definição da correlação que prevê $U_{b}$ com maior precisão (isto é, que fornece valores de $U_{b}$ mais próximos dos dados experimentais, $U_{b \text {,exp }}$ ) será feita com base na média dos $\Delta_{i-\exp }$ para cada gás combustível analizado (ou seja, metano, propano, etileno, acetileno, hidrogênio e butano). 


\section{RESULTADOS}

Nesta Seção são apresentados os dados experimentais da velocidade de blowout $U_{b, \exp }$ adotados como referência; as previsões da velocidade de blowout, $U_{b}$, obtidas por meio das correlações para jatos simples apresentadas na Subseção (3.2), incluindo a correlação proposta pela presente autora, Branco (2013); comparações entre $U_{b}$ e $U_{b, \text { exp }}$ de referência; e comentários destes resultados. Além destas informações, também são fornecidas respostas às questões propostas na Subseção (1.1) "Objetivos”, as quais estão disponíveis na Subseção (4.2).

\subsection{Análise das previsões das correlações para a velocidade de blowout}

Nesta Subseção são apresentados:

1. Os dados experimentais da velocidade de blowout, $U_{b, \text { exp }}$, adotados como referência, os quais foram calculados a partir de $M a_{b}$ digitalizado do trabalho de Kalghatgi (1981), segundo a metodologia apresentada na Subseção (3.1);

2. Os desvios $\Delta_{\text {exp }}$, definido pela Eq. (3.6), decorrentes da diferença entre $U_{b, \exp }$ obtido a partir de $M a_{b}$ digitalizado e $U_{b, \text { exp }}^{*}$ obtido a partir de $M a_{b} \pm 0,015$

3. As previsões das correlações para a velocidade de blowout, $U_{b}$, de jatos simples, propostas por Kalghatgi (1981), Broadwell; Dam e Mungal (1984), Dahm e Mayman (1990), Sousa (2010) e pela presente autora, Branco (2013), obtidas segundo a metodologia apresentada nas Subseções (3.2) e (3.3); e

4. Os desvios $\Delta_{i-\exp }$, definido pela Eq. (3.26), decorrentes da diferença entre os valores de $U_{b}$ previstos pelas correlações e os dados experimentais $U_{b, \text { exp }}$.

As previsões de $U_{b}$ foram comparadas com os dados experimentais $U_{b, \text { exp }}$ de Kalghatgi (1981), segundo a metodologia apresentada na Seção (3). Os resultados estão apresentados a seguir, 
para seis gases combustíveis (metano, propano, etileno, acetileno, hidrogênio e butano cormercial) e diferentes diâmetros de bocais.

\subsubsection{Resultados das previsões da velocidade de blowout para o gás metano}

A Tabela (4.1) apresenta as velocidades de blowout, $U_{b, \exp }$, calculadas a partir dos dados experimentais de Kalghatgi (1981); e as previsões das velocidades de blowout, $U_{b}$, para o gás metano, segundo as correlações propostas por Kalghatgi (1981), Broadwell; Dam e Mungal (1984), Dahm e Mayman (1990), Sousa (2010) e Branco (2013); e a Tabela (4.2) os respectivos desvios $\Delta_{i-\exp }$ entre $U_{b}$ e $U_{b, \exp }$. Estes resultados também podem ser visualizados na Figura (4.1), a qual ilustra os valores de $U_{b, \exp }$ e das previsões de $U_{b}$.

Tabela 4.1. Valores de $U_{b}$ previstos pelas correlações propostas por Kalghatgi (1981), Broadwell; Dam e Mungal (1984), Dahm e Mayman (1990), Sousa (2010) e Branco (2013) para o gás metano.

\begin{tabular}{|c|c|c|c|c|c|c|c|c|}
\hline \multirow[b]{3}{*}{$\begin{array}{c}\boldsymbol{d}_{\boldsymbol{n}} \\
{[\mathrm{mm}]}\end{array}$} & \multicolumn{2}{|c|}{$\begin{array}{c}\text { Kalghatgi } \\
\text { (1981) }\end{array}$} & \multicolumn{3}{|c|}{$\begin{array}{c}\text { Broadwell et al } \\
(\mathbf{1 9 8 4})\end{array}$} & \multirow{2}{*}{\begin{tabular}{c|}
$\begin{array}{c}\text { Sousa } \\
(\mathbf{2 0 1 0})\end{array}$ \\
Eq. \\
$(3.16)$ \\
\end{tabular}} & \multirow{2}{*}{$\begin{array}{c}\begin{array}{c}\text { Dahm } \\
(\mathbf{1 9 9 0})\end{array} \\
\text { Eq. } \\
(3.23) \\
\end{array}$} & \multirow{2}{*}{$\begin{array}{c}\begin{array}{c}\text { Branco } \\
(\mathbf{2 0 1 3})\end{array} \\
\text { Eq. } \\
(3.24) \\
\end{array}$} \\
\hline & $\begin{array}{l}\text { Experi- } \\
\text { mento }\end{array}$ & $\begin{array}{l}\text { Eq. } \\
(3.7)^{8}\end{array}$ & $\begin{array}{l}\text { Eq. } \\
(3.15)\end{array}$ & $\begin{array}{l}\text { Eq. } \\
(3.13)\end{array}$ & $\begin{array}{l}\text { Eq. } \\
(3.14)\end{array}$ & & & \\
\hline & $\begin{array}{l}\boldsymbol{U}_{b, \boldsymbol{e x p}} \\
{[\mathrm{m} / \mathrm{s}]}\end{array}$ & $\boldsymbol{U}_{\boldsymbol{b}}[\mathrm{m} / \mathrm{s}]$ & $\boldsymbol{U}_{b}[\mathrm{~m} / \mathrm{s}]$ & $\boldsymbol{U}_{\boldsymbol{b}}[\mathrm{m} / \mathrm{s}]$ & $\boldsymbol{U}_{b}[\mathrm{~m} / \mathrm{s}]$ & $\boldsymbol{U}_{\boldsymbol{b}}[\mathrm{m} / \mathrm{s}]$ & $\boldsymbol{U}_{\boldsymbol{b}}[\mathrm{m} / \mathrm{s}]$ & $\boldsymbol{U}_{\boldsymbol{b}}[\mathrm{m} / \mathrm{s}]$ \\
\hline 2,00 & 51,09 & 38,24 & 40,86 & 29,80 & 28,56 & 32,31 & 31,98 & 33,37 \\
\hline 3,00 & 58,79 & 57,12 & 61,28 & 44,70 & 42,84 & 48,46 & 47,96 & 50,05 \\
\hline 4,00 & 72,56 & 75,83 & 81,71 & 59,60 & 57,12 & 64,61 & 63,95 & 66,73 \\
\hline 5,00 & 89,33 & 94,38 & 102,14 & 74,50 & 71,40 & 80,76 & 79,94 & 83,41 \\
\hline 6,00 & 113,05 & 112,77 & 122,57 & 89,40 & 85,67 & 96,92 & 95,93 & 100,10 \\
\hline 8,00 & 141,21 & 149,07 & 163,43 & 119,20 & 114,23 & 129,22 & 127,90 & 133,46 \\
\hline 10,00 & 174,03 & 184,71 & 204,28 & 149,00 & 142,79 & 161,53 & 159,88 & 166,83 \\
\hline 12,00 & 217,01 & 219,71 & 245,14 & 178,80 & 171,35 & 193,83 & 191,85 & 200,19 \\
\hline
\end{tabular}

\footnotetext{
${ }^{8}$ Eq. (3.4) de Kalghatgi (1981), segundo o Caso (2), isto é, considerando escoamento incompressível no bocal (vide Subseção 3.2, Item 3.2.1).
} 


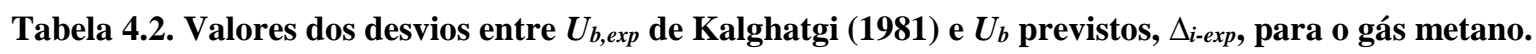

\begin{tabular}{c|cc|ccc|c|c|c}
\hline \hline & \multicolumn{2}{|c|}{$\begin{array}{c}\text { Kalghatgi } \\
(\mathbf{1 9 8 1})\end{array}$} & \multicolumn{3}{c|}{$\begin{array}{c}\text { Broadwell et al } \\
\mathbf{( 1 9 8 4 )}\end{array}$} & $\begin{array}{c}\text { Sousa } \\
(\mathbf{2 0 1 0})\end{array}$ & $\begin{array}{c}\text { Dahm } \\
(\mathbf{1 9 9 0})\end{array}$ & $\begin{array}{c}\text { Branco } \\
(\mathbf{2 0 1 3})\end{array}$ \\
\cline { 2 - 9 } & $\begin{array}{c}\text { Experi- } \\
\text { mento }\end{array}$ & Eq. & Eq. & Eq. & Eq. & Eq. & Eq. & Eq. \\
& $(3.15)$ & $(3.13)$ & $(3.14)$ & $(3.16)$ & $(3.23)$ & $(3.24)$ \\
\cline { 2 - 9 } & $\Delta_{\exp }[\%]$ & $\Delta_{i-\exp }[\%]$ & $\Delta_{i-\exp }[\%]$ & $\Delta_{i-\exp }[\%]$ & $\Delta_{i-\exp }[\%]$ & $\Delta_{i-\exp }[\%]$ & $\Delta_{i-\exp }[\%]$ & $\Delta_{i-\exp }$ \\
$\boldsymbol{d}_{\boldsymbol{n}}[\%]$ \\
\hline $\mathrm{mm}]$ & & & & & & & & \\
\hline 2,00 & 13,01 & 25,16 & 20,04 & 41,68 & 44,11 & 36,77 & 37,42 & 34,70 \\
3,00 & 11,3 & 2,85 & $-4,24$ & 23,97 & 27,14 & 17,58 & 18,42 & 14,87 \\
4,00 & 9,13 & $-4,51$ & $-12,61$ & 17,86 & 21,28 & 10,96 & 11,86 & 8,03 \\
5,00 & 7,4 & $-5,66$ & $-14,34$ & 16,60 & 20,08 & 9,59 & 10,51 & 6,62 \\
6,00 & 5,81 & 0,25 & $-8,42$ & 20,92 & 24,22 & 14,27 & 15,15 & 11,46 \\
8,00 & 4,61 & $-5,56$ & $-15,73$ & 15,59 & 19,10 & 8,49 & 9,42 & 5,49 \\
10,00 & 3,7 & $-6,14$ & $-17,39$ & 14,38 & 17,95 & 7,18 & 8,13 & 4,14 \\
12,00 & 2,91 & $-1,24$ & $-12,96$ & 17,61 & 21,04 & 10,68 & 11,59 & 7,75 \\
\hline \hline
\end{tabular}

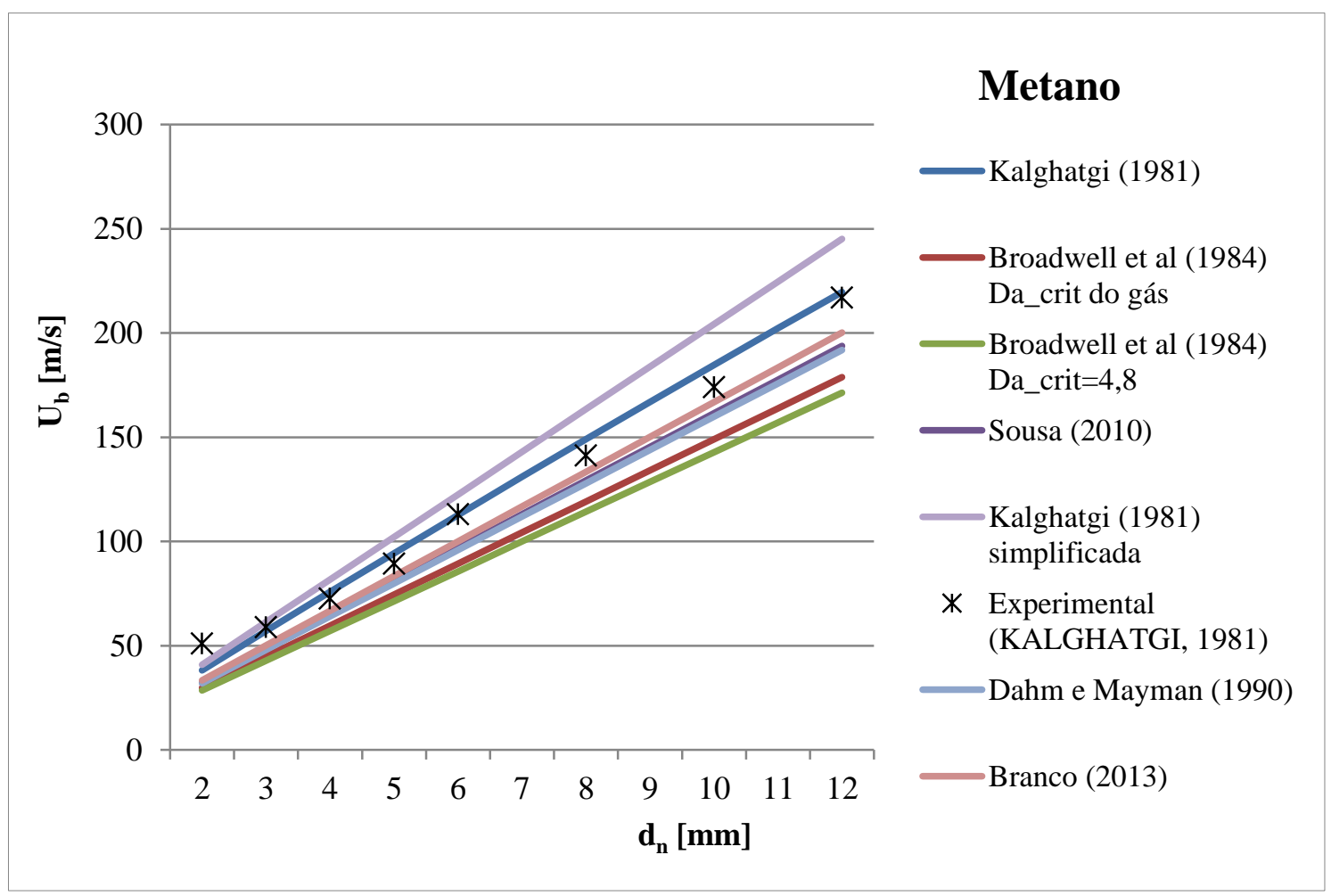

Figura 4.1. Valores de $U_{b}$ experimental (KALGHATGI, 1981) e previstos pelas correlações propostas por Kalghatgi (1981), Broadwell; Dam e Mungal (1984), Dahm e Mayman (1990), Sousa (2010) e Branco (2013) para o gás metano. 
A partir da Tabela (4.2) e Figura (4.1) verifica-se que a correlação proposta por Kalghatgi (1981) - seguida da correlação proposta pela presente autora, Branco (2013) - fornece valores de $U_{b}$ mais próximos dos dados experimentais do que as demais correlações, com exceção do caso em que $d_{n}=2,00 \mathrm{~mm}$ (em que a Eq. 3.15 é mais adequada).

Para $d_{n}=3,00 \mathrm{~mm}, d_{n}=4,00 \mathrm{~mm}, d_{n}=5,00 \mathrm{~mm}, d_{n}=6,00 \mathrm{~mm}$ e $d_{n}=12,00 \mathrm{~mm}$, a diferença entre $U_{b}$ previsto segundo Kalghatgi (1981) e $U_{b, \exp }$ pode ser associada ao processo de digitalização, pois $\Delta_{i-\exp }<\Delta_{\text {exp }}$, ou seja, $U_{b}$ encontra-se dentro da faixa delimitada por $U_{b, \exp } \pm \xi_{\text {exp }}$; Para $d_{n}=8,00 \mathrm{~mm}$ e $d_{n}=10,00 \mathrm{~mm}$, a diferença entre $U_{b}$ e $U_{b, \exp }$ não pode ser associada ao processo de digitalização $\left(\Delta_{i-\exp }>\Delta_{\text {exp }}\right)$.

\subsubsection{Resultados das previsões da velocidade de blowout para o gás propano}

A Tabela (4.3) apresenta as velocidades de blowout, $U_{b, \text { exp }}$, calculadas a partir dos dados experimentais de Kalghatgi (1981); e as previsões das velocidades de blowout, $U_{b}$, para o gás propano, segundo as correlações propostas por Kalghatgi (1981), Broadwell; Dam e Mungal (1984), Dahm e Mayman (1990), Sousa (2010) e Branco (2013); e a Tabela (4.4) os respectivos desvios $\Delta_{i-\exp }$ entre $U_{b}$ e $U_{b, \exp }$. A Figura (4.1) ilustra os valores de $U_{b, \exp }$ e das previsões de $U_{b}$.

Tabela 4.3. Valores de $U_{b}$ previstos pelas correlações propostas por Kalghatgi (1981), Broadwell; Dam e Mungal (1984), Dahm e Mayman (1990), Sousa (2010) e Branco (2013) para o gás propano.

\begin{tabular}{|c|c|c|c|c|c|c|c|c|}
\hline \multirow[b]{3}{*}{$\begin{array}{c}\boldsymbol{d}_{\boldsymbol{n}} \\
{[\mathrm{mm}]}\end{array}$} & \multicolumn{2}{|c|}{$\begin{array}{c}\text { Kalghatgi } \\
\text { (1981) }\end{array}$} & \multicolumn{3}{|c|}{$\begin{array}{c}\text { Broadwell et al } \\
(\mathbf{1 9 8 4})\end{array}$} & \multirow{2}{*}{$\begin{array}{c}\begin{array}{c}\text { Sousa } \\
(\mathbf{2 0 1 0})\end{array} \\
\text { Eq. } \\
(3.16)\end{array}$} & \multirow{2}{*}{$\begin{array}{c}\begin{array}{c}\text { Dahm } \\
(\mathbf{1 9 9 0})\end{array} \\
\text { Eq. } \\
(3.23)\end{array}$} & \multirow{2}{*}{$\begin{array}{c}\begin{array}{c}\text { Branco } \\
(\mathbf{2 0 1 3})\end{array} \\
\text { Eq. } \\
(3.24)\end{array}$} \\
\hline & $\begin{array}{l}\text { Experi- } \\
\text { mento }\end{array}$ & $\begin{array}{l}\text { Eq. } \\
(3.7)\end{array}$ & $\begin{array}{l}\text { Eq. } \\
(3.15)\end{array}$ & $\begin{array}{c}\text { Eq. } \\
(3.13)\end{array}$ & $\begin{array}{l}\text { Eq. } \\
(3.14)\end{array}$ & & & \\
\hline & $\begin{array}{l}U_{b, \exp } \\
{[\mathrm{m} / \mathrm{s}]}\end{array}$ & $\boldsymbol{U}_{\boldsymbol{b}}[\mathrm{m} / \mathrm{s}]$ & $\boldsymbol{U}_{\boldsymbol{b}}[\mathrm{m} / \mathrm{s}]$ & $\boldsymbol{U}_{\boldsymbol{b}}[\mathrm{m} / \mathrm{s}]$ & $\boldsymbol{U}_{\boldsymbol{b}}[\mathrm{m} / \mathrm{s}]$ & $\boldsymbol{U}_{\boldsymbol{b}}[\mathrm{m} / \mathrm{s}]$ & $\boldsymbol{U}_{\boldsymbol{b}}[\mathrm{m} / \mathrm{s}]$ & $\boldsymbol{U}_{\boldsymbol{b}}[\mathrm{m} / \mathrm{s}]$ \\
\hline 1,00 & 28,87 & 33,00 & 34,45 & 22,51 & 26,27 & 24,31 & 29,72 & 25,47 \\
\hline 2,00 & 68,43 & 64,01 & 68,91 & 45,03 & 52,53 & 48,62 & 59,44 & 50,95 \\
\hline 3,00 & 99,24 & 93,03 & 103,36 & 67,54 & 78,80 & 72,93 & 89,16 & 76,42 \\
\hline 5,00 & 149,97 & 145,08 & 172,27 & 112,57 & 131,33 & 121,55 & 148,60 & 127,37 \\
\hline 6,00 & 181,42 & 168,12 & 206,72 & 135,09 & 157,60 & 145,86 & 178,31 & 152,84 \\
\hline 8,00 & 211,55 & 208,21 & 275,63 & 180,11 & 210,13 & 194,48 & 237,75 & 203,79 \\
\hline
\end{tabular}


Tabela 4.4. Valores dos desvios entre $U_{b \text {,exp }}$ de Kalghatgi (1981) e $U_{b}$ previstos, $\Delta_{i-\exp }$, para o gás propano.

\begin{tabular}{|c|c|c|c|c|c|c|c|c|}
\hline \multirow[b]{3}{*}{$\begin{array}{c}\boldsymbol{d}_{\boldsymbol{n}} \\
{[\mathrm{mm}]}\end{array}$} & \multicolumn{2}{|c|}{$\begin{array}{c}\text { Kalghatgi } \\
\text { (1981) }\end{array}$} & \multicolumn{3}{|c|}{$\begin{array}{c}\text { Broadwell et al } \\
(\mathbf{1 9 8 4})\end{array}$} & \multirow{2}{*}{$\begin{array}{c}\begin{array}{c}\text { Sousa } \\
(\mathbf{2 0 1 0})\end{array} \\
\text { Eq. } \\
(3.16)\end{array}$} & \multirow{2}{*}{\begin{tabular}{|c|}
$\begin{array}{l}\text { Dahm } \\
(\mathbf{1 9 9 0 )}\end{array}$ \\
Eq. \\
$(3.23)$
\end{tabular}} & \multirow{2}{*}{$\begin{array}{c}\begin{array}{c}\text { Branco } \\
(\mathbf{2 0 1 3})\end{array} \\
\text { Eq. } \\
(3.24)\end{array}$} \\
\hline & $\begin{array}{l}\text { Experi- } \\
\text { mento }\end{array}$ & $\begin{array}{c}\text { Eq. } \\
(3.7)\end{array}$ & $\begin{array}{c}\text { Eq. } \\
(3.15)\end{array}$ & $\begin{array}{c}\text { Eq. } \\
(3.13)\end{array}$ & $\begin{array}{c}\text { Eq. } \\
(3.14)\end{array}$ & & & \\
\hline & $\Delta_{\exp }[\%]$ & $\Delta_{i-\exp }[\%]$ & $\Delta_{i-\exp }[\%]$ & $\Delta_{i-\exp }[\%]$ & $\Delta_{i-\exp }[\%]$ & $\Delta_{i-\exp }[\%]$ & $\Delta_{i-\exp }[\%]$ & $\begin{array}{c}\Delta_{\text {i-exp }} \\
{[\%]}\end{array}$ \\
\hline 1,00 & 12,92 & $-14,32$ & $-19,34$ & 22,01 & 9,02 & 15,79 & $-2,94$ & 11,76 \\
\hline 2,00 & 5,42 & 6,46 & $-0,70$ & 34,20 & 23,23 & 28,95 & 13,14 & 25,55 \\
\hline 3,00 & 3,71 & 6,26 & $-4,16$ & 31,94 & 20,59 & 26,51 & 10,16 & 22,99 \\
\hline 5,00 & 2,4 & 3,26 & $-14,87$ & 24,94 & 12,43 & 18,95 & 0,92 & 15,07 \\
\hline 6,00 & 1,95 & 7,33 & $-13,95$ & 25,54 & 13,13 & 19,60 & 1,71 & 15,75 \\
\hline 8,00 & 1,64 & 1,58 & $-30,29$ & 14,86 & 0,67 & 8,07 & $-12,39$ & 3,67 \\
\hline
\end{tabular}

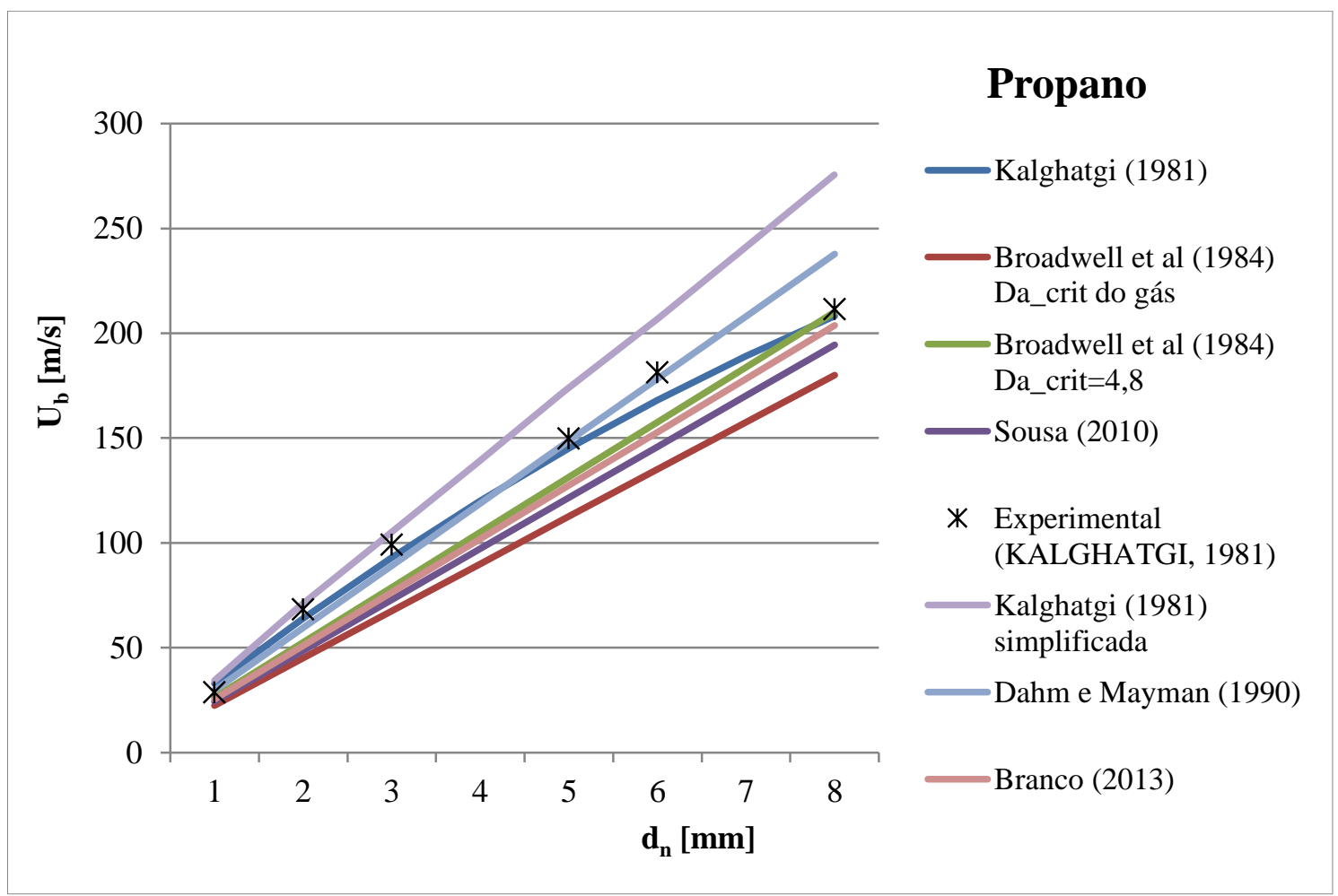

Figura 4.2. Valores de $U_{b}$ experimental (KALGHATGI, 1981) e previstos pelas correlações propostas por Kalghatgi (1981), Broadwell; Dam e Mungal (1984), Dahm e Mayman (1990), Sousa (2010) e Branco (2013) para o gás propano.

A partir da Tabela (4.4) e Figura (4.2) verifica-se que:

1. ao contrário do que foi observado para o gás metano, a correlação proposta por Dahm e Mayman (1990) fornece os menores $\Delta_{i-\exp }$ para a maioria $\operatorname{dos} d_{n}$; 
2. os maiores desvios entre as previsões e os dados experimentais, $\Delta_{i-\exp }$, ocorrem para correlação proposta por Broadwell; Dam e Mungal (1984) com $D a_{c r i t}$ do gás, seguida pela correlação proposta por Sousa (2010);

3. apesar da correlação apresentada por Kalghatgi (1981), Eq. (3.7), não ser a que fornece as melhores previsões de $U_{b}$ (menores $\Delta_{i-\exp }$ ), ela é a única que acompanha a tendência dos pontos experimentais, por não apresentar uma relação linear entre $U_{b}$ e $d_{n}$, como as demais correlações.

\subsubsection{Resultados das previsões da velocidade de blowout para o gás etileno}

A Tabela (4.5) apresenta as velocidades de blowout, $U_{b, e x p}$, calculadas a partir dos dados experimentais de Kalghatgi (1981); e as previsões das velocidades de blowout, $U_{b}$, para o gás etileno, segundo as correlações propostas por Kalghatgi (1981), Broadwell; Dam e Mungal (1984), Dahm e Mayman (1990), Sousa (2010) e Branco (2013); e a Tabela (4.6) os respectivos desvios $\Delta_{i-\exp }$ entre $U_{b}$ e $U_{b, \text { exp }}$. Estes resultados também podem ser visualizados na Figura (4.3), a qual ilustra os valores de $U_{b, \exp }$ e das previsões de $U_{b}$.

Tabela 4.5. Valores de $U_{b}$ previstos pelas correlações propostas por Kalghatgi (1981), Broadwell; Dam e Mungal (1984), Dahm e Mayman (1990), Sousa (2010) e Branco (2013) para o gás etileno.

\begin{tabular}{c|cc|ccc|c|c|c}
\hline \hline & \multicolumn{2}{|c|}{$\begin{array}{c}\text { Kalghatgi } \\
(\mathbf{1 9 8 1})\end{array}$} & \multicolumn{3}{c|}{$\begin{array}{c}\text { Broadwell et al } \\
(\mathbf{1 9 8 4})\end{array}$} & $\begin{array}{c}\text { Sousa } \\
(\mathbf{2 0 1 0})\end{array}$ & $\begin{array}{c}\text { Dahm } \\
(\mathbf{1 9 9 0})\end{array}$ & $\begin{array}{c}\text { Branco } \\
(\mathbf{2 0 1 3})\end{array}$ \\
\cline { 2 - 9 } & $\begin{array}{c}\text { Experi- } \\
\text { mento }\end{array}$ & $\begin{array}{c}\text { Eq. } \\
(3.7)\end{array}$ & $\begin{array}{c}\text { Eq. } \\
(3.15)\end{array}$ & $\begin{array}{c}\text { Eq. } \\
(3.13)\end{array}$ & $\begin{array}{c}\text { Eq. } \\
(3.14)\end{array}$ & $\begin{array}{c}\text { Eq. } \\
(3.16)\end{array}$ & $\begin{array}{c}\text { Eq. } \\
(3.23)\end{array}$ & $\begin{array}{c}\text { Eq. } \\
(3.24)\end{array}$ \\
\cline { 2 - 9 } $\boldsymbol{d}_{\boldsymbol{n}}$ & $\boldsymbol{U}_{\boldsymbol{b}, \text { exp }}$ & $\boldsymbol{U}_{\boldsymbol{b}}[\mathrm{m} / \mathrm{s}]$ & $\boldsymbol{U}_{\boldsymbol{b}}[\mathrm{m} / \mathrm{s}]$ & $\boldsymbol{U}_{\boldsymbol{b}}[\mathrm{m} / \mathrm{s}]$ & $\boldsymbol{U}_{\boldsymbol{b}}[\mathrm{m} / \mathrm{s}]$ & $\boldsymbol{U}_{\boldsymbol{b}}[\mathrm{m} / \mathrm{s}]$ & $\boldsymbol{U}_{\boldsymbol{b}}[\mathrm{m} / \mathrm{s}]$ & $\boldsymbol{U}_{\boldsymbol{b}}[\mathrm{m} / \mathrm{s}]$ \\
{$[\mathrm{mm}]$} & {$[\mathrm{m} / \mathrm{s}]$} & & & & & & & \\
\hline 1,00 & 79,32 & 70,05 & 73,86 & 47,48 & 52,42 & 50,89 & 59,70 & 54,06 \\
2,00 & 121,22 & 137,42 & 147,72 & 94,96 & 104,85 & 101,78 & 119,39 & 108,13 \\
3,00 & 150,11 & 202,12 & 221,58 & 142,43 & 157,27 & 152,68 & 179,09 & 162,19 \\
4,00 & 233,63 & 264,14 & 295,44 & 189,91 & 209,69 & 203,57 & 238,79 & 216,26 \\
5,00 & 294,92 & 323,49 & 369,30 & 237,39 & 262,12 & 254,46 & 298,48 & 270,32 \\
\hline \hline
\end{tabular}


Tabela 4.6. Valores dos desvios entre $U_{b, \exp }$ de Kalghatgi (1981) e $U_{b}$ previstos, $\Delta_{i-e x p}$, para o gás etileno.

\begin{tabular}{|c|c|c|c|c|c|c|c|c|}
\hline \multirow[b]{3}{*}{$\begin{array}{c}\boldsymbol{d}_{\boldsymbol{n}} \\
{[\mathrm{mm}]}\end{array}$} & \multicolumn{2}{|c|}{$\begin{array}{c}\text { Kalghatgi } \\
(1981)\end{array}$} & \multicolumn{3}{|c|}{$\begin{array}{c}\text { Broadwell et al } \\
(1984)\end{array}$} & \multirow{2}{*}{\begin{tabular}{|c|}
$\begin{array}{c}\text { Sousa } \\
(\mathbf{2 0 1 0})\end{array}$ \\
Eq. \\
$(3.16)$
\end{tabular}} & \multirow{2}{*}{\begin{tabular}{|c|}
$\begin{array}{l}\text { Dahm } \\
(\mathbf{1 9 9 0 )}\end{array}$ \\
Eq. \\
$(3.23)$
\end{tabular}} & \multirow{2}{*}{$\begin{array}{c}\begin{array}{c}\text { Branco } \\
(\mathbf{2 0 1 3})\end{array} \\
\text { Eq. } \\
(3.24)\end{array}$} \\
\hline & $\begin{array}{l}\text { Experi- } \\
\text { mento }\end{array}$ & $\begin{array}{l}\text { Eq. } \\
(3.7)\end{array}$ & $\begin{array}{l}\text { Eq. } \\
(3.15)\end{array}$ & $\begin{array}{l}\text { Eq. } \\
(3.13)\end{array}$ & $\begin{array}{l}\text { Eq. } \\
(3.14)\end{array}$ & & & \\
\hline & $\Delta_{\text {exp }}[\%]$ & $\Delta_{i-\exp }[\%]$ & $\Delta_{i-\exp }[\%]$ & $\Delta_{i-\exp }[\%]$ & $\Delta_{i-\exp }[\%]$ & $\Delta_{i-\exp }[\%]$ & $\Delta_{i-\exp }[\%]$ & $\begin{array}{l}\Delta_{i-e x p} \\
{[\%]}\end{array}$ \\
\hline 1,00 & 6,15 & 11,69 & 6,89 & 40,15 & 33,91 & 35,84 & 24,74 & 31,84 \\
\hline 2,00 & 3,97 & $-13,37$ & $-21,86$ & 21,67 & 13,51 & 16,03 & 1,51 & 10,80 \\
\hline 3,00 & 3,16 & $-34,65$ & $-47,61$ & 5,11 & $-4,77$ & $-1,71$ & $-19,31$ & $-8,05$ \\
\hline 4,00 & 1,91 & $-13,06$ & $-26,46$ & 18,71 & 10,25 & 12,87 & $-2,21$ & 7,44 \\
\hline 5,00 & 1,42 & $-9,68$ & $-25,22$ & 19,51 & 11,12 & 13,72 & $-1,21$ & 8,34 \\
\hline
\end{tabular}

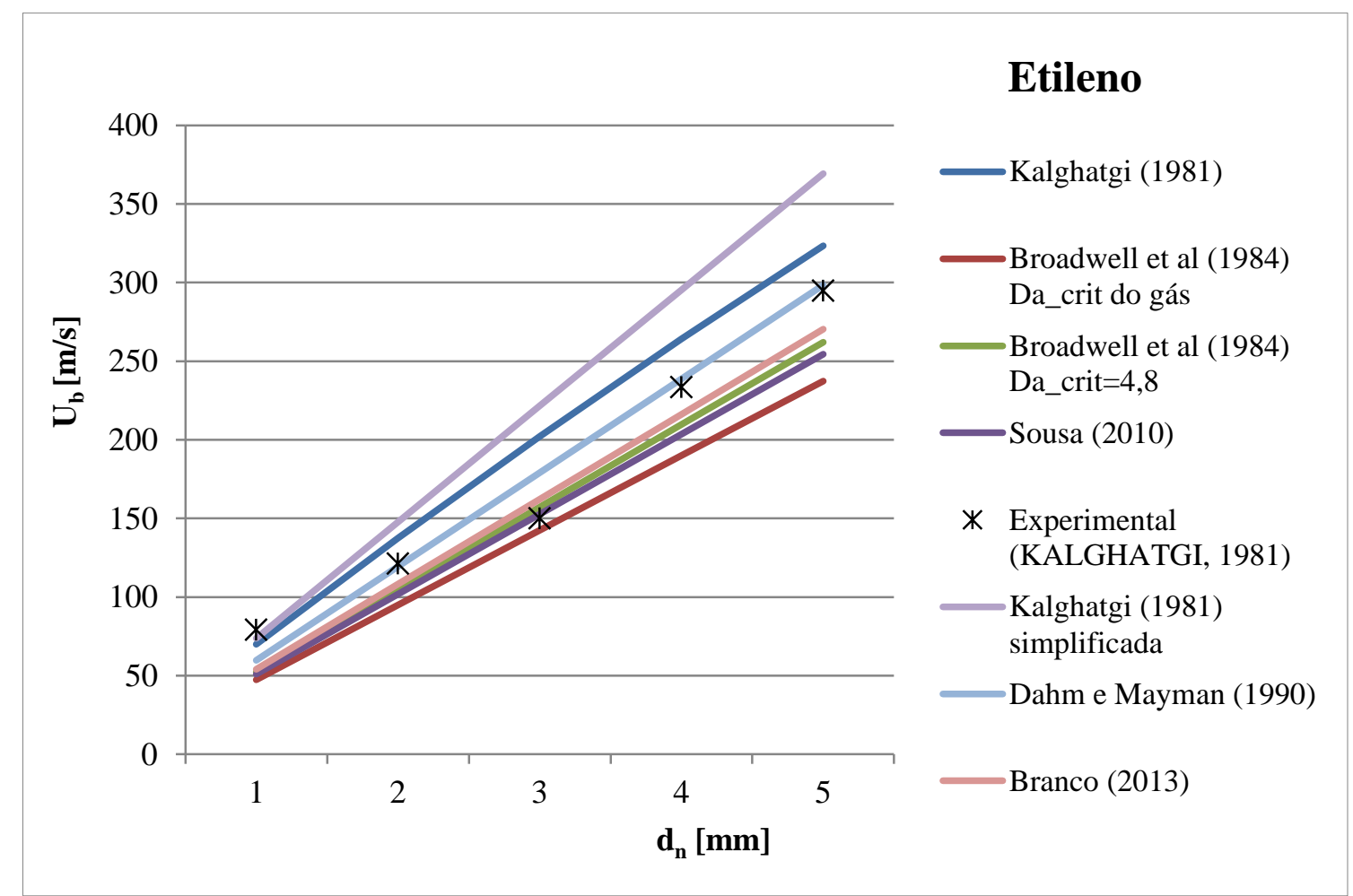

Figura 4.3. Valores de $U_{b}$ experimental (KALGHATGI, 1981) e previstos pelas correlações propostas por Kalghatgi (1981), Broadwell; Dam e Mungal (1984), Dahm e Mayman (1990), Sousa (2010) e Branco (2013) para o gás etileno.

A partir da Tabela (4.6) e Figura (4.3) verifica-se que: 
1. assim como foi observado para o gás propano, a correlação proposta por Dahm e Mayman (1990) fornece valores de $U_{b}$ próximos dos dados experimentais para a maioria dos diâmetros de bocais testados, ou seja, os menores $\Delta_{i-\exp }$ para a maioria $\operatorname{dos} d_{n}$;

2. os maiores desvios entre as previsões e os dados experimentais, $\Delta_{i-\text { exp }}$, ocorrem para correlação simplificada de Kalghatgi (1981), proposta por Broadwell; Dam e Mungal (1984);

\subsubsection{Resultados das previsões da velocidade de blowout para o gás acetileno}

A Tabela (4.7) apresenta as velocidades de blowout, $U_{b, \exp }$, calculadas a partir dos dados experimentais de Kalghatgi (1981); e as previsões das velocidades de blowout, $U_{b}$, para o gás acetileno, segundo as correlações propostas por Kalghatgi (1981), Broadwell; Dam e Mungal (1984), Dahm e Mayman (1990), Sousa (2010) e Branco (2013); e a Tabela (4.8) os respectivos desvios $\Delta_{i-\exp }$ entre $U_{b}$ e $U_{b, \exp }$. Estes resultados também podem ser visualizados na Figura (4.4), a qual ilustra os valores de $U_{b, \exp }$ e das previsões de $U_{b}$.

Tabela 4.7. Valores de $U_{b}$ previstos pelas correlações propostas por Kalghatgi (1981), Broadwell; Dam e Mungal (1984), Dahm e Mayman (1990), Sousa (2010) e Branco (2013) para o gás acetileno.

\begin{tabular}{c|cc|ccc|c|c|c}
\hline \hline & \multicolumn{2}{|c|}{$\begin{array}{c}\text { Kalghatgi } \\
(\mathbf{1 9 8 1})\end{array}$} & \multicolumn{3}{c|}{$\begin{array}{c}\text { Broadwell et al } \\
(\mathbf{1 9 8 4})\end{array}$} & $\begin{array}{c}\text { Sousa } \\
(\mathbf{2 0 1 0})\end{array}$ & $\begin{array}{c}\text { Dahm } \\
(\mathbf{1 9 9 0})\end{array}$ & $\begin{array}{c}\text { Branco } \\
(\mathbf{2 0 1 3})\end{array}$ \\
\cline { 2 - 9 } & $\begin{array}{c}\text { Experi- } \\
\text { mento }\end{array}$ & $\begin{array}{c}\text { Eq. } \\
(3.7)\end{array}$ & $\begin{array}{c}\text { Eq. } \\
(3.15)\end{array}$ & $\begin{array}{c}\text { Eq. } \\
(3.13)\end{array}$ & $\begin{array}{c}\text { Eq. } \\
(3.14)\end{array}$ & $\begin{array}{c}\text { Eq. } \\
(3.16)\end{array}$ & $\begin{array}{c}\text { Eq. } \\
(3.23)\end{array}$ & $\begin{array}{c}\text { Eq. } \\
(3.24)\end{array}$ \\
\cline { 2 - 9 } $\boldsymbol{d}_{\boldsymbol{n}}$ & $\begin{array}{c}\boldsymbol{U}_{\boldsymbol{b}, \boldsymbol{e x p}} \\
{\left[\boldsymbol{U}_{\boldsymbol{b}}[\mathrm{m} / \mathrm{s}]\right.}\end{array}$ & $\boldsymbol{U}_{\boldsymbol{b}}[\mathrm{m} / \mathrm{s}]$ & $\boldsymbol{U}_{\boldsymbol{b}}[\mathrm{m} / \mathrm{s}]$ & $\boldsymbol{U}_{\boldsymbol{b}}[\mathrm{m} / \mathrm{s}]$ & $\boldsymbol{U}_{\boldsymbol{b}}[\mathrm{m} / \mathrm{s}]$ & $\boldsymbol{U}_{\boldsymbol{b}}[\mathrm{m} / \mathrm{s}]$ & $\boldsymbol{U}_{\boldsymbol{b}}[\mathrm{m} / \mathrm{s}]$ \\
{$[\mathrm{mm}]$} & {$[\mathrm{m} / \mathrm{s}]$} & & & & & & & \\
\hline 0,20 & 87,81 & 57,78 & 60,62 & 46,80 & 38,02 & 50,47 & 43,96 & 54,10 \\
0,40 & 162,30 & 114,83 & 121,23 & 93,60 & 76,05 & 100,93 & 87,91 & 108,20 \\
0,60 & 191,15 & 171,16 & 181,85 & 140,39 & 114,07 & 151,40 & 131,87 & 162,30 \\
0,80 & 224,54 & 226,74 & 242,46 & 187,19 & 152,09 & 201,86 & 175,82 & 216,40 \\
1,00 & 289,43 & 281,60 & 303,08 & 233,99 & 190,12 & 252,33 & 219,78 & 270,50 \\
\hline \hline
\end{tabular}


Tabela 4.8. Valores dos desvios entre $U_{b, \exp }$ de Kalghatgi (1981) e $U_{b}$ previstos, $\Delta_{i-\exp }$, para o gás acetileno.

\begin{tabular}{|c|c|c|c|c|c|c|c|c|}
\hline \multirow[b]{3}{*}{$\begin{array}{c}\boldsymbol{d}_{\boldsymbol{n}} \\
{[\mathrm{mm}]}\end{array}$} & \multicolumn{2}{|c|}{$\begin{array}{c}\text { Kalghatgi } \\
(1981)\end{array}$} & \multicolumn{3}{|c|}{$\begin{array}{c}\text { Broadwell et al } \\
(1984)\end{array}$} & \multirow{2}{*}{$\begin{array}{c}\begin{array}{l}\text { Sousa } \\
(\mathbf{2 0 1 0})\end{array} \\
\text { Eq. } \\
(3.16) \\
\end{array}$} & \multirow{2}{*}{$\begin{array}{c}\begin{array}{l}\text { Dahm } \\
(\mathbf{1 9 9 0 )}\end{array} \\
\text { Eq. } \\
(3.23)\end{array}$} & \multirow{2}{*}{$\begin{array}{c}\begin{array}{c}\text { Branco } \\
(\mathbf{2 0 1 3})\end{array} \\
\text { Eq. } \\
(3.24)\end{array}$} \\
\hline & $\begin{array}{l}\text { Experi- } \\
\text { mento }\end{array}$ & Eq. (3.7) & $\begin{array}{l}\text { Eq. } \\
(3.15)\end{array}$ & $\begin{array}{c}\text { Eq. } \\
(3.13)\end{array}$ & $\begin{array}{c}\text { Eq. } \\
(3.14)\end{array}$ & & & \\
\hline & $\Delta_{\exp }[\%]$ & $\Delta_{i-\exp }[\%]$ & $\Delta_{i-\exp }[\%]$ & $\Delta_{i-\exp }[\%]$ & $\Delta_{i-\exp }[\%]$ & $\Delta_{i-\exp }[\%]$ & $\Delta_{i-\exp }[\%]$ & $\Delta_{i-\exp }[\%]$ \\
\hline 0,20 & 5,75 & 34,19 & 30,97 & 46,70 & 56,70 & 42,53 & 49,94 & 38,39 \\
\hline 0,40 & 3,02 & 29,24 & 25,30 & 42,33 & 53,14 & 37,81 & 45,83 & 33,33 \\
\hline 0,60 & 2,52 & 10,46 & 4,87 & 26,55 & 40,33 & 20,80 & 31,01 & 15,09 \\
\hline 0,80 & 2,1 & $-0,98$ & $-7,98$ & 16,63 & 32,26 & 10,10 & 21,70 & 3,62 \\
\hline 1,00 & 1,53 & 2,7 & $-4,72$ & 19,16 & 34,31 & 12,82 & 24,07 & 6,54 \\
\hline
\end{tabular}

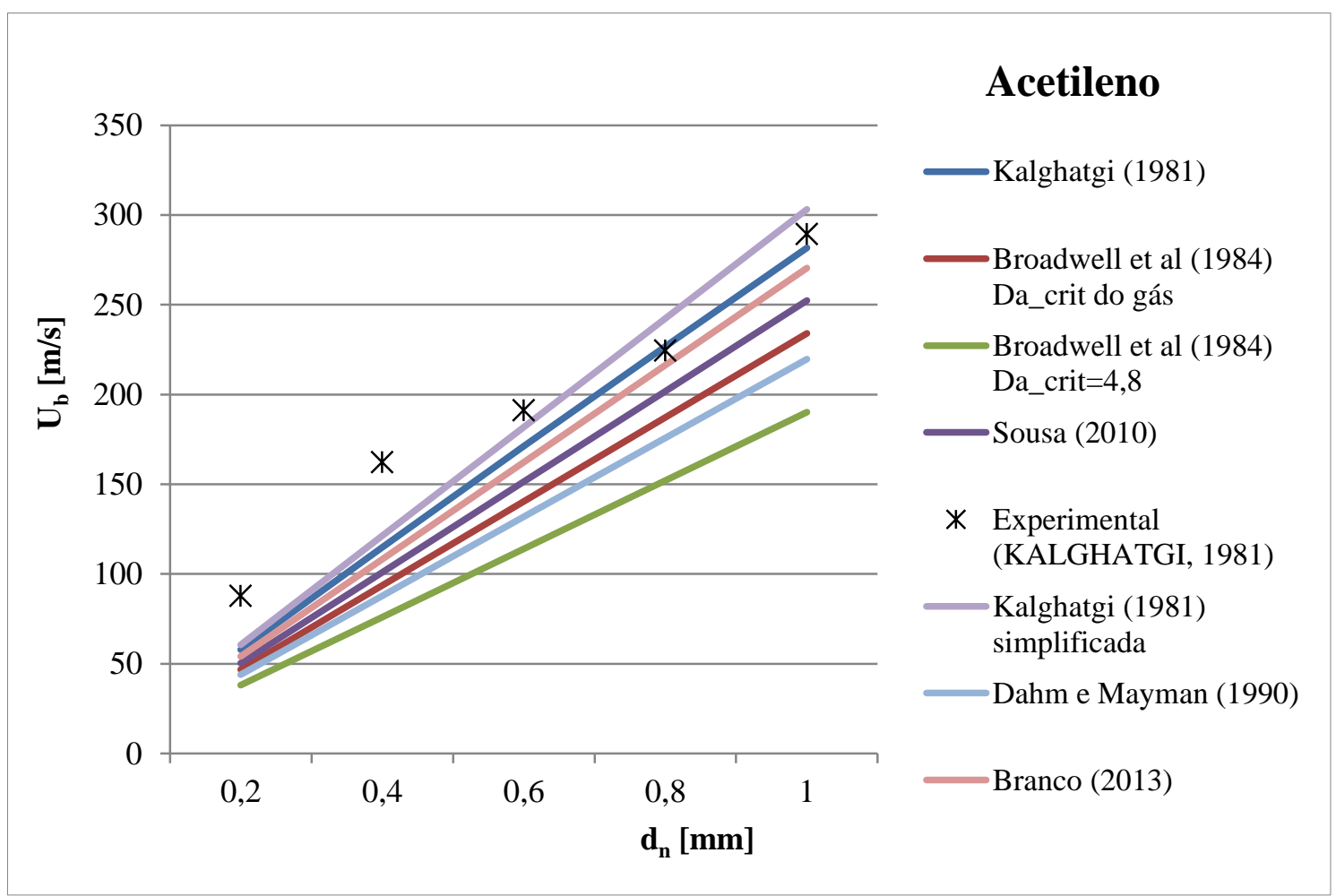

Figura 4.4. Valores de $U_{b}$ experimental (KALGHATGI, 1981) e previstos pelas correlações propostas por Kalghatgi (1981), Broadwell; Dam e Mungal (1984), Dahm e Mayman (1990), Sousa (2010) e Branco (2013) para o gás acetileno.

A partir da Tabela (4.8) e Figura (4.4) verifica-se que:

1. Para $d_{n}=0,20 \mathrm{~mm}, d_{n}=0,40 \mathrm{~mm}, d_{n}=0,60 \mathrm{~mm}$ e $d_{n}=1,00 \mathrm{~mm}$, a correlação simplificada de Kalghatgi (1981), proposta por Broadwell; Dam e Mungal (1984), 
fornece previsões de $U_{b}$ mais próximas dos dados experimentais, $U_{b, \exp }$, do que as demais correlações; apesar disso, a diferença entre $U_{b}$ previsto segundo esta correlação e $U_{b, \exp }$ não pode ser associada ao processo de digitalização, pois $\Delta_{i-\exp }>\Delta_{\text {exp }}$, ou seja, $U_{b}$ não encontra-se dentro da faixa delimitada por $U_{b, \exp } \pm \xi_{\text {exp }}$;

2. Para $d_{n}=0,80 \mathrm{~mm}$, a correlação proposta por Kalghatgi (1981) fornece previsões de $U_{b}$ mais próximas dos dados experimentais do que as demais correlações; sendo que para o primeiro diâmetro $\left(d_{n}=0,80 \mathrm{~mm}\right)$ a diferença entre $U_{b}$ previsto segundo Kalghatgi (1981) e $U_{b, \exp }$ pode ser associada ao processo de digitalização, pois $\Delta_{i-\exp }<$ $\Delta_{e x p}$, ou seja, $U_{b}$ encontra-se dentro da faixa delimitada por $U_{b, \exp } \pm \xi_{\text {exp }}$;

3. Os maiores desvios entre as previsões e os dados experimentais, $\Delta_{i-\text { exp }}$, ocorrem para a correlação proposta por Broadwell; Dam e Mungal (1984) com $D a_{\text {crit }}$ médio;

\subsubsection{Resultados das previsões da velocidade de blowout para o gás hidrogênio}

A Tabela (4.9) apresenta as velocidades de blowout, $U_{b, \exp }$, calculadas a partir dos dados experimentais de Kalghatgi (1981); e as previsões das velocidades de blowout, $U_{b}$, para o gás hidrogênio, segundo as correlações propostas por Kalghatgi (1981), Broadwell; Dam e Mungal (1984), Dahm e Mayman (1990), Sousa (2010) e Branco (2013); e a Tabela (4.10) os respectivos desvios $\Delta_{i-\exp }$ entre $U_{b}$ e $U_{b, \exp }$. A Figura (4.5) ilustra valores de $U_{b, \exp }$ e das previsões de $U_{b}$.

Tabela 4.9. Valores de $U_{b}$ previstos pelas correlações propostas por Kalghatgi (1981), Broadwell; Dam e Mungal (1984), Dahm e Mayman (1990), Sousa (2010) e Branco (2013) para o gás hidrogênio.

\begin{tabular}{c|cc|ccc|c|c|c}
\hline \hline & \multicolumn{2}{|c|}{$\begin{array}{c}\text { Kalghatgi } \\
\mathbf{( 1 9 8 1 )}\end{array}$} & \multicolumn{3}{c|}{$\begin{array}{c}\text { Broadwell et al } \\
(\mathbf{1 9 8 4})\end{array}$} & $\begin{array}{c}\text { Sousa } \\
(\mathbf{2 0 1 0})\end{array}$ & $\begin{array}{c}\text { Dahm } \\
(\mathbf{1 9 9 0})\end{array}$ & $\begin{array}{c}\text { Branco } \\
(\mathbf{2 0 1 3})\end{array}$ \\
\cline { 2 - 9 } & $\begin{array}{c}\text { Experi- } \\
\text { mento }\end{array}$ & Eq. & Eq. & Eq. & Eq. & Eq. & Eq. & Eq. \\
& $(3.15)$ & $(3.13)$ & $(3.14)$ & $(3.16)$ & $(3.23)$ & $(3.24)$ \\
\cline { 2 - 9 } & $\boldsymbol{U}_{\boldsymbol{b} \text {,exp }}$ & $\boldsymbol{U}_{\boldsymbol{b}}[\mathrm{m} / \mathrm{s}]$ & $\boldsymbol{U}_{\boldsymbol{b}}[\mathrm{m} / \mathrm{s}]$ & $\boldsymbol{U}_{\boldsymbol{b}}[\mathrm{m} / \mathrm{s}]$ & $\boldsymbol{U}_{\boldsymbol{b}}[\mathrm{m} / \mathrm{s}]$ & $\boldsymbol{U}_{\boldsymbol{b}}[\mathrm{m} / \mathrm{s}]$ & $\boldsymbol{U}_{\boldsymbol{b}}[\mathrm{m} / \mathrm{s}]$ & $\boldsymbol{U}_{\boldsymbol{b}}[\mathrm{m} / \mathrm{s}]$ \\
{$[\mathrm{mm}]$} & {$[\mathrm{m} / \mathrm{s}]$} & & & & & & & \\
\hline 0,60 & 993,37 & 1613,19 & 1856,75 & 827,96 & 758,96 & 891,08 & 803,34 & 876,37 \\
0,80 & 1221,19 & 2150,62 & 2475,67 & 1103,95 & 1011,95 & 1188,10 & 1071,12 & 1168,49 \\
\hline \hline
\end{tabular}


Tabela 4.10. Valores dos desvios entre $U_{b \text {,exp }}$ de Kalghatgi (1981) e $U_{b}$ previstos, $\Delta_{i-\exp }$, para o gás hidrogênio.

\begin{tabular}{|c|c|c|c|c|c|c|c|c|}
\hline \multirow[b]{3}{*}{$\begin{array}{c}\boldsymbol{d}_{\boldsymbol{n}} \\
{[\mathrm{mm}]}\end{array}$} & \multicolumn{2}{|c|}{$\begin{array}{c}\text { Kalghatgi } \\
\text { (1981) }\end{array}$} & \multicolumn{3}{|c|}{$\begin{array}{c}\text { Broadwell et al } \\
(\mathbf{1 9 8 4})\end{array}$} & \multirow{2}{*}{$\begin{array}{c}\begin{array}{c}\text { Sousa } \\
(\mathbf{2 0 1 0})\end{array} \\
\text { Eq. } \\
(3.16)\end{array}$} & \multirow{2}{*}{\begin{tabular}{|c|}
$\begin{array}{c}\text { Dahm } \\
(\mathbf{1 9 9 0 )}\end{array}$ \\
Eq. \\
$(3.23)$
\end{tabular}} & \multirow{2}{*}{$\begin{array}{c}\begin{array}{c}\text { Branco } \\
(\mathbf{2 0 1 3})\end{array} \\
\text { Eq. } \\
(3.24)\end{array}$} \\
\hline & $\begin{array}{l}\text { Experi- } \\
\text { mento }\end{array}$ & $\begin{array}{l}\text { Eq. } \\
(3.7)\end{array}$ & $\begin{array}{l}\text { Eq. } \\
(3.15)\end{array}$ & $\begin{array}{l}\text { Eq. } \\
(3.13)\end{array}$ & $\begin{array}{c}\text { Eq. } \\
(3.14)\end{array}$ & & & \\
\hline & $\Delta_{\exp }[\%]$ & $\Delta_{i-\exp }[\%]$ & $\Delta_{i-\exp }[\%]$ & $\Delta_{i-\exp }[\%]$ & $\Delta_{i-\exp }[\%]$ & $\Delta_{i-\exp }[\%]$ & $\Delta_{i-\exp }[\%]$ & $\begin{array}{l}\Delta_{i-\exp } \\
{[\%]}\end{array}$ \\
\hline 0,60 & 1,63 & $-62,4$ & $-86,91$ & 16,65 & 23,60 & 10,30 & 19,13 & 11,78 \\
\hline 0,80 & 1,20 & $-76,11$ & $-102,73$ & 9,60 & 17,13 & 2,71 & 12,29 & 4,32 \\
\hline
\end{tabular}

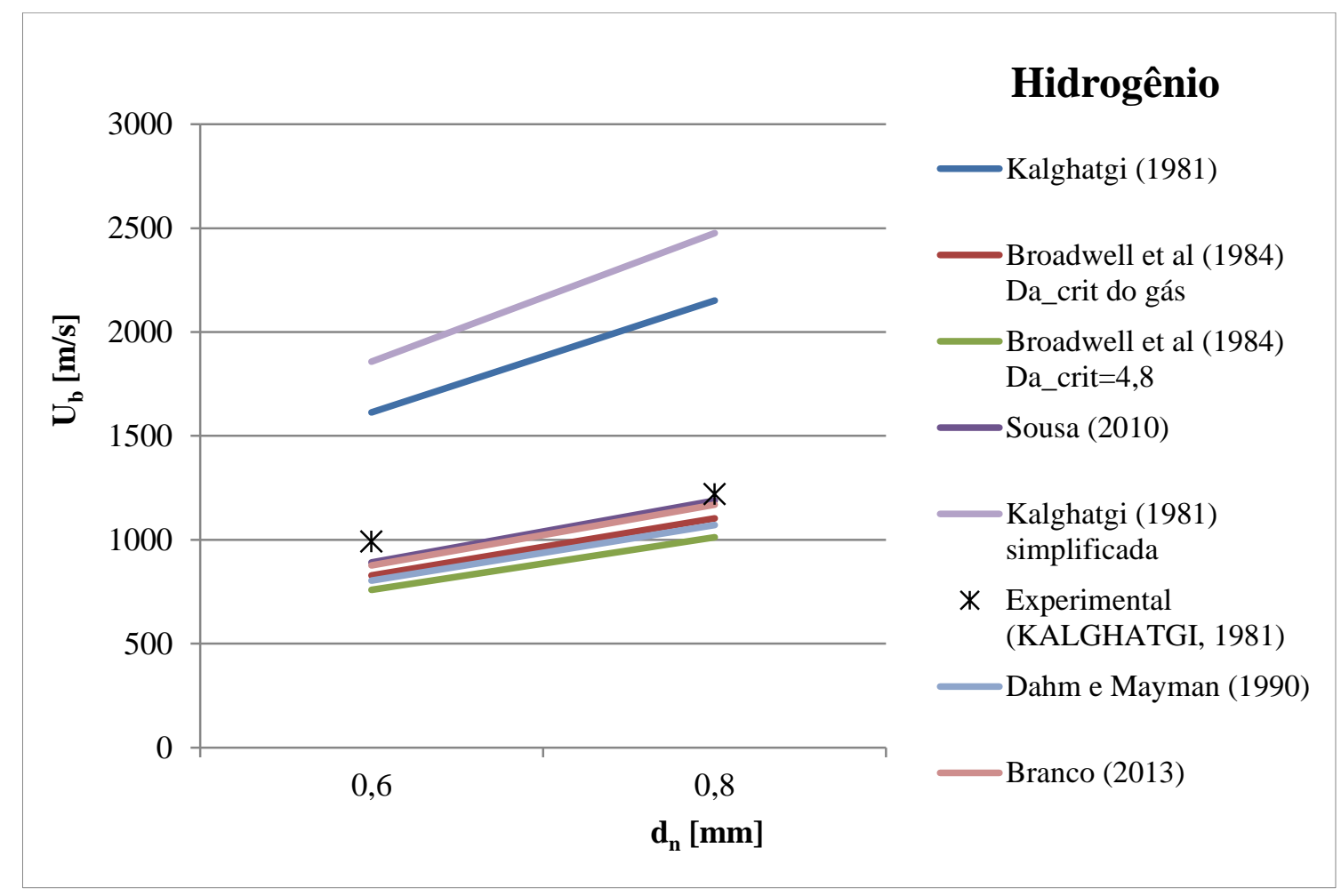

Figura 4.5. Valores de $U_{b}$ experimental (KALGHATGI, 1981) e previstos pelas correlações propostas por Kalghatgi (1981), Broadwell; Dam e Mungal (1984), Dahm e Mayman (1990), Sousa (2010) e Branco (2013) para o gás hidrogênio.

A partir da Tabela (4.10) e Figura (4.5) verifica-se que, para os dois diâmetros de bocais testados, a correlação proposta por Sousa (2010) fornece previsões de $U_{b}$ mais próximas dos dados experimentais, $U_{b, \exp }$, do que as demais correlações; apesar disso, a diferença entre $U_{b}$ previsto segundo esta correlação e $U_{b, \exp }$ não pode ser associada ao processo de digitalização, pois $\Delta_{i-\exp }>\Delta_{\exp }$, ou seja, $U_{b}$ não encontra-se dentro da faixa delimitada por $U_{b, \exp } \pm \xi_{\text {exp }}$; 


\subsubsection{Resultados das previsões da velocidade de blowout para o gás butano}

A Tabela (4.11) apresenta as velocidades de blowout, $U_{b, \text { exp }}$, calculadas a partir dos dados experimentais de Kalghatgi (1981); e as previsões das velocidades de blowout, $U_{b}$, para o gás butano, segundo as correlações propostas por Kalghatgi (1981), Broadwell; Dam e Mungal (1984), Dahm e Mayman (1990), Sousa (2010) e Branco (2013); e a Tabela (4.12) os respectivos desvios $\Delta_{i-\exp }$ entre $U_{b}$ e $U_{b, \exp }$. Estes resultados também podem ser visualizados na Figura (4.6), a qual ilustra os valores de $U_{b, \exp }$ e das previsões de $U_{b}$.

Tabela 4.11. Valores de $U_{b}$ previstos pelas correlações propostas por Kalghatgi (1981), Broadwell; Dam e Mungal (1984), Dahm e Mayman (1990), Sousa (2010) e Branco (2013) para o gás butano comercial.

\begin{tabular}{|c|c|c|c|c|c|c|c|c|}
\hline \multirow[b]{3}{*}{$\begin{array}{c}\boldsymbol{d}_{\boldsymbol{n}} \\
{[\mathrm{mm}]}\end{array}$} & \multicolumn{2}{|c|}{$\begin{array}{c}\text { Kalghatgi } \\
(1981)\end{array}$} & \multicolumn{3}{|c|}{$\begin{array}{c}\text { Broadwell et al } \\
(1984)\end{array}$} & \multirow{2}{*}{$\begin{array}{c}\begin{array}{c}\text { Sousa } \\
(\mathbf{2 0 1 0})\end{array} \\
\text { Eq. } \\
(3.16)\end{array}$} & \multirow{2}{*}{$\begin{array}{c}\begin{array}{c}\text { Dahm } \\
\mathbf{( 1 9 9 0 )}\end{array} \\
\text { Eq. } \\
(3.23)\end{array}$} & \multirow{2}{*}{$\begin{array}{c}\begin{array}{c}\text { Branco } \\
(\mathbf{2 0 1 3})\end{array} \\
\text { Eq. } \\
(3.24)\end{array}$} \\
\hline & $\begin{array}{l}\text { Experi- } \\
\text { mento }\end{array}$ & $\begin{array}{l}\text { Eq. } \\
(3.7)\end{array}$ & $\begin{array}{l}\text { Eq. } \\
(3.15)\end{array}$ & $\begin{array}{c}\text { Eq. } \\
(3.13)\end{array}$ & $\begin{array}{l}\text { Eq. } \\
(3.14)\end{array}$ & & & \\
\hline & $\begin{array}{l}U_{b, \exp } \\
{[\mathrm{m} / \mathrm{s}]}\end{array}$ & $\boldsymbol{U}_{\boldsymbol{b}}[\mathrm{m} / \mathrm{s}]$ & $\boldsymbol{U}_{\boldsymbol{b}}[\mathrm{m} / \mathrm{s}]$ & $\boldsymbol{U}_{\boldsymbol{b}}[\mathrm{m} / \mathrm{s}]$ & $\boldsymbol{U}_{\boldsymbol{b}}[\mathrm{m} / \mathrm{s}]$ & $\boldsymbol{U}_{\boldsymbol{b}}[\mathrm{m} / \mathrm{s}]$ & $\boldsymbol{U}_{\boldsymbol{b}}[\mathrm{m} / \mathrm{s}]$ & $\boldsymbol{U}_{\boldsymbol{b}}[\mathrm{m} / \mathrm{s}]$ \\
\hline 1,00 & 36,34 & 29,19 & 30,47 & 27,85 & 27,85 & 30,27 & 31,51 & 31,51 \\
\hline 2,00 & 72,16 & 56,17 & 60,94 & 55,69 & 55,69 & 60,54 & 63,01 & 63,01 \\
\hline 3,00 & 85,34 & 80,94 & 91,41 & 83,54 & 83,54 & 90,80 & 94,52 & 94,52 \\
\hline 4,00 & 109,32 & 103,51 & 121,88 & 111,38 & 111,38 & 121,07 & 126,02 & 126,02 \\
\hline
\end{tabular}

Tabela 4.12. Valores dos desvios entre $U_{b, \text { exp }}$ de Kalghatgi (1981) e $U_{b}$ previstos, $\Delta_{i \text {-exp }}$, para o gás butano comercial.

\begin{tabular}{|c|c|c|c|c|c|c|c|c|}
\hline \multirow[b]{3}{*}{$\begin{array}{c}\boldsymbol{d}_{\boldsymbol{n}} \\
{[\mathrm{mm}]}\end{array}$} & \multicolumn{2}{|c|}{$\begin{array}{c}\text { Kalghatgi } \\
(1981)\end{array}$} & \multicolumn{3}{|c|}{$\begin{array}{c}\text { Broadwell et al } \\
(1984)\end{array}$} & \multirow{2}{*}{$\begin{array}{c}\begin{array}{c}\text { Sousa } \\
(\mathbf{2 0 1 0})\end{array} \\
\begin{array}{c}\text { Eq. } \\
(3.16)\end{array}\end{array}$} & \multirow{2}{*}{$\begin{array}{c}\begin{array}{c}\text { Dahm } \\
\text { (1990) }\end{array} \\
\begin{array}{c}\text { Eq. } \\
(3.23)\end{array}\end{array}$} & \multirow{2}{*}{$\begin{array}{c}\begin{array}{c}\text { Branco } \\
\text { (2013) }\end{array} \\
\text { Eq. } \\
(3.24)\end{array}$} \\
\hline & $\begin{array}{l}\text { Experi- } \\
\text { mento }\end{array}$ & $\begin{array}{l}\text { Eq. } \\
(3.7)\end{array}$ & $\begin{array}{l}\text { Eq. } \\
(3.15)\end{array}$ & $\begin{array}{l}\text { Eq. } \\
(3.13)\end{array}$ & $\begin{array}{l}\text { Eq. } \\
(3.14)\end{array}$ & & & \\
\hline & $\Delta_{\exp }[\%]$ & $\Delta_{i-\exp }[\%]$ & $\Delta_{i-\exp }[\%]$ & $\Delta_{i-\exp }[\%]$ & $\Delta_{i-\exp }[\%]$ & $\Delta_{i-\exp }[\%]$ & $\Delta_{i-\exp }[\%]$ & $\begin{array}{l}\Delta_{i-\exp } \\
{[\%]} \\
\end{array}$ \\
\hline 1,00 & 9,26 & 19,69 & 16,17 & 23,38 & 23,38 & 16,72 & 13,31 & 13,31 \\
\hline 2,00 & 4,67 & 22,16 & 15,55 & 22,82 & 22,82 & 16,11 & 12,68 & 12,68 \\
\hline 3,00 & 3,95 & 5,15 & $-7,11$ & 2,11 & 2,11 & $-6,41$ & $-10,76$ & $-10,76$ \\
\hline 4,00 & 3,08 & 5,31 & $-11,49$ & $-1,89$ & $-1,89$ & $-10,75$ & $-15,28$ & $-15,28$ \\
\hline
\end{tabular}




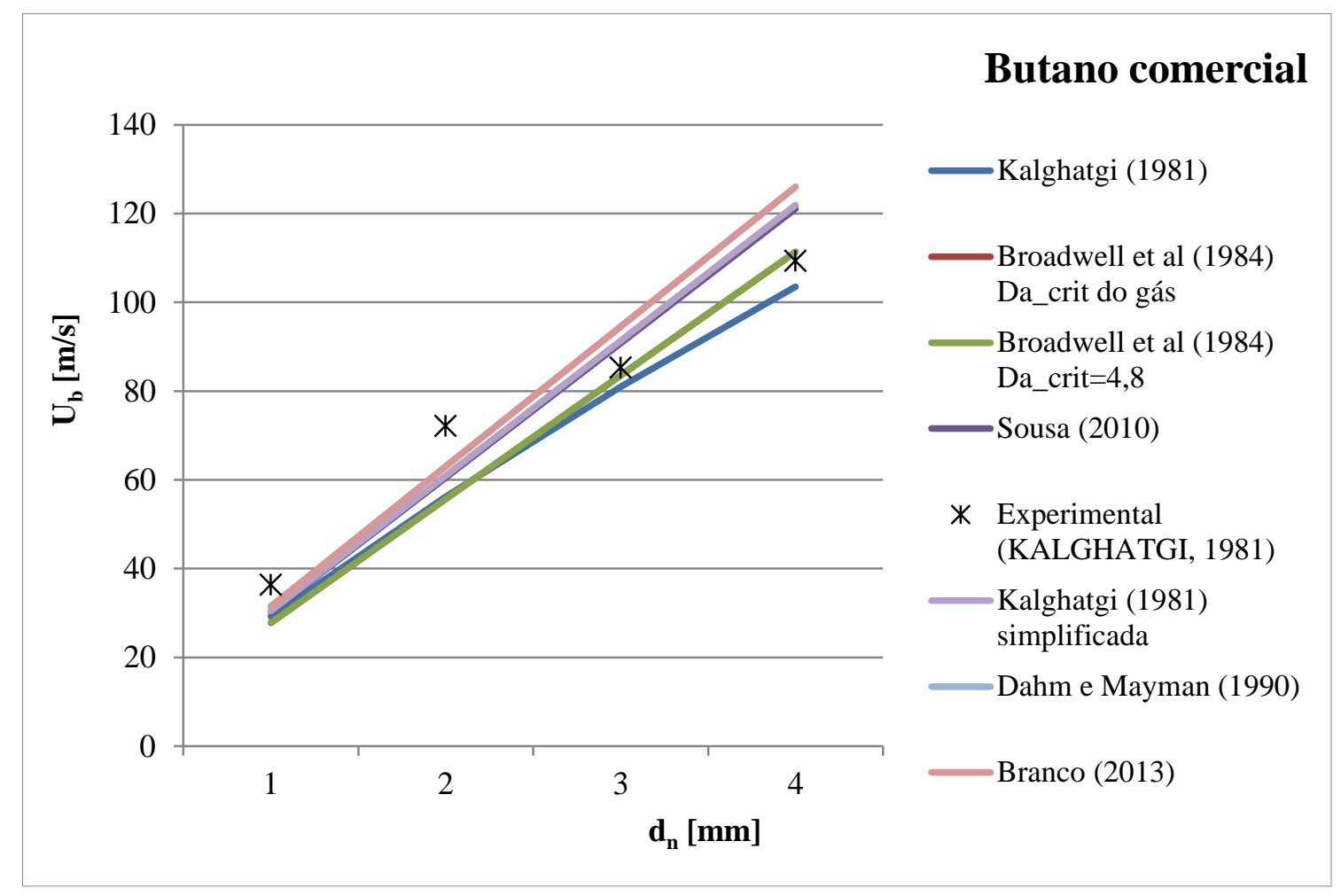

Figura 4.6. Valores de $U_{b}$ experimental (KALGHATGI, 1981) e previstos pelas correlações propostas por Kalghatgi (1981), Broadwell; Dam e Mungal (1984), Dahm e Mayman (1990), Sousa (2010) e Branco (2013) para o gás butano comercial.

A partir das Tabelas (4.11) e (4.12) e Figura (4.6) verifica-se que:

1. Para $d_{n}=1,00 \mathrm{~mm}$ e $d_{n}=2,00 \mathrm{~mm}$, as correlações propostas por Dahm e Mayman (1990) e por Branco (2013), fornecem previsões de $U_{b}$ mais próximas dos dados experimentais, $U_{b, \exp }$, do que as demais correlações; apesar disso, a diferença entre $U_{b}$ previsto segundo estas correlações e $U_{b, \exp }$ não pode ser associada ao processo de digitalização, pois $\Delta_{i-\exp }>\Delta_{\text {exp }}$, ou seja, $U_{b}$ não encontra-se dentro da faixa delimitada por $U_{b, \exp } \pm \xi_{\text {exp }}$

2. Para $d_{n}=3,00 \mathrm{~mm}$ e $d_{n}=4,00 \mathrm{~mm}$, as correlações propostas por Broadwell; Dam e Mungal (1984) com $D a_{c r i t}$ do gás e médio (igual 4,8) fornecem previsões de $U_{b}$ mais próximas dos dados experimentais do que as demais correlações; sendo que a diferença entre $U_{b}$ previsto segundo estas correlações e $U_{b, \exp }$ pode ser associada ao processo de digitalização, pois $\Delta_{i-\exp }<\Delta_{\text {exp }}$, ou seja, $U_{b}$ encontra-se dentro da faixa delimitada por $U_{b, \exp } \pm \xi_{\text {exp }}$ 
É interessante notar que as previsões da correlação de Kalghatgi (1981) simplificada por Broadwell; Dam e Mungal (1984) são muito semelhantes às previsões da correlação proposta por Sousa (2010), para todos os diâmetros de bocais (vide Tab. 4.12).

\subsubsection{Comentários referentes às previsões da velocidade de blowout}

A partir das análises das previsões das correlações propostas para prever a velocidade de blowout, $U_{b}$, apresentadas nesta Subseção (4.1), verificou-se que não há uma correlação que forneça previsões de $U_{b}$ mais próximas dos resultados experimentais, $U_{b, \text { exp }}$, para todos os gases combustíveis estudados e diâmetros de bocais, $d_{n}$, testados.

A Tabela (4.13) apresenta a média dos desvios entre $U_{b, \exp }$ e $U_{b}$ prevista por cada correlação analisada em função do gás combustível. E a Tabela (4.14) apresenta um resumo dos resultados desta Subseção (4.1), com base no critério apresentado na Subseção (3.5).

Tabela 4.13. Média dos desvios entre $U_{b, \text { exp }}$ de Kalghatgi (1981) e $U_{b}$ previstos, $\Delta_{i-e x p}$, para os seis gases combustíveis analisados.

\begin{tabular}{l|c|ccc|c|c|c}
\hline \hline \multirow{2}{*}{ Gás } & $\begin{array}{c}\text { Kalghatgi } \\
(\mathbf{1 9 8 1})\end{array}$ & \multicolumn{3}{|c|}{$\begin{array}{c}\text { Broadwell et al } \\
(\mathbf{1 9 8 4})\end{array}$} & $\begin{array}{c}\text { Sousa } \\
\mathbf{( 2 0 1 0 )}\end{array}$ & $\begin{array}{c}\text { Dahm } \\
(\mathbf{1 9 9 0})\end{array}$ & $\begin{array}{c}\text { Branco } \\
(\mathbf{2 0 1 3})\end{array}$ \\
\cline { 2 - 8 } & Eq. (3.7) & Eq. & Eq. & Eq. & Eq. & Eq. & Eq. \\
& & $(3.15)$ & $(3.13)$ & $(3.14)$ & $(3.16)$ & $(3.23)$ & $(3.24)$ \\
\hline Metano & 6,42 & 13,22 & 21,08 & 24,37 & 14,44 & 15,31 & 11,63 \\
Propano & 6,54 & 13,88 & 25,58 & 13,18 & 19,65 & 6,88 & 15,80 \\
Etileno & 16,49 & 25,61 & 21,03 & 14,71 & 16,03 & 9,79 & 13,29 \\
Acetileno & 15,51 & 14,77 & 30,28 & 43,35 & 24,81 & 34,51 & 19,40 \\
Hidrogênio & 69,26 & 94,82 & 13,13 & 20,37 & 6,50 & 15,71 & 8,05 \\
Butano & 13,08 & 12,58 & 12,55 & 12,55 & 12,50 & 13,01 & 13,01 \\
\hline \hline
\end{tabular}


Tabela 4.14. Correlações mais adequadas (I e II) para prever a velocidade de blowout em função do gás analisado e a faixa de diâmetros na qual foram avaliadas.

\begin{tabular}{lccc}
\hline \hline & $d_{n}(\mathrm{~mm})$ & $(\mathrm{I})$ & $(\mathrm{II})$ \\
\hline Metano & $2,0-12,0$ & Kalghatgi (1981) & Branco (2013) \\
Propano & $1,0-8,0$ & Kalghatgi (1981) & Dahm e Mayman (1990) \\
Etileno & $1,0-5,0$ & Dahm e Mayman (1990) & Branco (2013) \\
Acetileno & $0,2-1,0$ & Kalghatgi (1981) simplificada & Kalghatgi (1981) \\
Hidrogênio & $0,6-0,8$ & Sousa (2010) & Branco (2013) \\
Butano & $1,0-4,0$ & Sousa (2010) & Broadwell et al (1984) \\
\hline \hline
\end{tabular}

Nota: Análise realizada sob as condições ambientes de 1atm (101325 Pa) e 298K.

Nas colunas (I) e (II) desta tabela encontram-se as correlações que fornecem previsões de $U_{b}$ mais próximas dos dados experimentais (isto é, as menores médias dos desvios $\Delta_{i-\exp }$ entre $U_{b}$ e $\left.U_{b, \exp }\right)$ com base nos $d_{n}$ testados, ou seja:

1. Para o gás metano, a correlação proposta por Kalghatgi (1981) fornece previsões de $U_{b}$ mais próximas dos resultados experimentais, $U_{b, \text { exp }}$, seguida da correlação proposta pela presente autora, Branco (2013) - vide Tab. (4.2);

2. Para o gás hidrogênio, a correlação proposta por Sousa (2010), seguida da correlação proposta pela presente autora, Branco (2013), são as que fornecem previsões de $U_{b}$ mais próximas de $U_{b, \text { exp }}$, para os dois diâmetros testados, $d_{n}=0,60 \mathrm{~mm}$ e $d_{n}=0,8 \mathrm{~mm}$ (vide Tab. 4.10).

A diferença entre $U_{b}$ e $U_{b, \exp }$ de determinado gás combustível não pode ser associada somente ao erro $\xi_{\exp }$ resultante do processo de digitalização dos dados experimentais, uma vez que, nenhuma das correlações prevê $U_{b}$ dentro da faixa delimitada por $U_{b, \exp } \pm \xi_{\text {exp }}$ para todos os $d_{n}$ analisados.

Dentre os fatores que podem ser a causa da diferença entre $U_{b}$ e $U_{b, \text { exp }}$, tem-se:

1. Condições ambientes adotadas como referência para calcular $\rho_{\infty}, \rho_{f, n}$ e, consequentemente, $U_{b}$; 
2. Valores fornecidos por Kalghatgi (1981) e adotados para a viscosidade dinâmica, $\mu_{f, n}$ (avaliados a 273,15K); este parâmetro é utilizado para calcular a viscosidade cinemática $\left(v_{f, n}\right)$ e, consequentemente, $H_{s}, R e_{H_{s}}$ e $U_{b}$;

3. Influência do valor da velocidade de chama laminar, $S_{L}$, apresentado na Tabela (3.1), nas previsões de $U_{b}$;

4. Hipóteses assumidas na Subseção (3.1), também adotadas por Kalghatgi (1981), como escoamento isoentrópico, gás perfeito e calores específicos constantes;

5. Imperfeições nas correlações propostas.

A partir das análises de $U_{b}$ e $U_{b, \exp }$, também verificou-se que $U_{b}$ aumenta com o diâmetro do bocal, $d_{n}$, porém isso nem sempre ocorre de maneira linear, como é considerado nas correlações propostas por Broadwell; Dam e Mungal (1984) - Eqs. (3.13), (3.14) e (3.15) - e Sousa (2010), Eq. (3.16). A correlação proposta por Kalghatgi (1981), Eq. (3.7), é a única em que $U_{b}$ não varia linearmente com $d_{n}$. Como exemplo, peguemos o gás propano (vide Fig. 4.2); é nítida a dependência não linear de $U_{b} \operatorname{com} d_{n}$. A correlação proposta por Kalghatgi (1981), ainda que não forneça as previsões de $U_{b}$ mais próximas dos valores experimentais para todos os $d_{n}$, ela respeita a tendência destes dados.

Na Subseção (1.2) do presente trabalho relatou-se a importância da compreensão dos mecanismos de estabilidade de chamas para o dimensionamento de queimadores industriais e para a substituição de gás combustível em queimadores existentes. Por este motivo, o Apêndice D apresenta um caso simples de como verificar a viabilidade, do ponto vista de estabilidade de chama, da alteração de combustível (muitas vezes necessária por motivos econômicos ou de indisponibilidade) a ser utilizado por um mesmo queimador.

\subsection{Respostas às questões propostas}

A seguir são apresentadas as questões propostas na Subseção (1.1) “Objetivos" e suas respectivas respostas com relação à estabilidade de chamas difusão turbulenta, obtidas com base na presente revisão bibliográfica (Seção 2). 


\subsubsection{A altura de liftoff depende do diâmetro do bocal?}

A partir de resultados experimentais (com jatos de metano, propano, etileno e hidrogênio), Kalghatgi (1984) afirma que a altura de liftoff, $h$, é função das propriedades do gás combustível (velocidade de chama laminar $S_{L}$, viscosidade cinemática $v_{f, n}$ e densidade $\rho_{f, n}$ ), da velocidade deste gás na saída do bocal $\left(U_{n}\right)$ e da densidade do fluido no entorno do jato $\left(\rho_{\infty}\right)$, ou seja:

$$
h=C_{K, 2} \cdot v_{f, n}\left(\frac{U_{n}}{S_{L}^{2}}\right) \cdot\left(\frac{\rho_{f, n}}{\rho_{\infty}}\right)^{3 / 2}
$$

onde $C_{K, 2}$ é uma constante, cujo valor é aproximadamente 50 (vide Eq. 2.12). Logo, conclui-se que a altura de liftoff, $h$, não depende do diâmetro do bocal, $d_{n}$.

\subsection{2 É possível definir uma altura de blowout, $h_{b}$, como sendo a altura de descolamento imediatamente antes do blowout?}

Vanquickenborne e van Tigglen (1966) mostraram que o processo de blowout pode ser acionado quando a base da chama é empurrada a jusante de $H_{w}$, onde o contorno da fração mássica estequiométrica $\left(Y_{f}=Y_{f, s}\right)$ atinge sua largura máxima radial, $r_{w}$ (vide Fig. 1.2).

Kalghatgi (1984) afirma que as chamas de difusão descoladas sofrem blowout quando a altura de descolamento, $h$, atinge um valor entre $0,65 \cdot H_{s}$ e $0,75 \cdot H_{s}$, aproximadamente; onde $H_{s}$ é a distância axial a partir da saída do bocal em que a concentração do combustível cai para a condição estequiométrica (vide Eq. 2.3).

$$
H_{s}=\left[4 \cdot \frac{Y_{f, n}}{Y_{f, s}}\left(\frac{\rho_{f, n}}{\rho_{\infty}}\right)^{1 / 2}+5,8\right] \cdot d_{n}
$$

Karbassi (1997) afirma que é razoável supor que antes de blowout, a base da chama é estabilizada em uma posição, onde a concentração de combustível no eixo do jato está próxima do limite de flamabilidade inferior. Este autor assume esta localização como a altura de blowout e afirma que é a última posição possível para a existência de chamas descoladas. 
$\mathrm{Wu}$ et al (2006), a partir de resultados experimentais, confirmam a hipótese de Vanquickenborne e Van Tigglen (1966) e afirmam que a posição axial $H_{w}$ (distância a partir da saída do bocal até posição axial correspondente ao máximo raio do contorno estequiométrico) pode ser considerada como um ponto que separa as regiões estáveis e instáveis de chamas descoladas no processo de blowout. $H_{w}$ pode ser obtida a partir da solução numérica para $x$ da seguinte equação (vide Eq. 2.36):

$$
2 \ln \left(\frac{Y_{s}}{4 Y_{n} d_{e}} x-\frac{5,8 d_{n} Y_{s}}{4 Y_{n} d_{e}}\right)=-\frac{x}{x-5,8 d_{n}}
$$

Se a base da chama é empurrada para uma distância $x>H_{w}\left(r=r_{w}\right)$, a chama passa para a região pulsante e torna-se instável, desencadeando o processo de blowout. Na região pulsante $\left(h_{p, \text { inf }}<x<h_{p, \text { sup }}\right)$, o ponto de estabilização da chama tripla move-se ao longo do contorno estequiométrico, estabilizando a chama onde a base desta é limitada pelos contornos dos limites de flamabilidade (inferior e superior). Se a chama é deslocada além da ponta do contorno estequiométrico, $H_{s}$, ela recua a jusante de forma contínua e, finalmente, extingue-se $\left(x=h_{b}\right)$. Logo, segundo Wu et al (2006), existe uma posição axial $x=h_{b}\left(H_{s}<h_{b}<H_{L}\right)$, na qual a base da situa-se imediatamente antes do blowout. Porém, $h_{b}$ foi obtida experimentalmente (para jatos de metano e propano diluídos com nitrogênio e ar) e estes autores não forneceram nenhuma correlação para prevê-lo.

A partir do exposto no presente trabalho e no fato de que o fenômeno de blowout está diretamente associado à turbulência (instabilidades no escoamento e flutuações de velocidade, concentração, entre outros parâmetros) conclui-se que não é possível prever com exatidão a posição $h_{b}$, mas é possível definir uma faixa de distância axial $\left(H_{s}<h_{b}<H_{L}\right)$, na qual o blowout pode ser esperado.

\subsubsection{Esta altura de blowout, $h_{b}$, depende do diâmetro do bocal, $d_{n}$ ? Por quê?}

Como apresentado no Item anterior (4.2.2), a altura de blowout, $h_{b}$, encontra-se entre as posições $H_{S}$ e $H_{L}$, isto é, $H_{S}<h_{b}<H_{L}$. Uma vez que $H_{S}$ e $H_{L}$ são funções do diâmetro do bocal $d_{n}$, conclui-se que $h_{b}$ também dependa de $d_{n}$. 


\subsubsection{Qual critério (teoria/modelo) é mais adequado para definir estabilidade de chama de difusão turbulenta?}

A partir da revisão bibliográfica apresentada na Seção (2) do presente trabalho, verifica-se que não há um critério mais adequado para definir estabilidade de chama de difusão turbulenta. Todas as teorias são baseadas em modelos físicos e sustentadas por dados experimentais. O que há é uma preferência, por parte dos pesquisadores, pelos modelos de combustão pré-misturada (VANQUICKENBORNE e VAN TIGGLEN, 1966) e de mistura em larga escala (BROADWELL, DAHM e MUNGAL, 1984), uma vez que estes têm sido mais trabalhados e referenciados.

\subsubsection{Como a adição de um fluxo oxidante concorrente ao jato de gás combustível influi na estabilidade de uma chama de difusão turbulenta?}

Dahm e Dibble (1988) apresentaram resultados de investigações experimentais dos mecanismos de liftoff e blowout de chamas de difusão turbulenta de metano e propano, emergindo em um meio em movimento $\left(U_{\infty} \neq 0\right)$. Os autores observaram que: embora a velocidade do escoamento externo seja pequena $\left(U_{\infty} \leq 1,0 \mathrm{~m} / \mathrm{s}\right)$ em comparação com a velocidade de descarga no bocal $U_{n}$, a velocidade na ponta da chama e a velocidade na saída do bocal com a qual ocorre o blowout, $U_{b}$, decaem consideravelmente em comparação à condição de um jato simples de gás combustível emergindo em um meio quiescente $\left(U_{\infty}=0\right)$.

Karbassi (1997) realizou uma série de experimentos com o objetivo de obter curvas de estabilidade de combustíveis gasosos puros (metano, propano, etileno e hidrogênio) e misturados; e os efeitos nos limites de estabilidade da geometria do bocal e da adição de diluentes no jato de combustível e no fluxo concorrente ao jato. A partir dos experimentos, verificou que a velocidade do fluxo concorrente, $U_{\infty}$, afeta significantemente a estabilidade da chama. Dependendo da magnitude de $U_{\infty}$, é possível observar: apenas o blowout (baixos valores de $U_{\infty}$ ); blowout e blowoff (valores médios de $U_{\infty}$ ); e apenas o blowoff (maiores valores de $U_{\infty}$ ). 
Para aumentar os limites de estabilidade (velocidades do jato de gás combustível na saída do bocal com as quais ocorre descolamento, $U_{l}$, e blowout, $U_{b}$ ) de chamas de difusão turbulenta emergindo em um meio em movimento $\left(U_{\infty} \neq 0\right)$, pode-se: reduzir a velocidade do fluxo concorrente ao jato de gás combustível; alterar a geometria do bocal (forma e dimensões); adicionar gases combustíveis no fluido concorrente ao jato central; e, segundo Kim; Won e Chung (2007), aumentar a temperatura inicial do jato de gás combustível e do ar concorrente a este.

A Subseção (2.2) do presente trabalho apresenta com mais detalhes alguns trabalhos que englobam a estabilidade de chamas de difusão turbulenta de jatos concorrentes.

\subsubsection{Chamas de determinado gás combustível são mais estáveis quando emergem de bocais simples ou de bocais coaxiais?}

Segundo resultados experimentais de Feikema; Chen e Driscoll (1990), a adição de ar coaxial sem swirl reduz consideravelmente a velocidade de descarga do jato de gás combustível com a qual ocorre o blowout, $\left(U_{f, n}\right)_{b}$ (vide Fig. 2.14), ou seja, diminui a estabilidade da chama em comparação a de uma chama proveniente de um jato simples. Por outro lado, este ar reduz o comprimento da chama e, consequentemente, as emissões de $N O_{x}$, o que justifica a utilização de bocais coaxiais em turbinas a gás e alguns queimadores industriais.

Se for adicionado swirl ao jato de ar coaxial, a chama torna-se muito mais estável; por exemplo, para o caso de gás metano, a chama torna-se cerca de cinco vezes mais estável, com base na velocidade máxima de gás combustível $\left(U_{f, n}\right)_{b}$ sem swirl. Isto ocorre, pois o swirl reduz as velocidades e as taxas de deformações locais, próximas ao ponto onde a chama é estabilizada (FEIKEMA; CHEN; DRISCOLL, 1991).

A Subseção (2.3) do presente trabalho apresenta com mais detalhes alguns trabalhos que englobam a estabilidade de chamas de difusão turbulenta de jatos coaxiais. 


\section{CONCLUSÕES}

O presente trabalho fez uma revisão dos recentes progressos na compreensão de chamas de difusão turbulenta descoladas do bocal e das condições sob as quais estas chamas se estabilizam. Conceitos sobre os fenômenos de liftoff (descolamento da base da chama do bocal e posterior estabilização desta a certa distância do bocal) e de blowout (desprendimento e extinção da chama) também foram apresentados, assim como modelos e mecanismos físicos propostos que visam prever estes fenômenos e revelar o mecanismo de estabilização das chamas descoladas. Deu-se maior relevância ao fenômeno de blowout, uma vez que este é considerado um ponto especial que limita a estabilidade de chamas.

A partir da presente revisão bibliográfica, verificou-se que o blowout de uma chama de difusão turbulenta é um processo transitório, composto por uma série de eventos que ocorrem consecutivamente. $\mathrm{O}$ fato de este fenômeno estar diretamente associado ao escoamento turbulento, cuja descrição matemática e as soluções das equações de conservação de massa e energia são muito mais complexas do que as de escoamentos laminares, despertou o interesse de muitos pesquisadores, inclusive o da presente autora, de investir na possibilidade de estimar e caracterizar o limite e o processo de blowout com base na velocidade inicial ou número de Reynolds do jato e nas propriedades do gás combustível (e do ar, no caso de jatos coaxiais) na saída do bocal, ou seja, não utilizar parâmetros do escoamento ao longe, como intensidade de turbulência, taxa de mistura, gradientes de temperatura, de pressão, de concentração, entre outros.

Após um extenso estudo sobre o fenômeno de blowout, os parâmetros que o influem e trabalhos relacionados com o tema, a presente autora propôs uma correlação para a previsão da velocidade de blowout, a qual a denominou como "Branco (2013)". Esta correlação baseia-se nos movimentos de grande escala observados em jatos turbulentos e no adimensional número de Damköhler (relação entre o tempo de cinética química e o tempo de mistura dos reagentes e destes com os produtos da reação). Foi desenvolvida a partir da simplificação de uma correlação para jatos coaxiais, seguida da modificação de um parâmetro, o número de Damköhler. A nova correlação, aplicada para jatos simples, forneceu resultados mais próximos dos experimentais do que outras correlações que são referência para muitos trabalhos que abordam o tema estabilidade de chamas e blowout. Isto foi verificado por meio de comparações entre as 
previsões da correlação proposta com resultados experimentais e com previsões de outras correlações disponíveis na literatura, para seis gases combustíveis e diferentes diâmetros de bocais. As análises foram limitadas pelos dados experimentais disponíveis na literatura. Verificou-se que a velocidade de blowout de chamas de difusão turbulenta é função das propriedades do combustível, das características do bocal, das condições do ambiente e do adimensional número de Damköhler.

Uma vez que, chamas de difusão turbulenta ocorrem na maioria dos sistemas de combustão (como fornos e fornalhas industriais, câmaras de combustão de turbinas a gás, flares, entre outros); e que a compreensão dos mecanismos de estabilidade de chamas é de extrema importância tanto para o projeto/dimensionamento de queimadores utilizados nestes sistemas, como para a manutenção adequada do equipamento e/ou para a substituição de combustíveis em queimadores existentes; o presente trabalho contribui com o estado da arte em estabilidade de chamas, apresentando o fenômeno de blowout (considerado como o limite da estabilidade de chamas descoladas), os mecanismos envolvidos e os parâmetros que influem neste fenômeno, alternativas para prevê-lo e, conseqüentemente, como evitá-lo. 


\section{TRABALHOS FUTUROS}

Sugere-se como futuros trabalhos:

1. Determinar (por meio de experimentos ou comparação com resultados experimentais disponíveis na Literatura) os limites de aplicação das correlações apresentadas neste trabalho, ou seja, as condições de operação sob as quais estas correlações fornecem previsões de $U_{b}$ aceitáveis (próximas o suficiente de dados experimentais); e

2. Desenvolver uma metodologia para a previsão do blowout por meio de simulações de casos testes em um aplicativo de CFD, ou seja, através da análise de resultados obtidos por simulação numérica e baseada nos conceitos de estabilidade de chamas de difusão turbulentas. 


\section{REFERÊNCIAS BIBLIOGRÁFICAS}

AMERICAN GAS ASSOCIATION. Gas Engineers Handbook; ed. Industrial Press Inc., 1974.

ANNUSHKIN, Y. M.; SVERDLOV, E. D. Stability of Submerged Diffusion Flames in Subsonic and Underexpanded Supersonic Gas-Fuel Streams. Combustion, Explosion and Shock Waves, v. 14, n. 5, p. 597 - 605, 1979.

ANSYS. FLUENT 12.0: User's Guide. 2009. Disponível em:

https://www.sharcnet.ca/Software/Fluent6/html/ug/main_pre.htm

ARIMA, M. N. Estudo Teórico-Experimental de Jatos Bi-Dimensionais Confinados. Tese (Doutorado) - Escola Politécnica da Universidade de São Paulo, São Paulo, Brasil, 2009.

BECKER, H. A.; HOTTEL, H. C.; WILLIAMS, G. C. J. Fluid Mech. 30, p. 285 - 303, 1967.

BIRCH, A. D.; BROWN, D. R.; DODSON, M. G.; THOMAS, J. R. J. Fluid Mech. 88 , p. 431 - 449, 1978.

BOILEAU, M.; STAFFELBACH, G.; CUENOT, B.; POINSTO T.; BERAT, C. LES of an Ignition Sequence in a Gas Turbine Engine. Combustion and Flame, v.154, p. 2-22, 2008.

BORGNAKKE, C.; SONNTAG, R. E.; VAN WYLEN, G. J. Fundamentos da Termodinâmica. Editora Edgard Blücher, $6^{\mathrm{a}}$ ed., 2003.

BRADSHAW, P. An Introduction to Turbulence and its Measurement. Pergamon Press, 1971.

BRAY, K. N.; PETERS, N. Laminar Flamelets in Turbulent Flames. In P. A. Libby and F. A. Williams, editors, Turbulent Reacting Flows, p. 63 - 114. Academic Press, 1994.

BROADWELL, J. E.; DAM, W.J.A.; MUNGAL, M.G. Blowout of Turbulent Diffusion Flames. Symposium (International) on Combustion, The Combustion Institute, 20, p. 303 310, 1984.

BYGSTФYL, S.; MAGNUSSEN, B.F. A Model for Flame Extinction in Turbulent Flow. Symposium on Turbulent Shear Flows, 4, September 12-14, 1983. Karsruhe, Germany.

CETAE - Centro de Tecnologias Ambientais e Energéticas; IPT - Instituto de Pesquisas Tecnológicas do Estado de São Paulo; LETMCE - Laboratório de Energia Térmica, Motores, 
Combustíveis e Emissões. Determinação da Vazão Mínima de Combustível Estabilizador nos Queimadores das Caldeiras de Central Termoelétrica. I Escola de Combustão - Rede Nacional de Combustão, Florianópolis, Junho 2007. Disponível em:

http://redenacionaldecombustao.org/escoladecombustao/arquivos/EDC2007/palestras/Francis co_Domingues_A_Sousa-Combustivel_Estabilizador_Caldeiras.pdf . Acesso em: fev. 2011.

CHAO, Y. C.; CHANG, Y. L; WU, C. Y; CHENG, T. S. An experimental investigation of the blowout process of a jet flame. Proceedings of the Combustion Institute, Volume 28, p. $335-342,2000$.

CHAO, Y. -C.; WU, C. -Y.; LEE, K. -Y.; LI, Y. -H; CHEN, R. -H; CHENG, T. -S. Effects of Dilution on blowout Limits of Turbulent Jet Flames. Combust. Sci. and Tech., 176, p. $1735-1753,2004$.

CHUNG, S.H.; LEE, B. J. On the characteristics of laminar lifted flames in a nonpremixed jet. Combust. Flame, 86, p. 62 - 72, 1991.

DAHM, W. J. A.; DIBBLE, R. W. Coflowing Turbulent Jet Diffusion Flame Blowout, Symposium (International) on Combustion, The Combustion Institute, 22, p. 801 - 808, 1988.

DAHM, W. J. A.; MAYMAN, A. G. Blowout Limits of Turbulent Jet Diffusion Flames for Arbitrary Source Conditions. University of Michigan, Ann Arbor, Michigan 48109. AIAA Journal. v. 28, n. 7, p. 1157 - 1162, 1990.

FEIKEMA, D.; RUEY-HUNG CHEN,R.; DRISCOLL, J. F. Enhancement of Flame Blowout Limits by the Use of Swirl. Combustion and Flame 80, p. 183-195, 1990.

FEIKEMA, D.; RUEY-HUNG CHEN,R.; DRISCOLL, J. F. Blowout of Nonpremixed Flames: Maximum Coaxial Air Velocities Achievable, with and without Swirl. Combustion and Flame 86, p. 347-358, 1991.

GÜNTHER, R.; LENZE, B. The Stability of Free Jet Diffusion Flames. $14^{\text {th }}$ World Gas Conference, Toronto, International Gas Union, p. 1-15, 1979.

GÜNTHER, R.; HORCH, K.; LENZE, B. The Stabilization Mechanism of Free Jet Diffusion Flames. Combustion Institute (U.S.), IST Meeting, University of Bordeaux, France, p. 117 - 122, 1981.

HALL, L.; HORCH, K.; GÜNTHER, R. Die Stabilitat von Freistahl-Diffusions Flammen. Brennst.- Wärme-Kraft, 32, 26 - 31, 1980.

HINZE, J.O. Turbulence, an Introduction to its Mechanism and Theory. McGraw- Hill, 1959. 
HINZE, J.O.; VAN DER HEGGE ZIJNEN, B. G. Transfer of Heart and Matter in the Turbulent Mixing Zone of an Axially Symmetrical Jet. Applied Scientific Research. v. 1, n. 1, p. 435 - 461, 1949.

HOTTEL, H. C.; SAROFIM, A. F. Radiative Heat Transfer. Mc Graw-Hill, 1967.

JANICKA, J.; PETERS, N. Prediction of Turbulent Jet Diffusion Flame Lift-off Using a PDF Transport Equation. Symposium (International) on Combustion, The Combustion Institute, 19, p. 367-374, 1982.

KALGHATGI, G. T. Blowout stability of gaseous jet diffusion flames - part I: In still air. Combustion Science and Technology, 26, p. 233 - 239, 1981.

KALGHATGI, G. T. Liftoff Heights and Visible Lengths of Vertical Turbulent Jet Diffusion Flames in Still Air. Combustion Science and Technology, 41, p. 17 - 29, 1984.

KARBASSI, M. Analytical and Experimental Studies of the Stability Limits of Nonpremixed Flames in a Co-flowing Stream. 1997. 220p. Thesis - University of Calgary, Calgary, Alberta. September, 1997.

KHITRIM, L.N. The Physics of Combustion and Explosion, ed. Israel Program for Scientific Translation Ltd, 1975.

KIM, W. W.; LIENAU, J.; VAN SLOOTEN, P. R.; ET AL. Towards Modeling Lean Blow Out in Gas Turbine Flameholder Applications. Journal of Engineering for Gas Turbines and Power, v.128, p. 40 - 48, 2006.

KIM, K. N.; WON, S. H.; CHUNG, S. H. Characteristics of Turbulent Lifted Flames in Coflow Jets with Initial Temperature Variation. Proceedings of the Combustion Institute, v. 31, p. $1591-1598,2007$.

KIONI, P.N. ROGG, B. BRAY, K.N. LIÑÁN, A. Flame Spread in Laminar Mixing Layers: The Triple Flame. Combust. Flame 95, p. 276 - 290, 1993.

KNAUS, D. A.; MAGARI P. J.; HILL R. W.; ET AL. Improved Correlations for Augmentor Static Stability. AIAA Paper 389, 2007.

KNAUS, D. A.; MAGARI P. J.; HILL R. W.; ET AL. Predicting Augmentor Static Stability Using Local Damkohler Number. AIAA Paper 1027, 2008.

LAWN, C. J. Lifted Flames on Fuel Jets in Co-flowing Air. Progress in Energy and Combustion Science, 35, p. 1 - 30, 2009. 
LEWIS, B.; VON ELBE, G. Combustion, Flames and Explosions of Gases. $2^{\text {st }}$ Ed., Academic Press Inc., 1961.

LIPATNIKOV, A. N.; CHOMIAK, J. Molecular transport effects on turbulent flame propagation and structure. Progress in Energy and Combustion Science, vol. 31 pp. 1 - 73, 2005.

LYDERSEN, A. L. Fluid Flow and Heat Transfer, John Wiley and Sons. p. 344, 1979.

LYONS, K. M. Toward an Understanding of the Stabilization Mechanisms of Lifted Turbulent Jet Flames: Experiments. Progress in Energy and Combustion Science, v. 33, n. 2, p. $211-231,2007$.

MIAKE-LYE, R. C.; HAMMER, J. A. Lifted Turbulent Jet Flames: A Stability Criterion Based on the Jet Largescale Structure. Symposium (International) on Combustion, The Combustion Institute, 22, p. 817 - 824, 1988.

MÜLlER, C. M.; BREITBACH, H.; PETERS, N. Partidy Premixed Turbulent Flame Propagation in Jet Flames. Symposium (International) on Combustion, The Combustion Institute, 25, p. 1099 - 1106, 1994.

MUÑIZ, L.; MUNGAL, M.G. Combust. Flame 111, p. 16 - 31, 1997.

PETERS, N.; WILLIAMS, F. A. Liftoff Characteristics of Turbulent Jet Diffusion Flames. AIAA Journal 21, p. 423 - 429, 1983.

PETERS, N. Laminar Diffusion Flamelet Models in Non Premixed Combustion. Prog. Energy Combust. Sci., 10, p. 319 - 339, 1984.

PETERS, N. Laminar Flamelet Concepts in Turbulent Combustion. Symposium (International) on Combustion, The Combustion Institute, 2, p. 1231 - 1250, 1986.

PINTO, M. M. Gases Combustíveis. Química Industrial. Departamento de Engenharia de Produção da Universidade Federal do Espírito Santo, [20--].

PITTS, W. M. Assesment of Theories for the Behavior and Blowout of Lifted Turbulent Jet Diffusion Flames. Symposium (International) on Combustion, The Combustion Institute, 22, p. 809 - 816, 1988.

PITTS, W. M. Importance of Isothermal Mixing Processes to the Understanding of Liftoff and Blowout of Turbulent Jet Diffusion Flames. Combustion and Flame, 76, p. 197-212, 1989. 
POPE, S. B. Turbulent Flows. Cambridge University Press, Nova Iorque, Estados Unidos da América, 2000.

REYNOLDS, O. An Experimental Investigation of the Circumstances which Determine Whether the Motion of Water in Parallel Channels Shall be Direct or Sinuous and of the Law of Resistance in Parallel Channels. Philos. Trans. R. Soc. 174, p. 935 - 82, 1883.

RUETSCH, G.R.; VERVISCH, L.; LIÑÁN, A. Effects of Heat Release on Triple Flames. Physics of Fluids v. 7, p. 1447-1454, 1995.

SHIH, T. H.; LIOU, W. W.; SHABBIR, A.; YANG, Z.; ZHU, J. A New $\boldsymbol{k}$ - $\boldsymbol{\varepsilon}$ Eddy-Viscosity Model for High Reynolds Number Turbulent Flows - Model Development and Validation. Computers Fluids, 24 (3), p. 227 - 238, 1995.

SIVATHANU, Y. R.; FAETH, G. M. Generalized State Relationships for Scalar Properties in Non-Premixed Hydrocarbon/Air Flames. Combustion and Flame, 82, p. 211230, 1990.

SMITH, C. E.; NICKOLAUS, D.; LEACH, T.; KIEL, B.; GARWICK, K. LES Blowout Analysis of Premixed Flow Past V-gutter Flameholder. AIAA Paper 2007-170.

SOUSA, F. D. A. Expansão de Jatos e Chamas de Gases. São Paulo: Instituto de Pesquisas Tecnológicas, 2010. Material do Curso de Combustão Industrial.

SPALDING, D. B. A Mixing Rule for Laminar Flame Speed. Fuel, 35, p. 347-351, 1956.

StAmbuleanu, A. Flame Combustion Processes in Industry, ed. Abacus Press, 1976.

TAKAHASHI, F.; SCHMOLL, W. J. Lifting Criteria of Jet Diffusion Flames. Symposium (International) on Combustion, The Combustion Institute, 23, p. 677 - 683, 1990.

TENNEKES, H.; LUMLEY, J. L. A First Course in Turbulence. The Massachusetts Institute of Tecnology, USA, 1973.

THRING, M. W.; NEWBY, M. P. Combustion Length Enclosed Turbulent Jet Flames. $4^{\text {th }}$ Symposium (International) on Combustion, p. 789 - 796, 1952.

TURNS, S.R. An Introduction to Combustion - Concepts and Applications. Mc GrawHill, $2^{\text {nd }}$ edition, 2000.

VANQUICKENBORNE, L.; VAN TIGGELEN, A. The Stabilization Mechanism of Lifted Diffusion Flames. Combustion and Flame, v. 10, n. 1, p. 59 - 69, 1966. 
VIVAS, B. M. M. Determinação Experimental de Limites de Inflamabilidade e Temperatura de Auto-Ignição de Petro e Biocombustíveis em Tubo de Combustão. 2010, 88 p. Dissertação (Mestrado) - Setor de Tecnologia, Universidade Federal do Paraná, 2010.

WANG, H.; JIN, J. Reduced Chemical Kinetic Mechanism for Jet Fuel Combustion. AIAA Paper 6709, 2010.

WANG, H.; JIN, J. Lean Blowout Predictions of a Non-Premixed V-Gutter Stabilized Flame Using a Damkohler Number Methodology. Proceedings of ASME Turbo Expo 2011, Vancouver, British Columbia, Canada, 2011.

WOHL, K.; KAPP, N. M.; GAZLEY, G. The Stability of Open Flames, in Proceedings of the $3^{\text {rd }}$ International Symposium on Combustion, p. 3 - 21, The Combustion Institute, Pittsburgh, Pa, USA, 1949.

WU, C. Y.; CHAO, Y. C.; CHENG, T. S.; LI,Y. H.; LEE, K. Y.; YUAN, T. The Blowout Mechanism of Turbulent Jet Diffusion Flames. Combustion and Flame, 145, p. 481 - 494, 2006.

YUMLU, V. S. The Effects of Additives on the Burning Velocities of Flames and Their Possible Prediction by a Mixing Rule. Combustion and Flame, 12, p. 14 - 18, 1968. 


\section{APÊNDICE A - Conceitos fundamentais}

Este Apêndice apresenta uma breve descrição de alguns termos que são freqüentemente relatados ao longo deste trabalho. A compreensão destes termos é fundamental para o entendimento da análise desenvolvida. No entanto, o objetivo deste Apêndice é familiarizar o leitor com o vocabulário utilizado e não introduzir conceitos detalhados do mesmo.

\section{A.1 Turbulência}

Todo escoamento turbulento é instável, irregular, aparentemente aleatório, caótico, imprevisível e composto por muitas escalas (de comprimento, velocidade e tempo).

Uma característica essencial dos fluxos turbulentos é que suas propriedades (campo de velocidades, temperatura, pressão, etc.) variam significativamente e irregularmente no espaço e no tempo. Uma maneira muito utilizada para caracterizar esses escoamentos é decompor uma variável instantânea (propriedade do fluxo) em um valor médio $\bar{q}$ e uma flutuação $q^{\prime}$ (decomposição de Reynolds), como:

$$
q(t)=\bar{q}+q^{\prime}(t)
$$

onde

$$
\bar{q} \equiv \frac{1}{\Delta t} \int_{t_{1}}^{t_{2}} q(t) d t
$$

A Figura (A.1) mostra a variação temporal da componente axial da velocidade $U(t)$ medida na linha de centro de um jato turbulento. A linha horizontal representa a velocidade média, denotada por $\bar{U}$. Pode-se observar que a velocidade $U(t)$ apresenta oscilações significativas (cerca de $25 \%$ de $\bar{U}$ ) e está longe de ser periódica (há umas amplas escalas de tempo). Além disso, observa-se que $U(t)$ e sua média $\bar{U}$ são, em certo sentido, "estáveis", pois não são observadas grandes variações $U(t)$, nem $\bar{U}(t)$ passa longos períodos de tempo longe de $\bar{U}$. A Figura (A.2) mostra o perfil da velocidade média $\bar{U}$, medido em um jato turbulento em função 
da coordenada radial $r$. Em contraste com a velocidade $U$, a velocidade média $\bar{U}$ tem um perfil suave (um pouco diferente do perfil de um jato laminar).

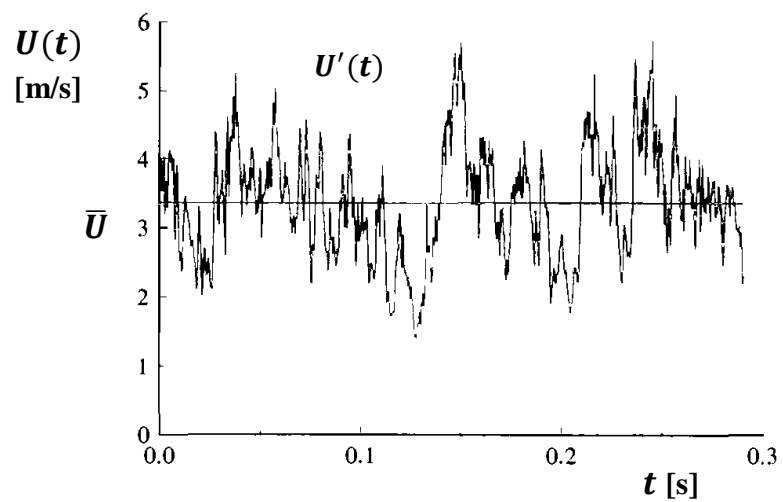

Figura A.1. Variação temporal da componente axial da velocidade $U(t)$ na linha de centro de um jato turbulento (POPE, 2000).

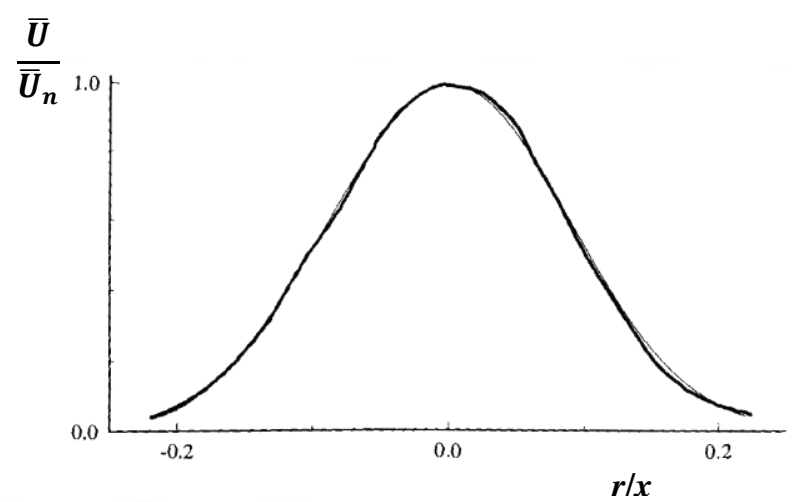

Figura A.2. Perfil da velocidade média em jato turbulento; subscrito 0: propriedade na saída do jato (POPE, 2000).

Escoamentos turbulentos são predominantes em aplicações de engenharia, como por exemplo: no interior de bombas, compressores, tubulações; em torno de veículos (aviões, automóveis, navios, submarinos); no interior de motores, caldeiras, fornos e reatores químicos (mistura de reagentes).

A eficácia da turbulência para o transporte e mistura de fluidos é de primordial importância em muitas aplicações, como para os casos de mistura de poluentes com o meio (atmosfera ou água, por exemplo), e de mistura de reagentes em dispositivos de combustão e em reatores químicos. Em comparação com o escoamento laminar, as taxas de transferência de calor e de massa em interfaces sólido-líquido e líquido-gás são muito maiores nos fluxos turbulentos. Logo, a principal motivação para o estudo dos fluxos turbulentos é que a maioria dos escoamentos reais é turbulenta; além de que a turbulência aumenta muito as taxas de momento, calor, transporte e mistura de matéria.

Para compreensão qualitativa da estrutura do escoamento turbulento, algumas escalas de comprimento são usadas, como: (1) a escala característica do escoamento ou macro-escala; (2) escala integral ou macro-escala da turbulência; (3) micro-escala de Taylor; e (4) micro-escala de Kolmogorov (TURNS, 2000). Quando o número de Reynolds é elevado há uma separação 
de escalas. Os movimentos de maior escala são fortemente influenciados pela geometria do fluxo (isto é, pelas condições de contorno), e eles controlam o transporte e a mistura. Por outro lado, o comportamento dos movimentos de pequena escala é determinado quase inteiramente pela taxa de energia recebida das macro-escalas e pela viscosidade do fluido. Por isso, diz-se que estes movimentos de pequena escala tem um caráter universal, ou seja, independente da geometria de fluxo.

Há muitos estudos que visam desenvolver modelos matemáticos tratáveis para os escoamentos de fluidos, sejam eles laminar ou turbulento. As leis que governam ambos são incorporadas nas equações Navier-Stokes. Considerando a diversidade e a complexidade dos escoamentos, é notável que estas equações, que são relativamente simples, os descrevem com precisão e detalhe. No entanto, no caso de escoamentos turbulentos, as equações descrevem todos os detalhes do campo de velocidades (das maiores para as menores escalas de comprimento e de tempo), gerando muitas informações e tornando, na maioria dos casos, a abordagem direta (por meio da solução das equações de Navier-Stokes) impossível. Esta abordagem direta para fluxos turbulentos é chamada de simulação numérica direta (DNS). Embora o DNS seja intratável para os fluxos de interesse prático, ou seja, com alto número de Reynolds, é uma poderosa ferramenta de pesquisa para investigar fluxos turbulentos simples em números de Reynolds moderados.

Para os fluxos de alto número de Reynolds, que são predominantes em aplicações, a alternativa é buscar uma abordagem estatística. Isto é, decrever o escoamento não em termos da velocidade $U(x, t)$, e sim em termos de uma função estatística, por exemplo, da velocidade média $\bar{U}(x, t)$. Um modelo baseado em funções estatísticas pode levar a um conjunto de equações tratáveis, uma vez que os campos estatísticos variam suavemente na posição e no tempo (POPE, 2000). Há muitos conceitos, técnicas e modelos utilizados na representação dos campos do escoamento turbulento, como: os modelos de viscosidade turbulenta (por exemplo, o modelo $k$ - $\varepsilon$ e o modelo $k$ - $\omega$ ); modelos das tensões de Reynolds; modelos baseados na função densidade de probabilidade (PDF) da velocidade; simulações dos grandes turbilhões (Large Eddy Simulation, LES); entre outros.

A simulação dos grandes turbilhões (LES) é uma ferramenta poderosa para a compreensão da complexa interação entre turbulência e reação química, e tem sido utilizada para simular os fenômenos de instabilidade de combustão, tais como a ignição (BOILEAU et al, 2008) e o blowout (KIM et al, 2006 e SMITH et al, 2007). No entanto, estes fenômenos são determinados 
pela química e dinâmica de fluidos reais, e ainda é muito caro, computacionalmente, implementar a turbulência e as reações químicas detalhadas diretamente no LES. Conseqüentemente, o LES não é uma ferramenta prática de projeto para prever os limites de blowout em um combustor real.

Os métodos tradicionais de solução numérica das equações de Navier-Stokes com média de Reynolds (RANS) não são capazes de calcular os fluxos instáveis com precisão. Como resultado, é essencial que projetistas de sistemas de combustão desenvolvam um modelo computacional que incorpore processos físicos complexos através de cálculos de CFD, de modo que se possa superar a diferença entre uma previsão precisa de blowout e capacidades computacionais disponíveis (WANG; JIN, 2011).

Características adicionais de modelos de turbulência (como $k-\varepsilon$ padrão, $k-\varepsilon$ RNG, $k-\varepsilon$ realizável, $k-\omega$, LES, DNS e PDF) podem ser encontradas em Tennekes e Lumley (1973), Pope (2000) e ANSYS (2009).

\section{A.2 Combustão}

Combustão é uma reação química exotérmica entre combustível e comburente (reagentes), que ocorre a elevadas temperaturas e com ritmos intensos. A velocidade com que se desenvolvem as transformações químicas é denominada taxa de reação, e pode ser caracterizada pela variação da concentração de uma das substâncias que participam das reações em função do tempo.

A taxa de reação é função da temperatura e para baixas temperaturas a liberação de energia devido à reação entre os reagentes é igual ou inferior à energia dissipada para o meio, portanto as reações químicas continuam a ocorrer lentamente sem elevação da temperatura. Entretanto, a partir de certo valor da temperatura, denominada temperatura de auto-ignição $\left(T^{*}\right)$, a energia liberada excede a energia dissipada e, conseqüentemente, a temperatura se eleva desencadeando uma variação abrupta da taxa de reação, ocorrendo a combustão.

A distinção entre combustão e uma reação química de oxidação lenta é feita pela observação da taxa de reação e da temperatura atingida pelos produtos da reação. No caso da oxidação lenta, mantendo-se a temperatura com valor inferior a $500 \mathrm{~K}$, a taxa de reação sofre pequenas variações e as reações se processam em períodos de vários minutos; na combustão, dada a 
ignição, ocorre uma variação abrupta da taxa de reação concomitantemente com a elevação da temperatura dos produtos de combustão e as reações se processam em frações de segundos, até exaurir um dos reagentes. A Figura (A.3) ilustra estes dois processos da reação química de um sistema contendo uma mistura de combustível e comburente. (SOUSA, 2010)

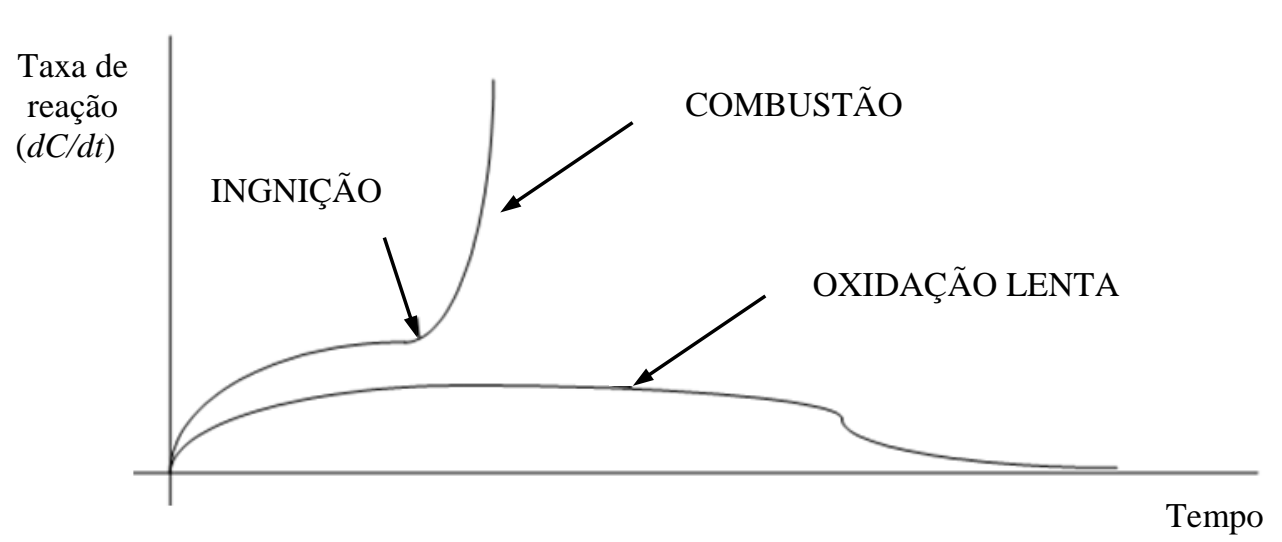

Figura A.3. Variação da taxa de reação em reações de oxidação lenta e rápida (combustão).

A região onde ocorrem as reações químicas é denominada frente de combustão, que se desloca em direção ao meio reagente. Adotado um sistema de referência que se desloca com a frente de combustão, após o estabelecimento do regime permanente, é possível verificar que algumas propriedades termodinâmicas que interferem na combustão variam.

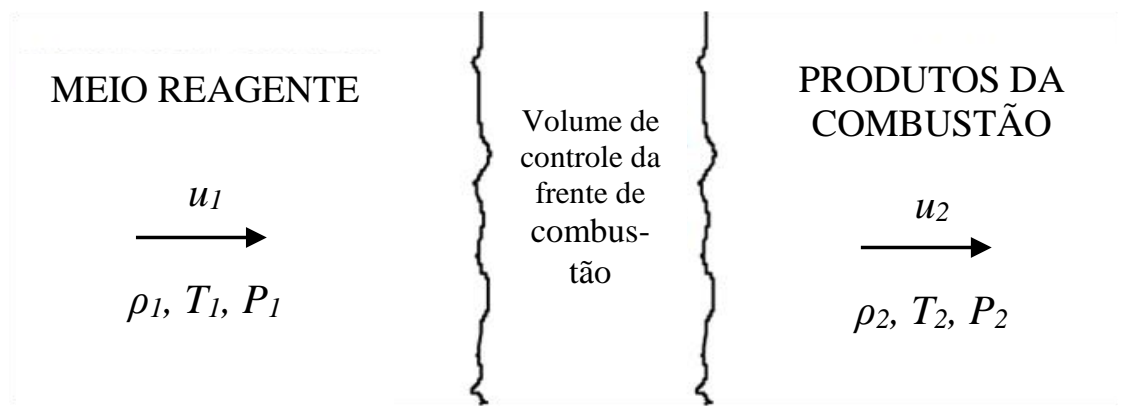

Figura A.4. Esquema de uma frente de combustão em regime permanente. (SOUSA, 2010)

Aplicando a equação da continuidade (Eq. A.3) e da conservação da quantidade de movimento (Eq. A.4) ao volume de controle da Figura (A.4), obtém-se: 


$$
\begin{gathered}
\rho_{1} u_{1}=\rho_{2} u_{2}=n \\
P_{1}+\rho_{1} u_{1}^{2}=P_{2}+\rho_{2} u_{2}^{2}
\end{gathered}
$$

Logo,

$$
\frac{P_{2}-P_{1}}{\frac{1}{\rho_{2}}-\frac{1}{\rho_{1}}}=-n^{2}
$$

Onde $u$ é a velocidade $(\mathrm{m} / \mathrm{s}) ; \rho$ é a massa específica $\left(\mathrm{kg} / \mathrm{m}^{3}\right) ; T$ é a temperatura $(\mathrm{K}) ; P$ é a pressão $\left(\mathrm{Pa}=\mathrm{N} / \mathrm{m}^{2}\right)$.

Analisando a Eq. (A.5), conclui-seque a pressão e a massa específica devem variar no mesmo sentido e, portanto:

1. $P$ e $\rho$ aumentam ao atravessar a frente de combustão, caracterizando o fenômeno de detonação;

2. $P$ e $\rho$ diminuem ao atravessar a frente de combustão, caracterizando o fenômeno de deflagração. $O$ fenômeno de deflagração normalmente é acompanhado da emissão de radiação visível, denominada chama, e é encontrado em aplicações de combustão industrial.

Em resumo, quando a onda de combustão se propaga com velocidades subsônicas $(M a<1)$, é denominada deflagração; quando se propaga com velocidades supersônicas $(M a>1)$, é referenciada como detonação. Os mecanismos fundamentais de propagação da deflagração e da detonação são diferentes e, por isso, estes fenômenos são distintos. Neste trabalho será abordada apenas a deflagração; detalhes e referências sobre detonação podem ser encontrados em Turns (2000).

A mistura de um combustível com o oxigênio (comburente) poderá reagir quimicamente se os produtos resultantes da reação, como $\mathrm{CO}_{2}$ e $\mathrm{H}_{2} \mathrm{O}$, apresentam um arranjo com potencial químico em nível inferior ao da mistura reagente (menor entalpia de formação) e, portanto, uma configuração mais estável. Entretanto, na condição ambiente, $P \cong 1 \mathrm{kgf} / \mathrm{cm}^{2}$ e $T \cong 300 \mathrm{~K}$, quase todas as misturas de combustível gasoso e comburente não reagem espontaneamente. Nestes casos, a ignição pode ser induzida por:

1. aquecimento dos reagentes até ocorrer a auto-ignição, ou seja, até a temperatura $T^{*}$; ou 
2. ignição forçada, caracterizada pela excitação de um ponto singular da mistura reagentes, por meio de uma fonte, enquanto o restante da mistura permanece numa temperatura inferior à da auto-ignição. A fonte pode ser uma faísca elétrica, um corpo incandescente ou uma chama externa "piloto".

Fisicamente, o processo de ignição forçada não difere da auto-ignição, entretanto na ignição forçada o processo da combustão é completado pela propagação da chama (deflagração) do local da ignição para o restante da mistura. As ignições forçadas propiciam inicialmente um aquecimento da mistura reagente na vizinhança da fonte. Elevando a taxa de reação, conseqüentemente eleva-se a temperatura e desencadeia-se a combustão na vizinhança da fonte, com a formação de uma frente de chama, que, em seguida se propaga em direção ao meio reagente, através do mecanismo de propagação da chama, envolvendo basicamente os fenômenos de transferência de calor e massa.

\section{A.3 Jatos}

Segundo Stambuleanu (1976), jato é o escoamento de um fluido (gás ejetor) descarregado por um bocal num meio gasoso. O gás ejetor arrasta os gases da vizinhança para o interior do jato e se expande geralmente em forma de cone. Logo, o jato é composto pela mistura de gás ejetor e gás arrastado. A Figura (A.5) ilustra um jato genérico, na qual é possível verificar a presença de três regiões distintas:

1. Região inicial, caracterizada pela existência de duas zonas, uma contendo somente o gás ejetor (I) descarregado pelo bocal, e outra em que há a formação da mistura dos gases (II);

2. Região de transição, na qual ocorre mudança do formato dos perfis da concentração e velocidade; e

3. Região principal (jato estabelecido), na qual os formatos dos perfis da concentração e da velocidade são semelhantes para qualquer seção transversal do jato. 


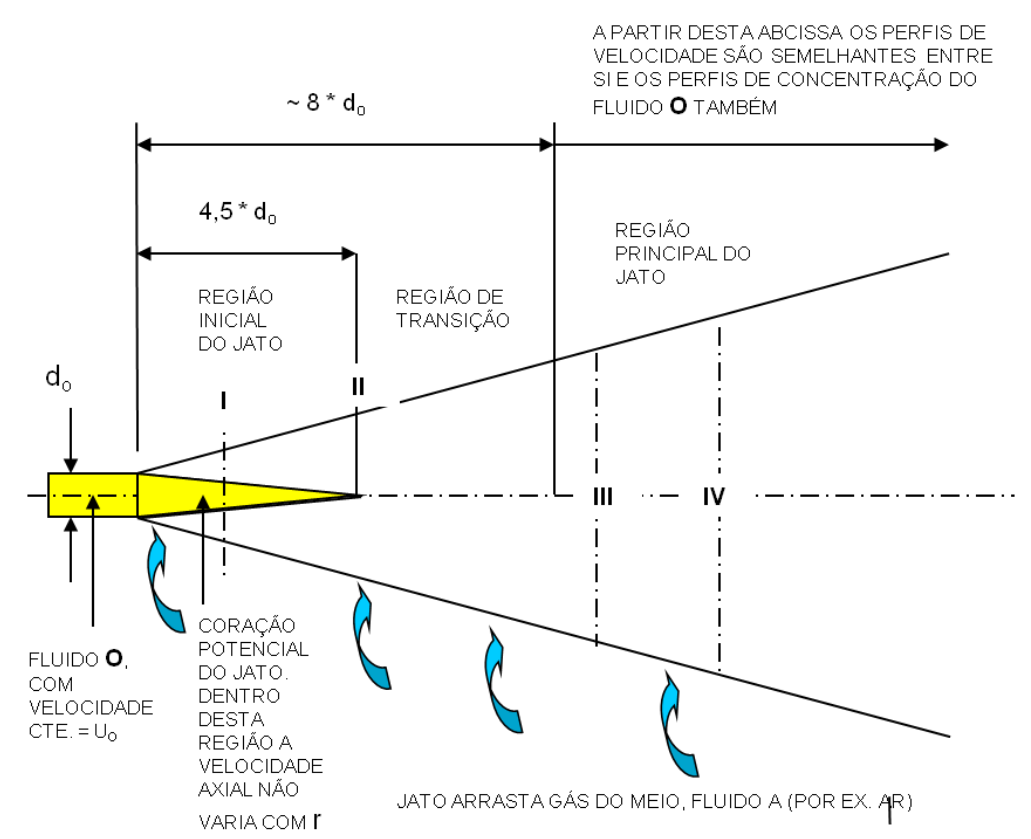

Figura A.5. Zonas de um jato livre genérico. (SOUSA, 2010)

Os jatos podem ser classificados como:

1. livres ou confinados. Os jatos livres não são influenciados pela parede e há gases na vizinhança em abundância em qualquer zona para se incorporar ao jato. Os jatos confinados são influenciados pelas paredes, e podem propiciar recirculação dos gases do jato quando há insuficiência de gases da vizinhança a serem arrastados. A recirculação dos gases da combustão aquece a mistura reagente, levando-a para a temperatura de ignição. Portanto a recirculação é um dos mecanismos para estabilizar a chama em jatos. Uma descrição detalhada a respeito destes tipos de jatos (confinados) pode ser encontrada em Arima (2009).

2. sem ou com rotação. Um jato genérico pode ter três componentes de velocidade, $U_{x}$, $U_{r}$ e $U_{\theta}$, respectivamente nas direções axial, radial e tangencial. Jatos sem rotação apresentam a velocidade tangencial, $U_{\theta}$, nula. Se $U_{\theta} \neq 0$, diz-se que o jato possui um índice de rotação (índice de $s w i r l$ ), $S$, definido como a relação entre a componente axial do momento da quantidade de movimento tangencial, $J_{\theta}$, e da quantidade de movimento axial, $J_{x}$, multiplicada por uma dimensão característica no bocal de descarga, $r_{n}$ (STAMBULEANU, 1976). 


$$
S=\frac{J_{\theta}}{J_{x} r_{n}}
$$

onde

$$
\begin{gathered}
J_{\theta}=2 \pi \int_{0}^{r_{n}} \rho\left(U_{x} U_{\theta}\right) r^{2} d r \\
J_{x}=2 \pi \int_{0}^{r_{n}} \rho U_{x}^{2} r d r+2 \pi \int_{0}^{r_{n}} p r d r
\end{gathered}
$$

Segundo Sousa (2010), um jato com elevado valor de $S$ reduz consideravelmente a extensão das zonas potencial e de transição, pois nestas regiões, as velocidades axiais próximas ao eixo do jato são negativas, ou seja, o escoamento ocorre no sentido do bocal. Quanto maior for o índice de swirl, maior será a extensão da região onde isto ocorre. A abertura e a taxa de arraste de um jato livre com rotação são maiores que as de um jato axial. Em resumo, o swirl é usado por duas razões: (1) estabiliza a chama pela formação de uma zona de recirculação, se o número de swirl é suficientemente grande; e (2) controla o comprimento da chama, dependendo do número de swirl, $S$.

A forma do jato depende da geometria do bocal. As geometrias mais utilizadas são:

1. singular de área transversal simples (por exemplo, circular ou retangular), como ilustrado na Figura (A.6); e

2. coaxial, no qual ocorre a descarga de dois fluidos em um escoamento anular concêntrico.

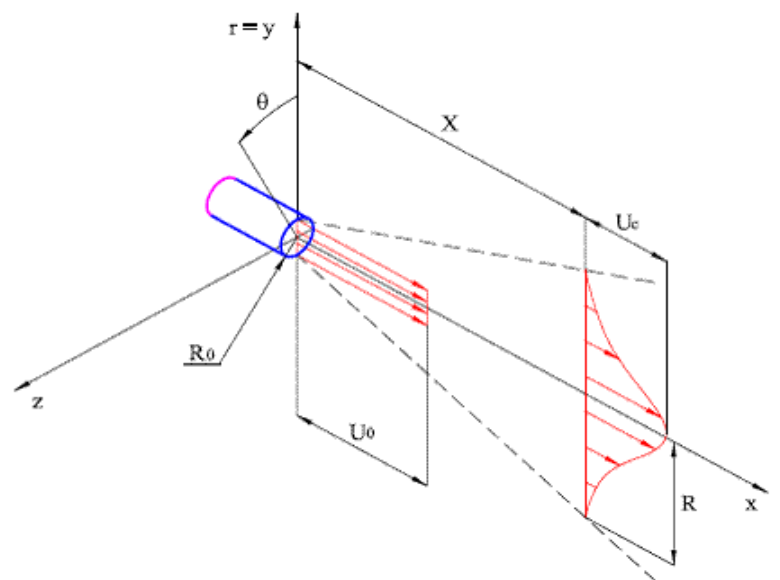

Figura A.6. Esquema de jato emergindo de um bocal singular de área transversal circular. (SOUSA, 2010) 


\section{A.4 Chamas}

A chama é uma propagação auto-sustentável de uma combustão localizada.

O comportamento da chama, tal como, sua estabilidade, forma e comprimento, depende do regime de escoamento dos reagentes e da velocidade de propagação de chama (SOUSA, 2010). A chama pode ser classificada como: pré-misturada ou de difusão (ou não pré-misturada); laminar ou turbulenta.

As chamas pré-misturadas são obtidas em queimadores que promovem a mistura dos reagentes, com teor de combustível dentro dos limites de flamabilidade, antes que sejam lançados na câmara de combustão.

As chamas de difusão (ou não pré-misturadas) são obtidas ao se realizar descargas de gás combustível e do comburente separadamente na região onde ocorre a combustão. Se as velocidades do gás e do comburente forem baixas (baixo número de Reynolds) a mistura entre o gás, o comburente e os produtos da combustão ocorrerá basicamente por difusão, estabelecendo-se, portanto uma chama de difusão laminar. Entretanto se pelo menos uma das velocidades for alta (elevado número de Reynolds) a mistura ocorrerá devido ao transporte macroscópico de massa, caracterizando um escoamento turbulento, formando então uma chama de difusão turbulenta. (SOUSA, 2010).

Nas chamas de difusão o ritmo global da reação e, conseqüentemente, o comprimento da chama acoplada a determinado bocal, são controlados basicamente pela mistura dos fluxos de gás combustível e ar. Assim, para um determinado bocal, o comprimento da chama não pode aumentar indefinidamente na medida em que se aumenta a vazão ou potência de operação, uma vez que com o aumento do número de Reynolds no bocal há o aparecimento da turbulência que aumenta acentuadamente o ritmo de mistura entre os reagentes. Detalhes da forma e comprimento destas chamas podem ser encontrados em Hottel; Sarofim (1967) e Stambuleanu (1976). 


\section{A.5 Limites de flamabilidade do combustível}

Limites de flamabilidade do combustível são valores extremos do teor de combustível na mistura, com os quais ocorre a propagação da chama. O limite inferior $(L I)$ caracteriza o mínimo teor de combustível necessário na mistura para que ocorra a propagação da chama, e o limite superior $(L S)$ é o máximo teor em que ainda ocorre a propagação da chama. Estes limites dependem da natureza do comburente, do estado da mistura reagente, pressão e temperatura, além das condições de contorno e do escoamento. É importante não confundir o conceito de flamabilidade com o de ignição; a ignição caracteriza o desencadeamento espontâneo das reações de combustão, enquanto a flamabilidade caracteriza a condição para a propagação da chama em uma mistura reagente que está num estado afastado da temperatura de ignição. (SOUSA, 2010). O cálculo dos limites de flamabilidade de uma mistura de gases combustíveis $\left(L I_{m}\right.$ ou $\left.L S_{m}\right)$ pode ser realizado por meio da Eq. (A.9) de Le Chatelier. A mistura de combustíveis não deve conter oxigênio, caso o oxigênio esteja presente, deve-se recalcular os teores dos constituintes isentos de oxigênio. Caso haja a presença de inertes, sugere-se a leitura de Lewis; Von Elbe (1961) e American Gas Association (1974), que apresentam detalhes sobre a influência destes componentes nos limites de flamabilidade da mistura e métodos analíticos de como obtê-los.

$$
L I_{m}=\frac{100}{\sum_{i}^{n} \frac{X_{i}}{L I_{i}}}=\frac{100}{\frac{X_{a}}{L I_{a}}+\frac{X_{b}}{L I_{b}}+\frac{X_{c}}{L I_{c}}+\cdots}
$$

Onde $X_{i}$ e $L I_{i}$ são a fração molar (em porcentagem) e o limite inferior do gás combustível $i$ na mistura de $n$ gases combustíveis, respectivamente. Para obter o limite superior da mistura $\left(L S_{m}\right)$, basta substituir $L I_{i}$ por $L S_{i}$ na Eq. (A.9)

\section{A.6 Velocidade de chama laminar}

A velocidade com a qual a onda de combustão se propaga é denominada velocidade de chama laminar, $S_{L}$. Esta velocidade pode ser determinada experimentalmente, e/ou calculada por meio de expressões empíricas. Existem diversos métodos para determinação da velocidade da chama. Segundo Sousa (2010), os mais utilizados são: 
1. método da propagação da chama no interior de dutos, que consiste na determinação direta da velocidade de deslocamento da frente de chama na mistura em repouso estático no interior de dutos; e

2. método do queimador tipo Bunsen, baseado nas medições realizadas no cone ou pirâmide de chama que se forma nestes queimadores.

Detalhes sobre estes e outros métodos para determinação de velocidade de chamas podem ser encontrados em Khitrim (1975), Lewis e Von Elbe (1961) e American Gas Association (1974).

A velocidade de chama laminar é influenciada, principalmente, pelos seguintes fatores:

1. temperatura dos gases não queimados $T_{u}$;

Segundo Turns (2000),

$$
S_{L} \propto T_{u} T_{b}^{-n / 2} \exp \left(-\frac{E_{A}}{2 R_{u} T_{b}}\right) P^{(n-2) / 2}
$$

onde $n$ é o grau da reação; e $E_{A}$ é a energia de ativação.

Andrews e Bradley (1972) sugerem, para chamas de metano-ar na proporção estequiométrica, que

$$
S_{L}(\mathrm{~cm} / \mathrm{s})=10+3,71 \cdot 10^{-4}\left[T_{u}(K)\right]^{2}
$$

Logo, um aumento de $T_{u}$ de $300 \mathrm{~K}$ para $600 \mathrm{~K}$, pode elevar $S_{L}$ de um fator de 3,3.

\section{2. pressão;}

Da eq. (A.10), $S_{L} \propto P^{(n-2) / 2}$. Andrews e Bradley (1972) sugerem, para chamas de metano-ar e $P>5$ atm, que:

$$
S_{L}(\mathrm{~cm} / \mathrm{s})=43 \cdot[P(\mathrm{~atm})]^{-0,5}
$$

3. razão de equivalência, $\phi$, definida como:

$$
\phi=\frac{\left(m_{a} / m_{f}\right)_{s}}{\left(m_{a} / m_{f}\right)}=\frac{\left(m_{f} / m_{a}\right)}{\left(m_{f} / m_{a}\right)_{s}}=\frac{\varphi_{s}}{\varphi}
$$


onde $m_{a}$ e $m_{f}$ referem-se as massas de ar e de combustível, respectivamente; e o subscrito s refere-se a condição estequiométrica.

A relação $\left(m_{a} / m_{f}\right)_{s}$ é obtida da reação de combustão estequiométrica, que, para hidrocarbonetos, é dada por:

$$
C_{x} H_{y}+a\left(O_{2}+3,76 N_{2}\right) \rightarrow x C O_{2}+(y / 2) H_{2} O+3,76 a N_{2}
$$

onde $a=x+y / 4$. Na Eq. (A.14) assumiu-se que o ar é composto por $21 \%$ de $\mathrm{O}_{2}$ e $79 \%$ de $\mathrm{N}_{2}$ (em volume). Portanto,

$$
\left(m_{a} / m_{f}\right)_{s}=4,76 a \frac{M M_{a}}{M M_{f}}
$$

onde $M M_{a}$ e $M M_{f}$ referem-se as massas moleculares de ar e de combustível, respectivamente. Quanto mais rica é a mistura, ou seja, $\phi>1$, maior é $S_{L}$.

\section{4. tipo de combustível.}

A Tabela (A.6.1) apresenta valores de $S_{L}$ obtidos experimentalmente por Law (1993) apud Turns (2000) para alguns combustíveis, na condição estequiométrica $(\phi=1)$ e pressão de 1 atm.

Tabela A.1. Velocidades de chama laminar, $S_{L}$, de alguns combustíveis gasosos.

(LAW, 1993 apud TURNS, 2000)

\begin{tabular}{lcc}
\hline \hline Combustível & Fórmula molecular & $\boldsymbol{S}_{\boldsymbol{L}}[\mathrm{m} / \mathrm{s}]$ \\
\hline Metano & $\mathrm{CH}_{4}$ & 0,40 \\
Acetileno & $\mathrm{C}_{2} \mathrm{H}_{2}$ & 1,36 \\
Etileno & $\mathrm{C}_{2} \mathrm{H}_{4}$ & 0,67 \\
Etano & $\mathrm{C}_{2} \mathrm{H}_{6}$ & 0,43 \\
Propano & $\mathrm{C}_{3} \mathrm{H}_{8}$ & 0,44 \\
Hidrogênio & $\mathrm{H}_{2}$ & 2,10 \\
Monóxido de carbono & $\mathrm{CO}$ & $0,22^{(*)}$ \\
BFG (gás de alto forno) & - & $0,08^{(*)}$ \\
\hline \hline
\end{tabular}

(*) Cálculo feito pela equipe de combustão do IPT (SOUSA, 2010). 
Turns (2000) apresenta a seguinte expressão analítica para determinar a velocidade de chama laminar:

$$
S_{L}=\left[-2 \alpha\left(\varphi_{s}+1\right) \frac{\dot{m}_{f}^{\prime \prime \prime}}{\rho_{u}}\right]^{1 / 2}
$$

onde $\varphi_{s}$ é a razão mássica oxidante/combustível estequiométrica $\left(m_{a} / m_{f}\right)_{s} ; \dot{m}_{f}^{\prime \prime \prime}$ é a taxa mássica de consumo de combustível por unidade de volume $\left(\mathrm{kg} / \mathrm{s} \cdot \mathrm{m}^{3}\right)$; e $\rho_{u}$ é a densidade dos gases não queimados $\left(\mathrm{kg} / \mathrm{m}^{3}\right) \rho_{u} \approx \rho_{\infty} ;$ e $\alpha$ é a difusividade térmica $\left(\mathrm{m}^{2} / \mathrm{s}\right)$ calculada da seguinte forma:

$$
\alpha=\frac{k(\bar{T})}{\rho_{u} c_{p}(\bar{T})}
$$

onde $k$ é a condutividade térmica e $\bar{T}$ é a temperatura obtida pela média aritmética entre a temperatura dos gases não queimados $\left(T_{u}\right)$ e a temperatura dos gases queimados $\left(T_{b}\right)$, ou seja, $\bar{T}=\frac{1}{2}\left(T_{u}+T_{b}\right)$. Turns (2000) sugere que se use $k, \rho_{u}$ e $c_{p}$ do ar, $T_{b}$ igual a temperatura adiabática dos gases e $T_{u}$ igual a temperatura ambiente.

Para chegar na Eq. (A.16), Turns (2000) parte das equações de conservação de massa, espécies e energia, para um volume de controle diferencial, e assume:

1. escoamento em regime permanente, unidimensional e área transversal constante;

2. energias cinética e potencial, trabalho das tensões viscosas e radiação térmica são negligenciáveis;

3. pressão constante (diferença de pressão através da chama é muito pequena);

4. difusão de massa binária governada pela Lei de Fick;

5. difusão de calor governada pela Lei de Fourier;

6. número de Lewis, $L e$, que expressa a razão entre difusividades térmica e mássica, igual à unidade;

$$
L e \equiv \frac{\alpha}{\mathcal{D}}=\frac{k}{\rho c_{p} \mathcal{D}}=1 \Rightarrow \frac{k}{c_{p}}=\rho \mathcal{D}
$$

7. o calor específico da mistura independe da temperatura e da composição; 
8. combustível e oxidante formam os produtos por meio de uma reação exotérmica;

9. o oxidante está presente na proporção estequiométrica ou em excesso; isto é, todo o combustível é completamente consumido na chama.

Logo, a expressão (A.16) tem muitas restrições e deve ser usada com cautela, principalmente, devido ao item (2) acima, que despreza a transferência de calor por radiação.

Métodos para o cálculo de $S_{L}$ de misturas podem ser encontrados no trabalho de Spalding (1956) e de Yumlu (1968). 


\section{APÊNDICE B - Análise dos dados experimentais}

Neste Apêndice são apresentados os dados experimentais relatados por Kalghatgi (1981), Broadwell; Dam e Mungal (1984) e Pitts (1989). Todos estes autores fornecem os dados em gráficos e para obtê-los utilizou-se o aplicativo Plot Digitizer ${ }^{9}$, como mencionado na Subseção (3.1).

Kalghatgi (1981) fornece seus resultados experimentais em função do número de Mach $\left(M a_{b}\right)$ na saída do bocal (na condição de blowout da chama). Para obter $U_{b, \exp }$ a partir de $M a_{b}$ utilizouse a metodologia e as hipóteses descritas nas Subseções (3.1) e (3.4), respectivamente. Em resumo, adotou-se a seguinte equação:

$$
U_{b, \exp }=M a_{b} \cdot \sqrt{\gamma_{f} R_{f} T_{0}} \cdot\left[1+\frac{\left(\gamma_{f}-1\right)}{2} M a_{b}^{2}\right]^{-1 / 2}
$$

Na qual, $M a_{b}$ é o número Mach digitalizado do trabalho de Kalghatgi (1981); $\gamma_{f}$ é a razão de calores específicos do gás dado por $\gamma_{f}=\left(c_{p} / c_{v}\right) ; R_{f}$ é a constante do gás; e $T_{0}$ é a temperatura de estagnação $\left(T_{o}=290 \mathrm{~K}\right)$.

Broadwell; Dam e Mungal (1984) e Pitts (1989) apresentam diretamente os valores de $U_{b, \exp }$ e afirmam ter extraído estas informações do trabalho de Kalghatgi (1981). Eles não informam como obtiveram $U_{b, \text { exp }}$ a partir de $M a_{b}$ de Kalghatgi (1981), ou seja, o equacionamento utilizado e as hipóteses adotadas.

O erro associado ao processo de digitalização foi estimado com base na incerteza da leitura dos valores lançados nos gráficos (ou seja, no tamanho do ponto utilizado pelos autores para indicar os resultados experimentais em seus gráficos). Assim, adotou-se:

1. para o trabalho de Kalghatgi (1981), $\pm 0,015$ em $M a_{b}$, que resulta em uma incerteza $\xi_{\text {exp }}$ nos valores de $U_{b, \exp }$ variável para cada combustível e diâmetro de bocal; e

\footnotetext{
${ }^{9}$ http://plotdigitizer.sourceforge.net/
} 
2. para o trabalho de Broadwell; Dam e Mungal (1984) e Pitts (1989), $\xi_{\text {exp }}= \pm 5,00 \mathrm{~m} / \mathrm{s}$ em $U_{b, \exp }$.

As Tabelas (B.1), (B.2), (B.3), (B.4), (B.5) e (B.6) apresentam as velocidades de blowout, $U_{b, \text { exp }}$, dos gases metano, propano, etileno, acetileno, hidrogênio e butano comercial, respectivamente; extraídas dos trabalhos de Kalghatgi (1981), Broadwell; Dam e Mungal (1984) e Pitts (1989). Estas tabelas também apresentam os valores de $\xi_{\text {exp }}$ em módulo (erro associado ao processo de digitalização de $\left.U_{b, \exp }\right)$.

Tabela B.1. Valores de $U_{b, \exp }$ experimentais relatados por Kalghatgi (1981), Broadwell; Dam e Mungal (1984) e Pitts (1989) para o gás metano.

\begin{tabular}{c|cc|c|c}
\hline \hline & \multicolumn{2}{|c|}{ Kalghatgi (1981) } & $\begin{array}{c}\text { Broadwell et al } \\
\mathbf{( 1 9 8 4 )}\end{array}$ & Pitts (1989) \\
$d_{n}[\mathrm{~mm}]$ & $U_{b, \exp }[\mathrm{m} / \mathrm{s}]$ & $\left|\xi_{\exp }\right|[\mathrm{m} / \mathrm{s}]$ & $U_{b, \exp [\mathrm{m} / \mathrm{s}]^{(*)}}$ & $U_{b, \exp [\mathrm{m} / \mathrm{s}]^{(*)}}$ \\
\hline 2,00 & 51,09 & 6,7 & 49,47 & 48,69 \\
3,00 & 58,79 & 6,6 & 59,73 & 60,16 \\
4,00 & 72,56 & 6,6 & 75,24 & 75,50 \\
5,00 & 89,33 & 6,6 & 90,76 & 93,21 \\
6,00 & 113,05 & 6,6 & 114,19 & 111,70 \\
8,00 & 141,21 & 6,5 & 145,24 & 140,82 \\
10,00 & 174,03 & 6,4 & - & 170,82 \\
12,00 & 217,01 & 6,3 & - & 214,07 \\
\hline \hline
\end{tabular}

$$
{ }^{(*)} \xi_{\exp }= \pm 5,00 \mathrm{~m} / \mathrm{s}
$$

Tabela B.2. Valores de $U_{b}$ experimentais relatados por Kalghatgi (1981), Broadwell; Dam e Mungal (1984) e Pitts (1989) para o gás propano.

\begin{tabular}{c|cc|c|c}
\hline \hline & \multicolumn{2}{|c|}{ Kalghatgi (1981) } & $\begin{array}{c}\text { Broadwell et al } \\
\mathbf{( 1 9 8 4 )}\end{array}$ & Pitts (1989) \\
$d_{n}[\mathrm{~mm}]$ & $U_{b, \exp }[\mathrm{m} / \mathrm{s}]$ & $\left|\xi_{\exp }\right|[\mathrm{m} / \mathrm{s}]$ & $U_{b, \exp [\mathrm{m} / \mathrm{s}]^{(*)}}$ & $U_{b, \exp }[\mathrm{m} / \mathrm{s}]^{(*)}$ \\
\hline 1,00 & 28,87 & 3,7 & 36,31 & 30,94 \\
2,00 & 68,43 & 3,7 & 64,73 & 68,23 \\
3,00 & 99,24 & 3,7 & 95,78 & 100,01 \\
4,00 & - & - & 110,99 & 114,55 \\
5,00 & 149,97 & 3,6 & 142,03 & 150,26 \\
6,00 & 181,42 & 3,5 & 175,72 & 181,24 \\
8,00 & 211,55 & 3,5 & 206,27 & 215,03 \\
\hline \hline
\end{tabular}

$$
{ }^{(*)} \xi_{\text {exp }}= \pm 5,00 \mathrm{~m} / \mathrm{s}
$$


Tabela B.3. Valores de $U_{b}$ experimentais relatados por Kalghatgi (1981), Broadwell; Dam e Mungal (1984) e Pitts (1989) para o gás etileno.

\begin{tabular}{c|cc|c|c}
\hline \hline & \multicolumn{2}{|c|}{ Kalghatgi (1981) } & $\begin{array}{c}\text { Broadwell et al } \\
\mathbf{( 1 9 8 4 )}\end{array}$ & Pitts (1989) \\
$d_{n}[\mathrm{~mm}]$ & $U_{b, \exp }[\mathrm{m} / \mathrm{s}]$ & $\left|\xi_{\exp }\right|[\mathrm{m} / \mathrm{s}]$ & $U_{b, \exp [\mathrm{m} / \mathrm{s}]^{(*)}}$ & $U_{b, \exp [\mathrm{m} / \mathrm{s}]^{(*)}}$ \\
\hline 1,00 & 79,32 & 4,9 & 84 & 79,41 \\
2,00 & 121,22 & 4,8 & 130 & 122,12 \\
3,00 & 150,11 & 4,7 & 154 & 160,17 \\
4,00 & 233,63 & 4,5 & 237 & 234,90 \\
5,00 & 294,92 & 4,2 & 303 & 299,49 \\
\hline \hline
\end{tabular}

$$
{ }^{(*)} \xi_{\exp }= \pm 5,00 \mathrm{~m} / \mathrm{s}
$$

Tabela B.4. . Valores de $U_{b}$ experimentais relatados por Kalghatgi (1981), Broadwell; Dam e Mungal (1984) e Pitts (1989) para o gás acetileno.

\begin{tabular}{c|cc|c|c}
\hline \hline & \multicolumn{2}{|c|}{ Kalghatgi (1981) } & $\begin{array}{c}\text { Broadwell et al } \\
\mathbf{( 1 9 8 4 )}\end{array}$ & Pitts (1989) \\
$d_{n}[\mathrm{~mm}]$ & $U_{b, \exp }[\mathrm{m} / \mathrm{s}]$ & $\left|\xi_{\exp }\right|[\mathrm{m} / \mathrm{s}]$ & $U_{b, \exp [\mathrm{m} / \mathrm{s}]^{(*)}}$ & $U_{b, \exp }[\mathrm{m} / \mathrm{s}]^{(*)}$ \\
\hline 0,20 & 87,81 & 5,1 & 97,54 & 116,35 \\
0,40 & 162,30 & 4,9 & 171,31 & 164,73 \\
0,60 & 191,15 & 4,8 & 202,83 & 191,20 \\
0,80 & 224,54 & 4,7 & 239,67 & 231,04 \\
1,00 & 289,43 & 4,4 & 297,62 & 298,18 \\
\hline \hline
\end{tabular}

$$
{ }^{(*)} \xi_{\text {exp }}= \pm 5,00 \mathrm{~m} / \mathrm{s}
$$

Tabela B.5. Valores de $U_{b}$ experimentais relatados por Kalghatgi (1981), Broadwell; Dam e Mungal (1984) e Pitts (1989) para o gás hidrogênio.

\begin{tabular}{c|cc|c}
\hline \hline & \multicolumn{2}{|c|}{ Kalghatgi (1981) } & Broadwell et al (1984) \\
$d_{n}[\mathrm{~mm}]$ & $U_{b, \exp }[\mathrm{m} / \mathrm{s}]$ & $\left|\xi_{\exp }\right|[\mathrm{m} / \mathrm{s}]$ & $U_{b, \exp }[\mathrm{m} / \mathrm{s}]^{(*)}$ \\
\hline 0,6 & 993,37 & 16,2 & 1002,33 \\
0,8 & 1221,19 & 14,6 & - \\
\hline \hline
\end{tabular}

$$
{ }^{(*)} \xi_{\exp }= \pm 5,00 \mathrm{~m} / \mathrm{s}
$$


Tabela B.6. Valores de $U_{b}$ experimentais relatados por Kalghatgi (1981), Broadwell; Dam e Mungal (1984) e Pitts (1989) para o gás butano comercial.

\begin{tabular}{c|cc|c|c}
\hline \hline & \multicolumn{2}{|c|}{ Kalghatgi (1981) } & $\begin{array}{c}\text { Broadwell et al } \\
\mathbf{( 1 9 8 4 )}\end{array}$ & Pitts (1989) \\
$d_{n}[\mathrm{~mm}]$ & $U_{b, \exp }[\mathrm{m} / \mathrm{s}]$ & $\left|\xi_{\text {exp }}\right|[\mathrm{m} / \mathrm{s}]$ & $U_{b, \exp }[\mathrm{m} / \mathrm{s}]^{(*)}$ & $U_{b, \exp }[\mathrm{m} / \mathrm{s}]^{(*)}$ \\
\hline 1,00 & 36,34 & 3,4 & 41,71 & 34,87 \\
2,00 & 72,16 & 3,4 & 75,47 & 65,88 \\
3,00 & 85,34 & 3,4 & 90,75 & 82,04 \\
4,00 & 109,32 & 3,4 & 108,71 & 107,54 \\
\hline \hline
\end{tabular}

$$
{ }^{(*)} \xi_{\text {exp }}= \pm 5,00 \mathrm{~m} / \mathrm{s}
$$

A partir dos dados de $U_{b, \exp }$ e $\xi_{\text {exp }}$ apresentados nas tabelas acima, verificou-se que os valores de $U_{b, \exp }$ (considerando a incerteza de $\pm 5,00 \mathrm{~m} / \mathrm{s}$ em $U_{b, \exp }$ ) digitalizados do trabalho de por Broadwell; Dam e Mungal (1984) e de Pitts (1989) encontram-se dentro da faixa delimitada pelos valores calculados de $U_{b, \exp } \pm \xi_{\text {exp }}$ do trabalho de Kalghatgi (1981), para todos os gases combustíveis e diâmetros de bocais. Logo, conclui-se que a metodologia utilizada para obter $U_{b, \exp }$ a partir de $M a_{b}$ é válida; e, portanto, os valores de $U_{b, \exp }$ adotados como referência, no presente trabalho, são os obtidos a partir dos experimentos realizados por Kalghatgi (1981) e da metodologia apresentada na Subseção (3.1).

A diferença entre os valores experimentais da velocidade de blowout apresentados nas tabelas acima, podem estar relacionados às hipóteses assumidas para obter $U_{b, \exp }$ apartir de $M a_{b}$ e aos erros $\xi_{\text {exp }}$ associados ao processo de digitalização. 


\section{APÊNDICE C - Análise do trabalho de Kalghatgi (1981)}

Este Apêndice apresenta uma análise das previsões da velocidade de blowout, $U_{b}$, obtidas a partir da seguinte correlação proposta por Kalghatgi (1981):

$$
U_{b}=\left[0,017 \cdot R e_{H_{S}} \cdot\left(1-3,5 \cdot 10^{-6} \cdot R e_{H_{S}}\right)\right] \cdot S_{L} \cdot\left(\frac{\rho_{f, n}}{\rho_{\infty}}\right)^{-3 / 2}
$$

onde $R e_{H_{S}}$ é o número de Reynolds baseado na posição $H_{S}$; e $H_{S}$ é distância ao longo do eixo do jato onde a concentração de combustível cai para a estequiométrica; ou seja,

$$
\begin{gathered}
\operatorname{Re}_{H_{S}}=\frac{H_{S} S_{L}}{v_{f, n}} \\
H_{s}=\left[4 \cdot \frac{Y_{f, n}}{Y_{f, s}}\left(\frac{\rho_{f, n}}{\rho_{\infty}}\right)^{1 / 2}+5,8\right] \cdot d_{n}
\end{gathered}
$$

A metodologia utilizada para esta análise está descrita na Subseção (3.2), Item (3.2.1). Em resumo, as previsões da correlação proposta por Kalghatgi (1981), Eq. (C.1), foram analisadas para dois casos:

1. o primeiro, denominado como Caso 1, admite que a densidade do gás na saída do bocal, $\rho_{f, n}$, é função do número de Mach, $M a_{b}$, e da relação de calores específicos $\gamma_{f}$ do gás, ou seja,

$$
\rho_{f, n}=\frac{P_{\infty}}{R_{f} T_{f, n}}=\frac{P_{\infty}}{R_{f} T_{0}} \cdot\left[1+\frac{\left(\gamma_{f}-1\right)}{2} M a_{b}^{2}\right]
$$

2. o segundo, Caso 2, assume que a densidade do gás na saída do bocal é constante e pode ser avaliada nas condições ambientes, isto é,

$$
\rho_{f, n}=\frac{P_{\infty}}{R_{f} T_{\infty}}
$$

Para ambos os Casos, adotaram-se as hipóteses descritas na Subseção (3.4). As previsões de $U_{b}$ são comparadas com dados experimentais de Kalghatgi (1981), denominados como $U_{b, \text { exp }}$, os quais foram adotados como referência no presente trabalho (vide Subseção 3.1). Os resultados 
desta análise estão apresentados a seguir, para os gases estudados por Kalghatgi (1981), ou seja, metano, propano, etileno, acetileno, hidrogênio e butano comercial.

Para facilitar a comparação entre o valor de $U_{b, \exp }$ obtido por meio dos dados experimentais (a partir de $M a_{b}$ digitalizado) e $U_{b}$ previsto pela correlação proposta por Kalghatgi (1981), para ambos os Casos (1 e 2), foram introduzidos quatro parâmetros:

1. $\left|\xi_{i-\exp }\right|$, que representa o módulo da diferença entre os valores de $U_{b, \exp }$ e $U_{b}$ segundo o Caso $i$ (1 ou 2), ou seja,

$$
\left|\xi_{i-\exp }\right|=\left|U_{b, \exp }-U_{b, i}\right|
$$

2. $\Delta_{i-\exp }$, que representa o desvio de $U_{b}$ previsto segundo o Caso $i$ (1 ou 2), com relação à $U_{b, \text { exp }}$, para determinado gás e diâmetro de bocal;

$$
\Delta_{i-\exp }(\%)=\frac{U_{b, \exp }-U_{b, i}}{U_{b, \exp }} \cdot 100=\frac{\xi_{i-\exp }}{U_{b, \exp }} \cdot 100
$$

3. $\left|\xi_{1-2}\right|$, que representa o módulo da diferença entre o valor de $U_{b}$ obtido segundo o Caso 1 e o valor de $U_{b}$ obtido segundo o Caso 2 , ou seja,

$$
\left|\xi_{1-2}\right|=\left|U_{b, 2}-U_{b, 1}\right|
$$

4. $\Delta_{2-1}$, que representa a variação da previsão do Caso 2 ( $\rho$ constante) com relação ao Caso 1 ( $\rho$ variável), para determinado gás e diâmetro de bocal.

$$
\Delta_{2-1}(\%)=\frac{U_{b, 1}-U_{b, 2}}{U_{b, 1}} \cdot 100=\frac{\xi_{1-2}}{U_{b, 1}} \cdot 100
$$

Para avaliar a influência da incerteza de $\pm 0,015$ em $M a_{b}$ (devido ao processo de digitalização dos dados experimentais) nos valores de $U_{b, \exp }$ e $U_{b}$ obtidos segundo o Caso 1 (no qual $\rho_{f, n}$ é função de $M a_{b}$ ), utilizou-se os seguintes parâmetros:

1. $\xi_{\text {exp }}$, que representa a diferença entre o valor de $U_{b, e x p}$ obtido a partir de $M a_{b}$ digitalizado e $U_{b, \exp }^{*}$ obtido a partir de $M a_{b} \pm 0,015$, ambos calculados por meio da Eq. (3.4);

$$
\xi_{\exp }=U_{b, \exp }-U_{b, \exp }^{*}
$$


2. $\Delta_{\text {exp }}$, que representa a variação entre o valor de $U_{b, \exp }$ obtido a partir de $M a_{b}$ digitalizado e $U_{b, \exp }^{*}$ obtido a partir de $M a_{b} \pm 0,015$, com relação ao primeiro, ambos calculados por meio da Eq. (3.4);

$$
\Delta_{\exp }(\%)=\frac{U_{b, \exp }-U_{b, \exp }^{*}}{U_{b, \exp }} \cdot 100=\frac{\xi_{\exp }}{U_{b, \exp }} \cdot 100
$$

3. $\xi_{1-1 *}$, que representa a diferença entre o valor de $U_{b}$ previsto com $M a_{b}$ digitalizado e $U_{b}^{*}$ previsto com $M a_{b} \pm 0,015$, ambos calculados por meio da Eq. (C.1), sob as hipóteses do Caso 1;

$$
\xi_{1-1 *}=U_{b, 1}-U_{b, 1}^{*}
$$

4. $\Delta_{1-1 *}$, que representa a variação entre o valor de $U_{b}$ previsto com $M a_{b}$ digitalizado e $U_{b}^{*}$ previsto com $M a_{b} \pm 0,015$, com relação ao primeiro, ambos calculados por meio da Eq. (C.1), sob as hipóteses do Caso 1.

$$
\Delta_{1-1 *}(\%)=\frac{U_{b, 1}-U_{b, 1}^{*}}{U_{b, 1}} \cdot 100=\frac{\xi_{1-1 *}}{U_{b, \exp }} \cdot 100
$$

Logo, todos os casos que apresentarem $\Delta_{i-\exp }>\Delta_{\text {exp }}$, para determinado gás e diâmetro de bocal, não podem ser associados apenas à incerteza do processo de digitalização.

Após uma análise detalhada de $\Delta_{e x p}, \xi_{\text {exp }}, \Delta_{1-1 *}$ e $\xi_{1-1 *}$, para todos os gases e diâmetros de bocais, verificou-se que:

1. os maiores valores de $\xi_{\text {exp }}$ e $\Delta_{\text {exp }}$ ocorrem para os menores diâmetros; e os maiores valores para os maiores diâmetros;

2. os menores valores de $\xi_{1-1 *}$ e $\Delta_{1-1 *}$ ocorrem para os menores diâmetros; e os maiores valores para os maiores diâmetros.

Assim, $\Delta_{\text {exp }}, \xi_{\text {exp }}, \Delta_{1-1 *}$ e $\xi_{1-1 *}$ estão limitados a partir dos valores obtidos (por meio das correlações e das digitalizações dos dados experimentais) para os diâmetros extremos (maior e menor), para determinado gás. Por esse motivo, estes parâmetros serão apresentados, nas análises a seguir apenas para os diâmetros maiores e menores de cada gás estudado. 


\section{C.1 Resultados da análise do trabalho de Kalghatgi (1981) para o gás metano}

A Tabela (C.1) apresenta os dados experimentais digitalizados do trabalho de Kalghatgi (1981) para o gás metano (duas primeiras colunas) e as respectivas velocidades de blowout, $U_{b, \exp }$, segundo o equacionamento apresentado na Subseção (3.1) do presente trabalho.

As Tabelas (C.2) e (C.3) apresentam as previsões da correlação da velocidade de blowout, $U_{b}$, para o gás metano; e os parâmetros necessários (e calculados) para obtê-las.

A Tabela (C.4) apresenta os valores de $U_{b, \text { exp }}$ oriundos dos dados experimentais $\left(M a_{b}\right)$ para o gás metano, as previsões da correlação proposta (Eq. C.1) e os respectivos desvios. Para facilitar a visualização dos resultados, $U_{b, \exp }$ e $U_{b}$ estão ilustrados na Figura (C.1).

Tabela C.1. Números de Mach, $M a_{b}$, e respectivas velocidades de blowout, $U_{b, e x p}$, para o gás metano.

\begin{tabular}{ccccc}
\hline \hline $\boldsymbol{d}_{\boldsymbol{n}}[\mathrm{mm}]$ & $\boldsymbol{M a}_{\boldsymbol{b}}$ & $\boldsymbol{T}_{\boldsymbol{f}, \boldsymbol{n}}[\mathrm{K}]$ & $\boldsymbol{c}[\mathrm{m} / \mathrm{s}]$ & $\boldsymbol{U}_{\boldsymbol{b}, \boldsymbol{e x p}}[\mathrm{m} / \mathrm{s}]$ \\
\hline 2,00 & 0,12 & 289,41 & 443,87 & $\mathbf{5 1 , 0 9}$ \\
3,00 & 0,13 & 289,21 & 443,73 & $\mathbf{5 8 , 7 9}$ \\
4,00 & 0,16 & 288,80 & 443,41 & $\mathbf{7 2 , 5 6}$ \\
5,00 & 0,20 & 288,18 & 442,94 & $\mathbf{8 9 , 3 3}$ \\
6,00 & 0,26 & 287,09 & 442,10 & $\mathbf{1 1 3 , 0 5}$ \\
8,00 & 0,32 & 285,46 & 440,84 & $\mathbf{1 4 1 , 2 1}$ \\
10,00 & 0,40 & 283,10 & 439,02 & $\mathbf{1 7 4 , 0 3}$ \\
12,00 & 0,50 & 279,28 & 436,04 & $\mathbf{2 1 7 , 0 1}$ \\
\hline \hline
\end{tabular}

Tabela C.2. Previsões da correlação da velocidade de blowout, $U_{b}$, proposta por Kalghatgi (1981) para o gás metano (Caso 1).

\begin{tabular}{cccccc}
\hline \hline $\boldsymbol{d}_{\boldsymbol{n}}[\mathrm{mm}]$ & $\boldsymbol{\rho}_{\boldsymbol{f}, \boldsymbol{n}}\left[\mathrm{kg} / \mathrm{m}^{3}\right]$ & $\boldsymbol{v}_{\boldsymbol{f}, \boldsymbol{n}}\left[\mathrm{m}^{2} / \mathrm{s}\right]$ & $\boldsymbol{H}_{\boldsymbol{S}}[\mathrm{m}]$ & $\boldsymbol{R}_{\boldsymbol{H}_{\boldsymbol{S}}}$ & $\boldsymbol{U}_{\boldsymbol{b}}[\mathrm{m} / \mathrm{s}]$ \\
\hline 2,00 & 0,67 & $1,52 \mathrm{E}-05$ & 0,10 & 2515,8 & 38,29 \\
3,00 & 0,67 & $1,52 \mathrm{E}-05$ & 0,15 & 3777,6 & 57,18 \\
4,00 & 0,68 & $1,52 \mathrm{E}-05$ & 0,20 & 5048,1 & 75,91 \\
5,00 & 0,68 & $1,52 \mathrm{E}-05$ & 0,25 & 6331,2 & 94,46 \\
6,00 & 0,68 & $1,51 \mathrm{E}-05$ & 0,30 & 7642,6 & 112,85 \\
8,00 & 0,68 & $1,50 \mathrm{E}-05$ & 0,40 & 10280,9 & 149,09 \\
10,00 & 0,69 & $1,49 \mathrm{E}-05$ & 0,50 & 13018,1 & 184,59 \\
12,00 & 0,70 & $1,47 \mathrm{E}-05$ & 0,60 & 15956,5 & 219,30 \\
\hline \hline
\end{tabular}


Tabela C.3. Previsões da correlação da velocidade de blowout, $U_{b}$, proposta por Kalghatgi (1981) para o gás metano (Caso 2)

\begin{tabular}{cccc}
\hline \hline $\boldsymbol{d}_{\boldsymbol{n}}[\mathrm{mm}]$ & $\boldsymbol{H}_{\boldsymbol{S}}[\mathrm{m}]$ & $\boldsymbol{R}_{\boldsymbol{H}_{\boldsymbol{S}}}$ & $\boldsymbol{U}_{\boldsymbol{b}}[\mathrm{m} / \mathrm{s}]$ \\
\hline 2,00 & 0,10 & 2403,58 & $\mathbf{3 8 , 2 4}$ \\
3,00 & 0,15 & 3605,38 & $\mathbf{5 7 , 1 2}$ \\
4,00 & 0,19 & 4807,17 & $\mathbf{7 5 , 8 3}$ \\
5,00 & 0,24 & 6008,96 & $\mathbf{9 4 , 3 8}$ \\
6,00 & 0,29 & 7210,75 & $\mathbf{1 1 2 , 7 7}$ \\
8,00 & 0,39 & 9614,33 & $\mathbf{1 4 9 , 0 7}$ \\
10,00 & 0,48 & 12017,92 & $\mathbf{1 8 4 , 7 1}$ \\
12,00 & 0,58 & 14421,50 & $\mathbf{2 1 9 , 7 1}$ \\
\hline \hline
\end{tabular}

Tabela C.4. Valores da velocidade de blowout experimentais e previstos pela correlação proposta por Kalghatgi (1981) (Casos 1 e 2) para o gás metano, e os respectivos desvios.

\begin{tabular}{c|cc|cc|cc|c}
\hline \hline & \multicolumn{2}{|c|}{ Experimental } & \multicolumn{2}{c|}{ Caso 1 } & \multicolumn{2}{c|}{ Caso 2 } & \\
$d_{n}$ & $U_{b, \text { exp }}$ & $\left|\Delta_{\text {exp }}\right|$ & $U_{b}$ & $\Delta_{1-\exp }$ & $U_{b}$ & $\Delta_{2-\exp }$ & $\Delta_{2-1}$ \\
{$[\mathrm{~mm}]$} & {$[\mathrm{m} / \mathrm{s}]$} & {$[\%]$} & {$[\mathrm{m} / \mathrm{s}]$} & {$[\%]$} & {$[\mathrm{m} / \mathrm{s}]$} & {$[\%]$} & {$[\%]$} \\
\hline 2,00 & $\mathbf{5 1 , 0 9}$ & 13,01 & $\mathbf{3 8 , 2 9}$ & 25,06 & $\mathbf{3 8 , 2 4}$ & 25,16 & 0,13 \\
3,00 & $\mathbf{5 8 , 7 9}$ & 11,30 & $\mathbf{5 7 , 1 8}$ & 2,74 & $\mathbf{5 7 , 1 2}$ & 2,85 & 0,12 \\
4,00 & $\mathbf{7 2 , 5 6}$ & 9,13 & $\mathbf{7 5 , 9 1}$ & $-4,61$ & $\mathbf{7 5 , 8 3}$ & $-4,51$ & 0,10 \\
5,00 & $\mathbf{8 9 , 3 3}$ & 7,40 & $\mathbf{9 4 , 4 6}$ & $-5,74$ & $\mathbf{9 4 , 3 8}$ & $-5,66$ & 0,08 \\
6,00 & $\mathbf{1 1 3 , 0 5}$ & 5,81 & $\mathbf{1 1 2 , 8 5}$ & 0,18 & $\mathbf{1 1 2 , 7 7}$ & 0,25 & 0,07 \\
8,00 & $\mathbf{1 4 1 , 2 1}$ & 4,61 & $\mathbf{1 4 9 , 0 9}$ & $-5,58$ & $\mathbf{1 4 9 , 0 7}$ & $-5,56$ & 0,01 \\
10,00 & $\mathbf{1 7 4 , 0 3}$ & 3,70 & $\mathbf{1 8 4 , 5 9}$ & $-6,07$ & $\mathbf{1 8 4 , 7 1}$ & $-6,14$ & $-0,06$ \\
12,00 & $\mathbf{2 1 7 , 0 1}$ & 2,91 & $\mathbf{2 1 9 , 3 0}$ & $-1,06$ & $\mathbf{2 1 9 , 7 1}$ & $-1,24$ & $-0,19$ \\
\hline \hline
\end{tabular}

A partir dos resultados apresentados na Tabela (C.4) e Figura (C.1), verifica-se que a hipótese de densidade constante (Caso 2) resulta em valores de $U_{b}$ muito próximos aos valores obtidos sob a hipótese de densidade variável (Caso 1), mesmo quando o número de Mach na saída do bocal é superior a 0,3 (valor normalmente adotado para "separar" escoamentos compressíveis de incompressíveis).

É notável a diferença, $\xi_{i-\text { exp }}$, entre os valores de $U_{b}$ (segundo os Casos 1 e 2) e $U_{b \text {,exp }}$, para $d_{n}$ igual a 2,00 $\mathrm{mm}$. Este fato precisa ser verificado. A princípio, esta diferença poderia ser atribuída à incerteza no processo de digitalização $\left( \pm 0,015\right.$ em $\left.M a_{b}\right)$. 


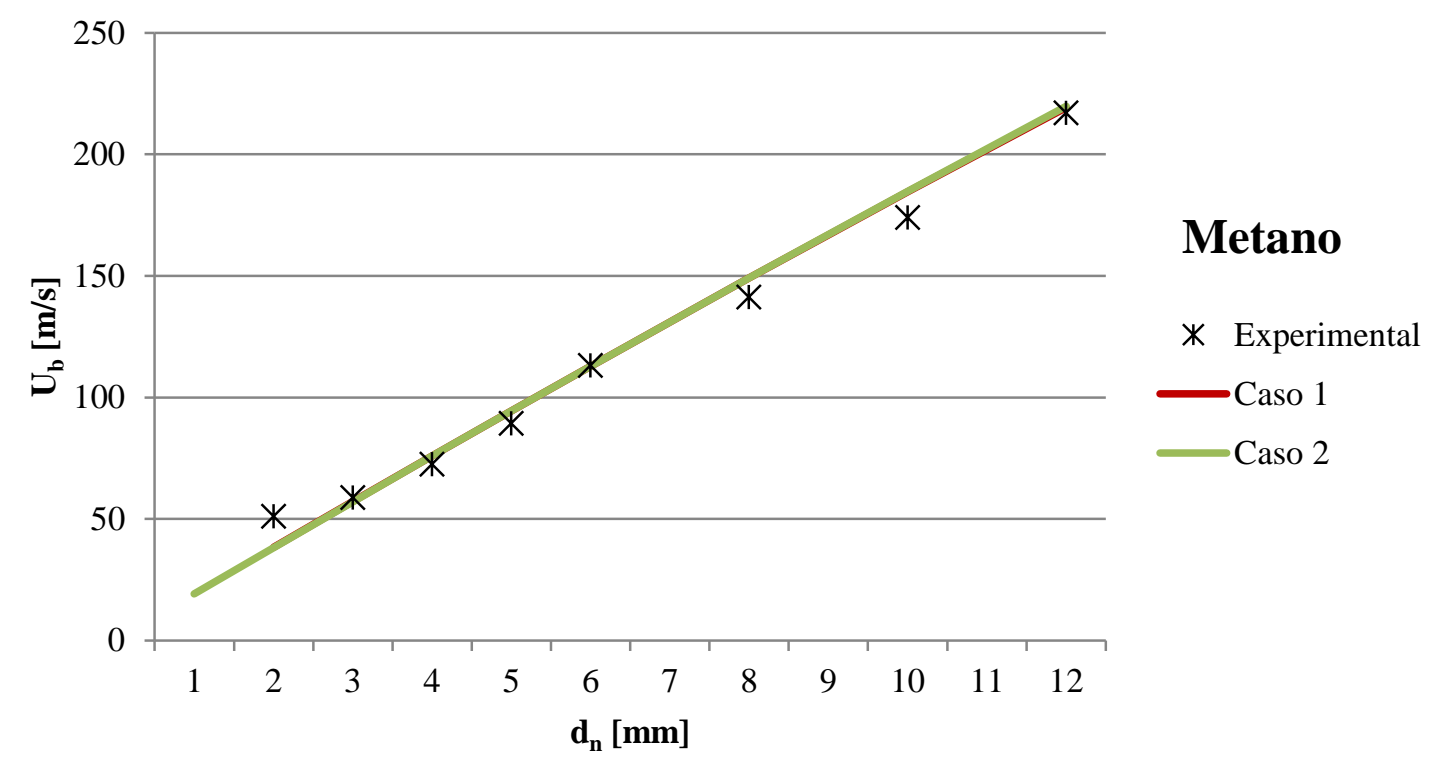

Figura C.1. Valores de $U_{b}$ experimentais e previstos pela correlação proposta por Kalghatgi (1981), sob as condições dos Casos 1 e 2 para o gás metano.

Após analisar esta possibilidade (para todos os diâmetros de bocais testados experimentalmente), verificou-se que, a variação de 0,015 em $M a_{b}$ :

1. resulta numa incerteza $\left(\xi_{\text {exp }}\right)$ na velocidade de blowout experimental, $U_{b, \exp }$, (Tab. C.1 e C.4) de $\pm 6,6 \mathrm{~m} / \mathrm{s}$ para $d_{n}=2,00 \mathrm{~mm}$ (aproximadamente $\pm 13,0 \%$ com relação ao valor de $U_{b, \exp }$ apresentado); e de $\pm 6,3 \mathrm{~m} / \mathrm{s}$ para $d_{n}=12,00 \mathrm{~mm}( \pm 2,9 \%)$;

2. resulta numa incerteza $\left(\xi_{1-1 *}\right)$ na previsão de $U_{b}$ desprezível (menor que $0,006 \mathrm{~m} / \mathrm{s}$ ) para quase todos os diâmetros, com exceção de $d_{n}=12,00 \mathrm{~mm}(0,17 \mathrm{~m} / \mathrm{s})$;

3. $\Delta_{1-\exp }>\Delta_{\text {exp }}$ para $d_{n}=2,0 \mathrm{~mm}\left(\Delta_{\text {exp }}= \pm 13,0 \%\right), d_{n}=8,0 \mathrm{~mm}\left(\Delta_{\text {exp }}= \pm 4,6 \%\right)$ e $d_{n}$ $=10,0 \mathrm{~mm}\left(\Delta_{\text {exp }}= \pm 3,7 \%\right)$, onde $\Delta_{1-\exp }$ encontra-se na Tabela (C.4); logo, para estes casos, a diferença entre $U_{b, \exp }$ e $U_{b}$ não deve ser atribuída apenas ao processo de digitalização de $M a_{b}$;

4. $\Delta_{1-\exp }<\Delta_{\text {exp }}$ para os demais diâmetros, e, portanto, a variação entre $U_{b, \exp }$ e $U_{b}$ pode ser atribuída ao processo de digitalização, entre outros aspectos (discutidos no item C.5 “Comentários”). 
A Tabela (C.5) apresenta os resultados desta análise para os diâmetros extremos, ou seja, $d_{n}=2,00 \mathrm{~mm}$ e $d_{n}=12,00 \mathrm{~mm}$.

Tabela C.5. Influência da incerteza da digitalização dos dados experimentais de Kalghatgi (1981) na velocidade de blowout, $U_{b}$, para o gás metano.

\begin{tabular}{cccccccc}
\hline \hline$d_{n}[\mathrm{~mm}]$ & $M a_{b}$ & $\begin{array}{c}U_{b, \exp } \\
{[\mathrm{m} / \mathrm{s}]}\end{array}$ & $\begin{array}{c}\xi_{\exp } \\
{[\mathrm{m} / \mathrm{s}]}\end{array}$ & $\begin{array}{c}\Delta_{\exp } \\
{[\%]}\end{array}$ & $\begin{array}{c}U_{b}(\text { Caso } 1) \\
{[\mathrm{m} / \mathrm{s}]}\end{array}$ & $\begin{array}{c}\xi_{1-1 *} \\
{[\mathrm{~m} / \mathrm{s}]}\end{array}$ & $\begin{array}{c}\Delta_{1-1 *} \\
{[\%]}\end{array}$ \\
\hline \multirow{3}{*}{2,00} & $\mathbf{0 , 1 2}$ & $\mathbf{5 1 , 0 9}$ & - & - & $\mathbf{3 8 , 2 9}$ & - & - \\
& 0,10 & 44,45 & 6,65 & 13,01 & 38,29 & 0,001 & 0,002 \\
& 0,13 & 57,74 & $-6,64$ & $-13,00$ & 38,29 & $-0,001$ & 0,003 \\
& $\mathbf{0 , 5 0}$ & $\mathbf{2 1 7 , 0 1}$ & - & - & $\mathbf{2 1 9 , 3 0}$ & - & - \\
\multirow{3}{*}{12,00} & 0,48 & 210,70 & 6,31 & 2,91 & 219,32 & $-0,02$ & $-0,008$ \\
& 0,51 & 223,30 & $-6,29$ & $-2,90$ & 219,28 & 0,02 & 0,008 \\
\hline \hline
\end{tabular}

\section{C.2 Resultados da análise do trabalho de Kalghatgi (1981) para o gás propano}

A Tabela (C.6) apresenta os valores de $U_{b, \exp }$ oriundos dos dados experimentais $\left(M a_{b}\right)$ para o gás propano, as previsões da correlação proposta (Eq. C.1) e os respectivos desvios. Os resultados, $U_{b, \exp }$ e $U_{b}$, estão ilustrados na Figura (C.2).

Tabela C.6. Valores da velocidade de blowout experimentais e previstos pela correlação proposta por Kalghatgi (1981) (Casos 1 e 2) para o gás propano, e os respectivos desvios.

\begin{tabular}{|c|c|c|c|c|c|c|c|c|}
\hline \multirow[b]{2}{*}{$\begin{array}{c}d_{n} \\
{[\mathrm{~mm}]}\end{array}$} & \multicolumn{3}{|c|}{ Experimental } & \multicolumn{2}{|c|}{ Caso 1} & \multicolumn{2}{|c|}{ Caso 2} & \multirow[b]{2}{*}{$\begin{array}{c}\Delta_{2-1} \\
{[\%]}\end{array}$} \\
\hline & $M a_{b}$ & $\begin{array}{c}U_{b, \exp } \\
{[\mathrm{m} / \mathrm{s}]} \\
\end{array}$ & $\begin{array}{c}\left|\Delta_{\text {exp }}\right| \\
{[\%]} \\
\end{array}$ & $\begin{array}{c}U_{b} \\
{[\mathrm{~m} / \mathrm{s}]}\end{array}$ & $\begin{array}{c}\Delta_{1-\exp } \\
{[\%]}\end{array}$ & $\begin{array}{c}U_{b} \\
{[\mathrm{~m} / \mathrm{s}]}\end{array}$ & $\begin{array}{c}\Delta_{2-\exp } \\
{[\%]}\end{array}$ & \\
\hline 1,00 & 0,12 & 28,87 & 12,92 & 32,99 & $-14,28$ & 33,00 & $-14,32$ & $-0,03$ \\
\hline 2,00 & 0,28 & 68,43 & 5,42 & 63,89 & 6,64 & 64,01 & 6,46 & $-0,20$ \\
\hline 3,00 & 0,40 & 99,24 & 3,71 & 92,62 & 6,66 & 93,03 & 6,26 & $-0,44$ \\
\hline 5,00 & 0,61 & 149,97 & 2,40 & 143,32 & 4,44 & 145,08 & 3,26 & $-1,23$ \\
\hline 6,00 & 0,74 & 181,42 & 1,95 & 164,89 & 9,11 & 168,12 & 7,33 & $-1,96$ \\
\hline 8,00 & 0,87 & 211,55 & 1,64 & 200,94 & 5,01 & 208,21 & 1,58 & $-3,62$ \\
\hline
\end{tabular}




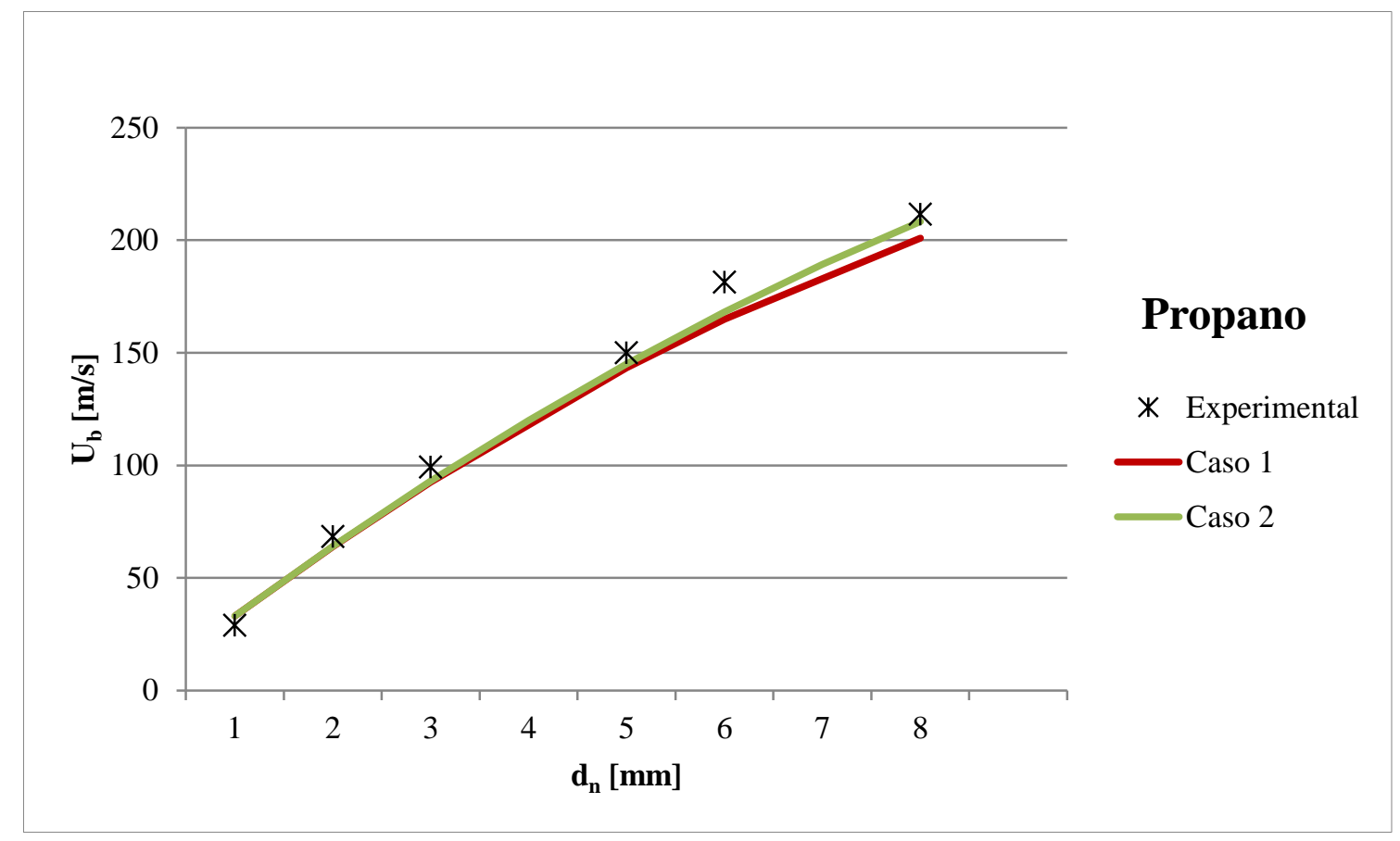

Figura C.2. Valores de $U_{b}$ experimentais e previstos pela correlação proposta por Kalghatgi (1981), sob as condições dos Casos 1 e 2 para o gás propano.

A partir dos resultados apresentados na Tabela (C.6) e Figura (C.2), verifica-se que a hipótese de densidade constante (Caso 2) resulta em resultados próximos aos de densidade variável (Caso 1), principalmente para $d_{n}<5,00 \mathrm{~mm}$ (ou $\left.M a_{b}<0,6\right)$. Assim como verificado para o gás metano, é notável a diferença $\left(\Delta_{i-\text { exp }}\right)$ entre $U_{b, \text { exp }}$ e $U_{b}$ para o menor diâmetro estudado, neste caso, $d_{n}$ igual a $1,00 \mathrm{~mm}$.

A influência da incerteza do processo de digitalização também foi analisada para o propano. Os resultados encontram-se na Tabela (C.7) para os diâmetros extremos, ou seja, $d_{n}=1,00 \mathrm{~mm}$ e $d_{n}=8,00 \mathrm{~mm}$. Verifica-se que, a variação de $\pm 0,015$ em $M a_{b}$ resulta:

1. numa incerteza $\left(\xi_{\text {exp }}\right)$ na velocidade de blowout experimental, $U_{b, \exp }$ de $\pm 3,7 \mathrm{~m} / \mathrm{s}$ para $d_{n}=1,00 \mathrm{~mm}$ e de $\pm 3,5 \mathrm{~m} / \mathrm{s}$ para $d_{n}=8,00 \mathrm{~mm}$, que correspondem a uma variação de $\pm 12,9 \%$ e $\pm 1,6 \%$, respectivamente, com relação ao valor de $U_{b, \exp }$ apresentado na Tabela (C.6);

2. numa incerteza $\left(\xi_{1-1 *}\right)$ na previsão de $U_{b}$ desprezível para $d_{n}=1,00 \mathrm{~mm}, d_{n}=2,00 \mathrm{~mm}$ e $d_{n}=3,00 \mathrm{~mm}$ (menor que $0,002 \mathrm{~m} / \mathrm{s}$ ); e pequena com relação a $\xi_{\text {exp }}$ para $d_{n}=5,00$ $\mathrm{mm}(0,04 \mathrm{~m} / \mathrm{s}), d_{n}=6,00 \mathrm{~mm}(0,08 \mathrm{~m} / \mathrm{s})$ e $d_{n}=8,00 \mathrm{~mm}(0,17 \mathrm{~m} / \mathrm{s})$; 
3. em $\Delta_{1-\exp }>\Delta_{\exp }$ para todos os diâmetros de bocais, e, portanto, a diferença entre $U_{b, \exp }$ e $U_{b}$ não deve ser atribuída apenas ao processo de digitalização de $M a_{b}$.

Tabela C.7. Influência da incerteza da digitalização dos dados experimentais de Kalghatgi (1981) na velocidade de blowout, $U_{b}$, para o gás propano.

\begin{tabular}{cccccccc}
\hline \hline$d_{n}[\mathrm{~mm}]$ & $M a_{b}$ & $\begin{array}{c}U_{b, \exp } \\
{[\mathrm{m} / \mathrm{s}]}\end{array}$ & $\begin{array}{c}\xi_{\exp } \\
{[\mathrm{m} / \mathrm{s}]}\end{array}$ & $\begin{array}{c}\Delta_{\exp } \\
{[\%]}\end{array}$ & $\begin{array}{c}U_{b} \text { (Caso 1) } \\
{[\mathrm{m} / \mathrm{s}]}\end{array}$ & $\begin{array}{c}\xi_{1-1 *} \\
{[\mathrm{~m} / \mathrm{s}]}\end{array}$ & $\begin{array}{c}\Delta_{1-1 *} \\
{[\%]}\end{array}$ \\
\hline \multirow{3}{*}{1,00} & $\mathbf{0 , 1 2}$ & $\mathbf{2 8 , 8 7}$ & - & - & $\mathbf{3 2 , 9 9}$ & - & - \\
& 0,10 & 25,14 & 3,73 & 12,92 & 32,99 & $-0,0001$ & $-0,0002$ \\
& 0,13 & 32,60 & $-3,73$ & $-12,91$ & 32,99 & 0,0001 & 0,0003 \\
& $\mathbf{0 , 8 7}$ & $\mathbf{2 1 1 , 5 5}$ & - & - & $\mathbf{2 0 0 , 9 4}$ & - & - \\
8,00 & 0,86 & 208,07 & 3,48 & 1,64 & 201,11 & $-0,1652$ & $-0,0008$ \\
& 0,89 & 215,01 & $-3,47$ & $-1,64$ & 200,77 & 0,1683 & 0,0008 \\
\hline \hline
\end{tabular}

\section{C.3 Resultados da análise do trabalho de Kalghatgi (1981) para o gás etileno}

A Tabela (C.8) apresenta os valores de $U_{b, \text { exp }}$ oriundos dos dados experimentais $\left(M a_{b}\right)$ para o gás etileno, as previsões da correlação proposta (Eq. C.1) para este gás e os respectivos desvios. Os resultados, $U_{b, \text { exp }}$ e $U_{b}$, estão ilustrados na Figura (C.3).

Tabela C.8. Valores da velocidade de blowout experimentais e previstos pela correlação proposta por Kalghatgi (1981) (Casos 1 e 2) para o gás etileno, e os respectivos desvios.

\begin{tabular}{|c|c|c|c|c|c|c|c|c|}
\hline \multirow[b]{2}{*}{$\begin{array}{c}d_{n} \\
{[\mathrm{~mm}]}\end{array}$} & \multicolumn{3}{|c|}{ "Experimental } & \multicolumn{2}{|c|}{ 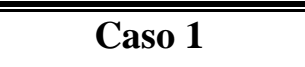 } & \multicolumn{2}{|c|}{ Caso 2} & \multirow[b]{2}{*}{$\begin{array}{c}\Delta_{2-1} \\
{[\%]}\end{array}$} \\
\hline & $M a_{b}$ & $\begin{array}{c}U_{b, \exp } \\
{[\mathrm{m} / \mathrm{s}]}\end{array}$ & $\begin{array}{c}\left|\Delta_{\text {exp }}\right| \\
{[\%]}\end{array}$ & $\begin{array}{c}U_{b} \\
{[\mathrm{~m} / \mathrm{s}]}\end{array}$ & $\begin{array}{c}\Delta_{1-\exp } \\
{[\%]}\end{array}$ & $\begin{array}{c}U_{b} \\
{[\mathrm{~m} / \mathrm{s}]}\end{array}$ & $\begin{array}{c}\Delta_{2-\exp } \\
{[\%]}\end{array}$ & \\
\hline 1,00 & 0,24 & 79,32 & 6,15 & 70,10 & 11,63 & 70,05 & 11,69 & 0,07 \\
\hline 2,00 & 0,37 & 121,22 & 3,97 & 137,35 & $-13,31$ & 137,42 & $-13,37$ & $-0,05$ \\
\hline 3,00 & 0,46 & 150,11 & 3,16 & 201,61 & $-34,31$ & 202,12 & $-34,65$ & $-0,25$ \\
\hline 4,00 & 0,73 & 233,63 & 1,91 & 262,01 & $-12,15$ & 264,14 & $-13,06$ & $-0,81$ \\
\hline 5,00 & 0,95 & 294,92 & 1,42 & 317,78 & $-7,75$ & 323,49 & $-9,68$ & $-1,79$ \\
\hline
\end{tabular}




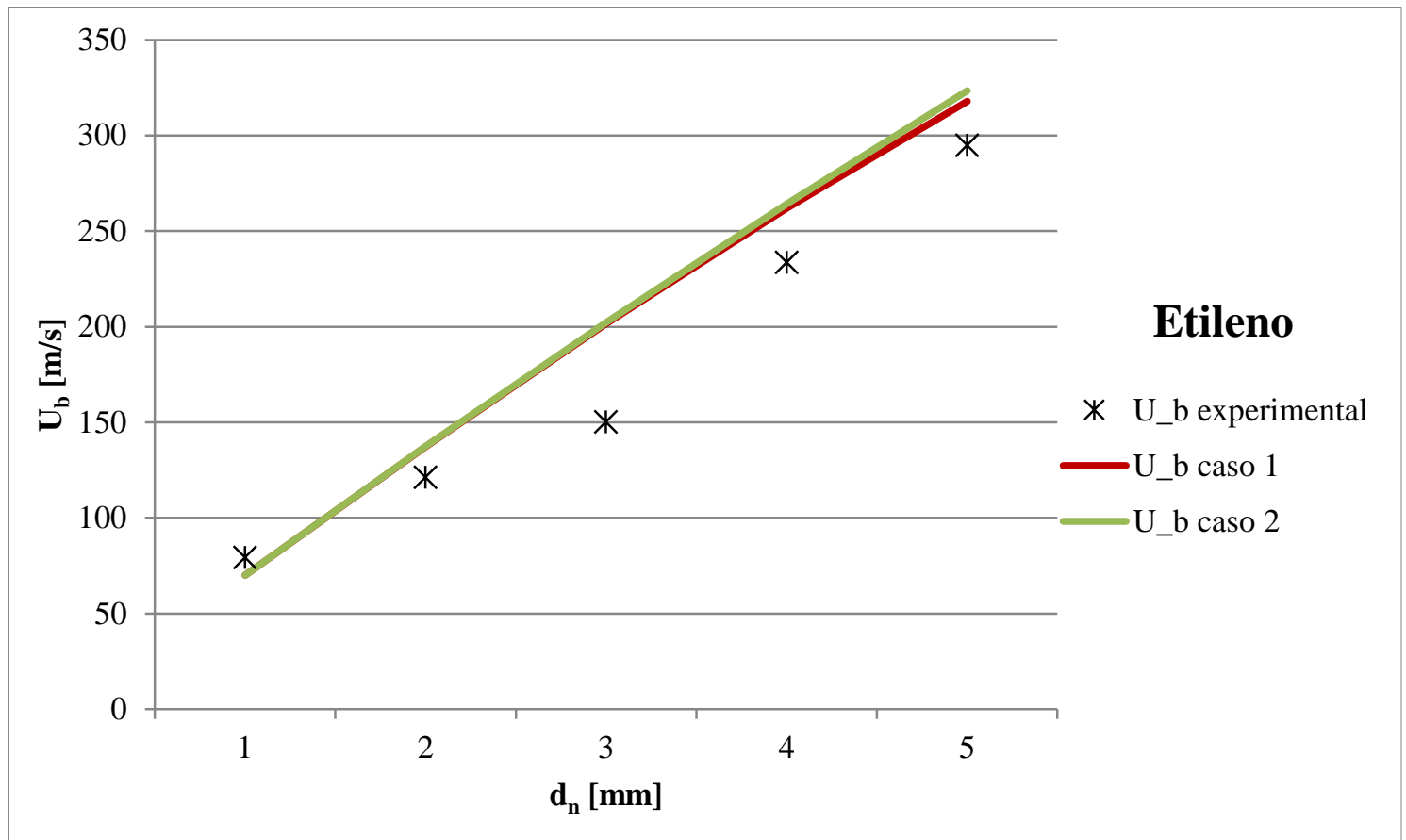

Figura C.3. Valores de $U_{b}$ experimentais e previstos pela correlação proposta por Kalghatgi (1981), sob as condições dos Casos 1 e 2 para o gás etileno.

A partir dos resultados apresentados na Tabela (C.9) e Figura (C.3), verifica-se que a hipótese de densidade constante (Caso 2) resulta em resultados próximos aos de densidade variável (Caso 1), principalmente para $d_{n} \leq 3,00 \mathrm{~mm}$ (ou $\left.M a_{b}<0,5\right)$. As maiores variações $\left(\Delta_{i-\exp }\right)$ entre $U_{b, \text { exp }}$ e $U_{b}$ ocorrem para $d_{n}=3,00 \mathrm{~mm}$.

Os resultados da incerteza de \pm 0,015 em $M a_{b}$ encontram-se na Tabela (C.9) para os diâmetros extremos, ou seja, $d_{n}=1,00 \mathrm{~mm}$ e $d_{n}=5,00 \mathrm{~mm}$. Verifica-se que, a variação de 0,015 em $M a_{b}$ resulta:

1. numa incerteza $\left(\xi_{\text {exp }}\right)$ na velocidade de blowout experimental, $U_{b, \text { exp }}$ de $\pm 4,9 \mathrm{~m} / \mathrm{s}$ para $d_{n}=1,00 \mathrm{~mm}$ e de $\pm 4,2 \mathrm{~m} / \mathrm{s}$ para $d_{n}=5,00 \mathrm{~mm}$, que correspondem a uma variação de $\pm 6,2 \%$ e $\pm 1,4 \%$, respectivamente, com relação ao valor de $U_{b, \exp }$ apresentado na Tabela (C.9);

2. numa incerteza $\left(\xi_{1-1 *}\right)$ na previsão de $U_{b}$ desprezível para $d_{n}=1,00 \mathrm{~mm}$ e $d_{n}=2,00$ $\mathrm{mm}($ menor que $0,003 \mathrm{~m} / \mathrm{s})$; e igual a $0,02 \mathrm{~m} / \mathrm{s}$ para $d_{n}=3,00 \mathrm{~mm}, 0,07 \mathrm{~m} / \mathrm{s}$ para $d_{n}=$ $4,00 \mathrm{~mm}$ e $0,02 \mathrm{~m} / \mathrm{s}$ para $d_{n}=5,00 \mathrm{~mm}$; 
3. em $\Delta_{1-\exp }>\Delta_{\exp }$ para todos os diâmetros de bocais, e, portanto, a diferença entre $U_{b, \exp }$ e $U_{b}$ não deve ser atribuída apenas ao processo de digitalização de $M a_{b}$.

Tabela C.9. Influência da incerteza da digitalização dos dados experimentais de Kalghatgi (1981) na velocidade de blowout, $U_{b}$, para o gás etileno.

\begin{tabular}{cccccccc}
\hline \hline$d_{n}[\mathrm{~mm}]$ & $M a_{b}$ & $\begin{array}{c}U_{b, \exp } \\
{[\mathrm{m} / \mathrm{s}]}\end{array}$ & $\begin{array}{c}\xi_{\exp } \\
{[\mathrm{m} / \mathrm{s}]}\end{array}$ & $\begin{array}{c}\Delta_{\exp } \\
{[\%]}\end{array}$ & $\begin{array}{c}U_{b} \text { (Caso 1) } \\
{[\mathrm{m} / \mathrm{s}]}\end{array}$ & $\begin{array}{c}\xi_{1-1 *} \\
{[\mathrm{~m} / \mathrm{s}]}\end{array}$ & $\begin{array}{c}\Delta_{1-1 *} \\
{[\%]}\end{array}$ \\
\hline \multirow{3}{*}{1,00} & $\mathbf{0 , 2 4}$ & $\mathbf{7 9 , 3 2}$ & - & - & $\mathbf{7 0 , 1 0}$ & - & - \\
& 0,23 & 74,44 & 4,88 & 6,15 & 70,10 & 0,0012 & 0,0017 \\
& 0,26 & 84,20 & $-4,87$ & $-6,14$ & 70,10 & $-0,0012$ & $-0,0018$ \\
& $\mathbf{0 , 9 5}$ & $\mathbf{2 9 4 , 9 2}$ & - & - & $\mathbf{3 1 7 , 7 8}$ & - & - \\
5,00 & 0,93 & 290,72 & 4,20 & 1,42 & 317,94 & $-0,1584$ & $-0,05$ \\
& 0,96 & 299,11 & $-4,18$ & $-1,42$ & 317,62 & 0,1616 & 0,05 \\
\hline \hline
\end{tabular}

\section{C.4 Resultados da análise do trabalho de Kalghatgi (1981) para o gás acetileno}

A Tabela (C.10) apresenta os valores de $U_{b, \exp }$ oriundos dos dados experimentais $\left(M a_{b}\right)$ para o gás acetileno, as previsões da correlação proposta (Eq. 3.4) e os respectivos desvios. Os resultados, $U_{b, \text { exp }}$ e $U_{b}$, estão ilustrados na Figura (C.4).

Tabela C.10. Valores da velocidade de blowout experimentais e previstos pela correlação proposta por Kalghatgi (1981) (Casos 1 e 2) para o gás acetileno, e os respectivos desvios.

\begin{tabular}{c|ccc|cc|cc|c}
\hline \hline & \multicolumn{3}{|c|}{ Experimental } & \multicolumn{3}{c|}{ Caso 1 } & \multicolumn{3}{c|}{ Caso 2 } & \\
$d_{n}$ & $M a_{b}$ & $U_{b, \exp }$ & $\left|\Delta_{\text {exp }}\right|$ & $U_{b}$ & $\Delta_{1-\exp }$ & $U_{b}$ & $\Delta_{2-\exp }$ & $\Delta_{2-1}$ \\
{$[\mathrm{~mm} / \mathrm{s}]$} & {$[\%]$} & {$[\mathrm{m} / \mathrm{s}]$} & {$[\%]$} & {$[\mathrm{m} / \mathrm{s}]$} & {$[\%]$} & {$[\%]$} \\
\hline 0,20 & 0,26 & $\mathbf{8 7 , 8 1}$ & 5,75 & $\mathbf{5 7 , 8 8}$ & 34,08 & $\mathbf{5 7 , 7 8}$ & 34,19 & 0,17 \\
0,40 & 0,48 & $\mathbf{1 6 2 , 3 0}$ & 3,02 & $\mathbf{1 1 5 , 0 8}$ & 29,09 & $\mathbf{1 1 4 , 8 3}$ & 29,24 & 0,21 \\
0,60 & 0,57 & $\mathbf{1 9 1 , 1 5}$ & 2,52 & $\mathbf{1 7 1 , 4 7}$ & 10,30 & $\mathbf{1 7 1 , 1 6}$ & 10,46 & 0,18 \\
0,80 & 0,68 & $\mathbf{2 2 4 , 5 4}$ & 2,10 & $\mathbf{2 2 7 , 0 4}$ & $-1,11$ & $\mathbf{2 2 6 , 7 4}$ & $-0,98$ & 0,13 \\
1,00 & 0,89 & $\mathbf{2 8 9 , 4 3}$ & 1,53 & $\mathbf{2 8 1 , 6 7}$ & 2,68 & $\mathbf{2 8 1 , 6 0}$ & 2,70 & 0,02 \\
\hline \hline
\end{tabular}




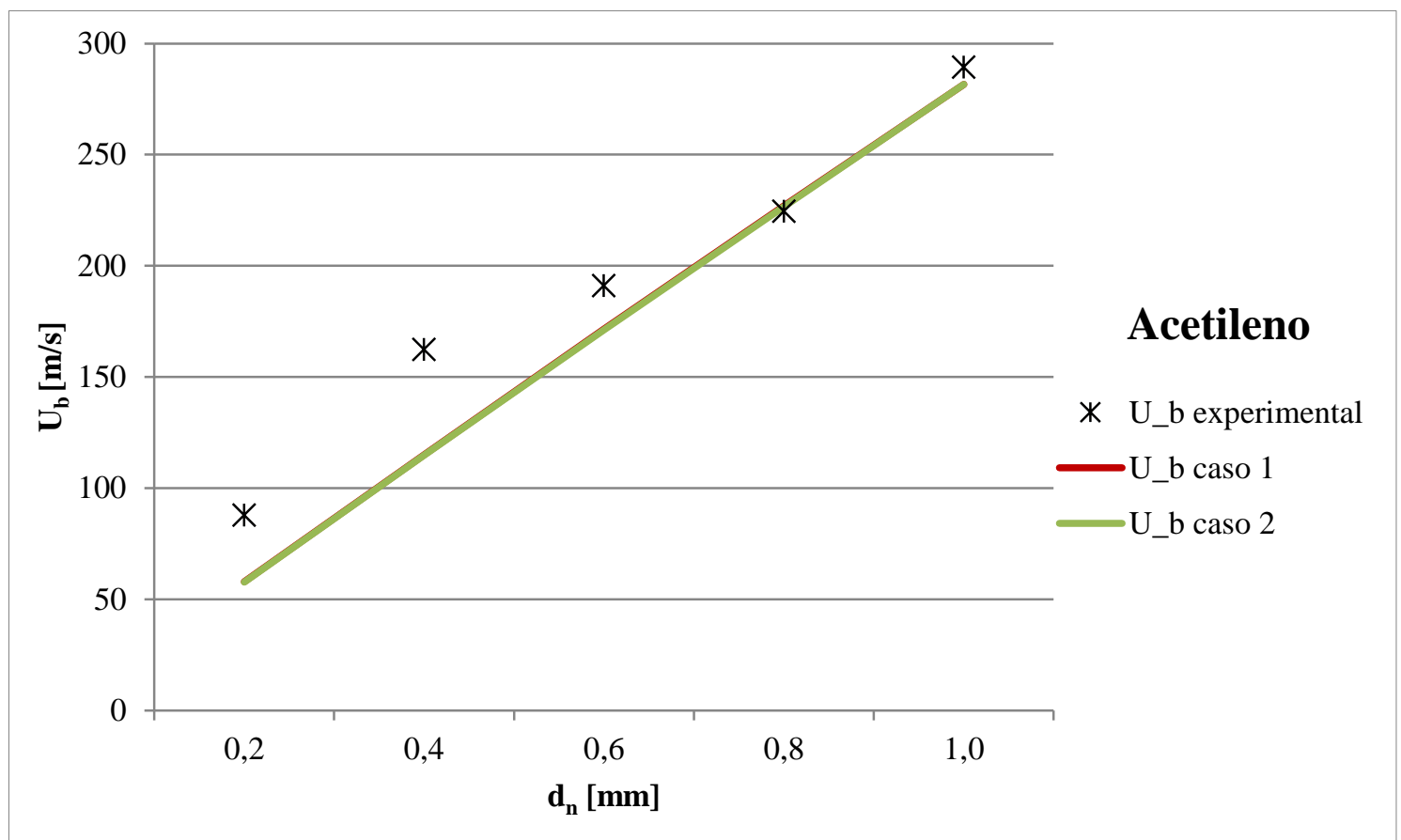

Figura C.4. Valores de $U_{b}$ experimentais e previstos pela correlação proposta por Kalghatgi (1981), sob as condições dos Casos 1 e 2 para o gás acetileno.

Novamente, verifica-se que $U_{b}$ segundo o Caso 2 (densidade constante) resulta em resultados próximos aos do Caso 1 (densidade como função de $M a_{b}$ ), para todos os $d_{n}$ e $M a_{b}$. As maiores variações entre $U_{b, \exp }$ e $U_{b}$ ocorrem para os menores diâmetros analisados.

A influência da incerteza do processo de digitalização também foi analisada para o gás acetileno e os resultados para $d_{n}=0,20 \mathrm{~mm}$ e $d_{n}=1,00 \mathrm{~mm}$ encontram-se na Tabela (C.11). Verificouse que, a variação de 0,015 em $M a_{b}$ resulta:

1. numa incerteza $\left(\xi_{\text {exp }}\right)$ na velocidade de blowout experimental, $U_{b, \text { exp }}$ de $\pm 5,1 \mathrm{~m} / \mathrm{s}$ para $d_{n}=0,20 \mathrm{~mm}$ e de $\pm 4,4 \mathrm{~m} / \mathrm{s}$ para $d_{n}=1,00 \mathrm{~mm}$, que correspondem a uma variação de $\pm 5,8 \%$ e $\pm 1,5 \%$, respectivamente, com relação ao valor de $U_{b, \exp }$ apresentado na Tabela (C.11);

2. numa incerteza $\left(\xi_{1-1 *}\right)$ na previsão de $U_{b}$ desprezível para todos os diâmetros de bocais (menor que $0,005 \mathrm{~m} / \mathrm{s}$ );

3. em $\Delta_{1-\exp }>\Delta_{\text {exp }}$ para quase todos os diâmetros de bocais, com excessão de $d_{n}=0,80$ $\mathrm{mm}$; portanto, salvo este caso, a diferença entre $U_{b, \exp }$ e $U_{b}$ não deve ser atribuída apenas ao processo de digitalização de $M a_{b}$. 
Tabela C.11. Influência da incerteza da digitalização dos dados experimentais de Kalghatgi (1981) na velocidade de blowout, $U_{b}$, para o gás acetileno.

\begin{tabular}{cccccccc}
\hline \hline$d_{n}[\mathrm{~mm}]$ & $M a_{b}$ & $\begin{array}{c}U_{b, \exp } \\
{[\mathrm{m} / \mathrm{s}]}\end{array}$ & $\begin{array}{c}\xi_{\text {exp }} \\
{[\mathrm{m} / \mathrm{s}]}\end{array}$ & $\begin{array}{c}\Delta_{\exp } \\
{[\%]}\end{array}$ & $\begin{array}{c}U_{b} \text { (Caso 1) } \\
{[\mathrm{m} / \mathrm{s}]}\end{array}$ & $\begin{array}{c}\xi_{1-1 *} \\
{[\mathrm{~m} / \mathrm{s}]}\end{array}$ & $\begin{array}{c}\Delta_{1-1 *} \\
{[\%]}\end{array}$ \\
\hline \multirow{3}{*}{0,20} & $\mathbf{0 , 2 6}$ & $\mathbf{8 7 , 8 1}$ & - & - & $\mathbf{5 7 , 8 8}$ & - & - \\
& 0,24 & 82,76 & 5,05 & 5,75 & 57,88 & 0,003 & 0,0045 \\
& 0,27 & 92,85 & $-5,04$ & $-5,74$ & 57,89 & $-0,003$ & $-0,0048$ \\
& $\mathbf{0 , 8 9}$ & $\mathbf{2 8 9 , 4 3}$ & - & - & $\mathbf{2 8 1 , 6 7}$ & - & - \\
1,00 & 0,88 & 284,99 & 4,44 & 1,53 & 281,68 & $-0,005$ & $-0,0016$ \\
& 0,91 & 293,85 & $-4,42$ & $-1,53$ & 281,67 & 0,005 & 0,0018 \\
\hline \hline
\end{tabular}

\section{C.5 Resultados da análise do trabalho de Kalghatgi (1981) para o gás hidrogênio}

O hidrogênio apresenta velocidade de blowout muito mais alta do que a dos demais gases analisados. Verificou-se que para $d_{n}=0,8 \mathrm{~mm}$ o jato de gás está "blocado", ou seja, $M a_{b}>1$. Nesse caso, utilizou-se a Eq. (4.1), sugerida por Kalghatgi (1981), para calcular o diâmetro efetivo $d_{e f}$ a ser aplicado nas correlações de $H_{S}$ e $U_{b}$. Para $d_{n}=0,8 \mathrm{~mm}$ e $M a_{b}=1,04$, obtevese $d_{e f}=8,004 \mathrm{~mm}$.

$$
d_{e f}=d_{n}\left[\frac{2+(\gamma-1) M a_{b}^{2}}{\gamma+1}\right]^{(\gamma+1) / 4(\gamma-1)} M a_{b}^{-1 / 2}
$$

A Tabela (C.12) apresenta os valores de $U_{b, \exp }$ oriundos dos dados experimentais $\left(M a_{b}\right)$ para o gás hidrogênio, as previsões da correlação proposta (Eq. C.1) e os respectivos desvios. Os resultados, $U_{b, \text { exp }}$ e $U_{b}$, estão ilustrados na Figura (C.5).

Tabela C.12. Valores da velocidade de blowout experimentais e previstos pela correlação proposta por Kalghatgi (1981) (Casos 1 e 2) para o gás hidrogênio, e os respectivos desvios.

\begin{tabular}{|c|c|c|c|c|c|c|c|c|}
\hline \multirow[b]{2}{*}{$\begin{array}{c}d_{n} \\
{[\mathrm{~mm}]}\end{array}$} & \multicolumn{3}{|c|}{ Experimental } & \multicolumn{2}{|c|}{ Caso 1} & \multicolumn{2}{|c|}{ Caso 2} & \multirow[b]{2}{*}{$\begin{array}{c}\Delta_{2-1} \\
{[\%]}\end{array}$} \\
\hline & $M a_{b}$ & $\begin{array}{c}U_{b, \exp } \\
{[\mathrm{m} / \mathrm{s}]}\end{array}$ & $\begin{array}{c}\left|\Delta_{\text {exp }}\right| \\
{[\%]}\end{array}$ & $\begin{array}{c}U_{b} \\
{[\mathrm{~m} / \mathrm{s}]}\end{array}$ & $\begin{array}{c}\Delta_{1-\exp } \\
{[\%]}\end{array}$ & $\begin{array}{c}U_{b} \\
{[\mathrm{~m} / \mathrm{s}]}\end{array}$ & $\begin{array}{c}\Delta_{2-\exp } \\
{[\%]}\end{array}$ & \\
\hline 0,60 & 0,81 & 993,37 & 1,63 & 1633,76 & $-64,47$ & 1613,19 & $-62,40$ & 1,26 \\
\hline 0,80 & 1,04 & 1221,19 & 1,20 & 2189,29 & $-79,27$ & 2150,62 & $-76,11$ & 1,77 \\
\hline
\end{tabular}




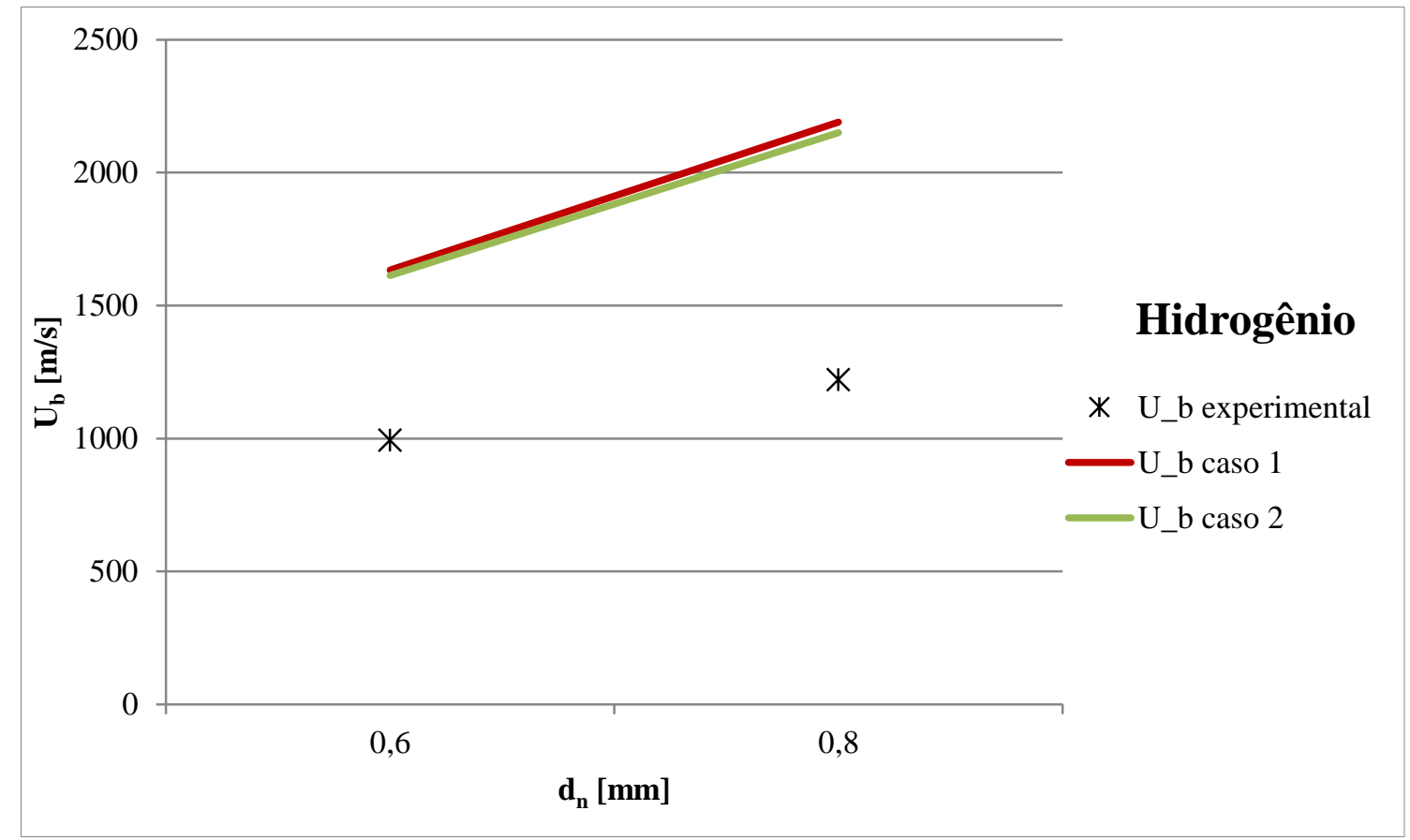

Figura C.5. Valores de $U_{b}$ experimentais e previstos pela correlação proposta por Kalghatgi (1981), sob as condições dos Casos 1 e 2 para o gás hidrogênio.

Comparando-se os valores de $\Delta_{i-\exp }$ e $\Delta_{2-1} \Delta_{2-1} \ll \Delta_{i-\exp }$ ) da Tabela (C.12), conclui-se que a hipótese de densidade constante (Caso 2) resulta em resultados próximos aos de densidade variável (Caso 1), para todos os $d_{n}$ e $M a_{b}$. As maiores variações $\left(\Delta_{i-\exp }\right)$ entre $U_{b, \exp }$ e $U_{b}$ ocorrem para $d_{n}=0,80 \mathrm{~mm}$. A partir desta Tabela e da Figura (C.5), é evidente que a Eq. (B.4), proposta por Kalghatgi (1981), não fornece boas previsões de $U_{b}$ para o hidrogênio (elevados $\left.\Delta_{i-\exp }\right)$. De qualquer forma, a influência da incerteza do processo de digitalização também foi analisada para o gás hidrogênio e os resultados para $d_{n}=0,60 \mathrm{~mm}$ e $d_{n}=0,80 \mathrm{~mm}$ encontramse na Tabela (C.13). Verificou-se que, a variação de 0,015 em $M a_{b}$ resulta:

1. numa incerteza $\left(\xi_{\text {exp }}\right.$ ) na velocidade de blowout experimental, $U_{b, \exp }$ de $\pm 16,2 \mathrm{~m} / \mathrm{s}$ para $d_{n}=0,60 \mathrm{~mm}$ e de $\pm 14,6 \mathrm{~m} / \mathrm{s}$ para $d_{n}=0,80 \mathrm{~mm}$, que correspondem a uma variação $\Delta_{\text {exp }}$ de $\pm 1,6 \%$ e $\pm 1,2 \%$, respectivamente, com relação ao valor de $U_{b, \exp }$ apresentado na Tabela (C.12);

2. numa incerteza $\left(\xi_{1-1 *}\right)$ na previsão de $U_{b}$ desprezível de $\pm 0,56 \mathrm{~m} / \mathrm{s}$ para $d_{n}=0,60 \mathrm{~mm}$ e $\pm 0,83 \mathrm{~m} / \mathrm{s}$ para $d_{n}=0,80 \mathrm{~mm}$ 
3. em $\Delta_{i-\exp } \gg \Delta_{\text {exp }}$ para quase todos os diâmetros de bocais; portanto, a diferença entre $U_{b, \exp }$ e $U_{b}$ não deve ser atribuída apenas ao processo de digitalização de $M a_{b}$.

Assim como para o propano e etileno, verificou-se que a variação de 0,015 em $M a_{b}$ resulta em $\Delta_{i-\exp }>\Delta_{\text {exp }}$ (ou seja, os valores de $U_{b}$ não encontram-se dentro da faixa $U_{b, \exp } \pm \xi_{\text {exp }}$ ) para todos os diâmetros de bocais testados; e, portanto, a diferença entre $U_{b, \exp }$ e $U_{b}$ não deve ser atribuída apenas ao processo de digitalização. A Tabela (C.13) apresenta os resultados desta análise para os diâmetros $d_{n}=0,60 \mathrm{~mm}$ e $d_{n}=0,80 \mathrm{~mm}$.

Tabela C.13. Influência da incerteza da digitalização dos dados experimentais de Kalghatgi (1981) na velocidade de blowout, $U_{b}$, para o gás hidrogênio.

\begin{tabular}{cccccccc}
\hline \hline$d_{n}[\mathrm{~mm}]$ & $M a_{b}$ & $\begin{array}{c}U_{b, \exp } \\
{[\mathrm{m} / \mathrm{s}]}\end{array}$ & $\begin{array}{c}\xi_{\exp } \\
{[\mathrm{m} / \mathrm{s}]}\end{array}$ & $\begin{array}{c}\Delta_{\exp } \\
{[\%]}\end{array}$ & $\begin{array}{c}U_{b}(\text { Caso } 1) \\
{[\mathrm{m} / \mathrm{s}]}\end{array}$ & $\begin{array}{c}\xi_{1-1 *} \\
{[\mathrm{~m} / \mathrm{s}]}\end{array}$ & $\begin{array}{c}\Delta_{1-1 *} \\
{[\%]}\end{array}$ \\
\hline \multirow{3}{*}{0,60} & $\mathbf{0 , 8 1}$ & $\mathbf{9 9 3 , 3 7}$ & - & - & $\mathbf{1 6 3 3 , 7 6}$ & - & - \\
& 0,80 & 977,15 & 16,22 & 1,63 & 1633,20 & 0,56 & 0,03 \\
& 0,83 & 1009,49 & $-16,12$ & $-1,62$ & 1634,32 & $-0,56$ & $-0,03$ \\
& $\mathbf{1 , 0 4}$ & $\mathbf{1 2 2 1 , 1 9}$ & - & - & $\mathbf{2 1 8 9 , 2 9}$ & - & - \\
0,80 & 1,02 & 1206,58 & 14,61 & 1,20 & 2188,46 & 0,83 & 0,04 \\
& 1,05 & 1235,69 & $-14,50$ & $-1,19$ & 2190,12 & $-0,83$ & $-0,04$ \\
\hline \hline
\end{tabular}

\section{C.6 Resultados da análise do trabalho de Kalghatgi (1981) para o gás butano}

A Tabela (C.14) apresenta os valores de $U_{b, \exp }$ oriundos dos dados experimentais $\left(M a_{b}\right)$ para o butano comercial, as previsões da correlação proposta (Eq. 3.4) e os respectivos desvios. Os resultados, $U_{b, \text { exp }}$ e $U_{b}$, estão ilustrados na Figura (C.6).

Tabela C.14. Valores da velocidade de blowout experimentais e previstos pela correlação proposta por Kalghatgi (1981) (Casos 1 e 2) para o gás butano comercial.

\begin{tabular}{c|ccc|cc|cc|c}
\hline \hline & \multicolumn{3}{|c|}{ Experimental } & \multicolumn{2}{c|}{ Caso 1 } & \multicolumn{2}{c|}{ Caso 2 } & \\
$d_{n}$ & $M a_{b}$ & $U_{b, \exp }$ & $\left|\Delta_{\text {exp }}\right|$ & $U_{b}$ & $\Delta_{1-\exp }$ & $U_{b}$ & $\Delta_{2-\exp }$ & $\Delta_{2-1}$ \\
{$[\mathrm{~mm}]$} & & {$[\mathrm{m} / \mathrm{s}]$} & {$[\%]$} & {$[\mathrm{m} / \mathrm{s}]$} & {$[\%]$} & {$[\mathrm{m} / \mathrm{s}]$} & {$[\%]$} & {$[\%]$} \\
\hline 1,00 & 0,16 & $\mathbf{3 6 , 3 4}$ & 9,26 & $\mathbf{2 9 , 1 7}$ & 19,75 & $\mathbf{2 9 , 1 9}$ & 19,69 & $-0,07$ \\
2,00 & 0,32 & $\mathbf{7 2 , 1 6}$ & 4,67 & $\mathbf{5 6 , 0 1}$ & 22,39 & $\mathbf{5 6 , 1 7}$ & 22,16 & $-0,29$ \\
3,00 & 0,38 & $\mathbf{8 5 , 3 4}$ & 3,95 & $\mathbf{8 0 , 5 0}$ & 5,67 & $\mathbf{8 0 , 9 4}$ & 5,15 & $-0,55$ \\
4,00 & 0,49 & $\mathbf{1 0 9 , 3 2}$ & 3,08 & $\mathbf{1 0 2 , 5 6}$ & 6,18 & $\mathbf{1 0 3 , 5 1}$ & 5,31 & $-0,93$ \\
\hline \hline
\end{tabular}




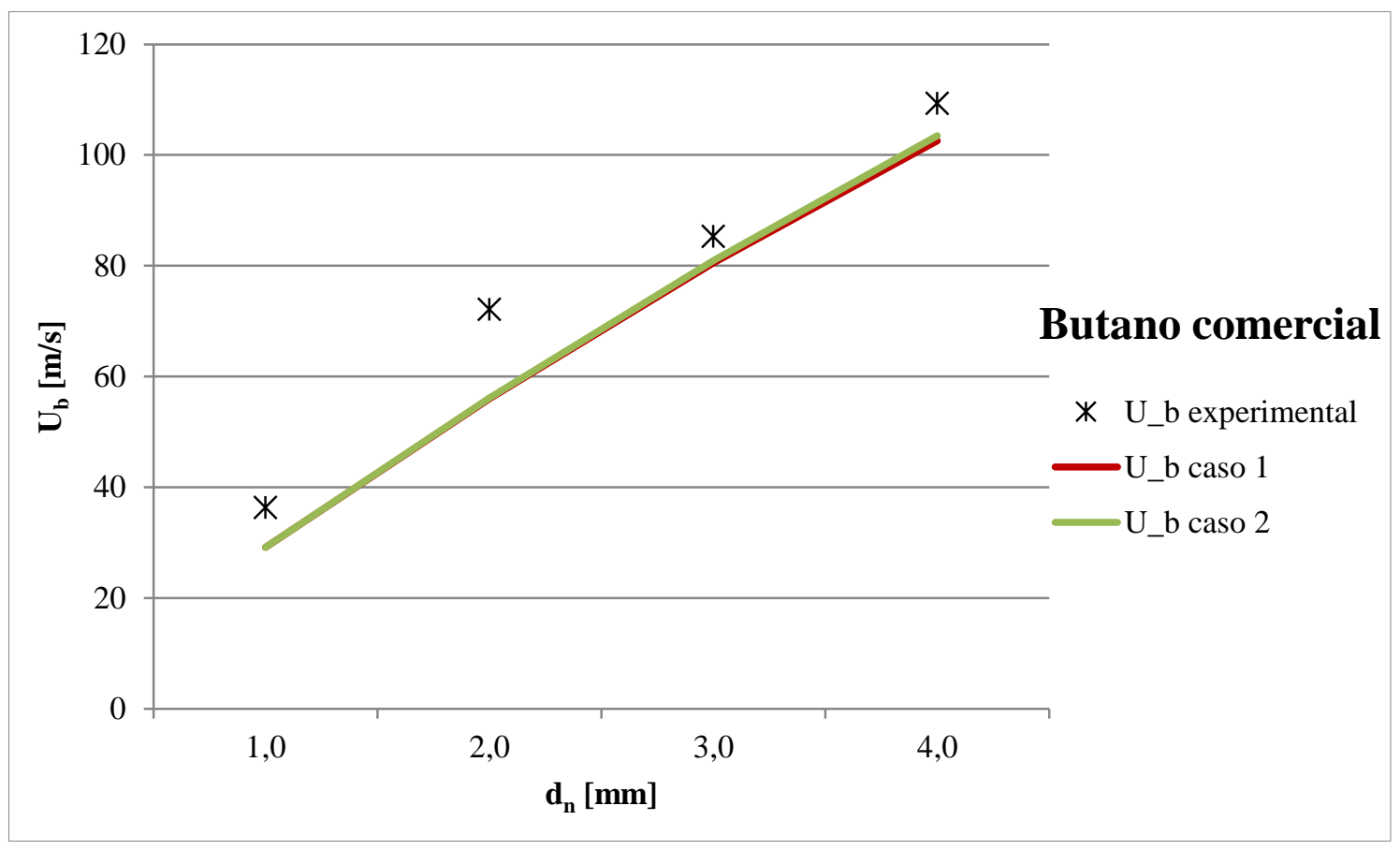

Figura C.6. Valores de $U_{b}$ experimentais e previstos pela correlação proposta por Kalghatgi (1981), sob as condições dos Casos 1 e 2 para o butano comercial.

É notável a diferença entre os valores de $U_{b, \exp }$ e $U_{b}$, principalmente para $d_{n}=2,00 \mathrm{~mm}$. A princípio, esta diferença poderia ser associada à incerteza no processo de digitalização $( \pm 0,015$ em $M a_{b}$ ). Após analisar esta possibilidade (para todos os diâmetros de bocais testados experimentalmente), verificou-se que, a variação de 0,015 em $M a_{b}$ resulta:

1. numa incerteza $\left(\xi_{\text {exp }}\right)$ na velocidade de blowout experimental, $U_{b, \exp }$, apresentada na Tabela (C.14), de $\pm 3,4 \mathrm{~m} / \mathrm{s}$ para todos os diâmetros de bocais, o que equivale aproximadamente a $\pm 9,3 \%, \pm 4,9, \pm 4,0 \%$ e $\pm 3,1 \%$ para $d_{n}$ igual a $1,00 \mathrm{~mm}, 2,00$ $\mathrm{mm}, 3,00 \mathrm{~mm}$ e 4,00 $\mathrm{mm}$, respectivamente;

2. numa incerteza $\left(\xi_{1-1 *}\right)$ na previsão de $U_{b}$ desprezível para $d_{n}=1,00 \mathrm{~mm}, d_{n}=2,00 \mathrm{~mm}$ e $d_{n}=3,00 \mathrm{~mm}$ (menor que $0,007 \mathrm{~m} / \mathrm{s}$ ); e aproximadamente $0,02 \mathrm{~m} / \mathrm{s}$ para $d_{n}=4,00$ $\mathrm{mm}$;

3. em $\Delta_{1-\exp }>\Delta_{\text {exp }}$ para todos os diâmetros de bocais, e, portanto, a diferença entre $U_{b, \exp }$ e $U_{b}$ não deve ser atribuída apenas ao processo de digitalização de $M a_{b}$.

Os resultados da incerteza de $\pm 0,015$ em $M a_{b}$ encontram-se na Tabela (C.15) para os diâmetros extremos, ou seja, $d_{n}=1,00 \mathrm{~mm}$ e $d_{n}=4,00 \mathrm{~mm}$. 
Tabela C.15. Influência da incerteza da digitalização dos dados experimentais de Kalghatgi (1981) na velocidade de blowout, $U_{b}$, para o butano comercial.

\begin{tabular}{cccccccc}
\hline \hline$d_{n}[\mathrm{~mm}]$ & $M a_{b}$ & $\begin{array}{c}U_{b, \exp } \\
{[\mathrm{m} / \mathrm{s}]}\end{array}$ & $\begin{array}{c}\xi_{\text {exp }} \\
{[\mathrm{m} / \mathrm{s}]}\end{array}$ & $\begin{array}{c}\Delta_{\exp } \\
{[\%]}\end{array}$ & $\begin{array}{c}U_{b} \text { (Caso 1) } \\
{[\mathrm{m} / \mathrm{s}]}\end{array}$ & $\begin{array}{c}\xi_{1-1 *} \\
{[\mathrm{~m} / \mathrm{s}]}\end{array}$ & $\begin{array}{c}\Delta_{1-1 *} \\
{[\%]}\end{array}$ \\
\hline \multirow{4}{*}{1,00} & $\mathbf{0 , 1 6}$ & $\mathbf{3 6 , 3 4}$ & - & - & $\mathbf{2 9 , 1 7}$ & - & - \\
& 0,15 & 32,98 & 3,37 & 9,26 & 29,17 & $-0,0002$ & $-0,0006$ \\
& 0,18 & 39,71 & $-3,37$ & $-9,26$ & 29,17 & 0,0002 & 0,0007 \\
& $\mathbf{0 , 4 9}$ & $\mathbf{1 0 9 , 3 2}$ & - & - & $\mathbf{1 0 2 , 5 6}$ & - & - \\
4,00 & 0,47 & 105,95 & 3,37 & 3,08 & 102,58 & $-0,0180$ & $-0,0176$ \\
& 0,50 & 112,69 & $-3,37$ & $-3,08$ & 102,54 & 0,0186 & 0,0181 \\
\hline \hline
\end{tabular}

\section{C.7 Comentários da análise do trabalho de Kalghatgi (1981)}

A partir dos resultados apresentados acima, verificou-se que a hipótese adotada no Caso 2 fornece resultados muito próximos dos previstos segundo o Caso $1\left(\xi_{2-1}<<\xi_{i-\exp }\right)$ para todos os gases estudados (metano, propano, etileno, acetileno, butano e hidrogênio). Além disso, para certos diâmetros de bocais, o Caso 2 prevê $U_{b}$ mais próximo do valor experimental do que o Caso $1\left(\xi_{2-e x p}<\xi_{1-e x p}\right)$.

Os valores da velocidade de blowout experimental e prevista segundo o Caso 2, $U_{b, \exp }$ e $U_{b}$, para quase todos os gases analisados (exceto o hidrogênio) estão apresentados na Figura (C.7). A correlação proposta não fornece boas previsões de $U_{b}$ para o hidrogênio.

A partir da análise da influência da incerteza de $\pm 0,015$ em $M a_{b}$, verificou-se que:

1. as maiores variações em $U_{b, \exp }\left(\Delta_{\exp }\right)$ ocorrem para os menores diâmetros de bocais; enquanto que os erros máximos em $U_{b}\left(\xi_{\text {exp }}\right)$ ocorrem para os maiores diâmetros; e

2. A variação em $U_{b, \exp }$ é insignificante com relação à previsão de $U_{b}$ segundo o Caso 1 ( $\xi_{1-1 *}$ é pequeno). 


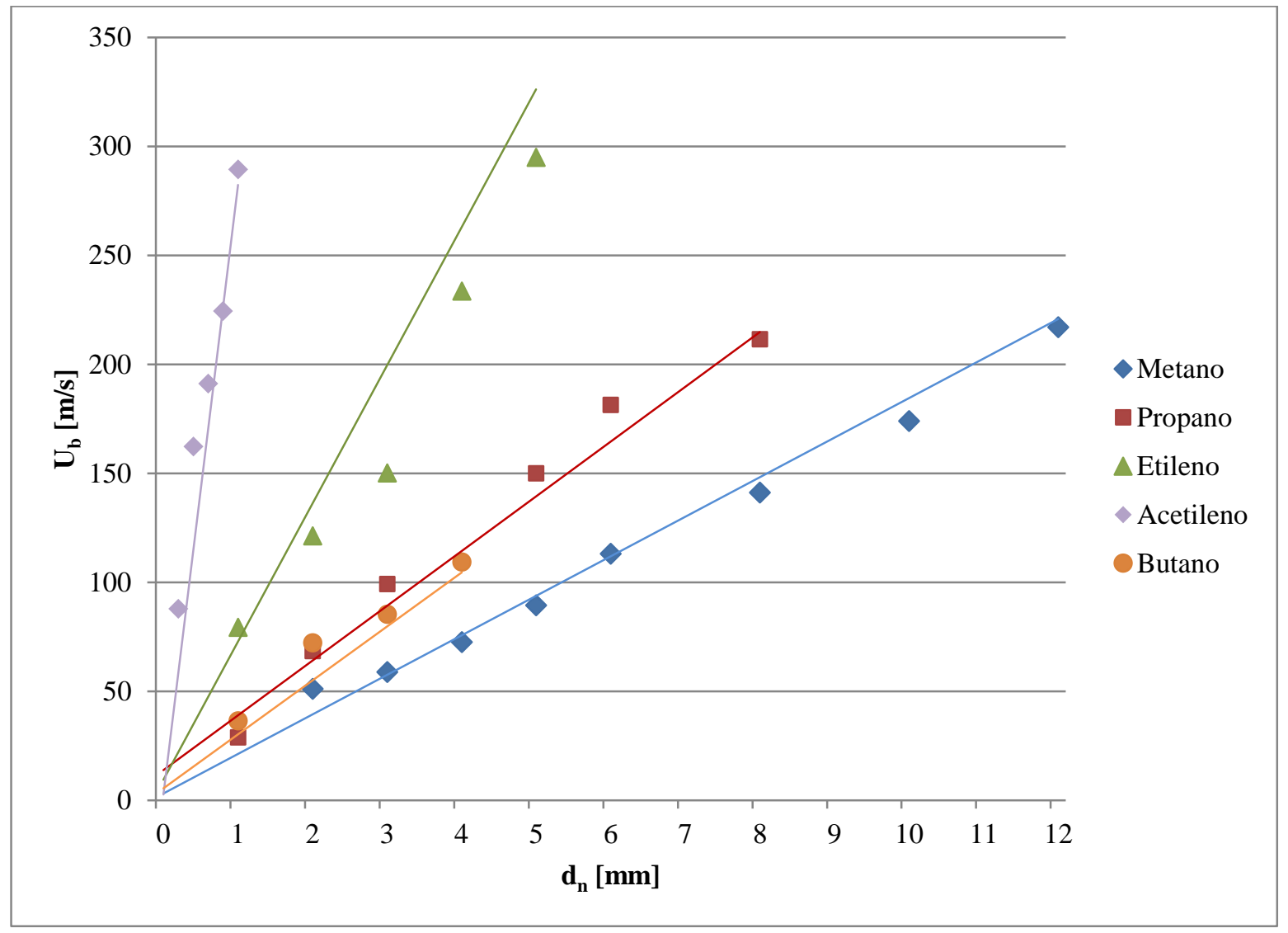

Figura C.1 Valores de $U_{b}$ experimentais e previstos pela correlação proposta por Kalghatgi (1981), sob as condições do Caso 2. 


\section{APÊNDICE D - Exemplo de verificação da estabilidade da chama devido à substituição de combustível}

O presente trabalho relatou a importância da compreensão dos mecanismos de estabilidade de chamas de difusão para o dimensionamento de queimadores industriais e para a substituição de gás combustível em queimadores existentes. Inclusive, a necessidade de verificação da estabilidade de uma chama após as características do combustível serem alteradas foi uma das justificativas deste documento.

Este Apêndice apresenta um caso simples de como pode ser inviável, do ponto vista de estabilidade de chama, a troca de combustível (muitas vezes necessária por motivos econômicos ou de indisponibilidade) a ser utilizado por um mesmo queimador.

Um queimador, cujo diâmetro do bocal é $d_{n}=2,0 \mathrm{~mm}$, utiliza butano como gás combustível e fornece uma potência $\mathcal{P}=10 \mathrm{~kW}$. Deseja-se verificar a possibilidade de substituir este combustível por metano. Para isso, é necessário calcular a velocidade do gás na saída do bocal, $U_{n}$, e assegurar que esta é inferior à velocidade de blowout, $U_{b}$, nas condições em que o queimador irá operar.

Adotando-se as hipóteses apresentadas na Subseção (3.4), a velocidade do gás na saída do bocal, $U_{n}$, pode ser calculada a partir da Eq. (D.1).

$$
U_{n}=\frac{\mathcal{P}}{\rho_{f, n} \cdot \mathrm{PCI}} \cdot\left(\frac{\pi}{4} d_{n}^{2}\right)^{-1}
$$

Na qual, $\rho_{f, n}$ é a densidade do gás combustível na saída do bocal $\left(\mathrm{em} \mathrm{kg} / \mathrm{m}^{3}\right)$; PCI é o poder calorífico inferior do gás (em $\mathrm{J} / \mathrm{kg}$ ); $\mathcal{P}$ é a potência (em W); e $d_{n}$ é o diâmetro do bocal (em metros).

Para os cálculos, adotou-se $\mathcal{P}=10 \mathrm{~kW}, \rho_{f, n}=0,002 \mathrm{~m}$, e os valores de PCI e $\rho_{f, n}$ conforme Tabela (D.1). Esta tabela também apresenta os valores obtidos das velocidades dos gases metano e butano na saída do bocal, $U_{n}$, calculados a partir da Eq. (D.1); e os dados experimentais da velocidade de blowout, $U_{b, \text { exp }}$, obtidos por Kalghatgi (1981) e apresentados anteriormente na Subseção (4.1), Tabelas (4.1) e (4.11) para os gases metano e butano, 
respectivamente. A incerteza $\left(\xi_{\text {exp }}\right)$ associada à $U_{b, \exp }$ foi discutida no Apêndice C. Esta é inferior a $\pm 6,6 \mathrm{~m} / \mathrm{s}$ para o metano e $\pm 3,4 \mathrm{~m} / \mathrm{s}$ para o butano.

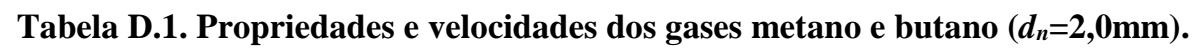

\begin{tabular}{lccccc}
\hline \hline & $\begin{array}{c}\text { PCS } \\
(\mathrm{kJ} / \mathrm{kg})\end{array}$ & $\begin{array}{c}\text { PCI } \\
(\mathrm{kJ} / \mathrm{kg})\end{array}$ & $\begin{array}{c}\rho_{f, n} \\
\left(\mathrm{~kg} / \mathrm{m}^{3}\right)\end{array}$ & $\begin{array}{c}U_{n} \\
(\mathrm{~m} / \mathrm{s})\end{array}$ & $\begin{array}{c}U_{b, \text { exp }} \\
(\mathrm{m} / \mathrm{s})\end{array}$ \\
\hline Metano, $\mathrm{CH}_{4}$ & 55546,3 & 50061,6 & 0,65 & 97,87 & 51,09 \\
Butano, $\mathrm{C}_{4} \mathrm{H}_{10}$ & 49567,5 & 45661,2 & 2,21 & 31,56 & 72,16 \\
\hline \hline
\end{tabular}

PCS e PCI avaliados a $15,5^{\circ} \mathrm{C}$ e 1,0 atm.

A partir da Tabela (D.1), verifica-se que a velocidade do gás metano na saída do bocal, $U_{n}$, é superior a sua velocidade de blowout, $U_{b, \text { exp }}$. Logo, do ponto de vista de estabilidade de chamas, esta nova configuração será instável (ocorrerá blowout da chama). Para que se possa utilizar o metano como combustível, mantendo a vazão mássica deste gás necessária para garantir a potência requerida pelo prcesso $(\mathcal{P}=10 \mathrm{~kW})$, será necessário alterar a configuração do queimador, por exemplo:

1. Modificar a geometria do bocal, aumentando o diâmetro $d_{n}$ de $2,0 \mathrm{~mm}$ para $4,0 \mathrm{~mm}$, o que resultaria em uma velocidade do metano na saída do bocal $U_{n}=24,47 \mathrm{~m} / \mathrm{s}$, inferior velocidade de blowout, $U_{b, \exp }=72,56 \mathrm{~m} / \mathrm{s}$ deste gás para $d_{n}=4,0 \mathrm{~mm}$ ); ou

2. Utilizar três queimadores semelhantes ao que anteriormente utilizava butano como combustível, cujos bocais têm diâmetro $d_{n}=2,0 \mathrm{~mm}$, o que resultaria em $U_{n}=32,62$ $\mathrm{m} / \mathrm{s}$, inferior velocidade de blowout, $U_{b, \exp }=51,09 \mathrm{~m} / \mathrm{s}$ do metano (para $d_{n}=2,0 \mathrm{~mm}$ ).

É importante ressaltar que além da estabilidade é necessário verificar outros parâmetros, como o comprimento da chama, se há a formação de compostos indesejáveis (resultantes da queima do combustível), entre outros fatores que podem afetar o processo. 